Cochrane Database of Systematic Reviews

\title{
Nutritional supplementation for hip fracture aftercare in older people (Review)
}

Avenell A, Smith TO, Curtain JP, Mak JCS, Myint PK

Avenell A, Smith TO, Curtain JP, Mak JCS, Myint PK.

Nutritional supplementation for hip fracture aftercare in older people.

Cochrane Database of Systematic Reviews 2016, Issue 11. Art. No.: CD001880.

DOI: 10.1002/14651858.CD001880.pub6.

www.cochranelibrary.com 
TABLE OF CONTENTS

HEADER

ABSTRACT

PLAIN LANGUAGE SUMMARY

SUMMARY OF FINDINGS

BACKGROUND

OBJECTIVES

METHODS

RESULTS

Figure 1.

Figure 2.

Figure 3.

Figure 4.

Figure 5.

Figure 6.

Figure 7.

DISCUSSION

AUTHORS' CONCLUSIONS

ACKNOWLEDGEMENTS

REFERENCES

CHARACTERISTICS OF STUDIES

DATA AND ANALYSES

Analysis 1.1. Comparison 1 Multinutrient supplements (oral, nasogastric, intravenous) versus control, Outcome 1 Mortality by end of study.

Analysis 1.2. Comparison 1 Multinutrient supplements (oral, nasogastric, intravenous) versus control, Outcome 2 Participants with complications at end of study.

Analysis 1.3. Comparison 1 Multinutrient supplements (oral, nasogastric, intravenous) versus control, Outcome 3 Participants with complications at end of study: random-effects model.

Analysis 1.4. Comparison 1 Multinutrient supplements (oral, nasogastric, intravenous) versus control, Outcome 4 Unfavourable outcome (death or complications) at end of study.

Analysis 1.5. Comparison 1 Multinutrient supplements (oral, nasogastric, intravenous) versus control, Outcome 5 Unfavourable outcome (death or complications) - oral supplements extra analyses.

Analysis 1.6. Comparison 1 Multinutrient supplements (oral, nasogastric, intravenous) versus control, Outcome 6 Adverse effects (putatively related to treatment).

Analysis 2.1. Comparison 2 Multinutrient supplements (oral, nasogastric routes, intravenous) versus control (split by nutritional status), Outcome 1 Mortality by end of study.

Analysis 2.2. Comparison 2 Multinutrient supplements (oral, nasogastric routes, intravenous) versus control (split by nutritional status), Outcome 2 Mortality by end of study - oral supplements only.

Analysis 2.3. Comparison 2 Multinutrient supplements (oral, nasogastric routes, intravenous) versus control (split by nutritional status), Outcome 3 Participants with complications at end of study.

Analysis 2.4. Comparison 2 Multinutrient supplements (oral, nasogastric routes, intravenous) versus control (split by nutritional status), Outcome 4 Unfavourable outcome (death or complications) at end of study.

Analysis 3.1. Comparison 3 Multinutrient supplements (oral, nasogastric routes, intravenous) versus control (by allocation concealment), Outcome 1 Mortality by end of study by risk of bias for allocation concealment.

Analysis 3.2. Comparison 3 Multinutrient supplements (oral, nasogastric routes, intravenous) versus control (by allocation concealment), Outcome 2 Participants with complications at end of study by risk of bias for allocation concealment.

Analysis 4.1. Comparison 4 High protein-containing supplements versus low protein- or non-protein-containing supplements, Outcome 1 Mortality by end of study.

Analysis 4.2. Comparison 4 High protein-containing supplements versus low protein- or non-protein-containing supplements, Outcome 2 Unfavourable outcome (death or complications) at end of study.

Analysis 5.1. Comparison 5 Thiamin (vitamin B1) and water soluble vitamins versus control, Outcome 1 Mortality by end of study.

Analysis 5.2. Comparison 5 Thiamin (vitamin B1) and water soluble vitamins versus control, Outcome 2 Participants with complications at end of study. 
Analysis 6.1. Comparison 6 Vitamin D versus control or lower dose supplementation, Outcome 1 Participants with complications at end of study.

Analysis 6.2. Comparison 6 Vitamin D versus control or lower dose supplementation, Outcome 2 Mortality by end of study. .... 131

Analysis 7.1. Comparison 7 Iron supplementation versus control, Outcome 1 Mortality by end of study.

Analysis 7.2. Comparison 7 Iron supplementation versus control, Outcome 2 Participants with complications at end of study. .

Analysis 8.1. Comparison 8 Taurine versus placebo, Outcome 1 Mortality by end of study.

Analysis 9.1. Comparison 9 Dietetic assistants versus usual care, Outcome 1 Mortality by end of study.

Analysis 9.2. Comparison 9 Dietetic assistants versus usual care, Outcome 2 Participants with complications at end of study. 
[Intervention Review]

\section{Nutritional supplementation for hip fracture aftercare in older people}

Alison Avenell 1 , Toby O Smith², James P Curtain 3 , Jenson CS Mak ${ }^{4}$, Phyo K Myint 5

1Health Services Research Unit, School of Medicine, Medical Sciences and Nutrition, University of Aberdeen, Aberdeen, UK. 2 Faculty of Medicine and Health Sciences, University of East Anglia, Norwich, UK. 3Department of General Medicine, Addenbrookes NHS Trust, Cambridge University Hospital, Cambridge, UK. ${ }^{4}$ Department of Aged Care and Rehabilitation, Gosford Hospital, Gosford, Australia. 5Division of Applied Health Sciences, School of Medicine, Medical Sciences and Nutrition, University of Aberdeen, Aberdeen, UK

Contact address: Alison Avenell, Health Services Research Unit, School of Medicine, Medical Sciences and Nutrition, University of Aberdeen, Health Sciences Building, Foresterhill, Aberdeen, AB25 2ZD, UK. a.avenell@abdn.ac.uk.

Editorial group: Cochrane Bone, Joint and Muscle Trauma Group.

Publication status and date: New search for studies and content updated (conclusions changed), published in Issue $11,2016$.

Citation: Avenell A, Smith TO, Curtain JP, Mak JCS, Myint PK. Nutritional supplementation for hip fracture aftercare in older people. Cochrane Database of Systematic Reviews 2016, Issue 11. Art. No.: CD001880. DOI: 10.1002/14651858.CD001880.pub6.

Copyright (c) 2016 The Cochrane Collaboration. Published by John Wiley \& Sons, Ltd.

\section{A B S T R A C T}

\section{Background}

Older people with hip fractures are often malnourished at the time of fracture, and subsequently have poor food intake. This is an update of a Cochrane review first published in 2000, and previously updated in 2010.

\section{Objectives}

To review the effects (benefits and harms) of nutritional interventions in older people recovering from hip fracture.

\section{Search methods}

We searched the Cochrane Bone, Joint and Muscle Trauma Group Specialised Register, CENTRAL, MEDLINE, MEDLINE In-Process \& Other Non-Indexed Citations, Embase, CAB Abstracts, CINAHL, trial registers and reference lists. The search was last run in November 2015.

\section{Selection criteria}

Randomised and quasi-randomised controlled trials of nutritional interventions for people aged over 65 years with hip fracture where the interventions were started within the first month after hip fracture.

\section{Data collection and analysis}

Two review authors independently selected trials, extracted data and assessed risk of bias. Where possible, we pooled data for primary outcomes which were: all cause mortality; morbidity; postoperative complications (e.g. wound infections, pressure sores, deep venous thromboses, respiratory and urinary infections, cardiovascular events); and 'unfavourable outcome' defined as the number of trial participants who died plus the number of survivors with complications. We also pooled data for adverse events such as diarrhoea.

\section{Main results}

We included 41 trials involving 3881 participants. Outcome data were limited and risk of bias assessment showed that trials were often methodologically flawed, with less than half of trials at low risk of bias for allocation concealment, incomplete outcome data, or selective reporting of outcomes. The available evidence was judged of either low or very low quality indicating that we were uncertain or very uncertain about the estimates.

Eighteen trials evaluated oral multinutrient feeds that provided non-protein energy, protein, vitamins and minerals. There was low-quality evidence that oral feeds had little effect on mortality ( $24 / 486$ versus $31 / 481$; risk ratio (RR) 0.81 favouring supplementation, $95 \%$ confidence interval ( $\mathrm{Cl}) 0.49$ to $1.32 ; 15$ trials). Thirteen trials evaluated the effect of oral multinutrient feeds on complications (e.g. pressure sore, 
infection, venous thrombosis, pulmonary embolism, confusion). There was low-quality evidence that the number of participants with complications may be reduced with oral multinutrient feeds (123/370 versus $157 / 367$; RR $0.71,95 \% \mathrm{Cl} 0.59$ to 0.86 ; 11 trials). Based on very low-quality evidence from six studies (334 participants), oral supplements may result in lower numbers with 'unfavourable outcome' (death or complications): RR $0.67,95 \% \mathrm{Cl} 0.51$ to 0.89 . There was very low-quality evidence for six studies (442 participants) that oral supplementation did not result in an increased incidence of vomiting and diarrhoea (RR $0.99,95 \% \mathrm{Cl} 0.47$ to 2.05 ).

Only very low-quality evidence was available from the four trials examining nasogastric multinutrient feeding. Pooled data from three heterogeneous trials showed no evidence of an effect of supplementation on mortality (14/142 versus $14 / 138 ; \mathrm{RR} 0.99,95 \% \mathrm{Cl} 0.50$ to 1.97$)$. One trial (18 participants) found no difference in complications. None reported on unfavourable outcome. Nasogastric feeding was poorly tolerated. One study reported no cases of aspiration pneumonia.

There is very low-quality evidence from one trial (57 participants, mainly men) of no evidence for an effect of tube feeding followed by oral supplementation on mortality or complications. Tube feeding, however, was poorly tolerated.

There is very low-quality evidence from one trial (80 participants) that a combination of intravenous feeding and oral supplements may not affect mortality but could reduce complications. However, this expensive intervention is usually reserved for people with non-functioning gastrointestinal tracts, which is unlikely in this trial.

Four trials tested increasing protein intake in an oral feed. These provided low-quality evidence for no clear effect of increased protein intake on mortality ( $30 / 181$ versus $21 / 180 ; \mathrm{RR} 1.42,95 \% \mathrm{Cl} 0.85$ to $2.37 ; 4$ trials) or number of participants with complications but very lowquality and contradictory evidence of a reduction in unfavourable outcomes (66/113 versus 82/110; RR $0.78,95 \% \mathrm{Cl} 0.65$ to $0.95 ; 2$ trials). There was no evidence of an effect on adverse events such as diarrhoea.

Trials testing intravenous vitamin B1 and other water soluble vitamins, oral 1-alpha-hydroxycholecalciferol (vitamin D), high dose bolus vitamin $D$, different oral doses or sources of vitamin $D$, intravenous or oral iron, ornithine alpha-ketoglutarate versus an isonitrogenous peptide supplement, taurine versus placebo, and a supplement with vitamins, minerals and amino acids, provided low- or very low-quality evidence of no clear effect on mortality or complications, where reported.

Based on low-quality evidence, one trial evaluating the use of dietetic assistants to help with feeding indicated that this intervention may reduce mortality (19/145 versus $36 / 157$; RR $0.57,95 \% \mathrm{Cl} 0.34$ to 0.95$)$ but not the number of participants with complications ( $79 / 130$ versus $84 / 125)$

\section{Authors' conclusions}

There is low-quality evidence that oral multinutrient supplements started before or soon after surgery may prevent complications within the first 12 months after hip fracture, but that they have no clear effect on mortality. There is very low-quality evidence that oral supplements may reduce 'unfavourable outcome' (death or complications) and that they do not result in an increased incidence of vomiting and diarrhoea. Adequately sized randomised trials with robust methodology are required. In particular, the role of dietetic assistants, and peripheral venous feeding or nasogastric feeding in very malnourished people require further evaluation.

\section{PLAIN LANGUAGE SUMMARY}

\section{Nutritional supplementation for older people after hip fracture}

\section{Background and aim}

Older people with hip fractures are often malnourished at the time of their fracture and many have poor food intake while in hospital. Malnutrition may hinder recovery after hip fracture. We reviewed the effects of nutritional interventions in older people recovering from hip fracture.

\section{Search results}

We searched the scientific literature up to November 2015 and include 41 studies including 3881 participants. All nutritional interventions were started within one month of hip fracture. The studies had flaws in their methods that may affect the validity of their results. Some evidence was very low quality which means we are very unsure of the results.

\section{Key results}

Eighteen studies examined the use of additional oral feeds that provided energy from sources other than protein, protein, some vitamins and minerals. There was low-quality evidence that these multinutrient oral feeds may not reduce mortality but that they may reduce the number of people with complications (e.g. pressure sore, infection, venous thrombosis, pulmonary embolism, confusion). There was very low-quality evidence that oral multinutrient feeds may reduce unfavourable outcome (death or complications) and that they did not result in increased vomiting and diarrhoea. 
Four studies examined nasogastric tube feeding, where liquid food is delivered via a tube inserted into the nose and passed down into the stomach, with non-protein energy, protein, some vitamins and minerals. These studies provided very low-quality evidence that tube feeding, which was poorly tolerated, did not seem to make a difference to mortality or complications. Unfavourable outcome was not recorded and there was insufficient evidence on adverse events.

One study provided very low-quality evidence that nasogastric tube feeding followed by oral feeds may not affect mortality or complications. It reported that tube feeding was poorly tolerated.

One study provided very low-quality evidence that giving feed into a vein initially and then by mouth may not affect mortality but may reduce complications. However, we were surprised that this intervention was being used in people who seemed to be able to take nutrition orally.

Increasing protein intake in an oral feed was tested in four studies. These provided low-quality evidence of no clear effect on mortality or complications and very low-quality evidence for a reduction in unfavourable outcome.

Studies testing intravenous vitamin B1 and other water soluble vitamins, oral 1-alpha-hydroxycholecalciferol (vitamin D), high dose bolus vitamin $D$, different oral doses or sources of vitamin $D$, intravenous or oral iron, ornithine alpha-ketoglutarate versus an isonitrogenous peptide supplement, taurine versus placebo, and a supplement with vitamins, minerals and amino acids, provided low- or very low-quality evidence of no clear effect on mortality or complications, where reported.

One study, evaluating the use of dietetic assistants to help with feeding, provided low-quality evidence that this may reduce mortality but not the numbers of people with complications.

\section{Conclusions}

Oral supplements with non-protein energy, protein, vitamins and minerals started before or soon after surgery may prevent complications after hip fracture in older people but may not affect mortality. Adequately sized randomised studies with better design are required. We suggest that the role of dietetic assistants, and of peripheral venous feeding or nasogastric feeding in very malnourished patients, require further evaluation. 


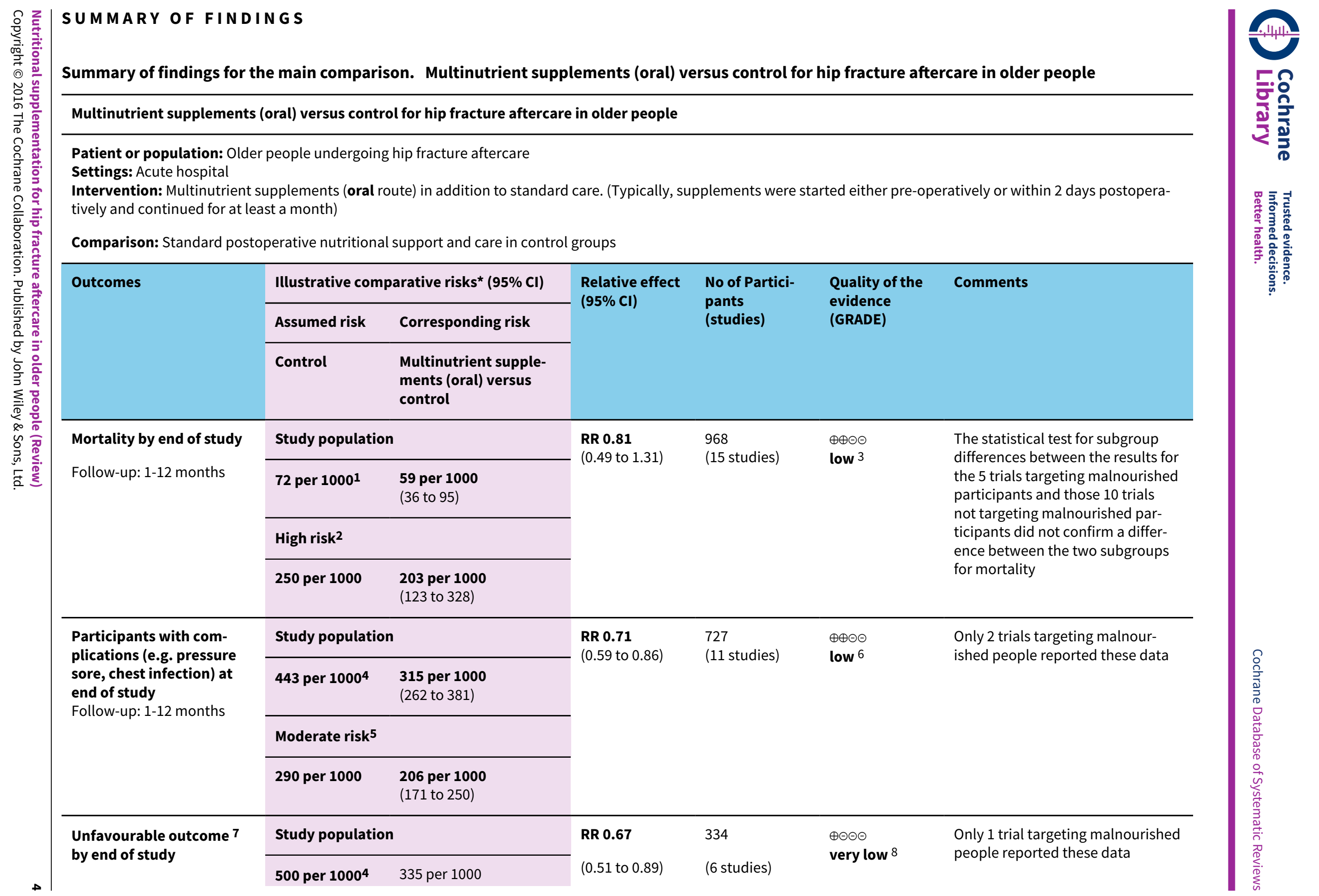




\begin{tabular}{|c|c|c|c|c|c|c|c|c|}
\hline \multirow{12}{*}{ 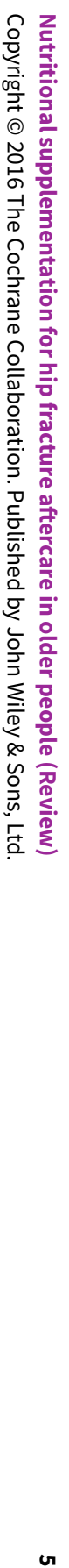 } & \multirow{4}{*}{$\begin{array}{l}\text { Follow-up: 1-12 months } \\
\text { Putative side effects of } \\
\text { treatment (e.g. vomiting } \\
\text { and diarrhoea) } \\
\text { Follow-up: during supple- } \\
\text { mentation period }\end{array}$} & \multicolumn{3}{|c|}{ (255 to 445$)$} & & & & \\
\hline & & \multicolumn{2}{|c|}{ Study population } & & \multirow{2}{*}{$\begin{array}{l}\text { RR } 0.99 \\
\text { (0.47 to } 2.05 \text { ) }\end{array}$} & \multirow{2}{*}{442} & \multirow{3}{*}{$\begin{array}{l}\oplus \ominus \ominus \ominus \\
\text { very low } 9\end{array}$} & \multirow{3}{*}{$\begin{array}{l}\text { Three of the } 6 \text { trials reported no } \\
\text { adverse effects }\end{array}$} \\
\hline & & \multirow[t]{2}{*}{50 per $1000^{4}$} & \multicolumn{2}{|l|}{50 per 1000} & & & & \\
\hline & & & \multicolumn{2}{|l|}{ (24 to 103$)$} & & & & \\
\hline & \multicolumn{8}{|c|}{$\begin{array}{l}\text { *The basis for the assumed risk (e.g. the median control group risk across studies) is provided in footnotes. The corresponding risk (and its } 95 \% \text { confidence interval) is } \\
\text { based on the assumed risk in the comparison group and the relative effect of the intervention (and its } 95 \% \mathrm{Cl} \text { ). } \\
\text { Cl: Confidence interval; RR: Risk ratio; }\end{array}$} \\
\hline & \multicolumn{8}{|c|}{$\begin{array}{l}\text { GRADE Working Group grades of evidence } \\
\text { High quality: Further research is very unlikely to change our confidence in the estimate of effect. } \\
\text { Moderate quality: Further research is likely to have an important impact on our confidence in the estimate of effect and may change the estimate. } \\
\text { Low quality: Further research is very likely to have an important impact on our confidence in the estimate of effect and is likely to change the estimate. } \\
\text { Very low quality: We are very uncertain about the estimate. }\end{array}$} \\
\hline & \multicolumn{8}{|c|}{$\begin{array}{l}\text { 1. The control group risk is the median control group risk across the } 9 \text { studies that reported one or more deaths in the control group. } \\
\text { 2. The high control group risk is based on the one-year mortality rate derived from Bentler } 2009(26 \%) \text { and Mariconda } 2015 \text { ( } 24.7 \% \text { for those over } 80 \text { years). Pooled estimate } \\
\text { includes no effect and } 95 \% \text { confidence intervals encompass relative risk increase greater than } 25 \% \text {. } \\
\text { 3. Downgraded } 1 \text { level for high risk of bias and } 1 \text { level for imprecision. } \\
\text { 4. The control group risk is the median control group risk across studies. } \\
\text { 5. Moderate control risk is derived from participants whilst in hospital in Mariconda } 2015 . \\
\text { 6. Downgraded } 2 \text { levels for very serious risk of bias. } \\
\text { 7. Unfavourable outcome was defined as the number of trial participants who died plus the number of survivors with complications. Where these data were unavailable, we } \\
\text { accepted a slightly different definition (mortality or survivors with a major complication or two or more minor complications) provided in } 3 \text { trials. } \\
\text { 8. Downgraded } 2 \text { levels for serious risk of bias and } 1 \text { for indirectness reflecting the mixed definition of the outcome measure. } \\
\text { 9. Downgraded } 3 \text { levels individually for risk of bias, inconsistency and imprecision. }\end{array}$} \\
\hline & \multicolumn{8}{|c|}{ Summary of findings 2. Multinutrient supplements (nasogastric) versus control for hip fracture aftercare in older people } \\
\hline & \multicolumn{8}{|c|}{ Multinutrient supplements (nasogastric) versus control for hip fracture aftercare in older people 7} \\
\hline & \multicolumn{8}{|c|}{$\begin{array}{l}\text { Patient or population: Older people undergoing hip fracture aftercare } \\
\text { Settings: Acute hospitals }\end{array}$} \\
\hline & \multicolumn{8}{|c|}{ Comparison: Standard postoperative nutritional support and care in control groups } \\
\hline & Outcomes & $\begin{array}{l}\text { Illustrative comp } \\
(95 \% \mathrm{Cl})\end{array}$ & tive risks* & $\begin{array}{l}\text { Relative effect } \\
(95 \% \mathrm{CI})\end{array}$ & $\begin{array}{l}\text { No of } \\
\text { pants }\end{array}$ & $\begin{array}{l}\text { Qua } \\
\text { evid }\end{array}$ & the & \\
\hline
\end{tabular}




\begin{tabular}{|c|c|c|c|c|c|c|}
\hline \multirow{3}{*}{ 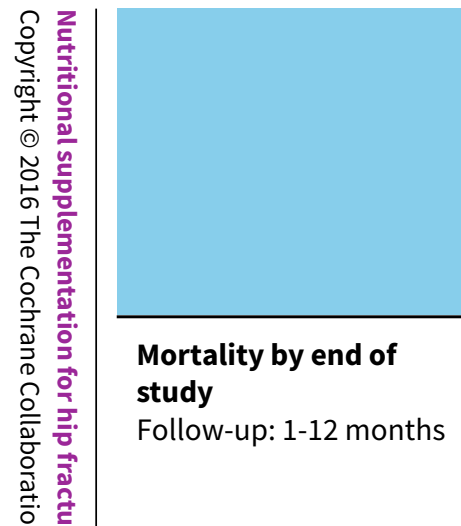 } & Control & $\begin{array}{l}\text { Corresponding } \\
\text { risk }\end{array}$ & & (studies) & (GRADE) & \\
\hline & \multicolumn{2}{|c|}{ Study Population } & \multirow{2}{*}{$\begin{array}{l}\text { RR: } 0.99 \\
(0.50 \text { to } 1.97)\end{array}$} & \multirow{2}{*}{$\begin{array}{l}280 \\
\text { (3 studies) }\end{array}$} & \multirow{2}{*}{$\begin{array}{l}\oplus \ominus \ominus \ominus \\
\text { very low }\end{array}$} & \multirow{2}{*}{$\begin{array}{l}\text { Only } 1 \text { trial targeting malnourished participants } \\
\text { reported these data }\end{array}$} \\
\hline & 156 per $1000^{2}$ & $\begin{array}{l}\mathbf{1 5 5} \text { per } 1000 \\
(78 \text { to } 308)\end{array}$ & & & & \\
\hline Participants with com- & \multicolumn{2}{|c|}{ Study Population } & \multirow{2}{*}{$\begin{array}{l}\text { RR: } \mathbf{1 . 0 9} \\
(0.73 \text { to } 1.64)\end{array}$} & \multirow{2}{*}{$\begin{array}{l}18 \\
\text { (1 study) }\end{array}$} & \multirow{2}{*}{$\begin{array}{l}\oplus \ominus \ominus \ominus \\
\text { very low } 5\end{array}$} & \multirow{2}{*}{$\begin{array}{l}\text { For consistency we have presented } 95 \% \mathrm{Cl} \text { here } \\
\text { but have used } 99 \% \mathrm{Cl} \text { for single trial data in the } \\
\text { main text: } 99 \% \mathrm{Cl} 0.64 \text { to } 1.86 .6\end{array}$} \\
\hline $\begin{array}{l}\text { sure sore, aspiration } \\
\text { pneumonia) at end of } \\
\text { study } \\
\text { Follow-up: } 6 \text { months }\end{array}$ & 800 per $1000^{4}$ & $\begin{array}{l}872 \text { per } 1000 \\
(584 \text { to } 1000)\end{array}$ & & & & \\
\hline $\begin{array}{l}\text { Unfavourable outcome } \\
\text { Follow-up: } 1 \text {-12 months }\end{array}$ & \multicolumn{2}{|l|}{ See comment } & \multicolumn{3}{|l|}{ See comment } & Outcome not reported \\
\hline $\begin{array}{l}\text { Putative side effects of } \\
\text { treatment (e.g. aspira- } \\
\text { tion pneumonia) }\end{array}$ & \multirow{2}{*}{\multicolumn{2}{|c|}{ See comment }} & \multirow[t]{2}{*}{ See comment } & & & $\begin{array}{l}\text { Insufficient data to draw any conclusions. How- } \\
\text { ever, poor toleration of tube feeding was not- } \\
\text { ed. }{ }^{1}\end{array}$ \\
\hline $\begin{array}{l}\text { Follow-up: during sup- } \\
\text { plementation period }\end{array}$ & & & & & & $\begin{array}{l}\text { There was no report of aspiration pneumonia } \\
\text { ( } 1 \text { study; } 140 \text { participants). One study reported } \\
18 \text { ( } 28 \% \text { of } 64 \text { ) participants in the intervention } \\
\text { group developed diarrhoea - this was ascribed } \\
\text { to antibiotics in } 16 \text { - but did not report on the } \\
\text { control group. One study ( } 18 \text { participants) re- } \\
\text { ported } 3 \text { cases of "bloating" in the intervention } \\
\text { group; it found no feed-induced diarrhoea }\end{array}$ \\
\hline
\end{tabular}

${ }^{*}$ The basis for the assumed risk (e.g. the median control group risk across studies) is provided in footnotes. The corresponding risk (and its $95 \%$ confidence interval) is based on the assumed risk in the comparison group and the relative effect of the intervention (and its 95\% $\mathrm{Cl}$ ).

Cl: Confidence interval; RR: Risk Ratio.

GRADE Working Group grades of evidence

High quality: Further research is very unlikely to change our confidence in the estimate of effect.

Moderate quality: Further research is likely to have an important impact on our confidence in the estimate of effect and may change the estimate.

Low quality: Further research is very likely to have an important impact on our confidence in the estimate of effect and is likely to change 
1. Nasogatric feeding was poorly tolerated but varied between studies. One study reported only $26 \%$ of the intervention group tolerated tube feeding for the full two weeks; another reported $78 \%$ completed the course (until hospital discharge).

2. The control group risk is the median control group risk across studies.

3. Downgraded 2 levels for serious risk of bias and one for inconsistency reflecting considerable heterogeneity $(12=69 \%)$

4. The control group risk is that of the control group in the sole study contributing data.

5. Downloaded 2 levels for serious risk of bias and one level for imprecision.

6. The choice of $99 \% \mathrm{Cls}$ reflected the extra burden of proof we considered appropriate for individual trials, in view of their generally poor quality. 


\section{B A C K G R O U N D}

\section{Description of the condition}

Hip (proximal femur) fractures are a common cause of substantial morbidity and mortality in older people living in industrialised societies (Kanis 2012). Nine months after their hip fracture people still have poorer quality of life than age and sex matched controls (Cranney 2005). Many people fail to return to their own homes and previous state of mobility after a hip fracture. In industrialised societies, mortality in the year after hip fracture may be as high as 30\% (Bentler 2009; Mariconda 2015), and averages 11\% during the first few months after fracture (Lyons 1997). Mortality in the first four months after hip fracture surgery is age dependent. For instance, mortality was reported as $5 \%$ in people aged 50 to 69 years, compared with $28 \%$ in those people aged 90 years or over in the Scottish Hip Fracture Audit Report (Holt 2008). A meta-analysis of prospective studies found the relative hazard for mortality during the first three months following hip fracture to be 5.75 (95\% Cl 4.94 to 6.67) for women, and higher in men at $7.95(95 \% \mathrm{Cl} 6.13$ to 10.30$)$ (Haentjens 2010). Excess mortality was also found to persist for as long as 10 years after hip fracture for both men and women. For those who survive, acute hospital costs are substantial, but longterm costs in rehabilitation and extra care in the community are even greater (Dolan 1998; Haentjens 2005; Johnell 1997).

People with hip fractures, who are more likely to be older and frailer, are often malnourished or at risk of becoming malnourished at the time of the fracture (Bachrach 2001; Bastow 1983a; Koren-Hakim 2012; Lumbers 2001). Social, psychological, physical, economic, medical and cognitive influences may all contribute to the risk of malnutrition. Dietary intake in people recovering from hip fracture in hospital is frequently suboptimal (Bell 2014; Jallut 1990; Lumbers 2001; Nematy 2004; Patterson 1992; Stableforth 1986).

Under-nutrition leads to depressed mood, muscle wasting and reduced muscle power, and impaired cardiac function (Keys 1950). All of these will impair mobility and increase the tendency to develop postoperative medical complications (e.g. pneumonia, pressure sores, deep venous thrombosis) and hinder recovery, both in hospital and subsequently (Lennard-Jones 1992), increasing health and social care costs. Malnutrition also impairs the immune response, which will enhance the risk of postoperative infection (Lesourd 1997). Poor nutritional status is associated with an increased risk of pressure ulcers after hip fracture (Lindholm 2008).

\section{Description of the intervention}

Examined in this review are nutritional interventions started within the first month after a hip fracture that are aimed at improving recovery from hip fracture by increasing the intake of energy, protein, vitamins and minerals, alone or in combination. Nutrition interventions can be provided by various routes: oral (by mouth), enteral (tube feeding into the stomach or small bowel, including percutaneous endoscopic gastrostomy) or parenteral (intravenous and intramuscular), also alone or in combination. Also considered are interventions that revolve round the administration of nutrition, such as the use of dietetic assistants in hospital.

\section{How the intervention might work}

There is an association between frailty, including that related to nutrition, and unfavourable outcomes following a hip fracture. Modification of nutritional status in the rehabilitation period, particularly early on, could be beneficial in reducing functional decline and reducing complications.

Making links between nutritional status and fracture recovery is complicated by the fact that markers of dietary protein depletion measured in blood, such as albumin, prealbumin, and transferrin are partly affected by fluid shifts and responses to injury and infection. Nevertheless, associations have been shown between low serum albumin and increased postoperative complications and poorer survival (Foster 1990; Patterson 1992). Another factor that has been implicated is vitamin $\mathrm{C}$, which is required for an effective immune response and collagen formation required for wound healing. Low leucocyte vitamin $\mathrm{C}$ levels have been associated with the development of pressure sores in people with hip fracture (Brown 1992a; Goode 1992).

More direct markers of nutritional status are anthropometric indices, such as weight in relation to height, triceps skinfold for body fat, and mid-upper arm circumference for muscle and fat mass. People with hip fracture have lower triceps skinfold and midupper arm circumference than healthy people in the same age category (Mansell 1990; Nematy 2004). In a study of 744 people with hip fracture, Bastow 1983a found that low triceps skinfold and arm muscle circumference was associated with lower calorie intake on the ward and predicted poorer survival after hip fracture.

\section{Why it is important to do this review}

As described above, people with hip fracture are sometimes undernourished, and poor food intake may occur during routine care, hindering recovery. There is therefore an argument for nutritional supplementation in this group, and consequently a need to evaluate the use of nutrition interventions in this group of people by examining the evidence from relevant randomised controlled trials. This is the seventh update of our Cochrane review first published in 2000, and previously updated in 2010 . The previous update (Avenell 2010) continued to point to the insufficiency of the available evidence to draw robust conclusions.

\section{O B JECTIVES}

To review the effects (benefits and harms) of nutritional interventions in older people recovering from hip fracture.

We considered comparisons where people with hip fracture, who were randomly allocated a nutritional intervention, including supplements, were compared with those allocated to no intervention or placebo. Where possible, effects were examined according to pre-existing nutritional status: malnourished or not malnourished.

We also considered comparisons between nutritional interventions if these were compared in a randomised controlled trial.

\section{METHODS}

\section{Criteria for considering studies for this review}

\section{Types of studies}

We included all randomised controlled trials (RCTs) and quasirandomised (e.g. allocation by date of birth or hospital record number) controlled trials of nutritional supplements post hip fracture. We also included trials that could not be analysed on an 
intention-to-treat basis, and those that lacked blinding or use of placebo treatment.

Studies of nutritional interventions that examined the secondary prevention of osteoporotic fractures after hip fracture were not considered in this review.

\section{Types of participants}

We included trials of older people recovering from any type of hip fracture. It was anticipated that most participants would be over 65 years of age. If the number of younger participants was relatively small, and provided there was adequate randomisation with unbiased distribution of this age group between the intervention and control groups, we retained them. Trials that focused specifically or mainly on younger people, people with multiple trauma or people with pathological fractures (e.g. cancerrelated fractures) were excluded. We also excluded trials published before 1980 with undefined geriatric populations or with mixed populations with fewer than five participants with hip fracture in each intervention group.

Studies reporting results on mixed populations of orthopaedic or other geriatric patients were only included, either if separate data were available from the participants with fracture of the hip, or when contact with the study authors resulted in the provision of such data.

The participants studied may have resided in a hospital or in a rehabilitation unit or any location after discharge from either of these facilities.

\section{Types of interventions}

We included trials of nutritional interventions aimed to improve the recovery from hip fracture by increasing the intake of energy, protein, vitamins and minerals, alone or in combination. Nutritional interventions were provided by oral (by mouth), enteral (tube feeding into the stomach or small bowel, including percutaneous endoscopic gastrostomy) or parenteral (intravenous and intramuscular) routes, alone or in combination. Interventions included those evaluating the administration of nutrition, such as the use of dietetic assistants. The interventions examined were started within the first month after hip fracture, and given for up to one year. Trials evaluating intravenous fluid administration in the immediate postoperative period for hydration purposes were excluded.

Interventions included multinutrient supplements (providing nonprotein energy, protein, vitamins and minerals) given orally, enterally or intravenously, compared with supplements containing less or none of these components, or no treatment. We included interventions of vitamins, minerals, amino acids or related compounds compared with lower doses, placebo or no treatment. We also included trials examining different policies to provide nutrition, for example, additional assistance from dietetic assistants.

\section{Types of outcome measures}

We sought information on the following outcomes, which we split into main outcomes (and further categorised into primary and secondary outcomes) and other outcomes. Additionally, we made the collection of 'unfavourable outcome' explicit.

\section{Main outcomes}

\section{Primary outcomes}

- All cause mortality

- Morbidity, postoperative complications (e.g. wound infections, pressure sores, deep venous thromboses, respiratory and urinary infections, cardiovascular events)

- 'Unfavourable outcome'. This was defined as the number of trial participants who died plus the number of survivors with complications. Alternatively, where these data were unavailable, we accepted a slightly different definition (mortality or survivors with a major complication or two or more minor complications) originally presented in Delmi 1990.

\section{Secondary outcomes}

- Length of hospital and rehabilitation unit stay

- Postoperative functional status (cognitive functioning, mobility and ability to perform activities of daily living)

- The level of care and extent of support required after discharge

- Patient perceived quality of life after discharge

- Fracture healing

- Putative side effects of treatment (e.g. diarrhoea, aspiration pneumonia, specific intravenous line complications)

\section{Other outcomes}

- Patient tolerance of/compliance with nutrition interventions

- Carer burden and stress

- Economic outcomes

For this update, we shortened the list of 'other outcomes' that appeared in previous versions of this review (Avenell 2010). The removed outcomes are listed in Differences between protocol and review.

\section{Search methods for identification of studies}

\section{Electronic searches}

We searched the Cochrane Bone, Joint and Muscle Trauma Group Specialised Register (9 October 2014), the Cochrane Central Register of Controlled Trials (CENTRAL; 2015 issue 12) in The Cochrane Library, MEDLINE (1966 to October Week 5 2015), MEDLINE In-Process \& Other Non-Indexed Citations (10 November 2015), Embase (1980 to 2015 Week 45), CAB Abstracts (1973 to 2015 Week 44), and the Cumulative Index to Nursing and Allied Health Literature (CINAHL) (1982 to 10 November 2015). For this update, the search results were limited from 2008 onwards.

In MEDLINE (Ovid), we combined the sensitivity-maximizing version of the Cochrane Highly Sensitive Search Strategy for identifying randomised trials (Lefebvre 2011) with subject-specific terms. We modified this strategy for use in the other databases (see Appendix 1 for search strategies).

We also searched the ISRCTN registry (17 February 2015), the WHO International Clinical Trials Registry Platform (17 February 2015), the UK Clinical Research Network Study Portfolio (17 February 2015), to identify ongoing trials. 
We did not apply any language restrictions. We have given details of the search methods used for the previous version of the review in Appendix 2.

\section{Searching other resources}

We checked reference lists of articles, searched books related to orthopaedics, geriatric medicine and nutrition, and corresponded with colleagues and investigators.

\section{Data collection and analysis}

\section{Selection of studies}

Two review authors (from AA, TS, JC) independently assessed reports of potentially eligible studies and resolved any differences by discussion.

\section{Data extraction and management}

Two review authors (from AA, TS, JC, JM) independently extracted data. We resolved all differences by discussion. We extracted data using a pre-derived data extraction form and entered the agreed results into Review Manager (RevMan) (RevMan 2014). If necessary, we contacted trialists for further information on methodology and data.

\section{Assessment of risk of bias in included studies}

In this update, two review authors (from AA, TS, JC, JM) independently assessed risk of bias in all included trials using the Cochrane 'Risk of bias' tool (Higgins 2011). This assesses sequence generation, allocation concealment, blinding of participants or personnel, blinding of outcome assessment, completeness of outcome data, selective outcome reporting and other potential sources of bias. We considered primary and secondary outcomes separately in our assessment of blinding of outcome assessment and completeness of outcome data. We resolved any differences of opinion by consensus or by consulting a third party.

Our risk of bias assessment superceded our assessment of methodological quality in previous versions of this review (Avenell 2010); see Differences between protocol and review.

\section{Measures of treatment effect}

For each study, risk ratios and $99 \%$ confidence intervals $(\mathrm{Cl})$ were calculated for dichotomous outcomes and mean differences and $99 \% \mathrm{Cls}$ for continuous outcomes. The choice of $99 \% \mathrm{Cls}$ reflects the extra burden of proof we considered appropriate for individual trials, in view of their generally poor quality. Summary estimates for meta-analysis are provided as $95 \% \mathrm{Cls}$.

\section{Unit of analysis issues}

Although we would have included cluster-randomised trials, the unit of randomisation in all included trials was the individual participant.

\section{Dealing with missing data}

We have presented mortality results using denominators based on the numbers of participants at randomisation (intention-totreat analysis), where available. Generally, we presented the results for other outcomes using denominators based on the numbers of participants available at follow-up. In some cases, we investigated the effect of drop outs and exclusions by conducting worst scenario analyses for the primary outcomes, where those who were missing to follow-up in the intervention group were assumed to have the poorer outcome but not those who were missing in the control group. We were alert to the potential mislabelling or non identification of standard errors and standard deviations. Unless missing standard deviations could be derived from confidence intervals or standard errors, we did not assume values in order to present these in the analyses.

\section{Assessment of heterogeneity}

Heterogeneity was assessed by visual inspection of the forest plot (analysis) along with consideration of the $\mathrm{Chi}^{2}$ test for heterogeneity and the $\mathrm{I}^{2}$ statistic (Higgins 2003).

\section{Assessment of reporting biases}

We considered that there were sufficient data available to present funnel plots to explore the potential for publication bias for multinutrient supplements and the outcomes of mortality and complications. Our search of 'grey literature', dogged pursuit of trials listed in clinical trial registers and contact with trial authors should have helped to avoid some publication bias.

\section{Data synthesis}

Where appropriate, we combined the results of comparable groups of trials using both fixed-effect, as the main analysis, and randomeffects models. We have presented all data for individual trials in meta-analyses as $99 \% \mathrm{Cls}$, and pooled data with $95 \% \mathrm{Cls}$.

\section{Subgroup analysis and investigation of heterogeneity}

Our primary subgroup analysis was based on pre-existing nutritional status (malnourished targeted versus malnourished not targeted). We also presented data on multinutrient supplements stratified by route of delivery: oral supplements, nasogastric tube feeding, nasogastric tube feeding and oral supplements, and intravenous feeding and oral supplements. To test whether the subgroups were statistically significantly different from one another, we tested the interaction using the inbuilt facility in RevMan 2014 that is based on methods outlined by Deeks 2011 in the Cochrane Handbook for Systematic Reviews of Interventions (Chapter 9).

\section{Sensitivity analysis}

We planned sensitivity analyses based on aspects of trial and review methodology. We have explored the risk of bias associated with inadequate concealment of allocation (unclear or high risk of selection bias) and the choice of statistical model for pooling data (fixed-effect versus random-effects).

\section{'Summary of findings' tables and assessment of the quality of the evidence}

We have presented the results for mortality, participants with complications and unfavourable outcomes (our primary outcome measures) and adverse events (e.g. vomiting and diarrhoea) in separate 'Summary of findings' tables for the comparisons of oral multinutrient supplements versus control and nasogastric multinutrient supplements versus control. For each outcome for each comparison, we graded the evidence as 'very low', 'low', 'moderate' or 'high' in accordance with the GRADE working group criteria (Guyatt 2008). 


\section{RESULTS}

\section{Description of studies}

\section{Results of the search}

We updated the search from 2008 to November 2015. We screened a total of 2459 records from the following databases: Cochrane Bone, Joint and Muscle Trauma Group Specialised Register (7), CENTRAL (340), MEDLINE (483), Embase (847), CAB Abstracts (234), and CINAHL (548). We did not identify any additional new trials from Current Controlled Trials, the WHO International Clinical Trials Registry Platform or the UK clinical research network study portfolio. We also identified one potentially eligible study from contact with the author (Luo 2015).

The search update resulted in the identification of 32 new studies (many published in multiple articles) for potential inclusion, for which we obtained reports. Upon study selection, we found 17 trials eligible for inclusion (Anbar 2014; Bischoff-Ferrari 2010; Botella-Carretero 2010; Chevalley 2010; Fabian 2011; Flodin 2014;
Glendenning 2009; Kang 2012; Luo 2015; Myint 2013; Papaioannou 2011; Parker 2010; Prasad 2009; Scivoletto 2010; Serrano-Trenas 2011; Van Stijn 2015; Wyers 2013), we excluded six studies (Bell 2014; Gunnarsson 2009; Hitz 2007; Hoekstra 2011; Holst 2012; Li 2012), we placed five in ongoing trials (ACTRN12609000241235; ACTRN12612000448842; NCT01404195; NCT01505985; Rowlands) and four await classification (Benati 2011; Bernabeu-Wittel 2016; Ekinci 2015; Ish-Shalom 2008).

We excluded one previously ongoing study (Cameron 2011). A second (NCT00523575) was published and is now an included study (Wyers 2013).

Overall, there are now 41 included studies, 43 excluded studies, seven ongoing trials and six studies awaiting classification.

Further details of the process of screening and selecting studies for inclusion in the review are illustrated in Figure 1. The results of the search reported in the previous version of the review (Avenell 2010) can be found in Appendix 3. 


\section{Figure 1. Study flow diagram}

24 included studies included in
previous version of review
(Avenell 2010)

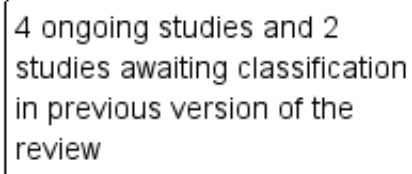

4 ongoing studies and 2 studies awaiting classification in previous version of the review

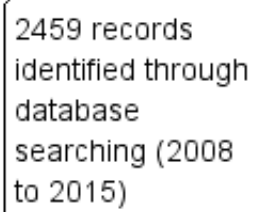

2459 records identified through database searching (2008 to 2015)

1 additional record identified through other sources

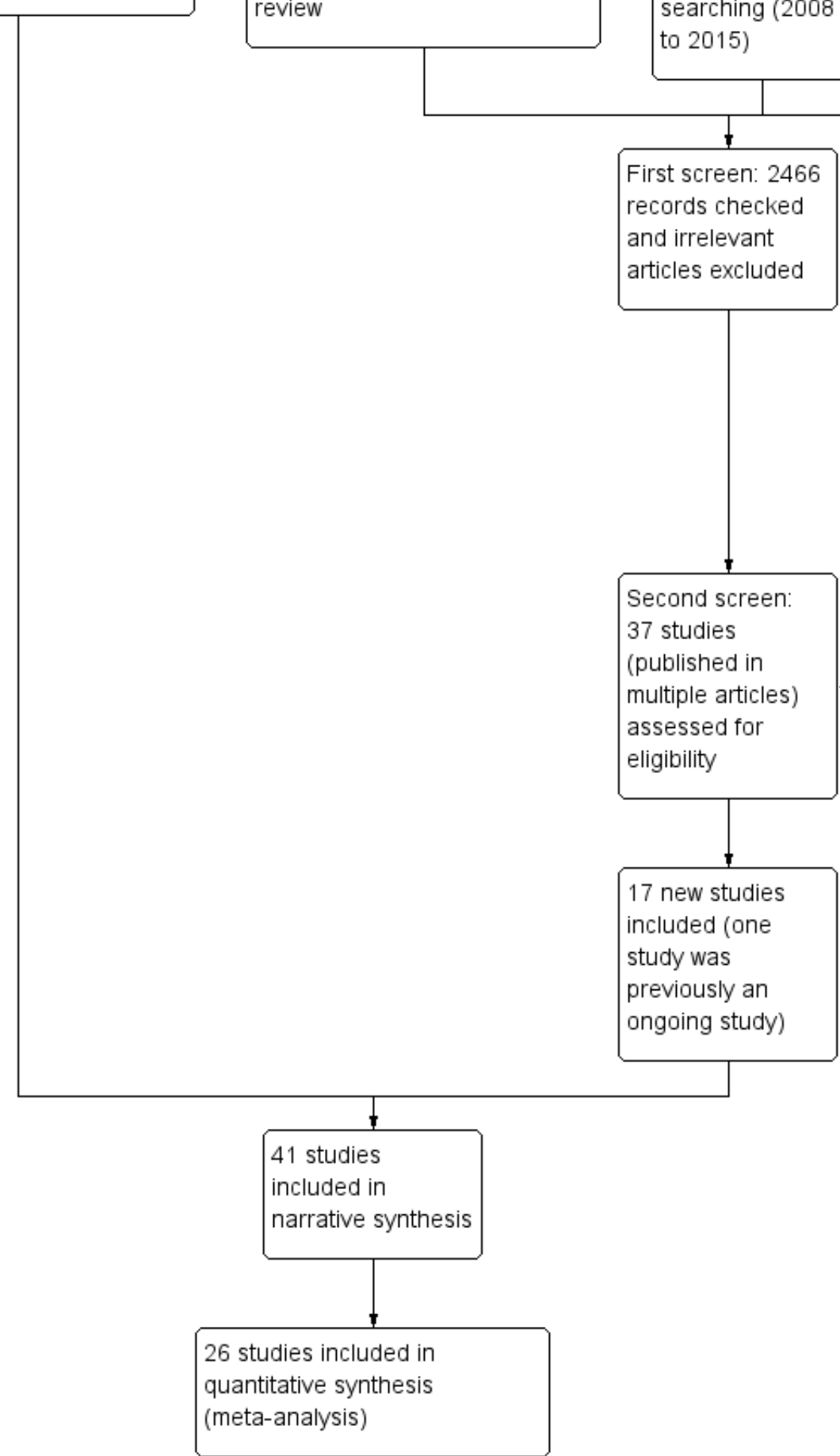

7 new studies excluded ( 1 was previously an ongoing study) classification (4 new and 2 from previous review)

7 ongoing studies ( 5 new and 2 from previous review)

\section{Included studies}

Details of study methods, population, interventions and outcomes of individual trials are provided in the Characteristics of included studies.
We obtained further details (including clarifications) on methodology, trial participants and outcomes, from trialists of 23 studies (Bastow 1983b; Botella-Carretero 2008; Botella-Carretero 2010; Brown 1992b; Bruce 2003; Chevalley 2010; Day 1988; Duncan 2006; Eneroth 2006; Espaulella 2000; Flodin 2014; Hankins 1996; Hartgrink 1998; Houwing 2003; Luo 2015; Miller 2006; Myint 2013; 
Neumann 2004; Parker 2010; Prasad 2009; Sullivan 1998; Sullivan 2004; Tidermark 2004) and other sources for two trials (Ronald Koretz for Gallagher 1992; Jane Robertson for Hoikka 1980).

\section{Design}

Thirty-seven trials were RCTs. The other four trials were quasirandomised trials (Bastow 1983b; Brown 1992b; Bruce 2003; Hoikka 1980). There were no cluster or cross-over randomised trials.

\section{Sample sizes}

The 41 included studies involved a total of 3881 participants. Sample size ranged from 10 participants in Brown 1992b to 318 participants in Duncan 2006.

\section{Setting}

The publication dates of the trials span 35 years, Hoikka 1980 being the earliest. Most of the trials were based in a single centre. Trials were conducted in 15 countries (Australia, Austria, Canada, China, Finland, Israel, Italy, Korea, the Netherlands, Russia, Spain, Sweden, Switzerland, UK, USA), with eight trials being conducted in the UK, five each in Australia and Switzerland, four in the USA, three in Spain, and three each in the Netherlands and Sweden.

\section{Participants}

The majority of participants were female and in 10 studies all participants were female (Bastow 1983b; Bean 1994; Brown 1992b; Bruce 2003; Chevalley 2010; Duncan 2006; Fabian 2011; SerranoTrenas 2011; Stableforth 1986; Tidermark 2004). Sullivan 1998 and Sullivan 2004 were the only studies where male participants formed the majority. Where reported, the mean age of participants was usually over 80 years. Luo 2015 and Papaioannou 2011 had younger participants with a mean age of 69 years. Gallagher 1992 gave no details on age, but the rest of the details provided in the abstract were compatible with an older population. Only Bean 1994 applied an upper age limit, this being 85 years.

All studies (except Miller 2006, which included participants with lower limb fractures) included only participants with hip fracture. We obtained separate data for participants with hip fracture for Miller 2006. Nineteen studies provided information on the types of hip fractures suffered by the participants (Anbar 2014; Day 1988; Delmi 1990; Eneroth 2006; Espaulella 2000; Flodin 2014; Hartgrink 1998; Myint 2013; Parker 2010; Prasad 2009; Schürch 1998; Scivoletto 2010; Serrano-Trenas 2011; Stableforth 1986; Sullivan 1998; Sullivan 2004; Tidermark 2004; Tkatch 1992; Wyers 2013). Seventeen studies excluded people with dementia or severe cognitive dysfunction. Many studies excluded people with a wide range of medical conditions (Anbar 2014; Bastow 1983b; Bean 1994; Bischoff-Ferrari 2010; Brown 1992b; Chevalley 2010; Delmi 1990; Eneroth 2006; Espaulella 2000; Flodin 2014; Luo 2015; Myint 2013; Schürch 1998; Scivoletto 2010; Tidermark 2004; Tkatch 1992; Van Stijn 2015; Wyers 2013). Eight studies indicated that consent (assent) was acceptable if given by a relative or guardian (Day 1988; Duncan 2006; Espaulella 2000; Hankins 1996; Houwing 2003; Parker 2010; Sullivan 1998; Sullivan 2004).

Eight studies, involving 616 participants, examined the effect of supplementation on malnourished participants (Bastow 1983b; Bean 1994; Brown 1992b; Gallagher 1992; Hankins 1996; Luo 2015; Miller 2006; Myint 2013). Gallagher 1992 and Luo 2015 defined participants as malnourished on the basis of serum albumin; other studies used anthropometric measurements, such as midupper arm circumference. Myint 2013 recruited participants if BMI was $<25 \mathrm{~kg} / \mathrm{m}^{2}$ and mean BMI was actually $21.7 \mathrm{~kg} / \mathrm{m}^{2}$. We discussed this with consultant geriatrician colleagues, who advised that participants in this trial be considered under 'malnourished targeted' category of subgroup analysis.

\section{Interventions}

The 41 included trials evaluated a variety of nutritional supplements, mostly in comparison with a control group. We have provided details of these and the method of delivery in individual studies in the Characteristics of included studies. The comparisons under test fell into five categories (as detailed below).

Four studies had three treatment groups each. Madigan 1994 had three groups: the two supplemented groups (one with a multivitamin and mineral supplement) were subsequently combined in the report, owing to small numbers at follow-up. Since these two groups both fit the criterion in this review for a 'multinutrient' supplement group, the combined results for these two groups, compared with the control, are also presented here. Botella-Carretero 2008 also had three groups: oral protein and energy, oral protein, and control; both supplemented groups have been combined for this review, also owing to small numbers. Papaioannou 2011 compared an initial oral bolus dose of 100,000 IU vitamin D2 versus 50,000 IU vitamin D2 versus placebo; followed by 1,000 IU vitamin D3 for 90 days in all groups. Finally, Chevalley 2010 compared three different protein sources: oral casein protein versus oral whey protein versus oral whey protein plus essential amino acids.

Miller 2006 had four groups: a nutrition supplementation group, a physical activity intervention group, a combined intervention group, and an attention control group. We have only used data from the nutritional supplementation only and control groups here. Bischoff-Ferrari 2010 had a factorial design with randomisation to two different doses of vitamin D3 and standard or extended physiotherapy.

We made the following comparisons:

\section{Multinutrient supplements (oral, nasogastric, intravenous) versus control}

The multinutrient supplements under investigation usually provided non-protein energy, protein, some vitamins and minerals. These were delivered either orally, via a nasogastric tube, intravenously, or combinations of these.

\section{Oral supplements}

The 18 studies testing oral supplements involved 1190 participants (Anbar 2014; Botella-Carretero 2008; Botella-Carretero 2010; Brown 1992b; Bruce 2003; Delmi 1990; Fabian 2011; Flodin 2014; Hankins 1996; Houwing 2003; Kang 2012; Luo 2015; Madigan 1994; Miller 2006; Myint 2013; Stableforth 1986; Tidermark 2004; Wyers 2013). Anbar 2014 undertook three measurements of resting energy expenditure to estimate requirements for the intervention group. Wyers 2013 included five dietetic visits and five follow-up phone calls for the intervention group. Interventions were usually started pre-operatively or in two days postoperatively and most continued for at least a month. 


\section{Nasogastric tube feeding}

Four studies involving 377 participants (Bastow 1983b; Gallagher 1992; Hartgrink 1998; Sullivan 1998), examined supplementation starting within five days of surgery and continued usually until oral intake was sufficient, or hospital discharge.

\section{Nasogastric tube feeding and oral supplements}

One study involving 57 participants (Sullivan 2004), examined supplementation postoperatively until oral intake was sufficient.

\section{Intravenous feeding and oral supplements}

One study involving 80 participants (Eneroth 2006) examined supplementation for the first 10 days in hospital.

\section{High protein-containing supplements versus low-protein or non- protein-containing supplements}

Protein supplementation was delivered within oral feeds, usually starting within a week of fracture and given for one to six months. This was assessed in four studies involving 371 participants (Espaulella 2000; Neumann 2004; Schürch 1998; Tkatch 1992). Whereas the protein supplement resulted in extra calories in the intervention group in Tkatch 1992, the energy content of both intervention and placebo groups were equivalent in Espaulella 2000 and Schürch 1998. Moderate quantities of minerals and vitamins were also provided with the protein supplement in Espaulella 2000 and Schürch 1998; none were in sufficient doses to detract from these being predominantly protein supplements. In Neumann 2004 there were differences in vitamin and mineral intakes between the high- and lower-protein supplements, and the carbohydrate intake in the lower-protein supplement resulting in similar energy contents of the two supplements.

\section{Comparison of different protein sources}

One study with 45 participants compared $20 \mathrm{~g}$ daily of oral casein protein versus $20 \mathrm{~g}$ of oral whey protein versus $15 \mathrm{~g}$ of oral whey protein and $5 \mathrm{~g}$ of essential amino acids in a ratio identical to casein, given from a mean of 10 days post-fracture for a month (Chevalley 2010).

\section{Vitamin supplementation versus control or lower dose} supplementation

This comparison was based on four studies involving 335 participants (Bischoff-Ferrari 2010; Day 1988; Hoikka 1980; Papaioannou 2011). Day 1988 investigated intravenous thiamin (vitamin B1) and water soluble vitamins versus control. Hoikka 1980 investigated the use of oral $1 \mathrm{mcg}$ 1-alpha-hydroxycholecalciferol and $1 \mathrm{~g}$ calcium as calcium carbonate daily versus placebo and $1 \mathrm{~g}$ calcium as calcium carbonate daily for four months. BischoffFerrari 2010 investigated daily 2000 IU vitamin D3 compared with daily 800 IU vitamin D3; all participants also received $1 \mathrm{~g}$ of calcium as calcium carbonate daily over one year. Papaioannou 2011 compared an initial oral bolus dose of 100,000 IU vitamin D2 versus 50,000 IU vitamin D2 versus placebo; followed by 1000 IU vitamin D3 for 90 days in all groups. Interventions were commenced pre-operatively or up to a mean of four days postoperatively and continued for between five days (Day 1988) and 3 to 12 months (Bischoff-Ferrari 2010; Hoikka 1980; Papaioannou 2011).

\section{Comparison of different vitamin D sources}

One study with 95 participants compared oral vitamin D3 1000 IU/ $\mathrm{d}$ and calcium carbonate equivalent to $600 \mathrm{mg} / \mathrm{d}$ to vitamin D2 $1000 \mathrm{IU} / \mathrm{d}$ and calcium carbonate equivalent to $600 \mathrm{mg} / \mathrm{d}$ for three months from the inpatient stay (Glendenning 2009).

\section{Iron supplementation versus control}

Three studies with 568 participants investigated oral or intravenous iron supplementation compared with no intervention or placebo, started pre-operatively or early postoperatively, for the first month after hip fracture (Parker 2010; Prasad 2009; Serrano-Trenas 2011).

\section{Vitamin, mineral and amino acid supplementation versus control}

One study with 107 participants investigated six weeks of an oral Restorfast supplement daily (L-carnitine, calcium, magnesium, vitamin D3, L-leucine) followed by 10 weeks of an oral Riabylex supplement daily (creatine, L-carnitine, coenzyme Q10, nicotinamide, pantothenic acid, riboflavin) (Scivoletto 2010). The start time for the intervention was unclear. Creatine, coenzyme $Q$ and L-carnitine were also included but are not vitamins, minerals or amino acids, and can be manufactured by the body.

\section{Isonitrogenous ornithine alpha-ketoglutarate versus peptide supplement}

One study with 59 participants made this comparison (Bean 1994). Ornithine alpha-ketogluturate is metabolised in part to the amino acid glutamine, and is used to improve nitrogen conservation. The interventions were probably delivered orally, and were given for two months, start time unclear.

\section{Taurine versus placebo}

One trial with 236 participants compared taurine with a placebo control (Van Stijn 2015). Taurine or placebo capsules were started pre-operatively and then supplied for six days postoperatively. Taurine, which has been described as a conditionally essential amino acid, is a semi-essential amino acid with antioxidant action to theoretically reduce oxidative stress which can be induced by surgical tissue injury. Taurine was provided three times a day with a scheme of 2-1-2 capsules of $1.2 \mathrm{~g}$ taurine to reach $6 \mathrm{~g}$ per day daily dose.

\section{Dietetic assistants versus usual care}

One study, involving 318 participants, tested the provision of extra assistance in the form of dietetic assistants, above that of dietitians and nurses, to help improve people's dietary intake (Duncan 2006). The dietetic assistants gave support for a median of 16 to 17 days; the start time for this assistance was unclear.

\section{Excluded studies}

We have given reasons for excluding 43 studies in the Characteristics of excluded studies. Six excluded studies were published in languages other than English, sufficient translation having been obtained to establish non-eligibility. The major reasons for exclusion included studies not being RCTs (Bachrach 2001; Bell 2014; Bradley 1995; Giaccaglia 1986; Groth 1988; Gunnarsson 2009; Harju 1989; Hoekstra 2011; Holst 2012; Kacmaz 2007; Lawson 2003; Ravetz 1959; Tassler 1981); studies not recruiting (or presenting separate data for) people who had sustained a hip fracture (Brocker 1994; Cameron 2011; Goldsmith 1967; Hitz 2007; Larsson 1990; Lauque 2000; Lawson 2003; Pedersen 
1999; Volkert 1996); and studies not presenting the outcomes of interest (Beringer 1986; Boudville 2002; Gegerle 1986; Stumm 2001; Wong 2004; Zauber 1992).

\section{Ongoing studies}

We have given details of seven ongoing trials in the Characteristics of ongoing studies. Of the ongoing studies, two (ACTRN12612000448842; Rowlands) with a total of 350 participants will examine the use of intravenous iron supplementation. The size of the trial by NCT00497978, which will examine the use of taurine supplementation, is unclear. ACTRN12609000241235 will recruit 150 participants to examine the effect of fish oils compared with other oils. In a trial with 340 participants, ACTRN12610000392066 will examine the use of oral 250,000 IU vitamin D3 compared with placebo. NCT01505985 and NCT01404195 will examine the use of oral multinutrient supplements compared with placebo or usual care in a total of 124 participants.

\section{Studies awaiting classification}

We have given details of the six studies in this category in the Characteristics of studies awaiting classification. We have requested further details from the trial investigators, where required.

\section{Risk of bias in included studies}

The quality of trial methodology, as reported, was disappointing and we could not rule out risk of bias associated with poor trial methods. Many of the trials failed to report trial methodology in sufficient detail. We obtained additional information on methods for nine trials (Brown 1992b; Bruce 2003; Day 1988; Espaulella 2000; Hankins 1996; Hartgrink 1998; Houwing 2003; Luo 2015; Sullivan 1998). We have summarised the risk of bias judgements in Figure 2 and Figure 3.

\section{Figure 2. Risk of bias graph: review authors' judgements about each risk of bias item presented as percentages across all included studies}

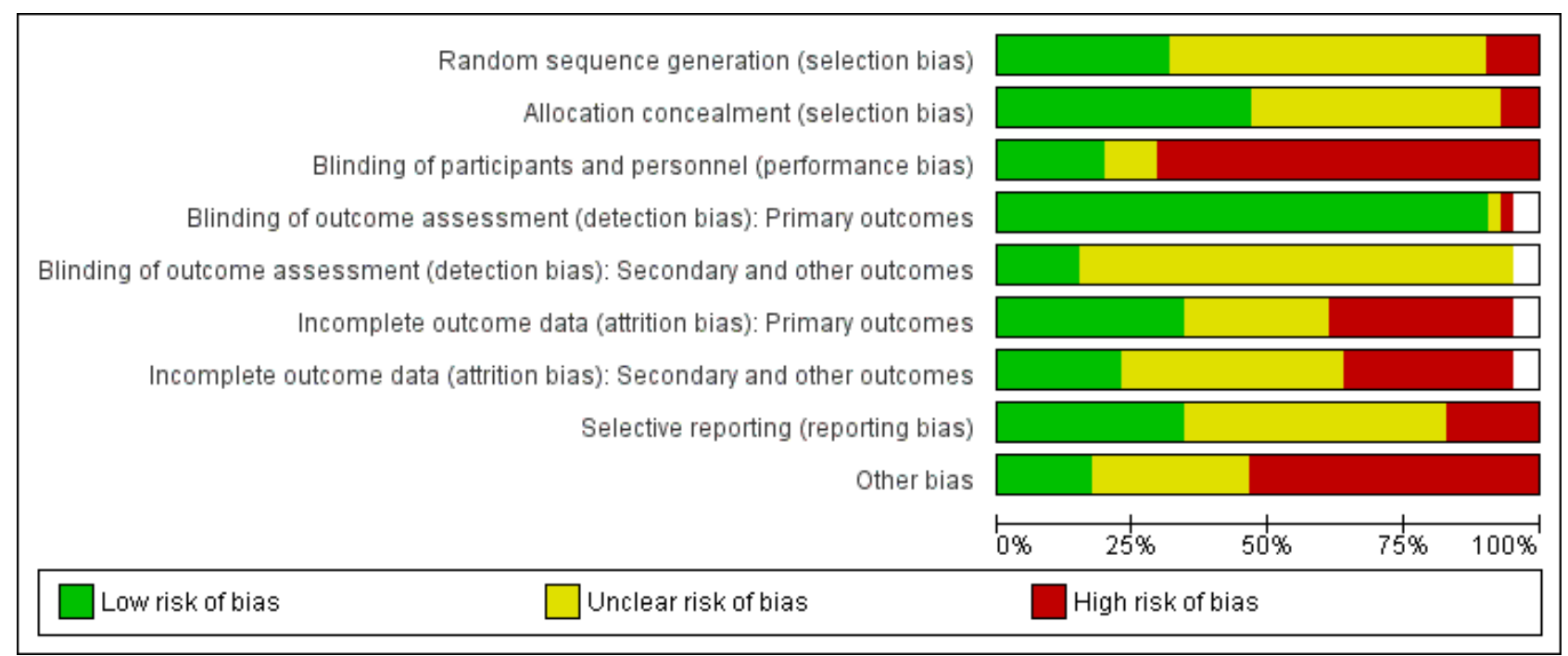


Figure 3. Risk of bias summary: review authors' judgements about each risk of bias item for each included study

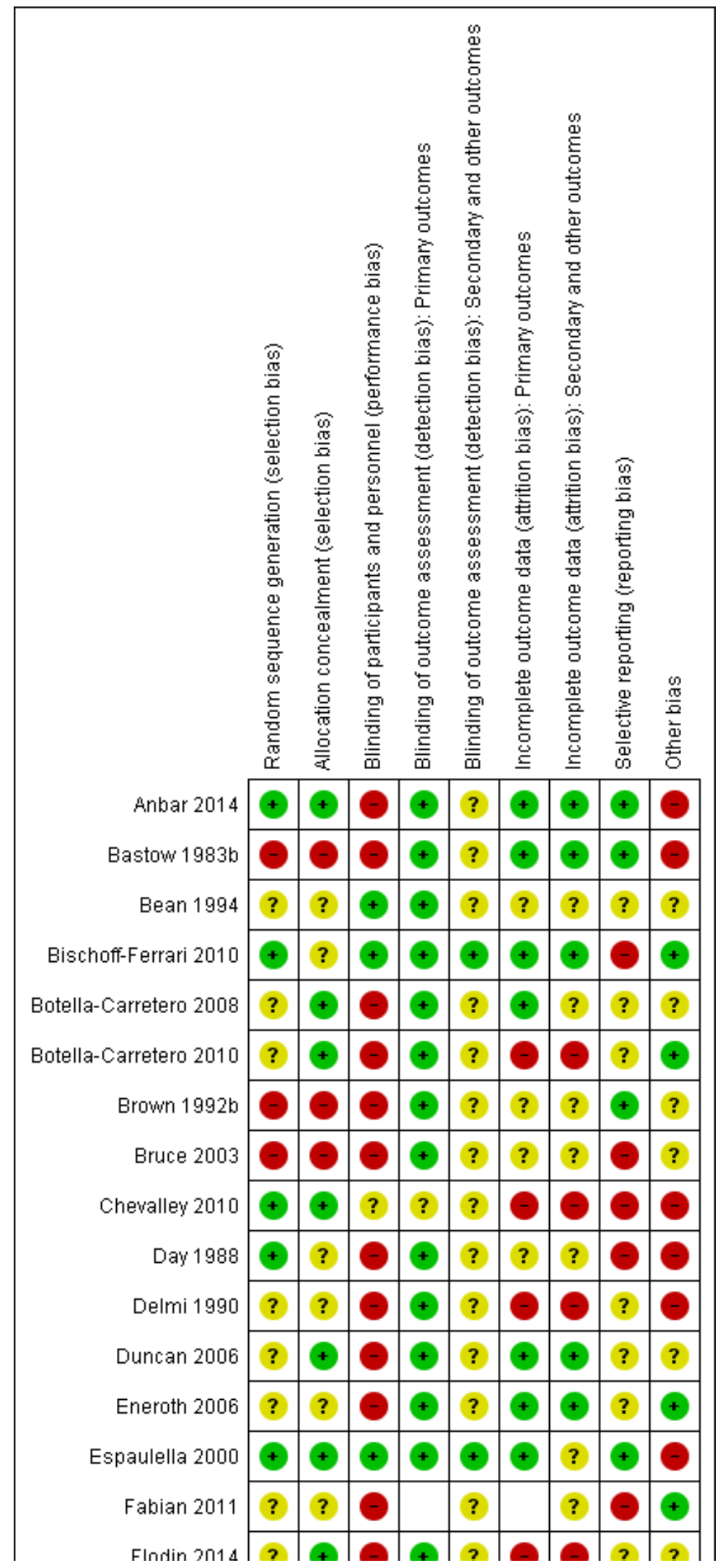


Figure 3. (Continued)

\begin{tabular}{|c|c|c|c|c|c|c|c|c|c|}
\hline & & & 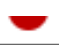 & & & & & $v$ & 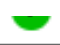 \\
\hline Flodin 2014 & $?$ & + & $\odot$ & + & $?$ & $\odot$ & $\odot$ & $?$ & $?$ \\
\hline Gallagher 1992 & $?$ & $?$ & $\odot$ & + & $?$ & $?$ & $?$ & $\odot$ & $?$ \\
\hline Glendenning 2009 & $?$ & + & + & + & $?$ & $\odot$ & $\odot$ & ? & $?$ \\
\hline Hankins 1996 & $?$ & $\oplus$ & $\odot$ & + & $?$ & + & $\odot$ & + & $\odot$ \\
\hline Hartgrink 1998 & $?$ & $?$ & $\odot$ & + & $?$ & $?$ & $?$ & $?$ & - \\
\hline Hoikka 1980 & - & $?$ & $?$ & & $?$ & & $?$ & $?$ & - \\
\hline Houwing 2003 & $\odot$ & $\odot$ & $\odot$ & + & + & $\odot$ & $\odot$ & $?$ & - \\
\hline Kang 2012 & $?$ & $?$ & $\odot$ & + & $?$ & $?$ & $?$ & $?$ & $?$ \\
\hline Luo 2015 & $\odot$ & $?$ & - & + & $?$ & $\odot$ & $\odot$ & $\Theta$ & $\odot$ \\
\hline Madigan 1994 & $?$ & $?$ & $\odot$ & + & $?$ & $\Theta$ & $\odot$ & + & $?$ \\
\hline Miller 2006 & + & $\oplus$ & $\odot$ & + & & $\oplus$ & & + & - \\
\hline Myint 2013 & $?$ & + & $\odot$ & + & + & $\odot$ & $\odot$ & + & + \\
\hline Neumann 2004 & $?$ & $?$ & $?$ & + & $?$ & $?$ & $\odot$ & $?$ & - \\
\hline Papaioannou 2011 & $\odot$ & $\odot$ & $\odot$ & + & + & $\Theta$ & $?$ & + & $\Theta$ \\
\hline Parker 2010 & $?$ & $\oplus$ & - & + & $?$ & + & $?$ & $?$ & + \\
\hline Prasad 2009 & + & $?$ & $\odot$ & $\odot$ & & $\odot$ & & $?$ & $?$ \\
\hline Schürch 1998 & $?$ & $?$ & $\odot$ & + & $?$ & + & $?$ & $?$ & $\odot$ \\
\hline Scivoletto 2010 & $?$ & $?$ & $\Theta$ & + & $?$ & $\Theta$ & $\Theta$ & $?$ & $?$ \\
\hline Serrano-Trenas 2011 & $?$ & + & - & + & $?$ & $\Theta$ & $\Theta$ & + & + \\
\hline Stableforth 1986 & $?$ & $?$ & - & $\odot$ & $?$ & $?$ & $?$ & $?$ & - \\
\hline Sullivan 1998 & ? & + & - & + & ? & + & + & $?$ & - \\
\hline Sullivan 2004 & $\odot$ & $\odot$ & - & + & $?$ & + & $\odot$ & + & $\Theta$ \\
\hline Tidermark 2004 & $?$ & $?$ & - & + & $?$ & $?$ & $?$ & + & $\Theta$ \\
\hline Tkatch 1992 & $?$ & $?$ & $?$ & 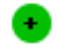 & $?$ & $\Theta$ & $\Theta$ & $?$ & $\odot$ \\
\hline Van Stijn 2015 & $\odot$ & + & + & + & + & $\odot$ & $\odot$ & + & $\odot$ \\
\hline Wyers 2013 & $\odot$ & $\odot$ & $\odot$ & + & $?$ & $?$ & $?$ & + & $\Theta$ \\
\hline
\end{tabular}

\section{Allocation}

\section{Sequence generation}

We judged random sequence generation as adequate resulting in low risk of bias in 13 trials (32\%) (Anbar 2014; Bischoff-Ferrari 2010; Chevalley 2010; Day 1988; Espaulella 2000; Houwing 2003; Luo 2015; Miller 2006; Papaioannou 2011; Prasad 2009; Sullivan 2004; Van Stijn 2015; Wyers 2013). Four trials (10\%) were quasirandomised and thus at high risk of bias (Bastow 1983b; Brown 1992b; Bruce 2003; Hoikka 1980). The remaining trials we judged to be at unclear risk of risk because of insufficient details.

\section{Allocation concealment}

Concealment of allocation was judged to be adequate resulting in low risk of bias in 19 (46\%) trials (Anbar 2014; BotellaCarretero 2008; Botella-Carretero 2010; Chevalley 2010; Duncan 2006; Espaulella 2000; Flodin 2014; Glendenning 2009; Hankins 1996; Houwing 2003; Miller 2006; Myint 2013; Papaioannou 2011; 
Parker 2010; Serrano-Trenas 2011; Sullivan 1998; Sullivan 2004; Van Stijn 2015; Wyers 2013). Allocation was unlikely to be concealed in three of the quasi-randomised studies (Bastow 1983b; Brown 1992b; Bruce 2003), which were judged to be at high risk of bias. The remaining trials were judged to be at unclear risk of risk because of insufficient details.

\section{Blinding}

We judged eight (20\%) trials to be at low risk of performance bias (blinding of participants and personnel) (Bean 1994; BischoffFerrari 2010; Espaulella 2000; Glendenning 2009; Houwing 2003; Papaioannou 2011; Schürch 1998; Van Stijn 2015). These trials generally had placebo interventions, or were comparisons of different kinds of supplement. We judged 29 trials at high risk of performance bias and four at unclear risk.

We judged almost all trials (95\%) to be at low risk of detection bias relating to blinding of outcome assessment for primary outcomes, with the exception of two trials reporting putative side effects of interventions (Chevalley 2010; Prasad 2009). Blinding of secondary or other outcomes was less likely to be judged low risk, with only six trials (15\%) judged as being low risk of detection bias (Bischoff-Ferrari 2010; Espaulella 2000; Houwing 2003; Myint 2013; Papaioannou 2011; Van Stijn 2015). The remaining trials we judged to be at unclear risk of detection bias for both domains.

\section{Incomplete outcome data}

We judged 15 trials to be at low risk of bias for incomplete outcome data (attrition bias) for primary outcomes. Fourteen trials were judged to be at high risk of bias in this category (Botella-Carretero 2010; Chevalley 2010; Delmi 1990; Flodin 2014; Glendenning 2009; Luo 2015; Madigan 1994; Myint 2013; Papaioannou 2011; Prasad 2009; Scivoletto 2010; Serrano-Trenas 2011; Tkatch 1992; Van Stijn 2015). The remainder were judged at unclear risk of attrition bias for primary outcomes, where reported.

Incomplete outcome data were more problematic for secondary outcome data, and we judged only 10 trials to be at low risk of attrition bias. Thirteen trials were judged to be at high risk of bias and the remainder, where secondary outcomes were reported, at unclear risk of attrition bias.

\section{Selective reporting}

We judged 14 trials (34\%) to be at low risk of bias for selective reporting of outcomes. However, we judged seven trials to be at high risk of bias (Bischoff-Ferrari 2010; Bruce 2003; Chevalley 2010; Day 1988; Fabian 2011; Gallagher 1992; Luo 2015), usually as a result of data not presented that would be expected from their methods, or data that were provided not mentioned in methods, for example, length of stay, mortality, functional status. The remainder were at unclear risk of selective reporting bias.

\section{Other potential sources of bias}

For other potential sources of bias, we assessed adequacy of the length of follow-up, adequacy of information on nutritional status, whether there were major between-group imbalances in key baseline characteristics, and whether there was drug company involvement.

Recovery from hip fracture in older people takes time, with longterm implications for morbidity and functional status. Sixteen studies followed up participants for six months or over; with six of these extending follow-up to one year (Bischoff-Ferrari 2010; Flodin 2014; Miller 2006; Schürch 1998; Van Stijn 2015; Wyers 2013).

Details of the nutritional status of the groups were often missing. Related to this was the lack of information on anthropometric parameters. While it is difficult to measure height and weight in people with hip fracture, 11 trials $(27 \%)$ failed to provide any information on baseline anthropometry (e.g. mid-upper arm circumference or weight) or an anthropometry-derived nutrition risk score.

An appraisal of the trials for baseline imbalances found important differences between the two groups for age in two trials (Papaioannou 2011; Sullivan 2004), for type of hip fracture in Tidermark 2004; and for body weight in Stableforth 1986.

Twenty trials reported receiving some drug company sponsorship or provision of supplements, and were judged to be at high risk of bias. One trial (Anbar 2014) was judged to be at high risk of bias as a result of stopping early due to poor recruitment, when the interim analysis showed a 'positive result'. Another trial (Van Stijn 2015) was judged to be at high risk of bias because the power calculation was based on a very unlikely $50 \%$ reduction in mortality.

\section{Effects of interventions}

See: Summary of findings for the main comparison Multinutrient supplements (oral) versus control for hip fracture aftercare in older people; Summary of findings 2 Multinutrient supplements (nasogastric) versus control for hip fracture aftercare in older people

We have listed the outcomes reported in the included studies in the Characteristics of included studies. These are grouped by 'main' (primary and secondary) outcomes and 'other' outcomes, as defined in the Types of outcome measures. The results presented concentrate on main outcomes.

The included studies often failed to report main outcomes. For example, only two trials reported participants' perceived quality of life after discharge (Tidermark 2004; Wyers 2013), though in the 'other' outcomes category, it was notable that carer burden and stress were also not reported.

Postoperative complications were reported as a very wide variety of individual conditions (including aspiration pneumonia, gastrointestinal ulcer, pressure sore, face flushing, deep hip joint infection, chest infection, urinary tract infection, deep venous thrombosis, pulmonary embolism, stroke, thrombophlebitis, ischaemic heart disease, cardiac failure, anaemia, hyponatraemia, confusion, anaphylaxis, and acute renal failure) and generic complications (gastrointestinal, surgical, infection, postoperative, life-threatening). It was not possible to undertake analyses according to the severity or type of complication. Putative sideeffects of supplementation are also presented separately. Those presented for individual studies are noted in the Characteristics of included studies. In order to give a more complete picture of morbidity, we opted to present the number of participants with complications at the end of individual studies. Results were not used from those studies, such as Tkatch 1992, which provided the numbers of complications but not the numbers of participants with complications. Results from Houwing 2003 were also not pooled since this trial only recorded pressure sores. 
For some trials we have presented the numbers of trial participants with 'unfavourable outcome'. As defined above, this is the sum of the participants who had died plus the survivors with complications. For most studies, we could not deduce this result from the available data. Results for 'unfavourable outcome' based on a slightly different definition (mortality or survivors with a major complication or two or more minor complications) originally presented in Delmi 1990, were available for three studies (Delmi 1990; Hankins 1996; Tkatch 1992) and we have used in them this review.

We have presented mortality results using denominators based on the numbers of participants at randomisation (intentionto-treat analysis). Generally, we have presented the results for other outcomes using denominators based on the numbers of participants available at follow-up. Exceptions to this are noted below.

Lengths of hospital stay in the acute hospital and rehabilitation hospital were often reported but we have not presented them in the analyses, or pooled them. This is because, even when means and standard deviations (SD) for these outcomes were reported, it was unlikely that lengths of stay were normally distributed.

In the following,we have presented results for the fixed-effect model. Where the conclusions reached by combining comparable groups of trials differed noticeably between the fixed-effect and random-effects models, we have also presented the results for the random-effects models.

\section{Multinutrient supplements (oral or nasogastric routes, or both) versus control}

Below we present the separate results by the route (oral, nasogastric or both) used for multinutrient supplementation, and then discuss the overall results for multinutrient supplementation. Finally, we investigate whether the results varied, according to whether the trials specifically targeted people who were malnourished, or according to trial quality (represented by whether allocation was concealed or not).

\section{Oral supplements}

Eighteen studies evaluated the effect of oral multinutrient supplementation (Anbar 2014; Botella-Carretero 2008; BotellaCarretero 2010; Brown 1992b; Bruce 2003; Delmi 1990; Fabian 2011; Flodin 2014; Hankins 1996; Houwing 2003; Kang 2012; Luo 2015; Madigan 1994; Miller 2006; Myint 2013; Stableforth 1986; Tidermark 2004; Wyers 2013) of which five (Brown 1992b; Hankins 1996; Luo 2015; Miller 2006; Myint 2013) targeted people who were malnourished. Follow-up was usually until discharge or for one month; three trials followed up for six months (Bruce 2003; Delmi 1990; Myint 2013) and four trials followed up for 12 months (Flodin 2014; Miller 2006; Tidermark 2004; Wyers 2013).

\section{Mortality}

Pooled mortality data from 15 studies showed no clear difference between the two groups in mortality at follow-up ranging from until hospital discharge to one year ( $24 / 486$ versus $31 / 481$; risk ratio (RR) $0.81,95 \%$ confidence interval $(\mathrm{Cl}) 0.49$ to 1.32 ; low-quality evidence downgraded two levels due to risk of bias and imprecision; Analysis 1.1, Figure 4). Five of these 15 studies reported no deaths in either group; all had short-term follow-up of up to discharge or for one month (Botella-Carretero 2008; Botella-Carretero 2010; Brown 1992b; Luo 2015; Stableforth 1986). Bruce 2003 reported similar percentages of participants in the two groups who had died or were in a nursing home at six months (23.4\% versus $24.6 \%$ ). Kang 2012 reported that supplementation reduced mortality but provided no data to support this. 
Figure 4. Forest plot of comparison: 1 Multinutrient supplements (oral, nasogastric, intravenous) versus control, outcome: 1.1 Mortality by end of study

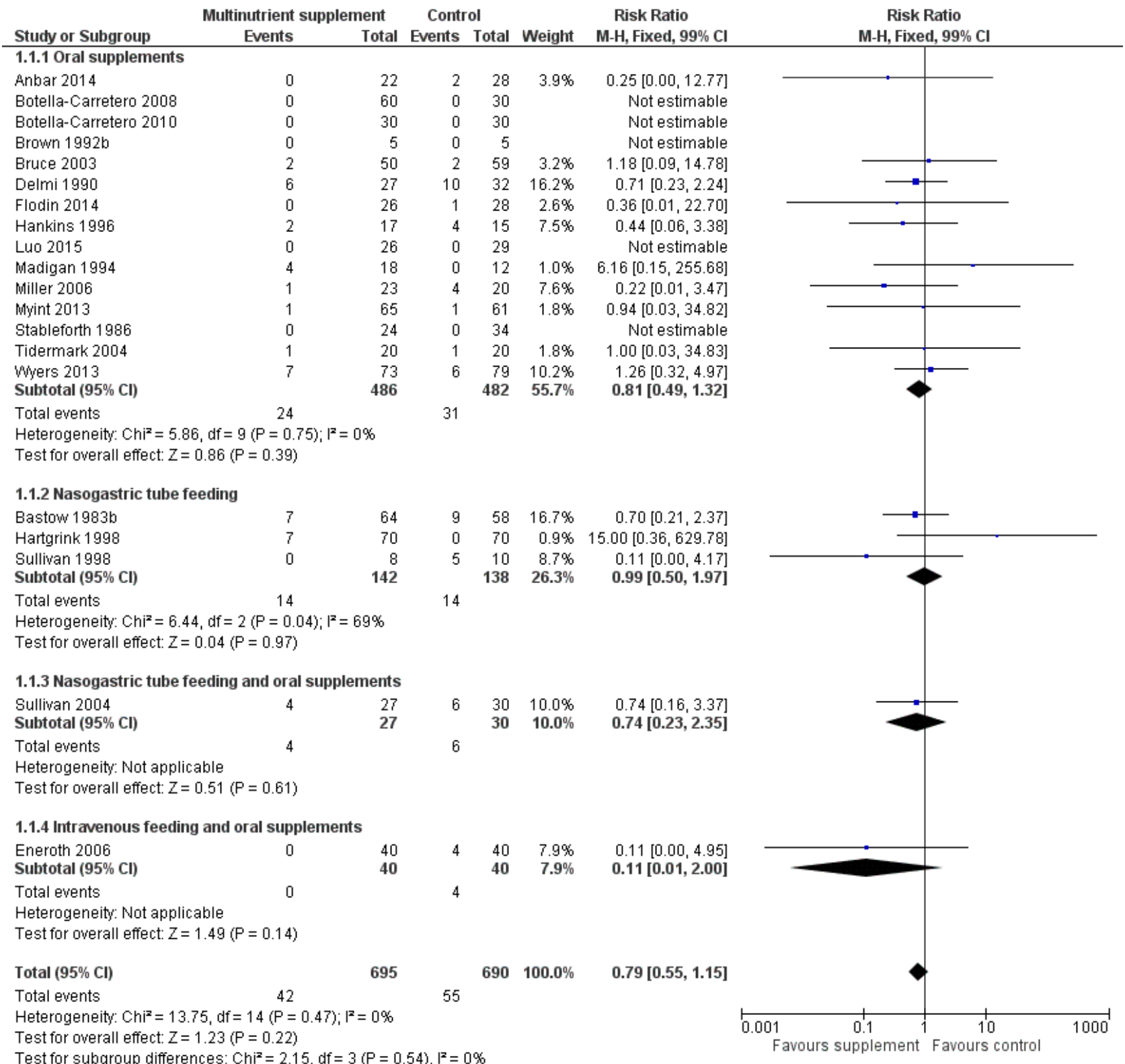

\section{Complications}

Thirteen studies reported the numbers of participants with complications at the end of the study (Anbar 2014; BotellaCarretero 2008; Botella-Carretero 2010; Delmi 1990; Flodin 2014; Hankins 1996; Kang 2012; Luo 2015; Madigan 1994; Myint 2013; Stableforth 1986; Tidermark 2004; Wyers 2013). Follow-up was usually until discharge or for one month but two trials followed up for six months (Delmi 1990; Myint 2013) and three trials followed up for 12 months (Flodin 2014; Tidermark 2004; Wyers 2013). Results from Houwing 2003 were not included since these were only for pressure sores: there was no difference between the two groups in the numbers of participants with this complication. Kang 2012 reported that supplementation reduced the rate of postoperative complications but did not provide any data to support this statement. Luo 2015 reported 20 adverse events in the supplemented group and 24 in the control group, with two events in the intervention group assessed as being possibly related to the supplement (nausea, pruritus); denominators were unclear. Pooled results from 11 studies showed a reduction in the participants with complications in the supplemented group (123/370 versus 157/367; RR 0.71 favouring supplementation, $95 \% \mathrm{Cl} 0.59$ to 0.86 ; low-quality evidence downgraded two levels due to serious risk of bias; Analysis 1.2, Figure 5). 
Figure 5. Forest plot of comparison: 1 Multinutrient supplements (oral, nasogastric, intravenous) versus control, outcome: 1.2 Participants with complications at end of study

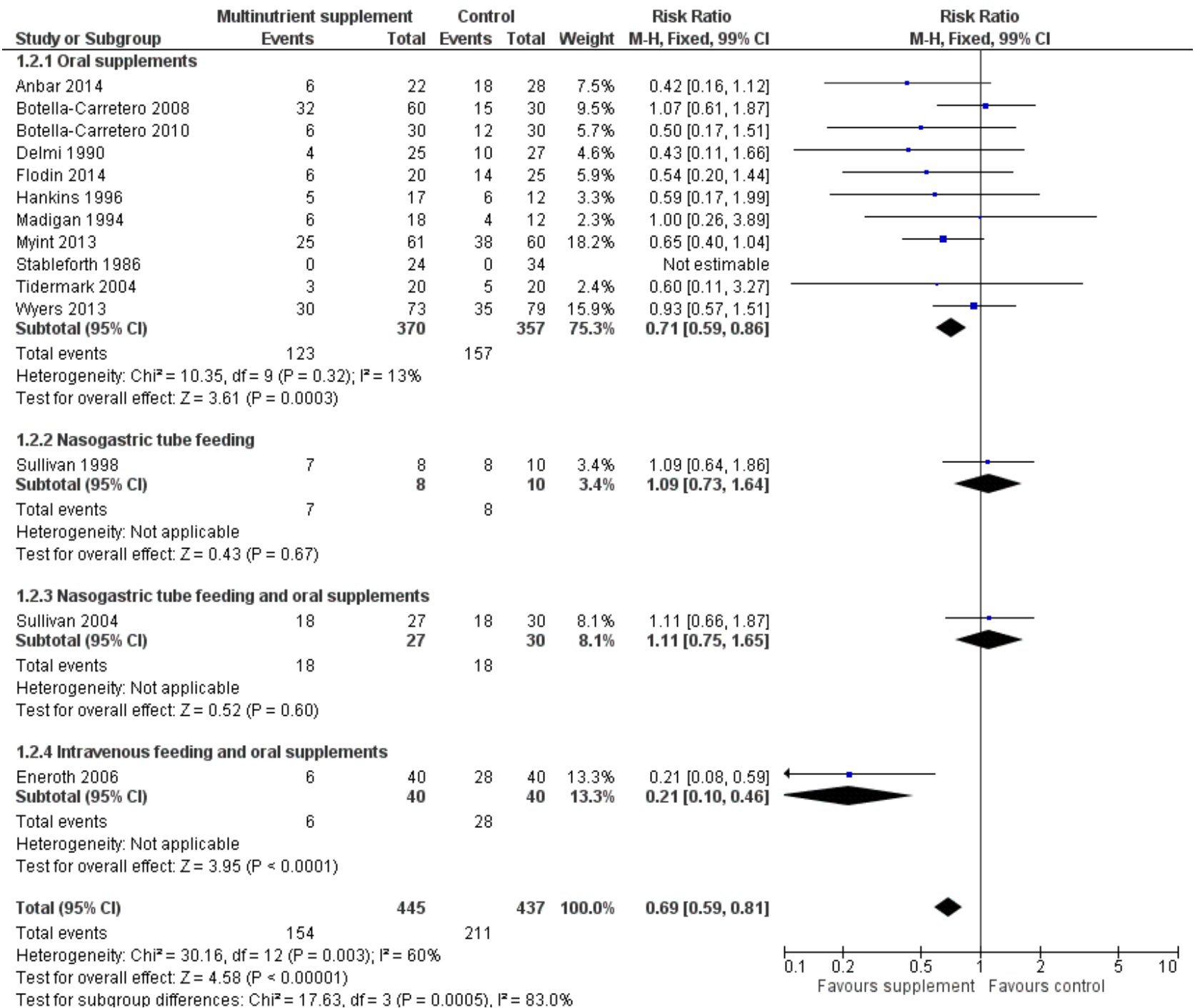

\section{Unfavourable outcome}

Six studies reported data for 'unfavourable outcome' (BotellaCarretero 2008; Botella-Carretero 2010; Delmi 1990; Flodin 2014; Hankins 1996; Stableforth 1986). However, three of these did not report any deaths. Data pooled using the fixed-effect model from these six trials for the combined outcome for mortality or complications ('unfavourable outcome') at final follow-up favoured the supplemented group (58/176 versus $67 / 158$; RR $0.67,95 \% \mathrm{Cl}$ 0.51 to 0.89 ; very low-quality evidence downgraded two levels for serious risk of bias and one for indirectness reflecting the mixed definition of the outcome measure; Analysis 1.4; Figure 6). The pooled results using the random-effects model showed similar results (RR 0.65, 95\% Cl 0.45 to 0.95; data not shown). Delmi 1990 presented results, without explanation of the missing participants, for only 52 participants out of the 59 originally randomised. Exploratory analysis for 'unfavourable outcome' based on numbers randomised (in all trials where available) in which it was assumed that all excluded participants in the supplemented group had complications at follow-up (66/184 versus $67 / 169$; RR $0.81,95 \% \mathrm{Cl}$ 0.62 to 1.04; Analysis 1.5) shows these findings are not robust.

Hankins 1996 also presented data for 'unfavourable outcome' in the acute hospital (14/17 versus $12 / 14$; RR $0.96,99 \% \mathrm{Cl} 0.64$ to 1.44 ) and post-discharge (8/17 versus $6 / 14$; RR $1.10,99 \% \mathrm{Cl} 0.39$ to 3.09); Analysis 1.5. Delmi 1990 presented data for similar outcomes but gave insufficient explanation of the denominators used in their report.

\section{Secondary outcomes Length of stay}

The duration of hospital stay was reported in 13 studies (Anbar 2014; Botella-Carretero 2010; Brown 1992b; Bruce 2003; Madigan 1994; Myint 2013; Sullivan 1998; Espaulella 2000; Neumann 2004; Parker 2010; Serrano-Trenas 2011; Day 1988; Scivoletto 2010), with variable effects for the interventions. We have presented data for those trials that allowed significance testing in Table 1. Anbar 2014 reported that hospitalisation was shorter in the intervention group (10.1 days versus 12.5 days: mean difference (MD) -2.40 days, $99 \% \mathrm{Cl}-5.60$ to 0.80 days). Botella-Carretero 2008 reported that hospital stay was similar for all three groups (the graph of these data clearly showed no differences). Botella-Carretero 2010 found 
that the length of acute hospital stay was similar in intervention and control groups (13.3 days versus 12.8 days: MD 0.50 days, $99 \% \mathrm{Cl}-2.26$ to 3.26 days). Botella-Carretero 2010 also reported that total length of hospital stay (including rehabilitation) was similar in intervention and control groups (19.0 (SD 4.2) days versus 18.9 (SD 4.4) days, denominators unclear). Brown 1992b, which included 10 participants only, reported a lower acute hospital stay for the supplementation group ( 27 days versus 48 days: MD -21.00 days, $99 \% \mathrm{Cl}-65.15$ to 23.15 days). Bruce 2003 reported no significant difference between the two groups in the mean length of hospital stay (17.7 days versus 16.6 days: MD 1.10 days, $99 \% \mathrm{Cl}$ -3.53 to 5.73 days). Delmi 1990 reported a statistically significantly lower median length of stay in acute and rehabilitation wards for the supplementation group (24 days (range 13 to 157 ) versus 40 days (range 10 to 259); reported $P<0.02$ ). Fabian 2011 reported that the duration of hospitalisation was shorter in supplemented participants (17(SD 4) versus 19 (SD 9) days, denominators unclear).

Hankins 1996 found that supplemented participants had a median acute and rehabilitation stay of 26 days (range 6 to 60) versus 21 days (range 3 to 60 ) for participants in the control group (reported $P$ = not significant). Madigan 1994 found that the acute hospital stay was 16 days in the combined intervention group and 15 days in the control group (MD 1.00 day, $99 \% \mathrm{Cl}-8.51$ to 10.51 days). Both groups, including several patients with other lower-limb fractures, in Miller 2006 stayed a median of 24 days in hospital. Myint 2013 found the length of stay in the rehabilitation ward was shorter in the intervention group (26.2 days versus 29.9 days: MD -3.70 days, $99 \% \mathrm{Cl}-8.30$ to 0.90 days). Tidermark 2004 reported no significant difference in median hospital stay during the first year after surgery in intervention and control groups ( 20 days (range 5 to 356 days) versus 27 days (range 5 to 197 days)). Wyers 2013 found the length of stay in acute and rehabilitation hospital to be similar for intervention and control groups (36 days, range 4 to 185 days, versus 38 days, range 3 to 183 days, reported $P=0.85$ ).

\section{Functional status and level of care required}

Trials reported a variety of functional outcomes in various ways; pooling was either not possible or not appropriate. Bruce 2003 reported no significant differences between the two groups in functional outcomes (fall in the Katz activities of daily living score: $41.7 \%$ versus $33.9 \%$ ) or living at home at six months $(63.8 \%$ versus $63.2 \%$ ). Hankins 1996 found no statistically significant effect of the supplement at two months on the Barthel Index of functional ability; median 56 (range 0 to 100) versus 40 (range 0 to 92). Luo 2015 reported no significant difference between study groups in gait speed or modified Barthel Index at 14 or 28 days. Madigan 1994 found that the combined intervention group were more likely to return to their premorbid mobility (non-return: $9 / 18$ versus $7 / 12$; RR $0.86,99 \% \mathrm{Cl} 0.36$ to 2.05 ; analysis not shown), but this may have reflected that significantly more supplemented participants were sent to a rehabilitation hospital. Myint 2013 reported no statistically significant difference between groups for the Elderly Mobility Scale or Functional Independence Measure. A higher proportion of participants in the intervention group were discharged to nursing homes (19/61 versus 15/60; RR $1.25,99 \% \mathrm{Cl} 0.70$ to 2.22 ).

Activities of daily living, assessed by the Katz score, in Tidermark 2004, were better maintained in the supplemented group at six months (dependence in bathing and one other function: 2/18 versus 8/16; RR $0.22,99 \% \mathrm{Cl} 0.04$ to 1.39 ; analysis not shown) but less so at 12 months (4/18 versus $6 / 16$; RR $0.63,99 \% \mathrm{Cl} 0.15$ to 2.59 ; analysis not shown), compared with the control group. Tidermark 2004 also found that mobility data were not significantly different between the two groups.

At six months postoperatively, Wyers 2013 found no significant effect from the intervention on functional status, activities of daily living or household activities of daily living. The frequency of hospital readmissions did not differ between groups.

\section{Quality of life}

Tidermark 2004 reported no significant difference between the two groups for health-related quality of life at six and 12 months, as assessed by the EuroQol questionnaire. At six months postoperation Wyers 2013 found no significant difference for Quality Adjusted Life Years (QALYs) (MD $-0.02,95 \% \mathrm{Cl}-0.12$ to 0.08 ).

\section{Fracture healing}

Tidermark 2004 found no significant difference between the two groups in fracture healing complications ( $4 / 18$ versus $7 / 17$; RR 0.54 , $99 \% \mathrm{Cl} 0.14$ to 2.10 ; analysis not shown).

\section{Putative side effects of treatment (e.g. vomiting and diarrhoea)}

Botella-Carretero 2008 reported vomiting, diarrhoea or both in $23 \%$ of participants taking the protein supplement, $30 \%$ of participants taking the protein and energy supplement, and $17 \%$ of controls. Botella-Carretero 2010 found that $3 \%$ of the intervention group and $10 \%$ of controls had vomiting, diarrhoea or both. Flodin 2014 reported that three participants in the control group and none in the intervention group had constipation or diarrhoea (denominators unclear). Hankins 1996 found that $12 \%$ of participants stopped the supplement as a result of nausea or diarrhoea. Luo 2015 reported two adverse events possibly related to supplements (nausea and pruritus). Myint 2013 found that six participants (10\%) reported intolerance of the supplements (including dislike of the taste, nausea, abdominal bloating and diarrhoea). Neumann 2004, Tidermark 2004 and Wyers 2013 reported no adverse effects in either group. Pooling of data from those trials providing data for both intervention and control groups showed no difference between the two groups (18/231 versus $11 / 211$; RR $0.99,95 \% \mathrm{Cl} 0.47$ to $2.05 ; 6$ studies; $\left.\right|^{2}=49 \%$; very low-quality evidence downgraded three levels due to risk of bias, inconsistency and imprecision; Analysis 1.6).

\section{Compliance}

Anbar 2014 reported that the supplemented group had a significantly higher mean daily energy and protein intake during the first 11 postoperative days (reported $P=0.001$ ). BotellaCarretero 2008 reported mean consumption of $41 \%$ for the protein supplement and $51 \%$ for the protein and energy supplement. Botella-Carretero 2010 found that $52 \%$ of supplementation was ingested. Bruce 2003 reported a mean consumption of 20.6 cans of supplement, out of a maximum possible of 28 . Delmi 1990 reported that the supplement did not reduce volitional food intake, and compliance appeared not to be a problem. Flodin 2014 reported that 7 of 18 participants complied with supplement prescription, and the remaining participants took half the prescribed supplementation. Hankins 1996 found that only $65 \%$ of participants managed to complete the full 30 days of supplementation. However, the supplement had no significant effect on ordinary food intake. Houwing 2003 found that the mean daily intake of the active or placebo supplements was $77 \%$ in 
both groups. Luo 2015 reported good compliance with intervention participants consuming $91 \%$ to $100 \%$ of recommended intake. Madigan 1994 also found that the oral supplement did not significantly affect volitional intake, but made no comment on compliance. Myint 2013 reported an overall compliance rate for supplements of $78 \%$. Wyers 2013 found that $67 \%$ of the participants adhered to the nutritional recommendations from the dietician and $79 \%$ were adherent to the supplements in hospital. After discharge, the adherence was $73 \%$ and $80 \%$, respectively.

Neither Brown 1992b, Tidermark 2004 nor Stableforth 1986 gave details on volitional food intake or compliance with the supplements. Specific data on adherence for participants with hip fracture in the nutrition-supplementation only group of Miller 2006 were not available.

\section{Carer burden and stress}

No study provided data for this outcome.

\section{Economic outcomes}

Wyers 2013 in the Netherlands undertook an economic evaluation of supplementation and dietetic support for three months. Based on QALYs and a societal perspective, the Incremental CostEffectiveness Ratio was 36,943 EUR/QALY. Based on total societal costs and a willingness to pay of EUR 20,000 , the probability that the intervention was cost-effective was $45 \%$.

\section{Nasogastric tube feeding}

\section{Primary outcomes}

Four studies examined nasogastric multinutrient supplementation (Bastow 1983b; Gallagher 1992; Hartgrink 1998; Sullivan 1998). Gallagher 1992, which was only published as an abstract, gave no denominators and so could not be included in the meta-analyses. Information provided by Ronald Koretz (personal communication), based on notes taken at a conference presentation by Gallagher 1992, indicated a possible failure to undertake intention-to-treat analysis. It seems likely that 12 participants allocated to the intervention group, who had feeding discontinued when their tube was pulled out, were crossed over to the control group in the analysis. There were also some differences in the results presented at the conference and in the published abstract.

Gallagher 1992 gave no information on mortality in the published abstract; two deaths were reported in the conference presentation. Pooling of mortality data from the other three studies showed no evidence of an effect (14/142 versus 14/138; RR $0.99,95 \% \mathrm{Cl}$ 0.50 to $1.97 ; 1^{2}=69 \%$; very low-quality evidence downgraded two levels for serious risk of bias and one level for inconsistency given the considerable heterogeneity; Analysis 1.1: Figure 4). All seven deaths in Hartgrink 1998 occurred in the intervention group during the two-week period of observation. This could have been due to chance, as the deaths were not obviously related to tube feeding (anaesthetic death, cardiac arrest, stroke and multi-organ failure), and did not appear to relate to aspiration pneumonia, a complication of tube feeding. Four of the deaths occurred in participants in whom tube feeding had not started, although the tube had been placed. It was evident that tube feeding was poorly tolerated, with only $26 \%$ of the intervention group tolerating feeding for the full two weeks. Conversely all five deaths occurred in the control group in Sullivan 1998; this might in part reflect the greater frailty of the control group at recruitment.
The four trials were heterogeneous in the nutritional status of the study participants. Unlike Hartgrink 1998, Bastow 1983b targeted nasogastric feeding on thin and very thin participants, defined by anthropometry. Seventy-eight per cent of participants tolerated nasogastric feeding until discharge from the ward, although 18 in the intervention group developed diarrhoea, which was ascribed to antibiotics in 16. Bastow 1983b did not report gastrointestinal complications in the control group. Bastow 1983b provided separate mortality data for the two participant subgroups (thin group: $5 / 39$ versus $4 / 35$; very thin group: $2 / 25$ versus $5 / 25$ ); a test for interaction did not indicate a subgroup difference $P=0.31$ (analysis not shown). Malnourished participants were not specifically targeted in Sullivan 1998. In Sullivan 1998 , the intervention group received supplements until discharge or until a good oral intake was achieved. People with low serum albumin readings, described as malnourished, were targeted in Gallagher 1992.

Only Sullivan 1998 provided data on participants developing medical complications in intervention and control groups $(1 / 8$ versus 8/10; RR 1.09, $99 \% \mathrm{Cl} 0.64$ to 1.86 ; very low-quality evidence downgraded two levels for serious risk of bias and one level for imprecision; Analysis 1.2: Figure 5). No study provided information on 'unfavourable outcome'.

\section{Secondary outcomes}

Three studies provided information on length of hospital stay. In the published abstract, Gallagher 1992 found that rehabilitation length of stay was 25 days in the intervention group and 33 days in the control group (reported $P=0.058$ ). However, in the notes taken from the conference presentation by Gallagher 1992, the length of stay was 22.7 days for the control group and 22.6 days for the intervention group. Sullivan 1998 reported no significant difference between the two groups in the length of acute care stay for survivors (38.2 days versus 23.7 days: MD 14.50 days, $99 \% \mathrm{Cl}$ -24.34 to 53.34 days). Bastow 1983b stated the median lengths of stay for the very thin group only (including those who died): a median of 29 days for the intervention group and 38 days for the control group (reported $P=0.04$ ). Hartgrink 1998 gave no information about length of stay but reported that the intervention group were less likely to have left hospital by two weeks (still in hospital at two weeks: 55/62 versus 53/67; RR $1.12,99 \% \mathrm{Cl} 0.92$ to 1.37; analysis not shown).

Where reported, physiotherapy goals were achieved more quickly in the intervention groups: Gallagher 1992 (published abstract), 12.7 days versus 16.2 days (reported $\mathrm{P}=$ not significant); Bastow 1983 b thin group: 10 days (range 4 to 20) versus 12 days (range 5 to 26 ) (reported $\mathrm{P}=0.04$ ); Bastow $1983 \mathrm{~b}$ very thin group: 16 days (range 5 to 34 ) versus 23 days (range 10 to 45 ) (reported $P=0.02$ ). Sullivan 1998 showed no statistically significant difference between intervention and control groups for activities of daily living at discharge (Katz index ( $0=$ independent to $12=$ totally dependent $)$ : 4.1 versus 5.9 ; $\mathrm{MD}-1.80,99 \% \mathrm{Cl}-7.17$ to 3.57$)$.

Sullivan 1998 reported that three out of eight in the intervention group had bloating in the early morning and none in the control group; there was no feed-induced diarrhoea. Sullivan 1998 did not report on aspiration pneumonia. Hartgrink 1998 reported no cases of aspiration pneumonia, a putative side effect, related to the tube feeding. 
Sullivan 1998 found that volitional food intake was not significantly affected by nasogastric feeding. Bastow 1983b found that nasogastric feeding significantly suppressed oral intake in the thin group but not in the very thin group. The suppression of food intake in the thin group amounted to $1.1 \mathrm{MJ}$, compared with daily nasogastric feeding which provided 4.2 MJ.

\section{Nasogastric tube feeding and oral supplements}

Sullivan 2004 evaluated nightly nasogastric feeding tailored to the calculated energy requirements of individual participants after taking account of the intake from meals. If the difference between calculated requirements and food intake decreased to 240 to 480 $\mathrm{kcal} /$ day participants were asked to drink one or two cans of the supplement orally instead of nasogastric feeding. This regimen was compared with standard care. The evidence for all outcomes was very low quality, downgraded by two levels for risk of bias and one level for imprecision. At six months there was very low-quality evidence of no significant differences between the two groups in mortality (4/27 versus 6/30; RR $0.74,99 \% \mathrm{Cl} 0.16$ to 3.37 ; Analysis 1.1; Figure 4) or postoperative complications (18/27 versus $18 / 30$; RR 1.11, 99\% Cl 0.66 to 1.87; Analysis 1.2; Figure 5).

There was no significant difference in hospital length of stay. The median (interquartile range) length of hospital stay for the intervention group was 9 days (7 to 21) and for the control group 9 days (7 to 15$)$, reported $P=0.817$ ).

Sullivan 2004 found no significant difference between intervention and control groups in the Katz Index of activities of daily living scores on discharge (median (interquartile range): 8 ( 4 to 11) versus 9 (7 to 11$)$; reported $P=0.503$ ), or the rate of discharge to an institution (25/27 versus 27/30; RR 1.03, $99 \% \mathrm{Cl} 0.83$ to 1.27 ; analysis not shown)

Five of the 27 intervention group participants never started tube feeding because of either refusal of tube placement or lack of toleration of the feeding tube. Targeted tube feeding was continued until the oral intake was deemed to be adequate in only five of the remainder, and only two participants required no tube reinsertions. Though there was no significant difference between the two groups in the incidence of diarrhoea (5/27 versus 3/30; RR 1.85, 99\% $\mathrm{Cl} 0.32$ to 10.68; Analysis 1.6), Sullivan 2004 reported that the diarrhoea in the intervention group was more difficult to control. In the first week, the intervention group met $86 \%$ of their calculated energy requirements compared with $63 \%$ for the control group (reported $\mathrm{P}$ $=0.002$ ); the difference between the two groups was not significant for the 22 trial participants assessed in the second week $(96 \%$ versus $95 \%$; reported $\mathrm{P}=0.942$ ).

\section{Intravenous feeding and oral supplements}

Eneroth 2006 evaluated three days of intravenous feeding followed by seven days of oral supplements compared with standard care in 80 participants. The only reported deaths were in the control group (0/40 versus 4/40: RR $0.11,99 \% \mathrm{Cl} 0.00$ to 4.95; very lowquality evidence downgraded one level from serious risk of bias and two from imprecision; Analysis 1.1; Figure 4). In contrast, there was a significant reduction in participants with complications in the supplementation group (6/40 versus $28 / 40$; RR $0.21,99 \%$ $\mathrm{Cl} 0.08$ to 0.59 ; very low-quality evidence downgraded one level for risk of bias, one level for imprecision (small single trial) and one for indirectness, since this intervention is usually reserved for people with non-functioning gastrointestinal tracts, which is unlikely in this population; Analysis 1.2; Figure 5). The mean length of hospital stay for both groups was 12.5 days. There was no significant difference between the two groups for those who were discharged to their own homes (14/40 versus 22/40, RR $0.64,99 \%$ $\mathrm{Cl} 0.33$ to 1.24; analysis not shown). There were three reports of venous thrombosis or thrombophlebitis in the control group and one report in the intervention group.

\section{Multinutrient supplements - overall results}

There was no clear difference between intervention and control groups in overall mortality when pooling the results of oral, nasogastric and intravenous multinutrient supplementation studies (42/695 versus 55/689; RR $0.79,95 \% \mathrm{Cl} 0.55$ to $1.15 ; 1385$ participants; 20 studies; $12=0 \%$; low-quality evidence downgraded two levels for risk of bias and imprecision; see Analysis 1.1; Figure 4). Funnel plot examination (Figure 6) did not show clear evidence of small study bias. 
Figure 6. Funnel plot of comparison: 1 Multinutrient supplements (oral, nasogastric, intravenous) versus control, outcome: 1.1 Mortality by end of study

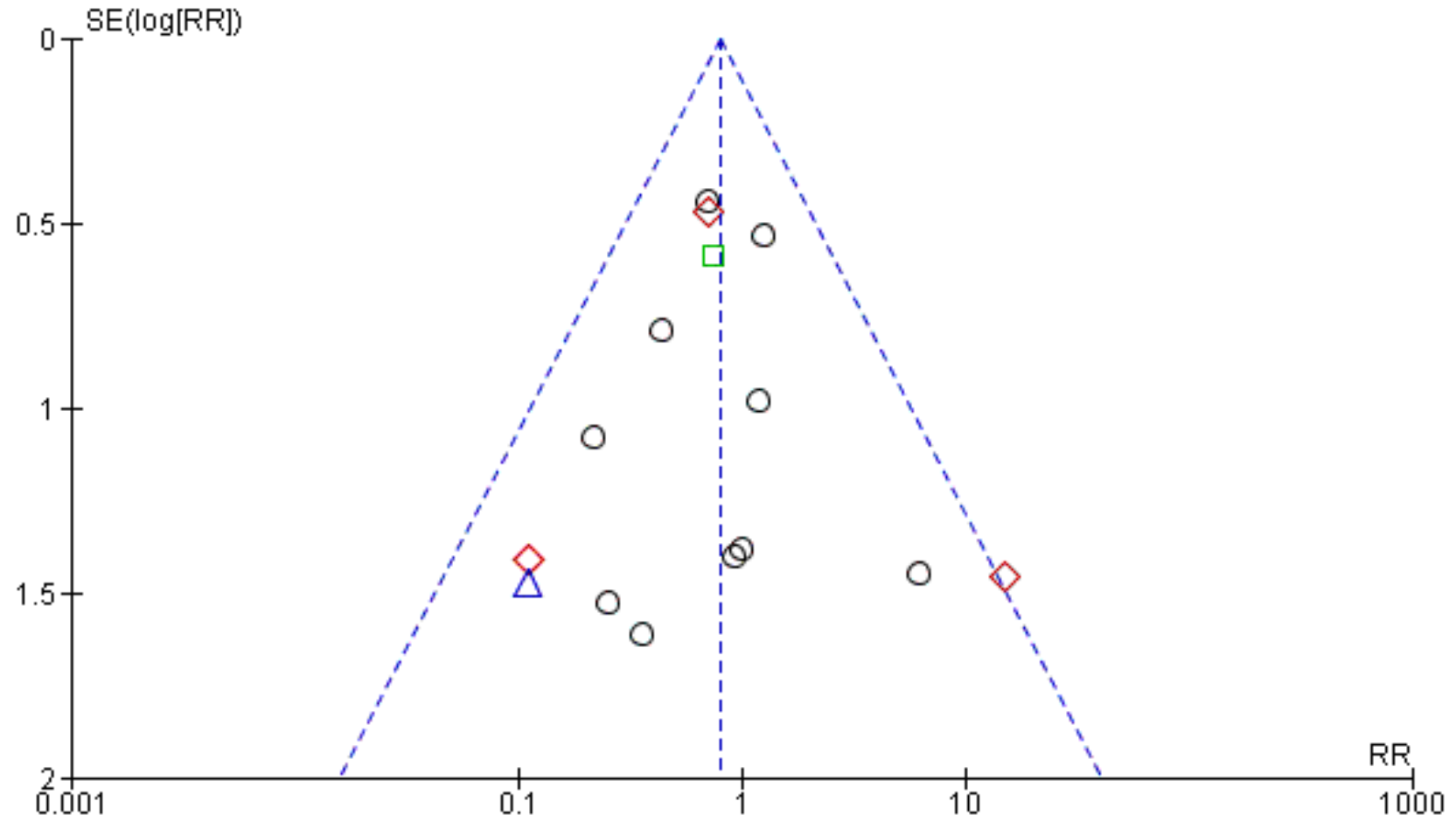

Subgroups

Oral supplements

Nasogastric tube feeding

Nasogastric tube feeding and oral supplements

Intravenous feeding and oral supplements

There were fewer participants with complications in the intervention compared with the control groups (154/445 versus 211/437; RR $0.69,95 \% \mathrm{Cl} 0.59$ to $0.81 ; 882$ participants; 14 studies; Analysis 1.2; Figure 5). However, although there was substantial heterogeneity for this outcome $\left(\mathrm{I}^{2}=60 \%, \mathrm{Chi}^{2}=30.16, \mathrm{P}=0.003\right)$; the result using the random-effects model was similar (RR 0.70, 95\%
$\mathrm{Cl} 0.53$ to 0.91 ; see Analysis 1.3). Funnel plot examination (Figure 7) did not show clear evidence of small study bias. The significant heterogeneity was reduced by removing Eneroth 2006 (resulting heterogeneity: $\left.\right|^{2}=35 \%$, Chi $^{2}=16.87, P=0.11$ ); RR 0.79, $95 \% \mathrm{Cl} 0.64$ to 0.98 from the pooled results of the remaining trials; analysis not shown. 
Figure 7. Funnel plot of comparison: 1 Multinutrient supplements (oral, nasogastric, intravenous) versus control, outcome: 1.2 Participants with complications at end of study

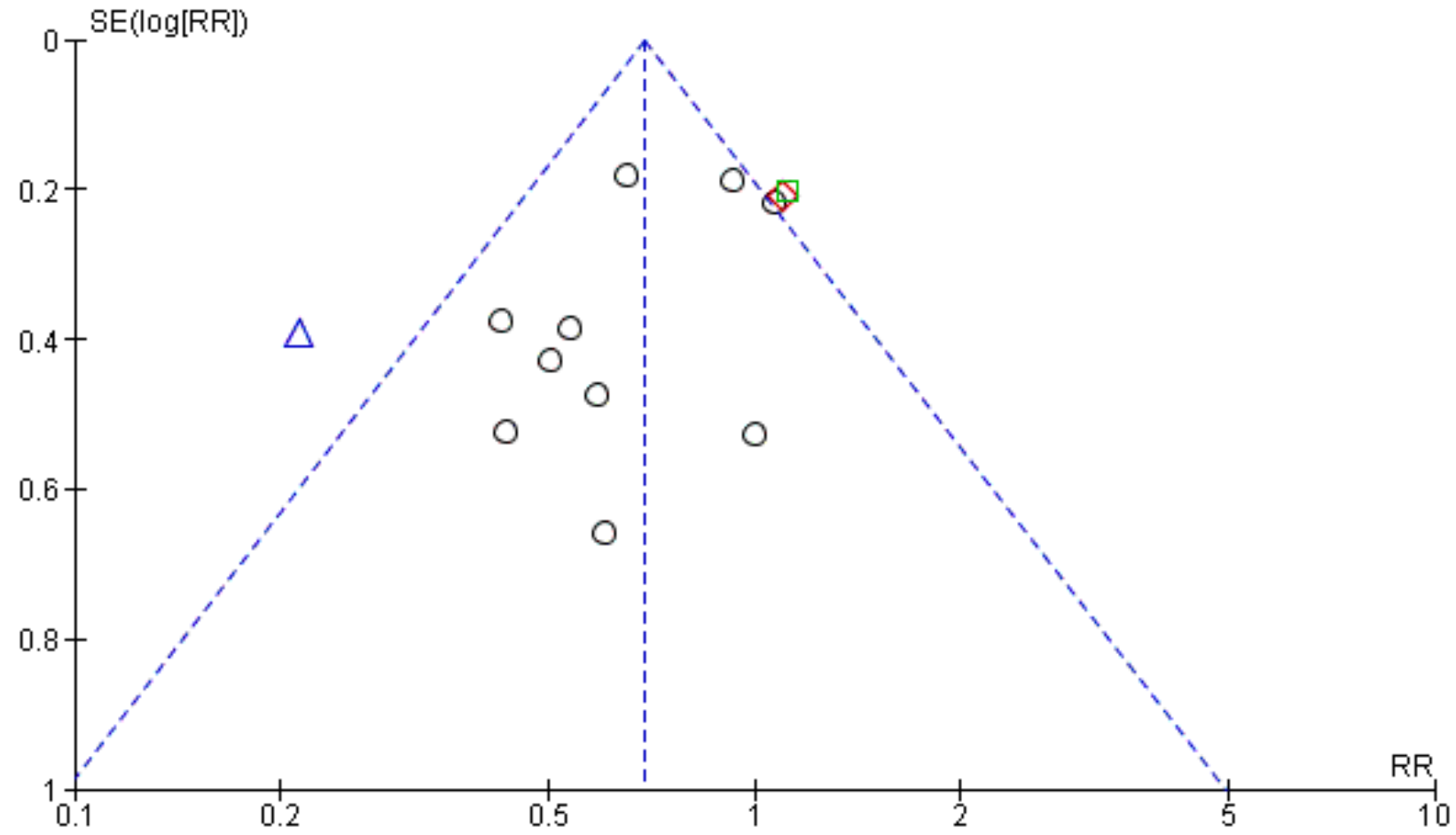

Subgroups

Oral supplements

Nasogastric tube feeding

Nasogastric tube feeding and oral supplements

Intravenous feeding and oral supplements

There were no data from nasogastric or intravenous trials on 'unfavourable outcome' (see Analysis 1.4).

\section{Subgroup and sensitivity analysis}

\section{Nutritional status of trial populations}

Subgrouping the trials according to whether they targeted malnourished participants or not showed a potential reduction in terms of mortality for supplementation in those that targeted malnourished participants (RR $0.55,95 \% \mathrm{Cl} 0.27$ to $1.11 ; 388$ participants, 6 studies) compared with those that did not (RR 0.92, $95 \% \mathrm{Cl} 0.59$ to $1.42 ; 997$ participants, 14 studies); Analysis 2.1. The results of the groups were not statistically significantly different from each other (test for interaction: $\mathrm{P}=0.23, \mathrm{I}=31.7 \%$ ) and thus the evidence does not confirm that malnourished participants are more likely to benefit. While there was greater contrast between the two subgroup groups when the data were restricted to oral supplementation, the test for interaction similarly did not confirm a difference between the two subgroups $(P=0.15,12=52.1 \%)$; Analysis 2.2.

The analyses for complications (see Analysis 2.3) and 'unfavourable outcome' (see Analysis 2.4) are also presented, but the greatly reduced available data for people who were malnourished limit their usefulness. The tests for subgroup differences indicated there were no differences for both outcomes $(12=0)$.

\section{Methodological quality}

We have presented the results for mortality subgrouped by whether allocation was concealed (low, unclear or high risk of bias) in the individual studies in Analysis 3.1. A test for interaction confirms the visual impression that the pooled results of the 10 trials with low risk of bias are not statistically significantly different from those of the three trials where allocation was high risk, or the seven trials where allocation concealment was of unclear risk $(P=0.21)$. The 'unclear concealment' group is clearly heterogeneous $\left(\mathrm{I}^{2}=52 \%\right)$ and it is inadvisable to draw any conclusions from the above test of interaction result. For the seven trials using oral supplementation alone and at low risk of allocation concealment, the risk ratio was 0.63 ( $95 \% \mathrm{Cl} 0.32$ to 1.25 , data not shown).

The results (Analysis 3.2) for participants with complications were subgrouped by whether allocation was concealed (low or unclear; no trials with high risk of bias). The five trials with unclear risk of bias had a lower risk of complications (19/127 versus 47/133; $\mathrm{RR} 0.38,95 \% \mathrm{Cl} 0.24$ to 0.61 ) than the nine trials with low risk of bias ( $135 / 318$ versus $164 / 304$; RR $0.78,95 \% \mathrm{Cl} 0.66$ to 0.92 ), test for subgroup differences $P=0.005,12=87.5 \%)$. Both groups of 
trials were clearly heterogeneous, $1^{2}$ was $51 \%$ and $45 \%$ respectively, and it is inadvisable, therefore, to draw any conclusions from the above test of interaction result. For the seven trials using oral supplementation alone with low risk of bias relating to allocation concealment, the risk ratio was $0.72(95 \% \mathrm{Cl} 0.60$ to 0.88 , data not shown).

\section{High protein-containing supplements versus low-protein or non-protein-containing supplements}

\section{Primary outcomes}

Three studies (Espaulella 2000; Schürch 1998; Tkatch 1992) investigated whether approximately $20 \mathrm{~g}$ of protein provided within an oral supplement on a daily basis influenced outcome from hip fracture. Neumann 2004 investigated whether a highprotein supplement providing an extra $12.2 \mathrm{~g}$ or more of protein (with some differences in vitamins and minerals also) influenced outcome. All four studies failed to carry out intention-to-treat analyses (although information was later provided on mortality and hospital complications of excluded participants in Espaulella 2000). Denominators were sometimes missing or unclear. Tkatch 1992 excluded some of the intervention group for poor compliance with supplement taking, whilst some of the controls were excluded for later taking a dietary supplement. Espaulella 2000 excluded five people from the intervention group and three from the control group for protocol violations, and two from the control group because they were unable to swallow. Thus, unavoidably, the results presented here are not intention-to-treat analyses. No significant effect on mortality could be demonstrated for the high protein supplement (30/181 versus 21/180; RR 1.42 favouring the control group, $95 \% \mathrm{Cl} 0.85$ to $2.37 ; 4$ studies; low-quality evidence, downgraded one level for risk of bias and one level for imprecision; Analysis 4.1).

None of the four trials provided sufficient information to evaluate numbers of participants with complications at the end of the study. Espaulella 2000 reported that 44 out of 61 in the intervention group and 57 of 67 in the control group developed at least one complication during the six months of the study (RR $0.85,99 \% \mathrm{Cl}$ 0.66 to 1.08; analysis not shown). Neumann 2004 reported that there were no differences between the groups for complications or adverse events. Taken together, these findings constitute very lowquality evidence downgraded two levels for risk of bias and one level for imprecision.

'Unfavourable outcome' (for Espaulella 2000: death or complication by the end of the study; for Tkatch 1992: death by the end of the study or, for survivors, a major complication or two or more minor complications present at the end of the study) was significantly reduced by protein supplementation $(66 / 113$ versus 82/110; RR $0.78,95 \% \mathrm{Cl} 0.65$ to 0.95 ; very low-quality evidence downgraded two levels for risk of bias and one for imprecision reflecting insufficiency in the available data; Analysis 4.2); this outcome was not reported by the other two studies.

An exploratory analysis looking at the effect of assuming that all excluded participants in the protein supplementation group had an 'unfavourable outcome' could not be undertaken. However the results for Espaulella 2000 should be viewed in the context of the greater number of deaths in the protein supplementation group. In Tkatch 1992, neither the results for unfavourable outcome in acute hospital (9/33 versus $13 / 29$; RR $0.61,99 \% \mathrm{Cl} 0.25$ to 1.50 ) nor in rehabilitation hospital (4/19 versus 14/22; RR 0.33, 99\% $\mathrm{Cl} 0.10$ to 1.12) were statistically significant; analyses not shown.

\section{Secondary outcomes}

Espaulella 2000 reported an acute hospital stay of 16.4 days in the intervention group and 17.2 days in the control group (MD -0.80 days, $99 \% \mathrm{Cl}-3.62$ to 2.02 days). Tkatch 1992 reported a statistically significantly $(P<0.05)$ lower median length of acute and rehabilitation hospital stay in the intervention group (combined stay: median 69.4 days versus 101.6 days; acute hospital stay: median 23.5 days versus 24.7 days; rehabilitation hospital: 78.6 days versus 91.8 days). Schürch 1998 reported mean figures of 18.0 days versus 16.9 days on the acute ward, and median stays of 33 versus 54 days in the rehabilitation ward (reported difference 21 days, $95 \% \mathrm{Cl} 4$ to 25 days; $\mathrm{P}=0.018$ ). Neumann 2004 reported the rehabilitation stay was not significantly different between the two groups ( 23.2 days versus 28.0 days; MD -4.80 days, $99 \% \mathrm{Cl}-12.29$ to 2.69 days). Neumann 2004 also reported no significant difference in the destination at discharge between the two groups.

Espaulella 2000 found no difference between intervention and control groups for mobility or Barthel Index scores six months after recruitment. Schürch 1998 also reported non-significant improvements in biceps muscle strength and activities of daily living score at six months; these were not reported as being measured by Tkatch 1992. Schürch 1998 reported that seven participants in the intervention group and 13 in the control group developed vertebral deformities after one year. Again denominators were not given; the difference was reported not to be statistically significant. Neumann 2004 found no significant difference between groups for the mobility subscale of the Functional Independence Measure at any time point including at three months post discharge.

Neither Schürch 1998 nor Tkatch 1992 gave information about the effect of the supplements on voluntary food intake. However, Schürch 1998 did report that six participants (15\%) dropped out because of nausea or diarrhoea in the intervention group and five participants (12\%) in the control group. Tkatch 1992 reported no digestive disturbances during hospitalisation in the protein supplemented group, and seven events in the control group. Espaulella 2000 reported that $64.7 \%$ (55/85) of the intervention group and $74.4 \%(64 / 86)$ of the control group had good consumption of the supplement. Neumann 2004 reported that participants had 19.8 days of the high-protein supplement, compared with 21.1 days for the lower-protein supplement. They found that energy intakes were not significantly different between the groups, but that the high-protein group also had significantly greater daily intakes of dietary fibre, vitamin $\mathrm{C}$ and polyunsaturated fatty acids.

\section{Comparison of different protein sources}

Chevalley 2010 compared 20 g daily of oral casein protein versus $20 \mathrm{~g}$ of oral whey protein versus $15 \mathrm{~g}$ of oral whey protein and $5 \mathrm{~g}$ of essential amino acids in a ratio identical to casein for a month. Five people from 15 of the casein group dropped out ( 2 refusal, 2 nausea, 1 diarrhoea), four from 15 of the whey group ( 2 refusal, 1 nausea, 1 diarrhoea) and two from 15 of the whey and amino acid group (1 refusal, 1 nausea). The type of supplement was reported as not influencing adherence. No other outcomes relevant to this review were reported. 


\section{Vitamin supplementation versus control or lower dose supplementation}

Day 1988 tested whether intravenous thiamin (vitamin B1) and other water soluble vitamins influenced postoperative mental function in participants. The daily dose of thiamin $(250 \mathrm{mg})$ provided over 300 times the UK reference nutrient intake for this vitamin; that of riboflavin, 3.6 times; of pyridoxine, 42 times; of nicotinamide and ascorbic acid, 13 times. Sixty-one per cent of the intervention group and $75 \%$ of the control group had satisfactory thiamin status at baseline. There was no significant difference in mortality (see Analysis 5.1: 6/28 versus 5/32; RR 1.37, 99\% Cl 0.33 to 5.62 ) or in the numbers of participants with complications (see Analysis 5.2: $15 / 28$ versus 13/32; RR $1.32,99 \% \mathrm{Cl} 0.65$ to 2.69). Likewise, the incidence of acute postoperative confusion, the primary outcome of Day 1988, did not differ between the two groups (11/28 versus $12 / 32$; RR $1.05,99 \% \mathrm{Cl} 0.45$ to 2.44 ; analysis not shown). The length of hospital stay was not affected (MD 6 days, $99 \% \mathrm{Cl}-15.75$ to 27.75 days), and residence at final follow-up was reported not to be affected by the intervention.

Hoikka 1980 compared oral 1-alpha-hydroxycholecalciferol (an active form of vitamin D) and $1 \mathrm{~g}$ calcium carbonate versus $1 \mathrm{~g}$ calcium carbonate. No data from main outcomes were reported, except for complications. Six, including two severe cases, out of 19 in the intervention group and two out of 18 in the control group developed hypercalcaemia (see Analysis 6.1: $6 / 19$ versus 2/18; RR $2.84,99 \% \mathrm{Cl} 0.41$ to 19.48 ). Hoikka 1980 reported that there was no effect on hand muscle strength over the six months post-fracture observation period.

Papaioannou 2011 compared an initial oral bolus dose of 100,000 IU vitamin D2 versus 50,000 IU vitamin D2 versus placebo; followed by 1000 IU vitamin D3 for 90 days in all groups. Combining both vitamin $D$ groups and comparing these with the placebo group, there was no significant difference found in the number of participants with a serious adverse event (this included death): $4 / 44$ versus $1 / 21$; RR $1.91,99 \% \mathrm{Cl} 0.12$ to 31.32; analysis not shown. There were two serious adverse events in each of the two vitamin $D$ groups. Compliance in hospital was $90 \%, 87 \%$ and $97 \%$, for high dose, low dose vitamin D groups and placebo; and $92 \%, 96 \%$ and $84 \%$ at home.

Bischoff-Ferrari 2010 investigated daily 2000 IU vitamin D3 compared with daily $800 \mathrm{IU}$ vitamin D3; all participants also received $1 \mathrm{~g}$ of calcium as calcium carbonate daily over one year, in a factorial design with standard or extended physiotherapy. Mortality (10/86 versus $10 / 87$; RR $1.01,99 \% \mathrm{Cl} 0.44$ to 2.31 ; Analysis 6.2), participants with fall-related injury requiring hospital readmission ( $7 / 86$ versus $18 / 87$; RR $0.39,99 \% \mathrm{Cl} 0.13$ to 1.16 ), participants with infection (1/86 versus $10 / 87$; RR $0.10,99 \% \mathrm{Cl} 0.01$ to 1.47), participants with other complications requiring hospital readmission (18/86 versus $13 / 87$; RR $1.40,99 \% \mathrm{Cl} 0.60$ to 3.28 ) did not differ significantly between the two vitamin $D$ intervention groups. The numbers of participants with complications were not provided. Mild hypercalcaemia was reported in one participant in the high dose vitamin D group and two in the low dose early in the study, and for two participants in the high dose group and one participant in the low dose group at the end of six months' followup.

Bischoff-Ferrari 2010 reported that comparing high dose with low dose vitamin $D$ did not reduce the rate of falls or improve muscle strength or function. The adjusted odds ratio for new nursing home admission for high versus low dose vitamin D was reported as 0.66 , $95 \% 0.31$ to 1.41). Compliance was reported as $93.6 \%$ for high dose vitamin $\mathrm{D}$ and $92.2 \%$ for low dose vitamin $\mathrm{D}$. An abstract reported that the higher versus standard dose of vitamin $D$ was cost neutral.

\section{Comparison of different vitamin D sources}

Glendenning 2009 compared oral vitamin D3 $1000 \mathrm{IU} / \mathrm{d}$ and calcium carbonate equivalent to $600 \mathrm{mg} / \mathrm{d}$ versus vitamin D2 $1000 \mathrm{IU} / \mathrm{d}$ and calcium carbonate equivalent to $600 \mathrm{mg} / \mathrm{d}$ for three months. Three of 47 participants from the vitamin D3 group died by three months compared with seven from 48 participants from the vitamin D2 group (RR $0.44,99 \% \mathrm{Cl} 0.08$ to 2.39 ). One participant from the vitamin D3 group and three participants from the vitamin $D$ group had mild hypercalcaemia (RR $0.34,99 \% \mathrm{Cl} 0.02$ to 6.36 ). Forty-seven percent of vitamin D3 participants compared with $59 \%$ of vitamin D2 participants took more than $80 \%$ of their tablets.

\section{Iron supplementation versus control}

Three studies with 568 participants compared oral or intravenous iron supplementation versus no intervention or placebo in the first month after hip fracture, as faster correction of anaemia as a consequence of surgery might help improve recovery (Parker 2010; Prasad 2009; Serrano-Trenas 2011). Based on low-quality evidence (downgraded due to risk of bias and imprecision from low number of events), there was no benefit of iron supplementation compared with not prescribing iron supplementation on mortality (39/282 versus 40/284; RR 0.97, 95\% Cl 0.65 to 1.46 ; 3 trials; Analysis 7.1) or on complications (16/132 versus 13/134; RR 1.23 , 95\% $\mathrm{Cl} 0.63$ to 2.42; 2 trials; Analysis 7.2). Purported adverse events related to supplementation were reported for 3/100 intervention participants randomised in Serrano-Trenas 2011 (one participant skin rash, two participants 'general discomfort'); 2/32 intervention participants in Prasad 2009 (constipation requiring laxatives), and 26/150 participants randomised in Parker 2010 (13 required discontinuation as a result of abdominal pain or altered bowel habit). Length of stay was shorter for participants receiving iron in Parker 2010 (MD -2.50 days, $99 \% \mathrm{Cl}-8.17$ to 3.17 days), and longer in Serrano-Trenas 2011 for participants receiving iron (MD 0.40 days, $99 \% \mathrm{Cl}-2.18$ to 2.98 days).

\section{Vitamin, mineral and amino acid supplementation versus control}

Scivoletto 2010 investigated six weeks of an oral Restorfast supplement daily (L-carnitine, calcium, magnesium, vitamin D3, Lleucine) followed by 10 weeks of an oral Riabylex supplement daily (creatine, L-carnitine, coenzyme Q10, nicotinamide, pantothenic acid, riboflavin) compared with no supplementation. Only 53 of 107 participants were available for follow-up at the end of the study.

Length of hospital stay was shorter for participants receiving supplementation in Scivoletto 2010 (MD -2.50 days, $99 \% \mathrm{Cl}-6.21$ to 1.21 days); time to ambulation was also shorter (MD -1.20 days, $99 \%$ $\mathrm{Cl}-10.16$ to 7.76 days). There was no benefit of supplementation on pressure sores in hospital $(3 / 38$ versus $6 / 41$; RR $0.54,99 \% \mathrm{Cl} 0.10$ to 3.03 ). For the 53 remaining participants, no difference between groups was found for functional recovery (14/27 versus 10/26; RR $1.35,99 \% \mathrm{Cl} 0.61$ to 2.99 ). 
Isonitrogenous ornithine alpha-ketoglutarate versus peptide supplements

Bean 1994, published only in abstract, investigated the effect of oral ornithine alpha-ketoglutarate, compared to an isonitrogenous peptide supplement, in 59 relatively undernourished older women with hip fracture. Unfortunately, no denominators for the intentionto-treat analyses were provided in the abstract, which reported that recruitment was slow and that compliance with the supplements for the full two months was poor. Bean 1994 reported that there was no difference in mortality (ornithine alpha-ketoglutarate supplemented $12.5 \%$, control $11.1 \%$, no denominators provided), compliance, duration of treatment or hospitalisation between the two groups. Bean 1994 reported there was no significant difference in complications but that major complications were significantly delayed in the intervention group (reported $\mathrm{P}<0.03$ ). No information was given in the abstract about the effect of the supplements on volitional food intake, although food diaries were kept.

\section{Taurine versus placebo}

Van Stijn 2015 compared oral taurine prescribed during the first six postoperative days following hip fracture surgery with placebo. Data were available for 187 participants at 12 months. There was no significant effect of the intervention on mortality (23/113 versus 27/123; RR 0.93, 99\% Cl 0.57 to 1.52; Analysis 8.1).

The total number of participants with complications at the end of the study was not reported. However data for six relevant postoperative complications were reported within the follow-up period in Van Stijn 2015. There was no difference between the groups for these complications that included infection (11/110 vs $18 / 122$, RR $0.68,99 \% \mathrm{Cl} 0.27$ to 1.71$)$, cardiovascular events $(5 / 110$ vs $13 / 122$, RR $0.43,99 \% \mathrm{Cl} 0.11$ to 1.58$)$, stroke (1/110 vs $2 / 122$, RR $0.55,99 \% \mathrm{Cl} 0.02$ to 12.77 ), delirium (26/110 vs $27 / 122$, RR $1.07,99 \%$ $\mathrm{Cl} 0.57$ to 1.99$)$, the requirement for a blood transfusion (19/110 vs $20 / 122$, RR $1.05,99 \% \mathrm{Cl} 0.50$ to 2.24$)$ and reoperation (6/110 vs $6 / 122$, RR $1.11,99 \% \mathrm{Cl} 0.26$ to 4.72 ). Length of hospital stay was reported as 13 days (SD 10) for the intervention group and 13 days (SD 11) for the control group, reported $P=0.83$; denominators unclear.

\section{Dietetic assistants versus usual care}

Duncan 2006 evaluated the use of dietetic assistants, who checked food preferences, helped order meals and supplements, provided feeding aids, assisted with food choice, and assisted with feeding at meal times. Since this trial was a sufficiently powered trial for mortality, $95 \% \mathrm{Cls}$ are also reported for this outcome.

Based on absolute number of deaths by four months postoperative, the risk of death was significantly lower $(P=0.03)$ in the intervention group (19/145 versus $36 / 157$; RR $0.57,95 \% \mathrm{Cl} 0.34$ to 0.95$)$. However, the possibility of increased mortality in the intervention group could not be ruled out when applying our stricter criteria $(P<0.01)$ : RR $0.57,99 \% \mathrm{Cl} 0.29$ to 1.11 ; low-quality evidence downgraded one level for risk of bias and one level for imprecision; Analysis 9.1. The incidence of complications was similar in the two groups $(79 / 130$ versus $84 / 125$; RR $0.90,99 \% \mathrm{Cl} 0.71$ to 1.15 ; low-quality evidence downgraded one level for risk of bias and one level for imprecision; Analysis 9.2). Duncan 2006 found no significant difference between the two groups in the lengths of stay in the acute ward (median 16 days versus 17 days; reported $\mathrm{P}=0.44$ ) or in hospital ( 34 days versus
32 days; reported $P=0.81$ ). Using their own scoring scheme, Duncan 2006 reported that patient satisfaction was significantly greater in the intervention group at discharge (reported $\mathrm{P}<0.0001$ ). The mean daily energy intake was $349 \mathrm{kcal}$ higher in the intervention group; this was mostly from supplements.

\section{DISCUSSION}

\section{Summary of main results}

The variety of interventions examined for hip fracture recovery and outcomes limited data synthesis, with the exception of multinutrient supplements providing non-protein energy, protein, some vitamins and minerals. The failure to confirm an effect does not mean that there is no effect, but may simply reflect few trials, poor study design and inadequate sample size.

\section{Multinutrient supplementation}

\section{Oral supplements}

Eighteen trials evaluated oral multinutrient feeds that provided non-protein energy, protein, vitamins and minerals. There was low-quality evidence that oral supplementation had little effect on mortality, with the $95 \%$ confidence interval $(\mathrm{Cl})$ including the possibility that oral supplementation could result in lower or higher mortality (risk ratio (RR) 0.81 favouring supplementation, $95 \% \mathrm{Cl}$ 0.49 to 1.32; 968 participants, 15 studies). Based on an illustrative risk of mortality of 72 per 1000 people with hip fracture (median mortality risk at 1 to 12 months' follow-up from study control groups featuring at least one death), this equates to 13 fewer deaths per 1000 (95\% Cl 36 fewer to 23 more deaths) over 1 to 12 months' follow-up. In high risk populations (i.e. people over 80 years old with an estimated mortality of 250 per 1000; Bentler 2009; Mariconda 2015), this equates to 47 fewer deaths per 1000 (95\% $\mathrm{Cl} 127$ fewer to 78 more deaths; Summary of findings for the main comparison). A subgroup analysis separating out trials that did or did not target malnourished people did not confirm a difference in treatment effect between the two subgroups.

There was low-quality evidence that oral supplementation resulted in fewer complications (RR $0.71,95 \% \mathrm{Cl} 0.59$ to 0.86 ; 727 participants, 11 studies). Based on an illustrative risk of postoperative complications of 443 per 1000 people with hip fracture, this equates to 128 fewer people with complications per 1000 (95\% Cl 62 to 181 fewer) over 1 to 12 months' follow-up. In moderate risk populations (i.e. people in the study by Mariconda 2015 with a complication rate of 290 per 1000), this equates to 84 fewer people per 1000 ( $95 \% \mathrm{Cl} 40$ to 119 fewer complications).

Based on very low-quality evidence, oral supplements may result in lower numbers of 'unfavourable outcome' (death or complications): RR $0.67,95 \% \mathrm{Cl} 0.51$ to $0.89 ; 334$ participants, 6 studies. As seen in Summary of findings for the main comparison, based on an illustrative risk of unfavourable outcomes for 500 per 1000 people with hip fracture, this equates to 165 fewer people with unfavourable outcomes per 1000 (95\% Cl 45 to 245 people with fewer unfavourable outcomes) over 1 to 12 months' follow-up.

There was very low-quality evidence that oral supplementation did not result in an increased incidence of vomiting and diarrhoea (RR $0.99,95 \% \mathrm{Cl} 0.47$ to $2.05 ; 442$ participants, 6 studies). 


\section{Nasogastric tube feeding}

Four trials examined nasogastric multinutrient feeding. As summarised in Summary of findings 2, there was very low-quality evidence that nasogastric tube feeding did not reduce mortality (RR $0.99,95 \% \mathrm{Cl} 0.50$ to $1.97 ; 280$ participants, 3 studies; $\mathrm{I}^{2}=69 \%$ ). Based on an illustrative risk of mortality of 156 per 1000 people with hip fracture, this result equates to 1 fewer death per $1000(95 \% \mathrm{Cl}$ 88 fewer to 152 more deaths) over 1 to 12 months. There was very low-quality evidence from just one study of 18 male participants of no clear difference between nasogastric tube feeding and no supplementation in complications following hip fracture surgery at six months' follow-up (7/8 versus $8 / 10 ; \mathrm{RR} 1.09,95 \% \mathrm{Cl} 0.73$ to 1.64). No study reported on unfavourable outcome (death or complication). Tube feeding was often poorly tolerated. There was no report of aspiration pneumonia. While 18 intervention group participants ( $28 \%$ of 64 ) had diarrhoea in one study, only two were attributed to tube feeding and the control rate was not reported.

\section{Nasogastric tube feeding and oral supplements}

There is very low-quality evidence from one trial of 57 participants, most of whom were male, of no clear effect of tube feeding followed by oral supplementation on mortality or complications. Tube feeding, however, was poorly tolerated.

\section{Intravenous feeding and oral supplements}

There is very low-quality evidence from one trial of 80 participants that a combination of intravenous feeding and oral supplements may not affect mortality but could reduce complications. However, it is notable that intravenous feeding is an expensive, technically complex intervention that is usually reserved for people with nonfunctioning gastrointestinal tracts, which is unlikely in this trial and thus the evidence was downgraded for 'indirectness'.

\section{Nutritional status subgroup analysis}

There was no evidence of a difference in risk or benefit between the results (mortality and participants with complications) of trials specifically targeting malnourished participants and those not targeting this population. Thus, there is no clear evidence to confirm that malnourished participants are more likely to benefit from multinutrient supplementation than those participants who are not malnourished.

\section{Increasing protein intake}

The four studies testing the effects of a higher protein intake are flawed by their failure to account for all participants. In particular, the results for mortality (greater in the high protein group) and 'unfavourable outcome' (fewer in the high protein group for Espaulella 2000 are contradictory and while many reasons for this, including that of random variation, can be put forward, none can be confirmed. Overall, there was low-quality evidence of no clear effect of a higher intake of protein on mortality (4 trials) or number of complications (data not presented from two trials) and very low-quality evidence for a reduction in unfavourable outcome. There was no evidence that higher protein intake led to an increase in adverse events such as nausea or diarrhoea.

\section{Other supplements}

No evidence can be found from the two studies of Day 1988 and Hoikka 1980 to recommend the supplementation of vitamin B1 and other water soluble vitamins, or 1-alpha-hydroxycholecalciferol.
Giving bolus vitamin D soon after hip fracture did not appear to have a beneficial affect on mortality or adverse events. Giving vitamin D2 compared to vitamin D3, or 2000 IU vitamin D3 daily compared to 800 IU vitamin D3 also did not appear to influence outcomes. Intravenous or oral iron supplementation did not appear to help recovery, and may increase gastrointestinal adverse events.

Vitamin, mineral and amino acid supplementation was reported to improve functional recovery in one trial (Scivoletto 2010). However more than half the participants were lost to followup, so this very low-quality evidence should be interpreted with great caution. Based on low-quality evidence, there was no beneficial effect of providing taurine supplements during the first six postoperative days on postoperative mortality or complications including requirement for blood transfusion in one trial (Van Stijn 2015). Ornithine alpha-ketoglutarate, compared with an isonitrogenous peptide supplement, may delay the onset of complications post hip-fracture, but this is based on very lowquality evidence from one unpublished study (Bean 1994) and no benefit on reducing the risks of postoperative complications. No trials examined the effect of specific amino acid formulations.

\section{Dietetic assistants}

Based on low-quality evidence, the use of dietetic assistants may reduce mortality but there is no clear effect on complications or length of hospital stay. Duncan 2006 reported increased consumption of supplements and greater patient satisfaction in the intervention group. These favourable results need to be checked in further randomised controlled trials involving more hospitals.

\section{Overall completeness and applicability of evidence}

Given that people with hip fracture are often malnourished, it is notable that this review gives no clear evidence that those who are malnourished are more likely to benefit from multinutrient supplementation than those who are not malnourished. The lack of difference in results of trials may be due not only to the small sample sizes, but also to the different definitions of malnutrition in individual trials. Possibly people who are malnourished benefit more from nutritional supplementation, but their malnutrition could be a marker for other co-morbidities which are more important in determining outcomes. Many of the most frail participants, who are more likely to be malnourished, were excluded from these trials, for example, participants with cognitive impairment.

Incomplete compliance with nutritional supplementation was a major problem in these studies. Inability to tolerate nasogastric tubes and problems with palatability of oral feeds are common, particularly in confused, frail people. Malnutrition in itself produces mental apathy (Keys 1950), which may further reduce supplement intake. Ensuring increased nutritional intake thus has a major implication for nursing care, and has ethical implications when a person appears unwilling to feed or tolerate nasogastric feeding. While the combined intervention of nutritional supplementation and exercises investigated in Miller 2006 was excluded from this review, the potential interaction between these two interventions merits further investigation.

Nasogastric feeding, if tolerated, allows the provision of higher supplements of energy ( $3.90 \mathrm{MJ}$ to $6.28 \mathrm{MJ}$, or $933 \mathrm{kcal}$ to $1500 \mathrm{kcal}$ daily, in the studies in this review), whereas oral supplements in the studies reviewed here generally provided under $2.51 \mathrm{MJ}(800$ 
kcal) daily. Thus nasogastric feeding, which potentially has more risk of complications, is likely to be targeted at those requiring higher levels of supplementation. Attempts to overcome the poor palatability of oral supplements, and thus increase intakes further, include special high energy hospital meals and the provision of frequent small snacks (Gall 1998). Related to this are other measures taken to encourage consumption of food by patients. For example, one of the excluded studies examined the effects of actively involving patients in their own dietary care, a procedure based on Salling's nursing model involving a dietary journal, information, guidance and instruction (Pedersen 1999). Dietetic assistants may be another way to increase food and supplement intake, as in Duncan 2006, which requires examination in further research, including an economic evaluation.

Intravenous feeding used in Eneroth 2006 provided an additional $1000 \mathrm{kcal}$ and $53 \mathrm{~g}$ protein daily, thus also allowing higher levels of supplementation. However, it also carried risks of fluid and electrolyte imbalance, hyperglycaemia and thrombophlebitis when delivered through a peripheral vein.

Nutritional supplementation should also be viewed in the context of general nutrition in hospitals. Given the high numbers of hip fracture patients with prior malnutrition, and the prolonged length of stay, it is surprising that nutrition, including the provision and uptake of basic foodstuffs, is often understated, or even overlooked, as a component of rehabilitative care programmes.

There is interest in the hypothesis that nutritional supplementation may attenuate bone loss after fracture, which may also help to decrease the risk of further fractures (Schürch 1998a).

\section{Quality of the evidence}

Following the GRADE assessment for the primary outcomes in this review, the quality of the evidence ranged from very low to low. For details for the oral and nasogastric multinutrient supplementation comparisons, please see Summary of findings for the main comparison and Summary of findings 2. Overall, the evidence was downgraded two or three levels due to a high risk of bias, limitations in the detailed design and execution of the trials, imprecision of the data and, less frequently, inconsistency and indirectness. Items for risk of bias assessment were often inadequately reported. The studies were often small and limited further by insufficient ascertainment of important outcomes, incomplete outcome data (especially for secondary outcomes), inadequate period of follow-up for recovery from fracture and selective reporting of outcomes. Due to the small number of events such as unfavourable outcomes and complications, the evidence was frequently downgraded due to imprecision. This was particularly the case for interventions that were tested by only a small number of trials.

\section{Potential biases in the review process}

We think that it is unlikely that the review process itself has introduced bias. Our search, updated fully on a regular basis, is comprehensive and we actively pursued unpublished trials and data as well as ongoing and newly registered trials. We have used robust methodology, including independent trial selection and review of included trials, throughout the review and updating processes. One potential issue is that we have pooled mortality, participants with complications, and unfavourable outcome data irrespective of length of follow-up. While, the influence of nutritional supplementation is more likely in the period immediately after hip fracture, we do not anticipate that our mixed follow-up approach would bias the results. In future updates, we will consider whether quality of life should become a main outcome.

\section{Agreements and disagreements with other studies or reviews}

One review author (AA) has contributed to two more general systematic reviews of protein and energy supplementation in older people at risk from malnutrition (Milne 2006; Milne 2009). The above described limitations in the studies of this review also apply to nutritional intervention trials for other patient groups. Milne 2009 found that while there was no significant reduction in mortality in the supplemented compared with control groups overall, mortality results were statistically significant when limited to trials in which participants $(N=2461)$ were defined as undernourished. They concluded that there was a beneficial effect on complications, as found here, but considered this needs confirmation.

One recent systematic review of protein and energy supplementation after hip fracture from China (Liu 2015), with studies published up until 2011, reached similar conclusions for mortality and complications, but with limited discussion of the quality of the evidence.

One systematic review of six small trials of oral nutritional support (Beck 2013) for medical and surgical patients starting after discharge from hospital was unable to demonstrate clear benefits on mortality and complications. Of note, is that our trials commenced supplementation whilst participants were still hospitalised, when they were at highest risk of underfeeding.

\section{AUTHORS' CONCLUSIONS}

\section{Implications for practice}

There is low-quality evidence that oral multinutrient supplements (comprising non-protein energy, protein, and some vitamins and minerals) started before or soon after surgery may prevent complications within the first 12 months after hip fracture, but that they have no clear effect on mortality. There is very lowquality evidence that oral supplements may reduce 'unfavourable outcome' (death or complications) and that they do not result in an increased incidence of adverse events, namely vomiting and diarrhoea.

There is very low-quality evidence of no clear effect on mortality or complications of nasogastric multinutrient feeding. Nasogastric feeding was poorly tolerated, but this and the insufficiency of the evidence from randomised trials does not rule out consideration of this intervention for very malnourished patients with extremely poor intakes not responsive to multinutrient oral supplements.

There is low-quality evidence that increasing protein intake in an oral feed had no clear effect on mortality or complications.

Although tested in just one trial and needing confirmation, there is low-quality evidence suggesting the use of dietetic assistants to help with feeding may reduce mortality but not the number of participants with complications. 
Since the evidence for other comparisons made usually by single trials was of very low quality and insufficient to inform practice, these are not described here.

\section{Implications for research}

Large, well-designed, adequately powered, preferably multi-centre trials are required. Such trials should stratify allocation according to basic nutritional status to enable robust a priori subgroup analysis. Future research should examine functional status (using standardised methods), the level of care required, compliance, patient-perceived quality of life, and direct and indirect costs after hip fracture. These are in addition to mortality, individual complications and length of stay in hospital and rehabilitation. An independent observer should assess outcomes and the period of follow-up should be at least one year. The design and reporting of any future trial should conform to the CONSORT statement or any future development of it (Begg 1996; Moher 2001; Schulz 2010). We propose the focus of these randomised trials should be on the following.

- Oral multinutrient supplementation, by sip feeds and changes to the hospital diet and snacks. These trials should seek to be as inclusive of the patient population as possible. As well as provision of these supplements, the use of extra staff to help with feeding, e.g. dietetic assistants, should be explored further.

- Nasogastric or intravenous multinutrient supplementation. These trials should be conducted only in the most malnourished patients, where oral supplementation is unable to provide sufficient intake.

Additionally, information on nutritional status and use of supplements should be collected in audits of hip fracture management. Such data could be used to investigate the relationship of nutritional status to outcome.

\section{ACK N O WLEDGEMEN TS}

For this version of the review, we are grateful for the helpful comments at editorial and external review from Helen Handoll and Jane Portlock. We also thank Lindsey Elstub and Joanne Elliott for their help on this version.

This project was supported by the National Institute for Health Research via Cochrane Infrastructure funding to the Cochrane Bone, Joint and Muscle Trauma Group. The views and opinions expressed therein are those of the authors and do not necessarily reflect those of the Systematic Reviews Programme, NIHR, NHS or the Department of Health. 


\section{R E F E R E N C E S}

\section{References to studies included in this review}

Anbar 2014 \{published data only\}

* Anbar R, Beloosesky Y, Cohen J, Madar Z, Weiss A, Theilla M, et al. Tight calorie control in geriatric patients following hip fracture decreases complications: a randomized, controlled study. Clinical Nutrition 2014;33:23-8.

Anbar R, Beloosesky Y, Madar Z, Theilla M, Koren-Hakim T, Weiss A, et al. Tight calorie control (TICACOS) in geriatric hip fracture patients. Clinical Nutrition, Supplement 2012;7(1):18.

Anbar R, Beloosesky Y, Madar Z, Theilla M, Koren-Hakim T, Weiss $\mathrm{A}$, et al. Tight calorie control in geriatric hip fracture patients: preliminary results of the geriatric TICACOS study. Clinical Nutrition, Supplement 2011;6(1):155.

Singer P. Tight caloric balance in geriatric patients (TICACOSiGP). clinicaltrials.gov/show/NCT01735435 (accessed 3 December 2015).

\section{Bastow 1983b \{published and unpublished data\}}

Allison SP. Personal communication 15 February 2000.

Allison SP. Reflections on a study of nutrition support in patients with femur neck fracture. Nutrition 1995;11(3):322-7.

* Bastow MD, Rawlings J, Allison SP. Benefits of supplementary tube feeding after fractured neck of femur: a randomised controlled trial. British Medical Journal (Clinical Research Edition) 1983;287(6405):1589-92. [MEDLINE: 6416514]

Bastow MD, Rawlings J, Allison SP. Controlled trial showing clinical benefit of tube feeding in elderly patients with fractured femur. Clinical Nutrition 1984;2 Suppl:57.

Bastow MD, Rawlings J, Allison SP. Overnight nasogastric tube feeding. Clinical Nutrition 1985;4(1):7-11.

\section{Bean 1994 \{published data only\}}

Bean N, Redden J, Goode H, Grimble G, Allison SP. Double-blind pilot trial, in elderly women with fractured femur, of ornithine alpha-ketoglutarate $v$. a defined formula oral supplement. Proceedings of the Nutrition Society 1994;53(3):203A.

\section{Bischoff-Ferrari 2010 \{published data only\}}

Bischoff-Ferrari $\mathrm{H}$. Early rehabilitation after hip fracture. clinicaltrials.gov/ct2/show/NCT00133640 (accessed 7 September 2015).

Bischoff-Ferrari H, Dawson-Hughes B, Orav E, Willett W, Egli A, Maetzel A, et al. The economic consequences of hip fractures: impact of home exercise and high dose-vitamin D. 32nd Annual Meeting of the American Society for Bone and Mineral Research Annual Meeting; 2010 Oct 15-9; Toronto, Canada. (accessed 3 December 2015); Vol. www.asbmr.org/education/2010abstracts.

* Bischoff-Ferrari HA, Dawson-Hughes B, Platz A, Orav EJ, Stahelin HB, Willett WC, et al. Effect of high-dosage cholecalciferol and extended physiotherapy on complications after hip fracture. A randomized controlled trial. Archives of Internal Medicine 2010;170(9):813-20.

Botella-Carretero 2008 \{published and unpublished data\} Botella-Carretero JI. Personal communication 23 January 2009.

* Botella-Carretero JI, Iglesias B, Balsa JA, Zamarron I, Arrieta F, Vazquez $C$. Effects of oral nutritional supplements in normally nourished or mildly undernourished geriatric patients after surgery for hip fracture: a randomized clinical trial. Journal of Parenteral and Enteral Nutrition 2008;32(2):120-8. [MEDLINE: 18407904]

Iglesias B, Botella-Carretero JI, Balsa JA, Arrieta F, Zamarron I, Vazquez $C$. Effects of oral nutritional supplements in geriatric patients after surgery for hip fracture. Clinical Nutrition Supplements 2007;2(2):97.

\section{Botella-Carretero 2010 \{published data only\}}

Botella-Carretero JI. Personal communication 26 October 2014.

* Botella-Carretero JI, Iglesias B, Balsa JA, Arrieta F, Zamarron I, Vazquez C. Perioperative oral nutritional supplements in normally and mildly undernourished geriatric patients submitted to surgery for hip fracture: a randomized clinical trial. Clinical Nutrition 2010;29(5):574-9.

Brown 1992b \{published and unpublished data\}

Brown KM. Personal communication May 1999.

* Brown KM, Seabrook NA. Effect of nutrition on recovery after fractured femur. Medical Audit News 1992;2(1):10-2.

Brown KM, Seabrook NA. Nutritional influences on recovery and length of hospital stay in elderly women following femoral fracture. Proceedings of the Nutrition Society 1992;51(2):132A.

Bruce 2003 \{published and unpublished data\}

Bruce D. Personal communication. October 2003.

* Bruce D, Laurance I, McGuiness M, Ridley M, Goldswain P. Nutritional supplements after hip fracture: poor compliance limits effectiveness. Clinical Nutrition 2003;22(5):497-500. [MEDLINE: 14512038]

\section{Chevalley 2010 \{published data only\}}

Chevalley T. Personal communication 14 October 2014.

* Chevalley T, Hoffmeyer P, Bonjour J-P, Rizzoli R. Early serum IGF-I response to oral protein supplements in elderly women with a recent hip fracture. Clinical Nutrition 2010;29(1):78-83.

Day 1988 \{published and unpublished data\} Day JJ. Personal communication 27 May 1999.

* Day JJ, Bayer AJ, McMahon M, Pathy MS, Spragg BP, Rowlands DC. Thiamine status, vitamin supplements and postoperative confusion. Age and Ageing 1988;17:29-34. 


\section{Delmi 1990 \{published data only\}}

Bonjour JP, Rapin CH, Rizzoli R, Tkatch L, Delmi M, Chevalley T, et al. Hip fracture, femoral bone mineral density, and protein supply in elderly patients. In: Munro HN, Schlierf G editor(s). Nutrition of the elderly. Nestlé nutrition workshop series. Vol. 29, New York: Raven Press, 1992:151-9. [ISBN 0881678740]

Bonjour JP, Schürch MA, Chevalley P, Ammann P, Rizzoli R. Protein intake, IGF-1 and osteoporosis. Osteoporosis International 1997;7 Suppl 3:S36-42.

Bonjour JP, Schürch MA, Rizzoli R. Nutritional aspects of hip fractures. Bone 1996;18(3 Suppl):139S-44S.

Bonjour JP, Schürch MA, Rizzoli R. Proteins and bone health. Pathologie-Biologie 1997;45(1):57-9.

* Delmi M, Rapin C-H, Bengoa J-M, Delmas PD, Vasey H, Bonjour J-P. Dietary supplementation in elderly patients with fractured neck of the femur. Lancet 1990;335:1013-6. [MEDLINE: 1970070]

Rapin CH, Bengoa JM, Kahn JM, Delmi M, Bonjour JP, Vasey H. A prospective randomised control study of oral dietary supplementation in patients with fractured necks of femur. Journal of Parenteral and Enteral Nutrition 1989;13(1):9S.

Duncan 2006 \{published and unpublished data\}

Duncan D. Personal communication March 152006.

Duncan D, Murison J, Martin R, Beck S, Johansen A. Adequacy of oral feeding among elderly patients with hip fracture. Age and Ageing 2001;30(Suppl 2):22.

Duncan DG, Beck SJ. Using dietetic assistants to improve the outcome of hip fracture - a randomised controlled trial of nutritional support in an acute trauma ward. Clinical Nutrition 2002;21(Suppl 1):41.

Duncan DG, Beck SJ, Hood K, Johansen A. Using dietetic assistants to improve the outcome of hip fracture - a randomised controlled trial of nutritional support in an acute trauma ward. Age and Ageing 2006;35(Suppl 3):i43.

* Duncan DG, Beck SJ, Hood K, Johansen A. Using dietetic assistants to improve the outcome of hip fracture: a randomised controlled trial of nutritional support in an acute trauma ward. Age and Ageing 2006;35(2):148-53. [MEDLINE: 16354710]

Duncan DG, Beck SJ, Johansen A. Using dietetic assistants to improve the outcome of hip fracture - a randomised controlled trial of nutritional support in an acute trauma ward. Journal of Human Nutrition and Dietetics 2002;15:461.

Johansen A. Using dietetic assistants to improve the outcome of hip fracture. In: The National Research Register, Issue 1, 2002. Oxford: Update Software 2002.

Eneroth 2006 \{published and unpublished data\}

Eneroth M. Personal communication 10 February 2009.

Eneroth M. Personal communication 17 March 2006.
Eneroth M, Olsson U-B, Thorngren K-G. Combined parenteral and oral nutritional supplementation decreases fracture-related complications. A prospective randomised trial of 80 patients with hip fractures. Journal of Bone and Joint Surgery - British Volume 2006;88(Suppl 1):44.

Eneroth M, Olsson U-B, Thorngren K-G. Insufficient fluid and energy intake in hospitalised patients with hip fracture. A prospective randomised study of 80 patients. Clinical Nutrition 2005;24:297-303. [MEDLINE: 15784492]

* Eneroth M, Olsson UB, Thorngren KG. Nutritional supplementation decreases hip fracture-related complications. Clinical Orthopaedics and Related Research 2006;(451):212-7. [MEDLINE: 16770284]

Espaulella 2000 \{published and unpublished data\}

* Espaulella J, Guyer H, Diaz-Escriu F, Mellado-Navas JA, Castells M, Pladevall M. Nutritional supplementation of elderly hip fracture patients. A randomized, double-blind, placebocontrolled trial. Age and Ageing 2000;29(5):425-31. [MEDLINE: 11108415]

Guyer H. Personal communication 13 June 2000.

\section{Fabian 2011 \{published data only\}}

Fabian E, Gerstorfer I, Thaler HW, Stundner H, Biswas P, Elmadfa I. Nutritional supplementation affects postoperative oxidative stress and duration of hospitalization in patients with hip fracture. Wiener Klinische Wochenschrift 2011;123(3-4):88-93.

\section{Flodin 2014 \{published data only\}}

Flodin L. Effects of bisphosphonates and nutritional supplementation after a hip fracture. clinicaltrials.gov/show/ NCT01950169 2013 (accessed 3 December 2015).

Flodin L. Personal communication. Personal communication 15 December 2014.

* Flodin L, Saaf M, Cederholm T, Al-Ani AN, Ackermann PW, Sanegard E, et al. Additive effects of nutritional supplementation, together with bisphosphonates, on bone mineral density after hip fracture: a 12-month randomized controlled study. Clinical Interventions in Aging 2014;9:1043-50.

Gallagher 1992 \{published and unpublished data\}

* Gallagher J, Schermbeck J, Dixon L, Labbe-Bell M. Aggressive early management of malnutrition in hip fracture patients. Journal of Parenteral and Enteral Nutrition 1992;16(1):19S.

Koretz R. Personal communication 7 September 1999.

\section{Glendenning 2009 \{published data only\}}

Chew G, Glendenning P, Taranto M, Inderjeeth C. Ergocalciferol and cholecalciferol induce comparable increases in vitamin $\mathrm{D}$ binding protein and free 25 -hydroxy-vitamin $\mathrm{D}$ with no significant change in free 1,25-dihydroxyvitamin $D$ in hip fracture patients. 32nd Annual Meeting of the American Society for Bone and Mineral Research Annual Meeting; Oct 15-9; Toronto, Canada 2010 (accessed 3 December 2015); Vol. www.asbmr.org/education/2010-abstracts. 
Glendenning P, Chew GT, Inderjeeth CA, Taranto M, Fraser WD. Calculated free and bioavailable vitamin $\mathrm{D}$ metabolite concentrations in vitamin D-deficient hip fracture patients after supplementation with cholecalciferol and ergocalciferol. Bone 2013;56(2):271-5.

* Glendenning P, Chew GT, Seymour HM, Gillett MJ, Goldswain PR, Inderjeeth CA, et al. Serum 25-hydroxyvitamin $D$ levels in vitamin D-insufficent hip fracture patients after supplementation with ergocalciferol and cholecalciferol. Bone 2009;45(5):870-5.

\section{Hankins 1996 \{unpublished data only\}}

${ }^{*}$ Hankins C. Dietary supplementation with sustagen in elderly patients with fractured neck of femur [MSc dissertation]. Sydney (Australia): University of Sydney, 1996.

Hankins C. Personal communication 11 June 1999.

\section{Hartgrink 1998 \{published and unpublished data\}}

Hartgrink HH. Personal communication 23 June 1999.

* Hartgrink HH, Wille J, König P, Hermans J, Breslau PJ. Pressure sores and tube feeding in patients with a fracture of the hip: a randomized clinical trial. Clinical Nutrition 1998;17:287-92.

\section{Hoikka 1980 \{published and unpublished data\}}

* Hoikka V, Alhava EM, Aro A, Karjalainen P, Rehnberg V. Treatment of osteoporosis with 1-alpha-hydroxycholecalciferol and calcium. Acta Medica Scandinavica 1980;207(3):221-4. [MEDLINE: 6989171]

Robertson J. Personal communication 2 February 1999.

\section{Houwing 2003 \{published and unpublished data\}}

Houwing R. Personal communication 29 October 2003.

Houwing R, Rozendaal M, Wouters-Wesseling W, Beulens J, Buskens E, Haalboom J. The effect of nutritional supplementation on the prevention of pressure ulcers (PU) in hip-fracture patients. Clinical Nutrition 2002;21(Suppl 1):84.

* Houwing RH, Rozendaal M, Wouters-Wesseling W, Beulens JW, Buskens E, Haalboom JR. A randomised, double-blind assessment of the effect of nutritional supplementation on the prevention of pressure ulcers in hip-fracture patients. Clinical Nutrition 2003;22(4):401-5. [MEDLINE: 12880608]

\section{Kang 2012 \{published data only\}}

Kang JH, Shin DW, Baik HW, Hong J. Short-term oral nutritional supplements and nutrition intervention in elderly patients after hip fracture surgery: a randomized controlled clinical trial. Clinical Nutrition, Supplement 2012;7(1):280.

Luo 2015 \{published data only\}

Luo M. Personal communication 17 November 2014.

* Luo M, Golubev G, Klyukvin I, Reznik L, Kuropatkin G, Oliver JS, et al. Oral nutrition supplement improved nutritional status in malnourished hip fracture patients: a randomized controlled study. Journal of Scientific Research and Reports 2015;4(6):480-9.
Luo M, Golybev G, Klyukvin I, Reznik L, Kuropatkin G, Voss AC. Oral nutritional supplement (ONS) improved nutritional status in malnourished patients receiving hip fracture surgery. Clinical Nutrition Supplements 2011;6:151.

Swearengin B. Effect of a medical food supplement in hospitalized patients recovering from surgery. clinicaltrials.gov/ ct2/show/NCT01011608 (accessed 4 December 2015).

Madigan 1994 \{unpublished data only\}

Madigan C. Benefits of dietary supplementation in elderly patients with fractured neck of femur. Sydney (Australia): University of Sydney, 1994.

Miller 2006 \{published and unpublished data\} Crotty M. Personal communication 20 February 2009.

Daniels LA, Miller M, Bannerman E, Whitehead C, Crotty M. Weight loss post lower limb fracture despite an intensive oral nutrition and exercise intervention. Clinical Nutrition 2003;22 Suppl:S86.

Daniels LA, Miller MD, Bannermann E, Crotty M. Adherence to nutritional supplements amongst orthopedic patients: an important clinical and study design issue. Clinical Nutrition 2005;24:535.

Miller MD, Bannerman E, Daniels LA, Crotty M. Lower limb fracture, cognitive impairment and risk of subsequent malnutrition: a prospective evaluation of dietary energy and protein intake on an orthopaedic ward. European Journal of Clinical Nutrition 2006;60(7):853-61. [MEDLINE: 16452913]

* Miller MD, Crotty M, Whitehead C, Bannerman E, Daniels LA. Nutritional supplementation and resistance training in nutritionally at risk older adults following lower limb fracture: a randomized controlled trial. Clinical Rehabilitation 2006;20(4):311-23.

Miller MD, Daniels LA, Bannerman E, Crotty M. Adherence to nutrition supplements among patients with a fall-related lower limb fracture. Nutrition in Clinical Practice 2005;20(5):569-78. [MEDLINE: 16207699]

Myint 2013 \{published data only\}

Myint MW. Personal communication 6 January 2015.

* Myint MW, Wu J, Wong E, Chan SP, To TS, Chau MW, et al. Clinical benefits of oral nutritional supplementation for elderly hip fracture patients: a single blind randomised controlled trial. Age and Ageing 2013;42(1):39-45.

Myint MWW. A randomized controlled study of nutritional intervention for geriatric hip fracture patients and its effect on rehabilitation outcomes. clinicaltrials.gov/ct2/show/ NCT01088139 (accessed 4 December 2015).

Neumann 2004 \{published and unpublished data\} Jensen G. Personal communication 6 January 2005.

* Neumann M, Friedmann J, Roy MA, Jensen GL. Provision of high-protein supplement for patients recovering from hip fracture. Nutrition 2004;20(5):415-9. [MEDLINE: 15105027] 
Neumann MM, Friedmann JM, Jensen GL. Provision of high protein supplement for patients recovering from hip fracture. Journal of Parenteral and Enteral Nutrition 2004;28(Suppl 1):S30.

\section{Papaioannou 2011 \{published data only\}}

Papaioannou A. A randomised, controlled comparison of vitamin D strategies in acute hip fracture patients. clinicaltrials.gov/show/NCT00424619 (accessed 4 December 2015).

* Papaioannou A, Kennedy CC, Giangregorio L, loannidis G, Pritchard J, Hanley DA, et al. A randomized controlled trial of vitamin $D$ dosing strategies after acute hip fracture: no advantage of loading doses over daily supplementation. BMC Musculoskeletal Disorders 2011;12:135.

Papaioannou A, Kennedy CC, Ioannidis G, Adachi JD, Hanley D, Giangregorio L, et al. High versus low vitamin D in acute hip fracture patients: a randomised, controlled trial. Osteoporosis International 2010;21(Suppl 1):S201.

Parker 2010 \{published data only\}

Parker M. Personal communication 16 October 2014.

Parker M. Randomised trial comparing iron supplementation versus placebo in the treatment of anaemia after hip fracture. clinicaltrials.gov/show/NCT00919230 (accessed 4 December 2015).

* Parker MJ. Iron supplementation for anemia after hip fracture surgery. A randomized trial of 300 patients. Journal of Bone and Joint Surgery - American Volume 2010;92(2):265-9.

\section{Prasad 2009 \{published data only\}}

Prasad N. Personal communication 24 October 2014.

* Prasad N, Rajamani V, Hullin D, Murray JM. Post-operative anaemia in femoral neck fracture patients: does it need treatment? A single blinded prospective randomised controlled trial. Injury 2009;40(10):1073-6.

\section{Schürch 1998 \{published data only\}}

Bonjour JP, Schürch MA, Chevalley P, Ammann P, Rizzoli R. Protein intake, IGF-1 and osteoporosis. Osteoporosis International 1997;7 Suppl 3:S36-42.

Rizzoli R, Schürch MA, Bonjour JP. Protein supplements after osteoporotic hip fracture. Annals of Internal Medicine 1998;129:1076.

Schürch M-A, Bonjour J-P, Slosman D, Rizzoli R. Protein supplements favourably influence the outcome after hip fracture [Un supplement proteique ameliore les suites d'une fracture du femur proximal]. Medecine et Hygiene 1999;57(2271):1876-8.

Schürch MA, Rizzoli R, Slosman D, Bonjour JP. Protein supplements increase serum IGF-1 and decrease proximal femur bone loss in patients with a recent hip fracture. Osteoporosis 1996: Proceedings of the 1996 World Congress on Osteoporosis; 1996 May 18-23; Amsterdam, The Netherlands. Amsterdam: Elsevier, 1996:327-9.
* Schürch MA, Rizzoli R, Slosman D, Vadas L, Vergnaud P, Bonjour JP. Protein supplements increase serum insulin-like growth factor-I levels and attenuate proximal femur bone loss in patients with recent hip fracture. A randomized, doubleblind, placebo-controlled trial. Annals of Internal Medicine 1998;128(10):801-9.

\section{Scivoletto 2010 \{published data only\}}

Derossi D, Bo A, Bergonzi R, Scivoletto G. Six-week administration of a mixture of ergogenic and osteotrophic ingredients (Restorfast ${ }^{\mathrm{TM}}$ ) improves the clinical course of elderly patients after hip fracture surgery [La somministrazione per sei settimane di un composto a base di sostanze osteotrofiche ed ergogene (RestorfastTM) migliora il decorso clinico in anziani sottoposti a chirurgia del femore]. Trends in Medicine 2009;9(4):235-42.

* Scivoletto G, Bo A, Derossi D, Bergonzi R. Ten week administration of a polynutritional supplement with muscle tone action (Riabylex $\mathrm{TM}$ ) improves the functional recovery in elderly hip fracture patients during home rehabilitation [In anziani in terapia riabilitativa domiciliare per pregressa frattura del femore, l'assunzione di un polinutriente ad azione muscolotonica (RiabylexTM) per 10 settimane migliora il recupero funzionale]. Trends in Medicine 2010;10(2):113-20.

\section{Serrano-Trenas 2011 \{published data only\}}

Serrano-Trenas JA, Ugalde PF, Cabello LM, Chofles LC, Lazaro PS, Benitez PC. Role of perioperative intravenous iron therapy in elderly hip fracture patients: a single-center randomized controlled trial. Transfusion 2011;51(1):97-104.

\section{Stableforth 1986 \{published data only\}}

Stableforth PG. Supplement feeds and nitrogen and calorie balance following femoral neck fracture. British Journal of Surgery 1986;73:651-5.

\section{Sullivan 1998 \{published and unpublished data\}}

Sullivan DH. Personal communication 10 February 2000.

* Sullivan DH, Nelson CL, Bopp MM, Puskarich-May CL, Walls RC. Nightly enteral nutrition support of elderly fracture patients: a phase I trial. Journal of the American College of Nutrition 1998;17(1):155-61.

Sullivan 2004 \{published and unpublished data\} Sullivan DH. Personal communication 14 April 2006.

* Sullivan DH, Nelson CL, Klimberg VS, Bopp MM. Nightly enteral nutrition support of elderly hip fracture patients: a pilot study. Journal of the American College of Nutrition 2004;23(6):683-91. [MEDLINE: 15637216]

\section{Tidermark 2004 \{published and unpublished data\}}

Carlsson P, Tidermark J, Ponzer S, Soderqvist A, Cederholm T. Food habits and appetite of elderly women at the time of a femoral neck fracture and after nutritional and anabolic support. Journal of Human Nutrition and Dietetics 2005;18(2):117-20. [MEDLINE: 15788020]

Tengstrand B, Cederholm T, Soderqvist A, Tidermark J. Effects of protein-rich supplementation and nandrolone on bone 
tissue after a hip fracture. Clinical Nutrition 2007;26(4):460-5. [MEDLINE: 17498850]

Tidermark J. Personal communication 14 October 2004.

Tidermark J. Quality of life and femoral neck fractures. Acta Orthopaedica Scandinavica. Supplementum 2003;74(309):1-42.

* Tidermark J, Ponzer S, Carlsson P, Soderqvist A, Brismar K, Tengstrand $B$, et al. Effects of protein-rich supplementation and nandrolone in lean elderly women with femoral neck fractures. Clinical Nutrition 2004;23(4):587-96.

Tidermark J, Ponzer S, Tengstrand B, Cederholm T. Liquid supplementation and nandrolone to elderly women. Clinical Nutrition 2002;21(Suppl 1):40.

\section{Tkatch 1992 \{published data only\}}

Bonjour JP, Rapin CH, Rizzoli R, Tkatch L, Delmi M, Chevalley T, et al. Hip fracture, femoral bone mineral density, and protein supply in elderly patients. In: Munro H, Schlierf G editor(s). Nutrition of the elderly. Nestle nutrition workshop series. Vol. 29, New York: Raven Press, 1992:151-9.

Bonjour JP, Schürch MA, Chevalley P, Ammann P, Rizzoli R. Protein intake, IGF-1 and osteoporosis. Osteoporosis International 1997;7 Suppl 3:S36-42.

Bonjour JP, Schürch MA, Rizzoli R. Nutritional aspects of hip fractures. Bone 1996;18(Suppl 3):139S-44S.

Bonjour JP, Schürch MA, Rizzoli R. Proteins and bone health. Patholgie-Biologie 1997;45(1):57-9.

* Tkatch L, Rapin CH, Rizzoli R, Slosman D, Nydegger V, Vasey H, et al. Benefits of oral protein supplementation in elderly patients with fracture of the proximal femur. Journal of the American College of Nutrition 1992;11(5):519-25.

\section{Van Stijn 2015 \{published data only\}}

Houdijk APJ. The effect of taurine on morbidity and mortality in the elderly hip fracture patient. clinicaltrials.gov/ct2/show/ NCT00497978 (accessed 15 December 2015).

* Van Stijn MF, Bruins AA, Vermeulen MA, Witlox J, Teerlink T, Schoorl MG, et al. Effect of oral taurine on morbidity and mortality in elderly hip fracture patients: a randomized trial. International Journal of Molecular Sciences 2015;16(6):12288-306. [DOI: 10.3390/ijms160612288; PUBMED: 26035756]

\section{Wyers 2013 \{published data only\}}

Breedveld-Peters J, Reijven PL, Wyers CE, Hendrikx AA, Verburg AD, Schols JM, et al. Qualitative analysis of barriers and facilitators for nutritional intervention in hip fracture patients. Clinical Nutrition, Supplement 2012;7(1):234.

Breedveld-Peters JJ, Reijven PL, Wyers CE, Hendrikx AA, Verburg AD, Schols JM, et al. Barriers and facilitators of nutritional intervention after hip fracture in integrated care as perceived by the different health care professionals: a qualitative interview study. e-SPEN Journal 2012;7(5):e182-8.
Breedveld-Peters JJ, Reijven PL, Wyers CE, Van Helden S, Arts JJ, Meesters B, et al. Integrated nutritional intervention in the elderly after hip fracture. A process evaluation. Clinical Nutrition, Supplement 2012;31(1):199-205.

Breedveld-Peters JJ, Reijven PL, Wyers CE, Van Helden S, Arts JJ, Meesters B, et al. Integrated nutritional intervention in the elderly after hip fracture. A process evaluation. Clinical Nutrition, Supplement 2012;7(1):43.

Dagnelie PC. Effectiveness and cost-effectiveness of nutritional screening and intervention in elderly subjects after hip fracture. clinicaltrials.gov/show/NCT00523575 (accessed 8 November 2009).

Wyers C, Reijven PL, Evers SM, Willems PC, Heyligers IC, Verburg $A D$, et al. Cost-effectiveness of nutritional intervention in hip fracture patients: a multi-centre randomised controlled trial (RCT). Clinical Nutrition, Supplement 2012;7(1):49.

Wyers CE. PhD thesis. Maastricht, the Netherlands: Maastricht University, 2012.

Wyers CE, Breedveld-Peters JJ, Reijven PL, Arts C, Thomassen BJ, Verburg AD, et al. Effect of nutritional intervention on nutritional intake and status in hip fracture patients: a multicentre randomised controlled trial (RCT). Clinical Nutrition, Supplement 2012;7(1):50-1.

Wyers CE, Breedveld-Peters JJ, Reijven PL, Van Helden S, Guldemond NA, Severens JL, et al. Efficacy and costeffectiveness of nutritional intervention in elderly after hip fracture: design of a randomized controlled trial. BMC Public Health 2010;10:212.

* Wyers CE, Reijven PL, Evers SM, Willems PC, Heyligers IC, Verburg $A D$, et al. Cost-effectiveness of nutritional intervention in elderly subjects after hip fracture. A randomized controlled trial. Osteoporosis International 2013;24(1):151-62.

\section{References to studies excluded from this review}

\section{Ashworth 2006 \{unpublished data only\}}

* Ashworth A. Nutritional supplementation and hip fracture patients - implications for future research trials. Proceedings of the Nutrition Society 2006;65:6A.

Ashworth A. Pilot study to compare nutritional intake of orthopaedic patients supplemented with snacks or oral nutritional supplements. National Research Register (NRR) Archive. portal.nihr.ac.uk/Profiles/NRR.aspx? Publication_ID=N0224145775 (accessed 8 November 2009). [NRR ID: N0224145775]

\section{Bachrach 2000 \{published data only\}}

* Bachrach-Lindström M, Johansson T, Unosson M, Ek A-C, Wahlström $O$. Nutritional status and functional capacity after femoral neck fractures: a prospective randomized one-year follow-up study. Aging: Clinical and Experimental Research 2000;12:366-74. 
Johansson T. Displaced femoral neck fractures. Linkoping University Medical Dissertations no. 731,. Sweden: University of Linkoping, 2002.

\section{Bachrach 2001 \{published data only\}}

Bachrach-Lindstrom M, Unosson M, Ek AC, Arnqvist HJ. Assessment of nutritional status using biochemical and anthropometric variables in a nutritional intervention study of women with hip fracture. Clinical Nutrition 2001;20(3):217-23.

Bell 2014 \{published data only\}

Bell JJ, Bauer JD, Capra S, Pulle RC. Multidisciplinary, multimodal nutritional care in acute hip fracture inpatients - results of a pragmatic intervention. Clinical Nutrition 2014;33(6):1101-7. [DOI: 10.1016/j.clnu.2013.12.003; PUBMED: 24388594]

Beringer 1986 \{published data only\}

Beringer TR, Ardill J, Taggart HM. Effect of calcium and stanozolol on calcitonin secretion in patients with femoral neck fracture. Bone and Mineral 1986;1(4):289-95.

\section{Boudville 2002 \{published data only\}}

Boudville AC, Bruce DG, Jarman A, Collins T. Do nutritional supplements reduce subsequent food intake in hip fracture patients?. Internal Medicine Journal 2002;32(Suppl):A33.

\section{Bradley 1995 \{published data only\}}

Bradley CF, Kozak C. Nursing care and management of the elderly hip fractured patient. Journal of Gerontological Nursing 1995;21:15-22.

\section{Brocker 1994 \{published data only\}}

* Brocker P, Vellas B, Albarede J-L, Poynard T. A two-centre, randomized, double-blind trial of ornithine oxoglutarate in 194 elderly, ambulatory, convalescent subjects. Age and Ageing 1994;23:303-6.

Vellas B, Poynard P, et al. Effects of ornithine alphaketoglutarate on elderly malnourished patients: a doubleblind study. Journal of Parenteral and Enteral Nutrition 1993;17(1):34S.

\section{Cameron 2011 \{published data only\}}

Au L, Cameron I, Kurrle S, Uy C. Effectiveness of oral nutritional supplementation for older women with hip and other fractures. Australian Society of Geriatric Medicine Annual Scientific Meeting; 2003 June 16-18; Melbourne (Australia). 2003.

Cameron ID. Personal communication. 26 November 2014.

* Cameron ID, Kurrle SE, Uy C, Lockwood KA, Au L, Schaafsma FG. Effectiveness of oral nutritional supplementation for older women after fracture: rationale, design and study of the feasibility of a randomized controlled study. BMC Geriatrics 2011;11:32.

\section{Carlsson 2005 \{published data only\}}

Carlsson P, Tidermark J, Ponzer S, Soderqvist A, Cederholm T. Food habits and appetite of elderly women at the time of a femoral neck fracture and after nutritional and anabolic support. Journal of Human Nutrition and Dietetics 2005;18:117-20. [MEDLINE: 15788020]
Crossley 1977 \{published data only (unpublished sought but not used)\}

Crossley A. A longitudinal study of thiamine status and the effect of supplementation in elderly patients recovering from orthopaedic surgery for fractured neck of femur [BSC dissertation]. Surrey (UK): University of Surrey, 1977.

Gegerle 1986 \{published data only\}

Gegerle P, Bengoa JM, Delmi M, Rapin CH, Loizeau E, Vasey H. Dietary survey on the effect of an oral nutritional supplement after femoral neck fracture [Enquete alimentaire apres fracture du col du femur. Effet d'un supplement dietetique sur les apports nutritionnels]. Schweizerische Rundschau fur Medizin Praxis 1986;75:933-5.

\section{Giaccaglia 1986 \{published data only\}}

Giaccaglia G, Malagù U, Antonelli M, Boschi S, Tabarroni I. Nutritional support in hip fracture operations on the elderly. Experience and results [Il supporto nutrizionale negli interventi di frattura dell'anca nell'anziano. Esperienze e risultati]. Minerva Anestesiologica 1986;52(11):397-400.

\section{Goldsmith 1967 \{published data only\}}

Goldsmith RS, Woodhouse CF, Ingbar SH, Segal D. Effect of phosphate supplements in patients with fractures. Lancet 1967;i:687-90.

\section{Groth 1988 \{published data only\}}

Groth F. Effects of wheat bran in the diet of postsurgical orthopaedic patients to prevent constipation. Orthopaedic Nursing 1988;7(4):41-6.

\section{Gunnarsson 2009 \{published data only\}}

Gunnarsson AK, Lonn K, Gunningberg L. Does nutritional intervention for patients with hip fractures reduce postoperative complications and improve rehabilitation? Journal of Clinical Nursing 2009;18(9):1325-33.

\section{Harju 1989 \{published data only\}}

Harju E, Punnonen R, Tuimala R, Salmi J, Paronen I. Vitamin $\mathrm{D}$ and calcitonin treatment in patients with femoral neck fracture: a prospective controlled clinical study. The Journal of International Medical Research 1989;17:226-42.

\section{Harwood 2004 \{published data only\}}

Harwood RH, Sahota O, Gaynor K, Masud T, Hosking DJ. A randomised, controlled comparison of different calcium and vitamin D supplementation regimens in elderly women after hip fracture: The Nottingham Neck of Femur (NoNOF) Study. Age and Ageing 2004;33(1):45-51.

\section{Hedström 2002 \{published data only\}}

Hedstrom M, Sjoberg K, Brosjo E, Astrom K, Dalen N. Changes in soft tissue body composition during treatment with anabolic steroids in women with hip fractures - a prospective randomized study on 64 female patients. Acta Orthopaedica Scandinavica. Supplementum 1998;69(280):31.

* Hedström M, Sjöberg K, Brosjö E, Åström K, Sjöberg H, Dalén N. Positive effects of anabolic steroids, vitamin D and calcium on muscle mass, bone mineral density and 
clinical function after a hip fracture. A randomised study of 63 women. Journal of Bone and Joint Surgery. British Volume 2002;84(4):497-503.

\section{Hitz 2007 \{published data only\}}

Hitz MF, Jensen JE, Eskildsen PC. Bone mineral density and bone markers in patients with a recent low-energy fracture: effect of $1 \mathrm{y}$ of treatment with calcium and vitamin D. American Journal of Clinical Nutrition 2007;86(1):251-9.

\section{Hoekstra 2011 \{published data only\}}

Hoekstra JC, Goosen JH, De Wolf GS, Verheyen CC. Effectiveness of multidisciplinary nutritional care on nutritional intake, nutritional status and quality of life in patients with hip fractures: a controlled prospective cohort study. Clinical Nutrition 2011;30(4):455-61.

\section{Holst 2012 \{published data only\}}

Holst M, Rasmussen HH, Laursen MB, Rasmussen S, Porup L, Haals DS. Standard plan for nutrition treatment in hip fracture patients: room for improvement. Clinical Nutrition, Supplement 2012;7(1):118-9.

\section{Hommel 2007 \{published data only\}}

Hommel A, Bjorkelund KB, Thorngren KG, Ulander K. Nutritional status among patients with hip fracture in relation to pressure ulcers. Clinical Nutrition 2007;26(5):589-96. [MEDLINE: 17662510]

\section{Kacmaz 2007 \{published data only\}}

Kacmaz Z, Kasici M. Effectiveness of bran supplement in older orthopaedic patients with constipation. Journal of Clinical Nursing 2007;16(5):928-36. [MEDLINE: 17462043]

\section{Kuzdenbaeva 1981 \{published data only\}}

Kuzdenbaeva RS, Shaykhiev US, Utegenov BA. Potassium orotate and polyvitamins in the therapy of patients with fractures [Orotat kaliia i polivitaminy pri lechenii bol'nykh s perelomami kostei]. Ortopediia Travmatologiia i Protezirovanie 1981;8:24-8.

\section{Larsson 1990 \{published data only\}}

Larsson J, Unosson M, Ek AC, Nilsson L, Thorslund S, Bjurulf P. Effect of dietary supplement on nutritional status and clinical outcome in 501 geriatric patients - a randomised study. Clinical Nutrition 1990;9(4):179-84. [EMBASE: 1990259199]

\section{Lauque $\mathbf{2 0 0 0}$ \{published data only\}}

Lauque S, Arnaud-Battandier F, Mansourian R, Guigoz Y, Paintin M, Nourhashemi F, et al. Protein-energy oral supplementation in malnourished nursing-home residents. A controlled trial. Age and Ageing 2000;29(1):51-6. [MEDLINE: 10690696]

\section{Lawson 2003 \{published data only\}}

Doshi MK, Lawson R, Ingoe LE, Colligan JM, Barton JR, Cobden I. Effect of nutritional supplementation on clinical outcome in post-operative orthopaedic patients. Clinical Nutrition 1998;17 Suppl 1:30.
Lawson R, Doshi MK, Ingoe LE, Colligan JM, Barton JR, Cobden I. Compliance of orthopaedic patients with nutritional supplementation. Proceedings of the Nutrition Society 1998;57:91A.

* Lawson RM, Doshi MK, Barton JR, Cobden I. The effect of unselected post-operative nutritional supplementation on nutritional status and clinical outcome of orthopaedic patients. Clinical Nutrition 2003;22(1):39-46.

Lawson RM, Doshi MK, Ingoe LE, Colligan JM, Barton JR, Cobden I. Compliance of orthopaedic patients with postoperative oral nutritional supplementation. Clinical Nutrition 2000;19(3):171-5.

\section{Li 2012 \{published data only\}}

Li HJ, Cheng HS, Liang J, Wu CC, Shyu YI. Functional recovery of older people with hip fracture: does malnutrition make a difference?. Journal of Advanced Nursing 2012;69(8):1691-703.

\section{Moller-Madsen 1988 \{published data only\}}

Møller-Madsen B, Tøttrup A, Hessov I, Jensen J. Nutritional intake and nutritional status of patients with a fracture of the femoral neck: value of oral supplements. Acta Orthopaedica Scandinavica. Supplementum 1988;227:48.

\section{Nusbickel 1989 \{published data only\}}

Nusbickel F, Nelson C, Puskarich C, McAndrew M. Perioperative nutritional evaluation of orthopaedic trauma patients. Orthopaedic Transactions 1989;13(3):756.

* Nusbickel FR, Nelson CL, Puskarich CL. Perioperative evaluation of orthopaedic patients. Orthopaedic Transactions 1989;13(3):614-5.

\section{Olofsson 2007 \{published data only\}}

Lundstrom M, Olofsson B, Stenvall M, Karlsson S, Nyberg L, Englund $U$, et al. Postoperative delirium in old patients with femoral neck fracture: a randomized intervention study. Aging: Clinical and Experimental Research 2007;19(3):178-86.

* Olofsson B, Stenvall M, Lundstrom M, Svensson O, Gustafson Y. Malnutrition in hip fracture patients: an intervention study. Journal of Clinical Nursing 2007;16(11):2027-38. [MEDLINE: 17419798]

Stenvall M, Olofsson B, Nyberg L, Lundstrom M, Gustafson Y. Improved performance in activities of daily living and mobility after a multidisciplinary postoperative rehabilitation in older people with femoral neck fracture: a randomized controlled trial with 1-year follow-up. Journal of Rehabilitation Medicine 2007;39(3):232-8. [MEDLINE: 17468792]

\section{Pedersen 1999 \{published data only\}}

Pedersen PU. Dietary intervention in elderly patients prevents loss of activities of daily living after orthopaedic surgery [Kostintervention forebygger postoperativt aktivitetstab hos aeldre ortopaedkirurgiske patienter]. Videnskab \& Sygepleje 1999;43:52-74.

Pedersen PU. Nutritional care: the effectiveness of actively involving older patients. Journal of Clinical Nursing 2005;14:247-55. [MEDLINE: 15669934] 
* Pedersen PU, Cameron U, Jensen L. Active involvement of elderly surgical orthopaedic patients in their own dietary care increases postoperative energy and protein intake [Aktiv inddragelse af aeldre ortopaedkirurgiske patienter i egen kostforplejning oger energi- og proteinindtagelsen postoperativt]. Videnskab \& Sygepleje 1999;21:28-44.

\section{Ravetz 1959 \{published data only\}}

Ravetz E. The effect of a protein supplement in the nutrition of the aged. Geriatrics 1959;14:567-73.

\section{Shaikhiev 1984 \{published data only\}}

Shaikhiev US, Kuzdenbaeva RS, Sideshev GI, Lukpanov EK. Regional administration of vitamins $\mathrm{C}$ and $\mathrm{B} 1$ and calcium gluconate in the treatment of closed diaphyseal fractures [Regionarnoe vvedenie vitaminov C, B1 i gliukonata kal'tsiia pri lechenii zakrytykh diafizarnykh perelomov]. Ortopediia Travmatologiia i Protezirovanie 1984;11:31-3.

Stumm 2001 \{published data only\}

Stumm RE, Thomas MS, Coombes J, Greenhill J, Hay J. Managing constipation in elderly orthopaedic patients using either pear juice or a high fibre supplement. Australian Journal of Nutrition and Dietetics 2001;58(3):181-5.

\section{Tassler 1981 \{published data only\}}

Tassler H. Changes in protein fraction and blood glucose level of aged injured patients with standardized oral nutrition [Veranderungen des proteinstatus und der blutzuckerspiegel beim alteren traumatisierten patienten unter standardisierter peroraler ernahrung]. Unfallheilkunde 1981;84(5):213-5.

\section{Taylor 1974 \{published data only\}}

Taylor TV, Rimmer S, Day B, Butcher J, Dymock IW. Ascorbic acid supplementation in the treatment of pressure-sores. Lancet 1974;2(7880):544-6.

\section{Thomas 2008 \{published data only\}}

Miller M. Individual nutrition therapy and exercise regime: a controlled trial of injured, vulnerable elderly. www.anzctr.org.au/trial_view.aspx?ACTRN=12607000017426 (accessed 19 August 2009).

* Thomas SK, Humphreys KJ, Miller MD, Cameron ID, Whitehead C, Kurrle S, et al. Individual nutrition therapy and exercise regime: a controlled trial of injured, vulnerable elderly (INTERACTIVE trial). BMC Geriatrics 2008; Vol. 8:4. Available from www.biomedcentral.com/1471-2318/8/4 (accessed 08 November 2009). [DOI: 10.1186/1471-2318-8-4]

\section{Volkert 1996 \{published and unpublished data\}}

Volkert D, Hübsch S, Oster P, Schlierf G. Nutritional support and functional status in undernourished geriatric patients during hospitalization and 6-month follow-up. Aging 1996;8(6):386-95.

\section{Williams 1989 \{published data only\}}

Driver L. Evaluation of supplemental nutrition in elderly orthopaedic patients [PhD thesis]. Surrey (UK): University of Surrey, 1994.

Driver LT, Lumbers M, Older J, Williams CM. A controlled trial of sip-feed supplements in orthopaedic patients: post- discharge clinical outcome in relation to supplementation and compliance. Proceedings of the Nutrition Society 1990;49:173A.

Williams CM, Driver L, Older J, Dickerson JWT. The use of a nutritional risk score in identifying patients who may benefit from sip-feed supplementation in hospital [abstract]. Proceedings of the Nutrition Society 1998;47:135A.

* Williams CM, Driver LT, Older J, Dickerson JW. A controlled trial of sip-feed supplements in elderly orthopaedic patients. European Journal of Clinical Nutrition 1989;43(4):267-74.

Wong 2004 \{published data only\}

Wong SY, Lau EM, Lau WW, Lynn HS. Is dietary counselling effective in increasing dietary calcium, protein and energy intake in patients with osteoporotic fractures? A randomized controlled clinical trial. Journal of Human Nutrition and Dietetics 2004;17:359-64. [MEDLINE: 15250845]

\section{Zauber 1992 \{published data only\}}

Zauber NP, Zauber AG, Gordon FJ, Tillis AC, Leeds HC, Berman E, et al. Iron supplementation after femoral head replacement for patients with normal iron stores. JAMA 1992;267(4):525-7.

\section{References to studies awaiting assessment}

Benati 2011 \{published data only\}

Benati G, Boschi F, Brandolini F, Coppola D, Delvecchio S, Lijoi F, et al. Effects of a perioperative specific oral supplementation in hip fracture old patients. European Wound Management Association Journal 2011;Suppl 2:129.

\section{Bernabeu-Wittel 2016 \{published data only\}}

Efficacy of ferric carboxymaltose with or without EPO reducing red-cell transfusion packs in hip fracture perioperative period (PAHFRAC). clinicaltrials.gov/ct2/show/NCT01154491 (accessed 4 December 2015).

Bernabeu-Wittel M. Personal communication 22 September 2014.

Bernabeu-Wittel M, Aparico R, Romero M, Murcia-Zaragoza J, Monte-Secades R, Rosso C, et al. Ferric carboxymaltose with or without erythropoietin for the prevention of red-cell transfusions in the perioperative period of osteoporotic hip fractures: a randomized controlled trial. The PAHFRAC-01 project. BMC Musculoskeletal Disorders 2012;13:27.

* Bernabeu-Wittel M, Romero M, Ollero-Baturone M, Aparicio R, Murcia-Zaragoza J, Rincon-Gomez M, et al. Ferric carboxymaltose with or without erythropoietin in anemic patients with hip fracture: a randomized clinical trial. Transfusion 2016;56(9):2199-211.

\section{Ekinci 2015 \{published data only\}}

Ekinci O, Yanik S, Terzioglu B, Yilmaz Akyuz E, Dokuyucu A, Erdem $S$. The effect of calcium $\beta$-hydroxy- $\beta$-methylbutyrate, vitamin $D$ and protein supplementation on postoperative immobilization in elderly malnourished patients with hip fracture: a randomized controlled study. Clinical Nutrition 2015;34(Suppl 1):S102. 


\section{Gerstorfer 2008 \{published data only\}}

Gerstorfer I, Biswas P, Stundner H, Pienaar S, Elmadfa I, Thaler HW. Therapeutic nutritional care of patients with hip fractures. Clinical Nutrition Supplements 2008;3(1):215.

\section{Ish-Shalom 2008 \{published data only\}}

Ish-Shalom S, Segal E, Salganik T, Raz B, Bromberg IL, Vieth R. Comparison of daily, weekly and monthly vitamin D3 in ethanol dosing protocols for two months in elderly hip fracture patients. Journal of Clinical Endocrinology and Metabolism 2008;93(9):3430-5.

\section{Stratton 2006 \{published data only\}}

Stratton RJ, Bowyer G, Elia M. Fewer complications with liquid supplements than food snacks in fracture patients at risk of malnutrition. Clinical Nutrition Supplements 2007;2(2):9.

Stratton RJ, Bowyer G, Elia M. Food snacks or liquid oral nutritional supplements as first-line treatment for malnutrition in post-operative patients. Proceedings of the Nutrition Society 2006;65:4A.

\section{References to ongoing studies}

\section{ACTRN12609000241235 \{published data only\}}

Miller M. Personal communication 7 September 2014.

* Miller M. Does a high dose fish oil intervention improve outcomes in older adults recovering from hip fracture? www.anzctr.org.au/ACTRN12609000241235.aspx (accessed 8 November 2009).

\section{ACTRN12610000392066 \{published data only\}}

Mak J. Replenishment of Vitamin D in hip fractured patients (REVITAHIP) trial. www.anzctr.org.au/Trial/Registration/ TrialReview.aspx?id=335465\&isReview=true (accessed 23 September 2016).

* Mak JC, Mason R, Klein L, Cameron ID. Improving mobility and reducing disability in older people through early high-dose vitamin D replacement following hip fracture: a protocol for a randomized controlled trial and economic evaluation. Geriatric Orthopaedic Surgery and Rehabiliation 2011;2(3):94-9.

Mak JS, Klein LA, Finnegan T, Mason RS, Cameron ID. An initial loading-dose vitamin $D$ versus placebo after hip fracture surgery: baseline characteristics of a randomized controlled trial (REVITAHIP). BMC Geriatrics 2014;14:101.

Mak, JC, Klein LA, Mason RS, Cameron ID. An initial loadingdose vitamin $D$ versus placebo after hip fracture surgery: gait velocity, falls and mortality in the REVITAHIP study. Fragility Fracture Network Conference, 2014 Sep 4-6; Madrid. 2014.

\section{ACTRN12612000448842 \{published data only\}}

Harper M. Does Intravenous iron therapy reduce the need for blood transfusion and improve post operative blood count following surgery for broken neck of femur. www.anzctr.org.au/ TrialSearch.aspx?searchTxt=362379\&isBasic=True (accessed 23 September 2016).
NCT00497978 \{published data only\}

Houdijk AP. Personal communication 18 September 2014.

* Houdijk AP. The effect of taurine on morbidity and mortality in the elderly hip fracture patient. clinicaltrials.gov/show/ NCT00497978 (accessed 8 November 2009).

\section{NCT01404195 \{published data only\}}

Malafarina V. Hyperprotein nutritional intervention in elderly patients with hip fracture and sarcopenia (HIPERPROT). clinicaltrials.gov/ct2/show/NCT01404195 (accessed 4 December 2015).

* Malafarina V, Uriz-Otano F, Gil-Guerrero L, Iniesta R, Zulet MA, Martinez JA. Study protocol: high-protein nutritional intervention based on $\beta$-hydroxy- $\beta$-methylbutirate, vitamin D3 and calcium on obese and lean aged patients with hip fractures and sarcopenia. The HIPERPROT-GER study. Maturitas 2013;76(2):123-8.

\section{NCT01505985 \{published data only\}}

Bischoff-Ferrari $\mathrm{H}$. Hip fracture surgery and oral nutritional supplements (HIATUS). clinicaltrials.gov/ct2/show/ NCT01505985 (accessed 9 December 2015).

Rowlands \{published data only\}

Rowlands M, Forward DP, Sahota O, Moppett IK. The effect of intravenous iron on postoperative transfusion requirements in hip fracture patients: study protocol for a randomized controlled trial. Trials 2013;14(1):288.

\section{Additional references}

\section{Avenell 2001a}

Avenell A, Handoll HH, Grant AM. Lessons for search strategies from a systematic review, in The Cochrane Library, of nutritional supplementation in patients after hip fracture. American Journal of Clinical Nutrition 2001;73(5):505-10.

\section{Bastow 1983a}

Bastow MD, Rawlings J, Allison SP. Undernutrition, hypothermia, and injury in elderly women with fractured femur: an injury response to altered metabolism?. Lancet 1983;1(8317):143-6.

\section{Beck 2013}

Beck AM, Holst M, Rasmussen HH. Oral nutritional support of older (65 years+) medical and surgical patients after discharge from hospital: systematic review and meta-analysis of randomized controlled trials. Clinical Rehabilitation 2013;27:19-27. [DOI: 10.1177/0269215512445396]

\section{Begg 1996}

Begg C, Cho M, Eastwood S, Horton R, Moher D, Olkin I, et al. Improving the quality of reporting of randomized controlled trials. The CONSORT statement. JAMA 1996;276:637-9.

\section{Bentler 2009}

Bentler SE, Liu L, Obrizan M, Cook EA, Wright KB, Geweke JF, et al. The aftermath of hip fracture: discharge placement, 
functional status change, and mortality. American Journal of Epidemiology 2009;170(10):1290-9.

\section{Brown 1992a}

Brown KM, Seabrook NA. Nutritional influences on recovery and length of hospital stay in elderly women following femoral fracture. Proceedings of the Nutrition Society 1992;51:132A.

\section{Cranney 2005}

Cranney AB, Coyle D, Hopman WM, Hum V, Power B, Tugwell PS. Prospective evaluation of preferences and quality of life in women with hip fractures. Journal of Rheumatology 2005;32(12):2393-9. [MEDLINE: 16331770]

\section{Deeks 2011}

Deeks JJ, Higgins JPT, Altman DG. Chapter 9: Analysing data and undertaking meta-analyses. In: Higgins JPT, Green S (editors). Cochrane Handbook for Systematic Reviews of Interventions Version 5.1.0 (updated March 2011). The Cochrane Collaboration, 2011. Available from handbook.cochrane.org.

\section{Dickersin 1994}

Dickersin K, Scherer R, Lefebvre C. Systematic reviews: Identifying relevant studies for systematic reviews. BMJ 1997;309:1286-91.

\section{Dolan 1998}

Dolan P, Torgerson DJ. The cost of treating osteoporotic fractures in the United Kingdom female population. Osteoporosis International 1998;8:611-7.

\section{Foster 1990}

Foster MR, Heppenstall RB, Friedenberg ZB, Hozack WJ. A prospective assessment of nutritional status and complications in patients with fractures of the hip. Journal of Orthopaedic Trauma 1990;4:49-57.

\section{Gall 1998}

Gall MJ, Grimble GK, Reeve NJ, Thomas SJ. Effect of providing fortified meals and between-meal snacks on energy and protein intake of hospital patients. Clinical Nutrition 1998;17:259-64.

\section{Goode 1992}

Goode HF, Burns E, Walker BE. Vitamin C depletion and pressure sores in elderly patients with femoral neck fracture. $B M J$ 1992;305:925-7.

\section{Guyatt 2008}

Guyatt GH, Oxman AD, Vist GE, Kunz R, Falck-Ytter Y, AlonsoCoello $P$, et al. GRADE: an emerging consensus on rating quality of evidence and strength of recommendations. $B M J$ 2008;336:924.

\section{Haentjens 2005}

Haentjens P, Lamraski G, Boonen S. Costs and consequences of hip fracture occurrence in old age: an economic perspective. Disability and Rehabilitation 2005;27(18-19):1129-41. [MEDLINE: 16278182]

\section{Haentjens 2010}

Haentjens P, Magaziner J, Colon-Emeric CS, Vanderschueren D, Milisen K, Velkeniers B, et al. Meta-analysis: excess mortality after hip fracture among older women and men. Annals of Internal Medicine 2010;152(6):380-90.

\section{Higgins 2003}

Higgins JPT, Thompson SG, Deeks JJ, Altman DG. Measuring inconsistency in meta-analyses. BMJ 2003;327:557-60.

\section{Higgins 2011}

Higgins JPT, Altman DG, Sterne JAC. Chapter 8: Assessing risk of bias in included studies. In: Higgins JPT, Green S (editors). Cochrane Handbook for Systematic Reviews of Interventions Version 5.1.0 (updated March 2011). The Cochrane Collaboration, 2011. Available from www.handbook.cochrane.org.

\section{Holt 2008}

Holt G, Smith R, Duncan K, Finlayson DF, Gregori A. Early mortality after surgical fixation of hip fractures in the elderly. Journal of Bone and Joint Surgery - British Volume 2008;90B:1357-63.

\section{Jallut 1990}

Jallut D, Tappy L, Kohut M, Bloesch D, Munger R, Schutz Y, et al. Energy balance in elderly patients after surgery for a femoral neck fracture. Journal of Parenteral and Enteral Nutrition 1990;14:563-8.

\section{Johnell 1997}

Johnell O. The socioeconomic burden of fractures: today and in the 21st century. American Journal of Medicine 1997;103:20S-6S.

\section{Kanis 2012}

Kanis JA, Odén A, McCloskey EV, Johansson H, Wahl DA, Cooper $C$ on behalf of the IOF Working Group on Epidemiology and Quality of Life. A systematic review of hip fracture incidence and probability of fracture worldwide. Osteoporosis International 2012;23(9):2239-56.

\section{Keys 1950}

Keys A, Brozek J, Henschel A, Mickelsen O, Taylor HL, editors. The Biology of Human Starvation. Minneapolis: University of Minnesota, 1950.

\section{Koren-Hakim 2012}

Koren-Hakim T, Weiss A, Hershkovitz A, Otzrateni I, Grosman B, Frishman $\mathrm{S}$, et al. The relationship between nutritional status of hip fracture operated elderly patients and their functioning, comorbidity and outcome. Clinical Nutrition 2012;31(6):917-21.

\section{Lefebvre 2011}

Lefebvre C, Manheimer E, Glanville J. Chapter 6: Searching for studies. In: Higgins JPT, Green S (editors). Cochrane Handbook for Systematic Reviews of Interventions Version 5.1.0 (updated March 2011). The Cochrane Collaboration, 2011. Available from handbook.cochrane.org. 


\section{Lennard-Jones 1992}

Lennard-Jones, J E (editor). A positive approach to nutrition as treatment. Report on the role of enteral and parenteral feeding in hospital and at home. Working party chaired by J E LennardJones. London: King's Fund Centre, 1992. [ISBN 1857170164. pbk]

\section{Lesourd 1997}

Lesourd BM. Nutrition and immunity in the elderly: modification of immune responses with nutritional treatments. American Journal of Clinical Nutrition 1997;66:478S-84S.

\section{Lindholm 2008}

Lindholm C, Sterner E, Romanelli M, Pina E, Torra y Bou J, Hietanen $\mathrm{H}$, et al. Hip fracture and pressure ulcers - the PanEuropean Pressure Ulcer Study - intrinsic and extrinsic risk factors. International Wound Journal 2008;5:315-28. [MEDLINE: 18494637]

\section{Liu 2015}

Liu M, Yang J, Yu X, Huang X, Vaidya S, Huang F, et al. The role of perioperative oral nutritional supplementation in elderly patients after hip fracture surgery. Clinical Interventions in Aging 2015;10:849-58.

\section{Lumbers 2001}

Lumbers M, New SA, Gibson S, Murphy MC. Nutritional status in elderly female hip fracture patients: comparison with an age-matched home living group attending day centres. British Journal of Nutrition 2001;85:733-40. [MEDLINE: 11430778]

\section{Lyons 1997}

Lyons AR. Clinical outcomes and treatment of hip fractures. American Journal of Medicine 1997;103(2A):51S-64S.

\section{Mansell 1990}

Mansell PI, Rawlings J, Allison SP, Bendall MJ, Pearson M, Bassey EJ, et al. Low anthropometric indices in elderly females with fractured neck of femur. Clinical Nutrition 1990;9:190-4.

\section{Mariconda 2015}

Mariconda M, Costa GG, Cerbasi S, Recano P, Aitanti E, Gambacorta M, et al. The determinants of mortality and morbidity during the year following fracture of the hip. Bone and Joint Journal 2015;97(3):383-90.

\section{Milne 2006}

Milne AC, Avenell A, Potter J. Protein and energy supplementation in older people: a meta-analysis. Annals of Internal Medicine 2006;144:37-48.

\section{Milne 2009}

Milne AC, Potter J, Vivanti A, Avenell A. Protein and energy supplementation in elderly people at risk from malnutrition. Cochrane Database of Systematic Reviews 2009, Issue 2. [DOI: 10.1002/14651858.CD003288.pub3]

\section{Moher 2001}

Moher D, Schulz KF, Altman DG, for the CONSORT group. The CONSORT statement: revised recommendations for improving the quality of reports of parallel-group randomised trials. Lancet 2001;357:1191-4.

\section{Nematy 2004}

Nematy M, Hickson M, Brynes AE, Ruxton C, Frost GS. A pilot survey to investigate the nutritional status of patients with a fractured neck of femur and level of nutritional support provided during treatment. Proceedings of the Nutrition Society 2004;63:77A.

\section{Patterson 1992}

Patterson BM, Cornell CN, Carbone B, Levine B, Chapman D. Protein depletion and metabolic stress in elderly patients who have a fracture of the hip. Journal of Bone and Joint Surgery American Volume 1992;74:251-60.

\section{RevMan 2014 [Computer program]}

Nordic Cochrane Centre, The Cochrane Collaboration. Review Manager 5 (RevMan 5). Version 5.3. Copenhagen: Nordic Cochrane Centre, The Cochrane Collaboration, 2014.

\section{Schulz 2010}

Schulz KF, Altman DG, Moher D, for the CONSORT Group. CONSORT 2010 Statement: updated guidelines for reporting parallel group randomised trials. BMJ 2010;340(7748):698-702.

\section{Schürch 1998a}

Schürch MA, Rizzoli R, Slosman D, Vadas L, Vergnaud P, Bonjour JP. Protein supplements increase serum insulin-like growth factor-I levels and attenuate proximal femur bone loss in patients with recent hip fracture. A randomized, doubleblind, placebo-controlled trial. Annals of Internal Medicine 1998;128(10):801-9.

\section{References to other published versions of this review}

\section{Avenell 2000a}

Avenell A, Handoll HHG. Nutritional supplementation for hip fracture aftercare in the elderly. Cochrane Database of Systematic Reviews 2000, Issue 1. [DOI: 10.1002/14651858.CD001880]

\section{Avenell 2000b}

Avenell A, Handoll HHG. Nutritional supplementation for hip fracture aftercare in the elderly. Cochrane Database of Systematic Reviews 2000, Issue 4. [DOI: 10.1002/14651858.CD001880]

\section{Avenell 2001b}

Avenell A, Handoll HHG. Nutritional supplementation for hip fracture aftercare in the elderly. Cochrane Database of Systematic Reviews 2001, Issue 3. [DOI: 10.1002/14651858.CD001880]

\section{Avenell 2002}

Avenell A, Handoll HHG. Nutritional supplementation for hip fracture aftercare in the elderly. Cochrane Database of Systematic Reviews 2002, Issue 3. [DOI: 10.1002/14651858.CD001880] 


\section{Avenell 2004}

Avenell A, Handoll HHG. Nutritional supplementation for hip fracture aftercare in the elderly. Cochrane Database of Systematic Reviews 2004, Issue 1. [DOI: 10.1002/14651858.CD001880.pub2]

\section{Avenell 2005}

Avenell A, Handoll HHG. Nutritional supplementation for hip fracture aftercare in older people. Cochrane Database of Systematic Reviews 2005, Issue 2. [DOI: 10.1002/14651858.CD001880.pub3]

\section{Avenell 2006}

Avenell A, Handoll HHG. Nutritional supplementation for hip fracture aftercare in older people. Cochrane Database of Systematic Reviews 2006, Issue 4. [DOI: 10.1002/14651858.CD001880.pub4]

\section{Avenell 2010}

Avenell A, Handoll HHG. Nutritional supplementation for hip fracture aftercare in older people. Cochrane Database of Systematic Reviews 2010, Issue 1. [DOI: 10.1002/14651858.CD001880.pub5]

* Indicates the major publication for the study

\section{CHARACTERISTICS OF STUDIES}

Characteristics of included studies [ordered by study ID]

Anbar 2014

Methods

Method of randomisation: concealed, computer-generated programme

Intention-to-treat analysis: carried out

Lost to follow-up: all participants followed-up

Participants

Location: ortho-geriatric unit, Department of Geriatrics, Rabin Medical Center, Petah Tikva, Israel

Period of study: May 2010-December 2011

50 participants

Inclusion criteria: $>65$ years, admitted following hip fracture within $48 \mathrm{~h}$ of the injury and orthopaedic surgery was the treatment of choice

Exclusion criteria: presented to hospital $>48 \mathrm{~h}$ after the injury, receiving steroids and/or immunosuppression therapy; active oncologic disease, multiple fractures, diagnosed dementia, required supplemental nasal oxygen which precluded the measurement of resting energy expenditure (REE)

Sex: 33 female, 17 male

Age: mean 83 years

Fracture type: $40 \%$ pertrochanteric, $20 \%$ subcapital, $6 \%$ subtrochanteric, $6 \%$ base of femoral neck, $28 \%$ other

(a) Calories with an energy goal determined by three REE measurements in first $7 \mathrm{~d}$ using indirect calorimetry (IC) (Fitmate, Cosmed, Italy) which was based on hospital-prepared diets (standard or texture-adapted). Oral nutritional supplements (ONS) amount adjusted to make up the difference between energy received from hospital food and measured energy expenditure. These ONS were provided in the form of Ensure plus (Abbott Laboratories) containing $355 \mathrm{kcal} / 237 \mathrm{ml}$ and $13.5 \mathrm{~g}$ protein or Glucerna (Abbott Laboratories) containing $237 \mathrm{kcal} / 237 \mathrm{ml}$ and $9.9 \mathrm{~g}$ protein $/ 237 \mathrm{ml}$. The participant, family and caregivers educated regarding importance of nutritional support and more attention was given to personal food preferences. 24 -h food diaries were filled in by the medical staff, family and caregivers.

(b) Usual hospital food (standard or texture-adapted) and a fixed dose of ONS if already prescribed prior to hospitalisation. Hospital-prepared diets provided a mean of $1800 \mathrm{kcal}$ and $80 \mathrm{~g}$ of protein if meals completely eaten by the participants

Allocated: $22 / 28$ 
Anbar 2014 (Continued)

Assessed: $22 / 28$

Length of follow-up: length of hospital stay
Main outcomes:
Mortality
Length of hospital stay
Total complications
Infectious complications
Pressure ulcers
Other outcomes:
Protein and energy intakes
$\begin{aligned} & \text { Power calculation indicated needed } 66 \text { participants. In view of the slow rate of expected recruitment } \\ & \text { an interim analysis was planned after } 50 \text { participants. In the presence of a positive result, the study was } \\ & \text { discontinued. No funder reported }\end{aligned}$

\section{Risk of bias}

\begin{tabular}{|c|c|c|}
\hline Bias & Authors' judgement & Support for judgement \\
\hline $\begin{array}{l}\text { Random sequence genera- } \\
\text { tion (selection bias) }\end{array}$ & Low risk & $\begin{array}{l}\text { States "Randomization was performed using a concealed, computer generat- } \\
\text { ed program." }\end{array}$ \\
\hline $\begin{array}{l}\text { Allocation concealment } \\
\text { (selection bias) }\end{array}$ & Low risk & $\begin{array}{l}\text { States "Randomization was performed using a concealed, computer gener- } \\
\text { ated program. RA enrolled participants and assigned them to interventions } \\
\text { while YB enrolled patients but was blinded to the intervention." Comment: } \\
\text { probably done }\end{array}$ \\
\hline $\begin{array}{l}\text { Blinding of participants } \\
\text { and personnel (perfor- } \\
\text { mance bias) } \\
\text { All outcomes }\end{array}$ & High risk & No placebo group \\
\hline $\begin{array}{l}\text { Blinding of outcome as- } \\
\text { sessment (detection bias) } \\
\text { Primary outcomes }\end{array}$ & Low risk & $\begin{array}{l}\text { No placebo group. Comment: unlikely to have been influenced by lack of } \\
\text { blinding }\end{array}$ \\
\hline $\begin{array}{l}\text { Blinding of outcome as- } \\
\text { sessment (detection bias) } \\
\text { Secondary and other out- } \\
\text { comes }\end{array}$ & Unclear risk & No placebo group. Comment: may have been influenced by lack of blinding \\
\hline $\begin{array}{l}\text { Incomplete outcome data } \\
\text { (attrition bias) } \\
\text { Primary outcomes }\end{array}$ & Low risk & All participants accounted for, with no drop-outs. \\
\hline $\begin{array}{l}\text { Incomplete outcome data } \\
\text { (attrition bias) } \\
\text { Secondary and other out- } \\
\text { comes }\end{array}$ & Low risk & All participants accounted for, with no drop-outs. \\
\hline
\end{tabular}


Anbar 2014 (Continued)
Selective reporting (re-
Low risk
No protocol available, but expected outcomes reported porting bias)

Other bias

High risk

Power calculation indicated needed 66 participants. In view of the slow rate of expected recruitment an interim analysis was planned after 50 participants. In the presence of a positive result, the study was discontinued. No funder reported

\section{Bastow 1983b}

$\begin{array}{ll}\text { Methods } & \text { Method of randomisation: quasi-randomised } \\ \text { Intention-to-treat analysis: appears so } \\ \text { Lost to follow-up: appears none }\end{array}$

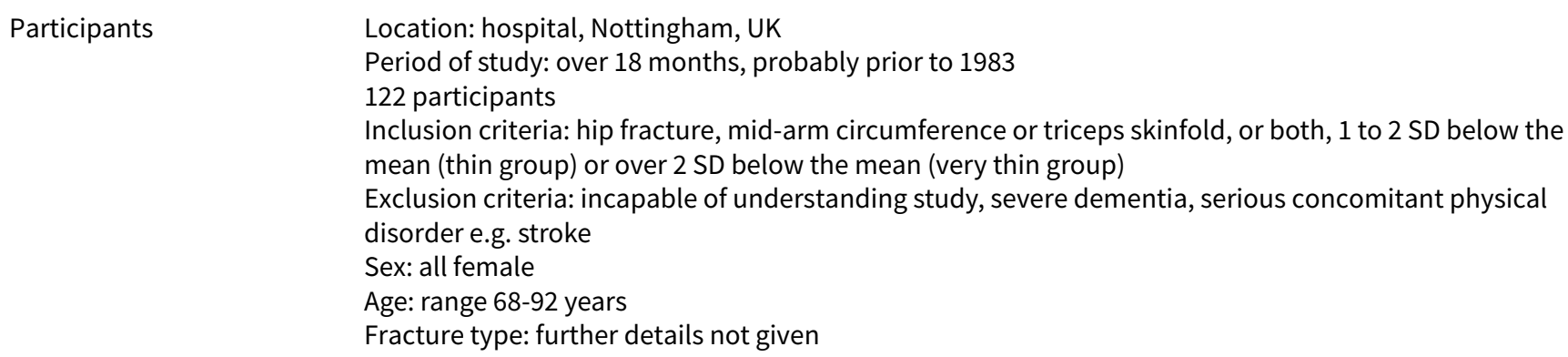

Interventions Timing of intervention: nasogastric feeding started within $5 \mathrm{~d}$ of surgery, $8 \mathrm{~h}$ overnight with tube disconnected during the day, until discharge or death. Feeding stopped if participant did not tolerate tube or removed tube on 3 occasions

(a) $1 \mathrm{~L} \mathrm{Clinifeed} \mathrm{Iso} \mathrm{(4.2} \mathrm{MJ} \mathrm{or} 1000 \mathrm{kcal}, 28 \mathrm{~g}$ protein, $270 \mathrm{mosmol} / \mathrm{L}$ ) via fine bore nasogastric tube using peristaltic pump, and normal ward diet, with free access to snacks and drinks

(b) Normal ward diet, with free access to snacks and drinks

Allocated: $64 / 58$

Assessed: 60/49 for independent mobility

\begin{tabular}{ll}
\hline Outcomes & Length of follow-up: until discharge or death \\
Main outcomes: & Mortality \\
Morbidity and complications: infection \\
Length of stay: hospital stay \\
Postoperative functional status: days to weight bearing with support, days to independent mobility \\
Putative side effects of treatment: aspiration, diarrhoea \\
Other outcomes: \\
Voluntary food intake \\
Patient compliance: tolerance of tube, duration of feeding \\
There was an administrative limit imposed of a maximum of 6 participants being fed at one time. Da- \\
ta presented from 1983 paper for numbers of participants are correct, error in number of participants \\
in 1985 paper. Slight discrepancy with days to reach independent mobility presented in 1984 abstract. \\
Reply from trialists (15 February 2000) gave details of randomisation (on recall: either by date of admis- \\
sion or birth), outcome assessment, inclusion criteria, denominators and baseline comparability
\end{tabular}

\section{Risk of bias}

Bias Authors' judgement Support for judgement


Bastow 1983b (Continued)

Random sequence genera- High risk Quasi-randomised. On recall by trialists: "either on the basis of odd and even tion (selection bias) dates of birth or of admission".

\begin{tabular}{|c|c|c|}
\hline $\begin{array}{l}\text { Allocation concealment } \\
\text { (selection bias) }\end{array}$ & High risk & $\begin{array}{l}\text { Quasi-randomised. On recall by trialists: "either on the basis of odd and even } \\
\text { dates of birth or of admission". }\end{array}$ \\
\hline
\end{tabular}

Blinding of participants High risk No placebo group. Comment: likely to have been influenced by lack of blinding
and personnel (perfor-
mance bias)
All outcomes

\begin{tabular}{ll}
\hline $\begin{array}{l}\text { Blinding of outcome as- } \\
\text { sessment (detection bias) } \\
\begin{array}{l}\text { Primary outcomes }\end{array}\end{array} \quad$ Low risk & $\begin{array}{l}\text { No placebo group. Comment: unlikely to have been influenced by lack of } \\
\text { blinding }\end{array}$
\end{tabular}

Primary outcomes

Blinding of outcome as- $\quad$ Unclear risk No placebo group. Comment: may have been influenced by lack of blinding
sessment (detection bias)
Secondary and other out-
comes

$\begin{aligned} & \text { Incomplete outcome data } \\ & \text { (attrition bias) }\end{aligned}$
Primary outcomes risk

\begin{tabular}{|c|c|c|}
\hline $\begin{array}{l}\text { Incomplete outcome data } \\
\text { (attrition bias) } \\
\text { Secondary and other out- } \\
\text { comes }\end{array}$ & Low risk & All participants accounted for, with no drop-outs. \\
\hline $\begin{array}{l}\text { Selective reporting (re- } \\
\text { porting bias) }\end{array}$ & Low risk & $\begin{array}{l}\text { Protocol not available, but study report includes all outcomes reported in } \\
\text { methods and those that would be expected. Comment: probably done }\end{array}$ \\
\hline Other bias & High risk & $\begin{array}{l}\text { States that Bastow was "supported by a grant from Rousell Laboratories Ltd", } \\
\text { manufacturers of Clinifeed nasogastric feed used in trial }\end{array}$ \\
\hline
\end{tabular}

Bean 1994

$\begin{array}{ll}\text { Methods } & \text { Method of randomisation: states double-blind, but no other details } \\ \text { Intention-to-treat analysis: claimed by authors, but no details to support } \\ \text { Lost to follow-up: details not given }\end{array}$

Interventions Timing of interventions: start time unclear, twice daily for 2 months,

(a) Cetornan (ornithine alpha-ketoglutarate) $20 \mathrm{~g} / \mathrm{d}(0.293 \mathrm{MJ}$ or $70 \mathrm{kcal}, 2.73 \mathrm{~g} \mathrm{~N}$ ), presumed orally

(b) Pro-up (defined formula peptide supplement, $0.293 \mathrm{MJ}$ or $70 \mathrm{kcal}, 2.73 \mathrm{~g} \mathrm{~N}$ ), presumed orally Allocated: ?/? 
Bean 1994 (Continued)

Assessed: ?/?

\begin{tabular}{ll}
\hline Outcomes & Length of follow-up: 6 months \\
Main outcomes: \\
Mortality \\
Morbidity and complications: all complications and delay in major complications (nr) \\
Length of stay: duration of treatment or hospitalisation (nr) \\
Postoperative functional status: fatigue score (nr) \\
Other outcomes: \\
Food intake (nr) \\
Patient compliance: proportion completing 2 months' treatment (nr) \\
Conference abstract only. No denominators for intention-to-treat analysis, so cannot use data in analy- \\
sis. Data on arm muscle circumference, fatigue score and food intake presented for 35 participants \\
completing 2 months of treatment. Request for further details (including denominators) sent 19 May \\
1999, re-sent 4 February 2000
\end{tabular}

\section{Risk of bias}

\begin{tabular}{lll}
\hline Bias & Authors' judgement & Support for judgement \\
\hline $\begin{array}{l}\text { Random sequence genera- } \\
\text { tion (selection bias) }\end{array}$ & Unclear risk & Abstract only. No details provided \\
\hline $\begin{array}{l}\text { Allocation concealment } \\
\text { (selection bias) }\end{array}$ & Unclear risk & $\begin{array}{l}\text { Abstract only. States "randomized in a double-blind fashion", no other details } \\
\text { provided }\end{array}$ \\
\hline $\begin{array}{l}\text { Blinding of participants } \\
\text { and personnel (perfor- } \\
\text { mance bias) } \\
\text { All outcomes }\end{array}$ & Low risk & Abstract only. States "double-blind" and "unlabelled identical sachets" \\
\hline
\end{tabular}

Blinding of outcome as-
sessment (detection bias) $\quad$ Low risk Abstract only. Comment: unlikely to have been influenced by unblinding

Primary outcomes

\begin{tabular}{lll}
\hline $\begin{array}{l}\text { Blinding of outcome as- } \\
\text { sessment (detection bias) }\end{array}$ & Unclear risk & $\begin{array}{l}\text { Abstract only. States "double-blind" and "unlabelled identical sachets". Com- } \\
\text { ment: unclear if done }\end{array}$
\end{tabular}
ction bias) Secondary and other outcomes

\begin{tabular}{lll}
\hline $\begin{array}{l}\text { Incomplete outcome data } \\
\text { (attrition bias) } \\
\text { Primary outcomes }\end{array}$ & Unclear risk & Abstract only. Insufficient details on attrition and exclusions provided \\
\hline $\begin{array}{l}\text { Incomplete outcome data } \\
\text { (attrition bias) }\end{array}$ & Unclear risk & Abstract only. Insufficient details on attrition and exclusions provided \\
$\begin{array}{l}\text { Secondary and other out- } \\
\text { comes }\end{array}$ & \\
\hline $\begin{array}{l}\text { Selective reporting (re- } \\
\text { porting bias) }\end{array}$ & Unclear risk & Abstract only. Insufficient details provided \\
\hline \begin{tabular}{l} 
Other bias \\
\hline
\end{tabular} & Unclear risk & Abstract only. Insufficient details provided. No details on sponsor
\end{tabular}


Method of randomisation: Factorial design computer-based randomisation performed by study statistician. Randomisation for the dosage of cholecalciferol was double-blinded

Intention-to-treat analysis: carried out

Lost to follow-up: $14 \%$ lost to follow-up

Participants

Location: Triemli City Hospital, Zurich, Switzerland

Period of study: screening for recruitment 2005-2007

173 participants

Inclusion criteria: age 65 years or older, surgical repair of acute hip fracture, Folstein Mini-Mental State Examination score of 15 or more, understand German, able to walk at least $3 \mathrm{~m}$ before fracture

Exclusion criteria: prior hip fracture at the newly fractured hip, metastatic cancer or chemotherapy in last year, severe visual or hearing impairment, creatinine clearance of $15 \mathrm{~mL} / \mathrm{min}$ or less, kidney stone in the past 5 years, hypercalcaemia, primary hyperparathyroidism or sarcoidosis

Sex: 137 female, 36 male

Age: mean 84 years

Fracture type: further details not given

(a) With breakfast, participants took a study capsule containing $1200 \mathrm{IU}$ of cholecalciferol. For breakfast and at bedtime, participants took a tablet containing $400 \mathrm{IU}$ of cholecalciferol and $500 \mathrm{mg}$ of elemental calcium as calcium carbonate (Nycomed, Wädenswil, Switzerland).

(b) With breakfast, participants took a placebo capsule (identical in appearance and taste to active tablet). For breakfast and at bedtime, participants took a tablet containing $400 \mathrm{IU}$ of cholecalciferol and $500 \mathrm{mg}$ of elemental calcium as calcium carbonate (Nycomed, Wädenswil, Switzerland).

Groups $\mathrm{a}$ and $\mathrm{b}$ were also randomised to standard or extended physiotherapy

Allocated: $86 / 87$

Assessed: $73 / 75$

Outcomes

Length of follow-up: 12 months

Main outcomes:

Mortality

Complications

Functional status

Level of care

Putative side effects

Other outcomes:

Compliance

\section{Notes}

\section{Risk of bias}


Bischoff-Ferrari 2010 (Continued)

\begin{tabular}{lll} 
Bias & Authors' judgement & Support for judgement \\
\hline $\begin{array}{l}\text { Random sequence genera- } \\
\text { tion (selection bias) }\end{array}$ & Low risk & States "computer-based randomization" \\
\hline $\begin{array}{l}\text { Allocation concealment } \\
\text { (selection bias) }\end{array}$ & Unclear risk & $\begin{array}{l}\text { States "Randomization for the dosage of cholecalciferol was double-blinded, } \\
\text { whereas randomization for PT (physiotherapy) was single-blinded (all study } \\
\text { staff except the treating physiotherapist who instructed the home program } \\
\text { were blinded to the PT treatment allocation). Comment: allocation conceal- } \\
\text { ment unclear }\end{array}$
\end{tabular}

Blinding of participants Low risk States double-blind and vitamin D placebo identical in appearance and taste
and personnel (perfor-
mance bias)
All outcomes

Blinding of outcome as- Low risk States double-blind and vitamin D placebo identical in appearance and taste sessment (detection bias)

Primary outcomes

\begin{tabular}{|c|c|c|}
\hline $\begin{array}{l}\text { Blinding of outcome as- } \\
\text { sessment (detection bias) } \\
\text { Secondary and other out- } \\
\text { comes }\end{array}$ & Low risk & States double-blind and vitamin D placebo identical in appearance and taste \\
\hline $\begin{array}{l}\text { Incomplete outcome data } \\
\text { (attrition bias) } \\
\text { Primary outcomes }\end{array}$ & Low risk & Reasons for missing data provided and missing data balanced across groups \\
\hline $\begin{array}{l}\text { Incomplete outcome data } \\
\text { (attrition bias) } \\
\text { Secondary and other out- } \\
\text { comes }\end{array}$ & Low risk & Reasons for missing data provided and missing data balanced across groups \\
\hline $\begin{array}{l}\text { Selective reporting (re- } \\
\text { porting bias) }\end{array}$ & High risk & $\begin{array}{l}\text { Trial registration on clinicaltrials.gov gives outcomes of numbers of people } \\
\text { who fell, disability, health care utilisation and quality of life (EuroQol); not pro- } \\
\text { vided in published paper }\end{array}$ \\
\hline Other bias & Low risk & $\begin{array}{l}\text { Funded by Swiss National Foundations, Vontobel Foundation (charitable foun- } \\
\text { dation), } \\
\text { Baugarten Foundation }\end{array}$ \\
\hline
\end{tabular}

\section{Botella-Carretero 2008}

\begin{tabular}{ll}
\hline Methods & $\begin{array}{l}\text { Method of randomisation: sealed opaque envelopes, prepared independently from recruitment } \\
\text { Intention-to-treat analysis: unclear } \\
\text { Lost to follow-up: details given }\end{array}$ \\
\hline Participants & Location: Hospital Ramon y Cajal, Madrid, Spain \\
& Period of study: February 2006-February 2007 \\
& 90 participants \\
Inclusion criteria: $>65$ years, surgery for hip fracture, written informed consent \\
Exclusion criteria: weight loss $>5 \%$ in previous month or $>10 \%$ in previous 6 months, and/or albumin $<$ \\
$27 \mathrm{~g} / \mathrm{dL}$. Acute or chronic renal failure, hepatic insufficiency or cirrhosis (Child B or C), severe heart fail- \\
ure (New York heart classification III or IV), respiratory failure, gastrointestinal condition precluding ad- \\
equate oral intake. Also: previous oral nutrition supplements or nutrition support in previous 6 months.
\end{tabular}


Botella-Carretero 2008 (Continued)

Sex: 71 female, 19 male

Age: mean age 84 years

Fracture type: 58\% gamma nail surgery (presumed extracapsular fractures), $42 \%$ total hip replacement (presumed intracapsular fractures)

Timing of intervention: started $48 \mathrm{~h}$ after operation, until hospital discharge
(a) Four $10 \mathrm{~g}$ packets a day of Vegenat-med Proteina (Vegenat SA, Badajoz, Spain) each providing $9 \mathrm{~g}$
protein and $38 \mathrm{kcal}$, dissolved in water, milk or soup from diet
(b) Two $200 \mathrm{ml}$ bricks a day (Resource Hiperproteico, Novartis Medical Nutrition, Barcelona) providing
total of $37.6 \mathrm{~g}$ protein and $500 \mathrm{kcal}$
(c) no oral nutrition supplements
Allocated: $30 / 30 / 30$
Assessed: $28 / 30 / 27$
Length of follow-up: up to hospital discharge
Main outcomes:
Mortality
Complications: urinary, respiratory, wound infection; pressure ulcer, dysphagia, ischaemic heart dis-
ease; severe hyponatraemia; anaphylaxis; vomiting and/or diarrhoea
Length of acute hospital stay
Level of care: time to mobilisation
Other outcomes:
Energy and protein intake

Notes

Emailed 22 January 2009 requesting mortality information. Author replied 23 January confirming no participants had died during the trial.

\section{Risk of bias}

\begin{tabular}{lll}
\hline Bias & Authors' judgement & Support for judgement \\
\hline $\begin{array}{l}\text { Random sequence genera- } \\
\text { tion (selection bias) }\end{array}$ & Unclear risk & States "randomized" only. No further details provided \\
\hline $\begin{array}{l}\text { Allocation concealment } \\
\text { (selection bias) }\end{array}$ & Low risk & $\begin{array}{l}\text { States used of "sealed opaque envelopes". Independent preparation of en- } \\
\text { velopes: "The investigator recruiting the patients ....had no role in the ran- } \\
\text { domisation process" }\end{array}$ \\
\hline
\end{tabular}

\begin{tabular}{|c|c|c|}
\hline $\begin{array}{l}\text { Blinding of participants } \\
\text { and personnel (perfor- } \\
\text { mance bias) } \\
\text { All outcomes }\end{array}$ & High risk & No placebo provided \\
\hline $\begin{array}{l}\text { Blinding of outcome as- } \\
\text { sessment (detection bias) } \\
\text { Primary outcomes }\end{array}$ & Low risk & $\begin{array}{l}\text { No details provided on blinding of outcome assessment, but outcome assess- } \\
\text { ment unlikely to have been influenced by unblinding. }\end{array}$ \\
\hline
\end{tabular}

\begin{tabular}{|c|c|c|}
\hline $\begin{array}{l}\text { Blinding of outcome as- } \\
\text { sessment (detection bias) } \\
\text { Secondary and other out- } \\
\text { comes }\end{array}$ & Unclear risk & $\begin{array}{l}\text { No details provided on blinding of outcome assessment, and outcome assess- } \\
\text { ment may have been influenced by unblinding }\end{array}$ \\
\hline
\end{tabular}

\begin{tabular}{lll}
\hline $\begin{array}{l}\text { Incomplete outcome data } \\
\text { (attrition bias) }\end{array}$ & Low risk & All participants accounted for in analysis \\
Primary outcomes & \\
\hline $\begin{array}{l}\text { Incomplete outcome data } \\
\text { (attrition bias) }\end{array}$ & Unclear risk & $\begin{array}{l}\text { Denominators unclear for length of hospital stay, length of immobilisation and } \\
\text { supplement intake }\end{array}$
\end{tabular}


Botella-Carretero 2008 (Continued)

Secondary and other out-

comes

\begin{tabular}{lll}
\hline $\begin{array}{l}\text { Selective reporting (re- } \\
\text { porting bias) }\end{array}$ & Unclear risk & Insufficient details provided \\
\hline Other bias & Unclear risk & $\begin{array}{l}\text { Funding source (Fundacion para la Investigacion Biomedica, Hospital Ramon y } \\
\text { Cajal, Madrid, Spain) and source of supplemental nutrition (Hospital Ramon y } \\
\text { Cajal) do not appear related to manufacturer of the supplements. }\end{array}$ \\
\hline
\end{tabular}

Botella-Carretero 2010

Method of randomisation: randomised, open two-arm trial, using sealed opaque envelopes
Intention-to-treat analysis: in acute hospital; complications, length of stay, mobilisation not collected
after moved to another centre for rehabilitation
Lost to follow-up: $53 \%$ lost to complete follow-up (moved to another centre for rehabilitation)

Larticipants
Period of study: recruitment May 2007-September 2008
60 participants
Inclusion criteria: age $>65$ years, hip fracture where orthopaedic surgery considered treatment of
choice
Exclusion criteria: moderate-severe malnutrition (weight loss of $>5 \%$ in the previous month or $>10 \%$
in the previous 6 months, and/or serum albumin concentrations $<2.7 \mathrm{~g} / \mathrm{dL}$ ), acute and/or chronic renal
failure, hepatic insufficiency or cirrhosis (Child B or C), severe heart failure with class III or IV of the New
York Heart Association, respiratory failure, gastrointestinal condition precluding adequate oral nutri-
tional intake.

Sex: 44 female, 16 male

Age: mean 84 years

Fracture type: fracture type not given

Interventions Timing of intervention: from admission (including pre-operative) until discharge

(a) Energy and protein supplements by means of commercial enteral nutrition for oral intake (Fortimel, $200 \mathrm{~mL}$ bricks, each provides $20 \mathrm{~g}$ protein and $200 \mathrm{kcal}$, Nutricia Advanced Medical Nutrition Danone Group) to aim at $40 \mathrm{~g}$ of protein and $400 \mathrm{kcal}$ per day ( 2 bricks a day) and every participant was prescribed a standard or texture-adapted diet to meet their calculated metabolic rate. The Harris-Benedict equation was employed to calculate the basal metabolic rate and a coefficient of 1.3 was employed to estimate the total metabolic rate. In-hospital diets provided a mean of $100 \mathrm{~g}$ of protein per day (range 80-120 g).

(b) Every participant was prescribed a standard or texture-adapted diet to meet their calculated metabolic rate. The Harris-Benedict equation was employed to calculate the basal metabolic rate and a coefficient of 1.3 was employed to estimate the total metabolic rate. In-hospital diets provide a mean of $100 \mathrm{~g}$ of protein per day (range $80-120 \mathrm{~g}$ ).

Allocated: $30 / 30$

Assessed: $18 / 14$ 
Botella-Carretero 2010 (Continued)

\author{
Main outcomes: \\ Mortality \\ Postoperative hospital stay, \\ Postoperative hospital complications \\ Requiring rehabilitation \\ Other outcomes: \\ Compliance
}

\title{
Notes
}

Emailed jbotella.hrc@salud.madrid.org 25 November 2014 to enquire about numbers in intervention and control groups going to rehabilitation hospital (text differs from flow chart) and whether data were collected in rehabilitation hospital for complications, mobilisation and length of stay. Replied with further information 26 November 2014 for all these queries

\section{Risk of bias}

\begin{tabular}{lll}
\hline Bias & Authors' judgement & Support for judgement \\
\hline $\begin{array}{l}\text { Random sequence genera- } \\
\text { tion (selection bias) }\end{array}$ & Unclear risk & $\begin{array}{l}\text { States "patients were randomized using sealed opaque envelopes to yield two } \\
\text { groups with } 30 \text { patients each." }\end{array}$ \\
\hline $\begin{array}{l}\text { Allocation concealment } \\
\text { (selection bias) }\end{array}$ & Low risk & $\begin{array}{l}\text { States "patients were randomized using sealed opaque envelopes to yield two } \\
\text { groups with } 30 \text { patients each... The investigators who designed the study pre- } \\
\text { pared the envelopes and assigned participants to their groups, but had no } \\
\text { contact with the patients throughout the study. The investigator recruiting the } \\
\text { patients, administering the interventions and evaluating the outcomes had no } \\
\text { role on the randomization process." }\end{array}$ \\
\hline
\end{tabular}

Blinding of participants High risk No placebo group. Comment: likely to have been influenced by lack of blinding
and personnel (perfor-
mance bias)
All outcomes

\begin{tabular}{|c|c|c|}
\hline $\begin{array}{l}\text { Blinding of outcome as- } \\
\text { sessment (detection bias) } \\
\text { Primary outcomes }\end{array}$ & Low risk & $\begin{array}{l}\text { No placebo group. States also "The investigator recruiting the patients, admin- } \\
\text { istering the interventions and evaluating the outcomes had no role on the ran- } \\
\text { domization process." Comment: unlikely to have been influenced by lack of } \\
\text { blinding }\end{array}$ \\
\hline
\end{tabular}

\begin{tabular}{lll}
\hline $\begin{array}{l}\text { Blinding of outcome as- } \\
\text { sessment (detection bias) }\end{array}$ & Unclear risk & $\begin{array}{l}\text { No placebo group. States "The investigator recruiting the patients, administer- } \\
\text { ing the interventions and evaluating the outcomes had no role on the random- } \\
\text { Secondary and other out- }\end{array}$ \\
ization process." Comment: may have been influenced by lack of blinding
\end{tabular}
comes

\begin{tabular}{|c|c|c|}
\hline $\begin{array}{l}\text { Incomplete outcome data } \\
\text { (attrition bias) } \\
\text { Primary outcomes }\end{array}$ & High risk & $\begin{array}{l}\text { Missing outcome data balanced in numbers across intervention (18) and con- } \\
\text { trol groups (14), but proportion high enough to likely induce a clinically rele- } \\
\text { vant bias in observed effect size }\end{array}$ \\
\hline $\begin{array}{l}\text { Incomplete outcome data } \\
\text { (attrition bias) } \\
\text { Secondary and other out- } \\
\text { comes }\end{array}$ & High risk & $\begin{array}{l}\text { Missing outcome data balanced in numbers across intervention (18) and con- } \\
\text { trol groups (14), but proportion high enough to likely induce a clinically rele- } \\
\text { vant bias in observed effect size }\end{array}$ \\
\hline $\begin{array}{l}\text { Selective reporting (re- } \\
\text { porting bias) }\end{array}$ & Unclear risk & Insufficient details provided to judge \\
\hline
\end{tabular}


Botella-Carretero 2010 (Continued)

Other bias Low risk
States "The funding source, Fundacion para la Investigacion Biomedica, Hospital Ramon y Cajal (FIBio-RyC), Madrid, Spain, had no role in the study design, the collection, analysis, and interpretation of data, the writing of the report, or the decision to submit the paper for publication. The ONS employed in this study were provided by the Hospital Ramo 'n y Cajal, Madrid, Spain."

Brown 1992b

\begin{tabular}{ll} 
Methods & Method of randomisation: alternating numbers \\
& Intention-to-treat analysis: carried out \\
& Lost to follow-up: no losses to follow-up \\
\hline Participants & Location: hospital, Ipswich, UK \\
& Period of study: 6 months, probably prior to 1992 \\
& 10 participants \\
& Inclusion criteria: thin (based on weight for height, triceps skinfold, mid-arm circumference - 2 out of 3 \\
& more than 1 SD below reference mean), elderly, women with hip fracture \\
& Exclusion criteria: malignant disease, mental illness, renal or hepatic failure, neurological disorder, \\
& stroke, diabetes \\
& Sex: all female \\
& Age: not given, but "elderly" \\
& Fracture type: trochanteric or subcapital hip fracture
\end{tabular}

Interventions

Timing of intervention: from second day of admission until discharge (including rehabilitation hospital) (a) Participant offered oral nutritional supplement Fresubin (Fresenius) calculated to make up deficit between intake from normal hospital diet and requirement. Fresubin provides $4.2 \mathrm{~kJ}$ or $1 \mathrm{kcal} / \mathrm{ml}$, as $15 \%$ protein energy, $30 \%$ fat energy and $55 \%$ carbohydrate energy

(b) Normal hospital diet

Allocated: $5 / 5$

Assessed: $5 / 5$

\begin{tabular}{ll}
\hline Outcomes & Length of follow-up: no details (21+ days) \\
& Main outcomes: \\
& Mortality \\
& Morbidity and complications: pressure sore $(\mathrm{nr})$ \\
& Length of stay: days to discharge from orthopaedic surgeon \\
& Postoperative functional status: 2-stage walking goals \\
& Other outcomes: \\
& Dietary intake $(\mathrm{nr})$
\end{tabular}

Notes Author provided protocol of trial and information on method of randomisation and outcome assessment. Request for further details (other outcomes, period of follow-up) sent 19 May 1999, re-sent 3 February 2000

\section{Risk of bias}

\begin{tabular}{lll}
\hline Bias & Authors' judgement & Support for judgement \\
\hline $\begin{array}{l}\text { Random sequence genera- } \\
\text { tion (selection bias) }\end{array}$ & High risk & Alternating numbers (information from trial author) \\
\hline $\begin{array}{l}\text { Allocation concealment } \\
\text { (selection bias) }\end{array}$ & High risk & $\begin{array}{l}\text { Alternating numbers (information from trial author), states randomly assigned } \\
\text { with no further details }\end{array}$ \\
\hline $\begin{array}{l}\text { Blinding of participants } \\
\text { and personnel (perfor- } \\
\text { mance bias) }\end{array}$ & High risk & No placebo group. Comment: likely to have been influenced by lack of blinding \\
\hline
\end{tabular}


Brown 1992b (Continued)

All outcomes

\begin{tabular}{|c|c|c|}
\hline $\begin{array}{l}\text { Blinding of outcome as- } \\
\text { sessment (detection bias) }\end{array}$ & Low risk & $\begin{array}{l}\text { No placebo group. Comment: unlikely to have been influenced by lack of } \\
\text { blinding }\end{array}$ \\
\hline
\end{tabular}

Primary outcomes

Blinding of outcome as-
sessment (detection bias) $\quad$ Unclear risk No placebo group. Comment: may have been influenced by lack of blinding
Secondary and other outcomes

Incomplete outcome data Unclear risk Insufficient details provided on pressure sores
(attrition bias)
Primary outcomes

Incomplete outcome data Unclear risk Insufficient details provided on 2-stage walking goals

(attrition bias)

Secondary and other out-

comes

\begin{tabular}{lll}
\hline $\begin{array}{l}\text { Selective reporting (re- } \\
\text { porting bias) }\end{array}$ & Low risk & Protocol available and all outcomes provided \\
\hline Other bias & Unclear risk & Source of funding for study unclear \\
\hline
\end{tabular}

Bruce 2003

\begin{tabular}{ll}
\hline Methods & Method of randomisation: quasi-randomised by year of birth \\
& Intention-to-treat analysis: unclear (though likely) \\
& Lost to follow-up: no withdrawals but some unaccounted "missing data points" \\
\hline Participants & Location: hospital, Freemantle, Australia \\
& Period of study: recruitment June 1998-December 1999 \\
& 109 participants \\
Inclusion criteria: women with hip fracture, consent given \\
Exclusion criteria: BMI < 20 or $>30 \mathrm{~kg} / \mathrm{m} 2$, nursing home resident, resident outside metropolitan Perth \\
(preventing follow-up), diseases expected to influence nutritional intake (malignancy, severe organ \\
failure), diabetes (to avoid potential hyperglycaemia), fracture due to major trauma \\
Sex: 109 female \\
Age: mean 84 years \\
Fracture type: further details not given
\end{tabular}

Interventions Timing of intervention: started within 2 to $3 \mathrm{~d}$ after surgery, for $28 \mathrm{~d}$

(a) One $235 \mathrm{ml}$ can of Sustagen Plus daily (Mead Johnston), providing $352 \mathrm{kcal}$ or $1.47 \mathrm{MJ}, 17.6 \mathrm{~g}$ protein, $11.8 \mathrm{~g}$ fat, $44.2 \mathrm{~g}$ carbohydrate, $376 \mathrm{mcg}$ retinol equivalents, $1.2 \mathrm{mcg}$ vitamin $\mathrm{D}, 2.4 \mathrm{mg}$ vitamin $\mathrm{E}$, $15 \mathrm{mg}$ vitamin C, $0.4 \mathrm{mg}$ thiamin, $0.5 \mathrm{mg}$ riboflavin, $8.7 \mathrm{mg}$ niacin, $0.6 \mathrm{mg}$ vitamin B6, $0.9 \mathrm{mcg}$ vitamin B12, $71 \mathrm{mcg}$ folate, $1.9 \mathrm{mg}$ pantothenic acid, $14 \mathrm{mcg}$ biotin, $259 \mathrm{mg}$ sodium, $491 \mathrm{mg}$ potassium, $371 \mathrm{mg}$ chloride, $263 \mathrm{mg}$ calcium, $261 \mathrm{mg}$ phosphorus, $3.8 \mathrm{mg}$ iron, $106 \mathrm{mg}$ magnesium, $3.8 \mathrm{mg}$ zinc, $41 \mathrm{mcg}$ iodine, $0.4 \mathrm{mg}$ copper, $0.6 \mathrm{mg}$ manganese, $19 \mathrm{mcg}$ selenium, $19 \mathrm{mcg}$ chromium, $47 \mathrm{mcg}$ molybdenum; chocolate and vanilla flavours. Dietitian carried out preliminary taste test and offered encouragement and strategies to help with compliance, e.g. ways to alter taste and timing of supplement. And routine care

(b) Routine care

Allocated: 50/59

Assessed: ?/? 
Bruce 2003 (Continued)

Main outcomes:

Mortality: combined outcome with need for nursing home

Length of stay: hospital

Postoperative functional status: \% with fall in Katz score

Level of care and extent of support required after discharge: \% discharged home, \% home at 6 months

Other outcomes:

Patient compliance: consumption of cans of supplement

Notes

Percentages provided in report indicate variation in denominators used. Requests for further details of denominators and mortality during study sent 13 August 2003 and 13 October 2003. Reply received October 2003 giving details of denominators, mortality, withdrawals, and details of vitamin and mineral content of supplement

\section{Risk of bias}

\begin{tabular}{lll}
\hline Bias & Authors' judgement & Support for judgement \\
\hline $\begin{array}{l}\text { Random sequence genera- } \\
\text { tion (selection bias) }\end{array}$ & High risk & "Quasi-randomisation of cases was carried out using their date of birth." \\
\hline $\begin{array}{l}\text { Allocation concealment } \\
\text { (selection bias) }\end{array}$ & High risk & $\begin{array}{l}\text { "Quasi-randomisation of cases was carried out using their date of birth" but } \\
\text { nurse co-ordinators and unit dietitian responsible for carrying out the study } \\
\text { and collecting the data }\end{array}$ \\
\hline $\begin{array}{l}\text { Blinding of participants } \\
\text { and personnel (perfor- } \\
\text { mance bias) } \\
\text { All outcomes }\end{array}$ & High risk & No placebo group. Comment: likely to have been influenced by lack of blinding \\
\hline
\end{tabular}

$\begin{array}{lll}\begin{array}{l}\text { Blinding of outcome as- } \\ \text { sessment (detection bias) }\end{array} \quad \text { Low risk } & \begin{array}{l}\text { No placebo group. Comment: unlikely to have been influenced by lack of } \\ \text { blinding }\end{array}\end{array}$

Primary outcomes

Blinding of outcome as- Unclear risk No placebo group. Comment: may have been influenced by lack of blinding
sessment (detection bias)

Secondary and other outcomes

\begin{tabular}{lll}
\hline $\begin{array}{l}\text { Incomplete outcome data } \\
\text { (attrition bias) } \\
\text { Primary outcomes }\end{array}$ & Unclear risk & $\begin{array}{l}\text { Missing outcome data balanced in numbers across groups, but reasons for } \\
\text { missing outcome data unclear }\end{array}$ \\
\hline $\begin{array}{l}\text { Incomplete outcome data } \\
\text { (attrition bias) } \\
\begin{array}{l}\text { Secondary and other out- } \\
\text { comes }\end{array}\end{array}$ & Unclear risk & $\begin{array}{l}\text { Missing outcome data balanced in numbers across groups, but reasons for } \\
\text { missing outcome data unclear }\end{array}$ \\
\hline $\begin{array}{l}\text { Selective reporting (re- } \\
\text { porting bias) }\end{array}$ & High risk & $\begin{array}{l}\text { Hospital mortality, admissions to nursing home, cognitive impairment stated } \\
\text { in methods, but not provided }\end{array}$ \\
\hline \begin{tabular}{l} 
Other bias \\
\hline
\end{tabular} & Unclear risk & Source of funding for study unclear \\
\hline
\end{tabular}

Chevalley 2010

Methods Method of randomisation: block randomisation of 15 . Table of randomisation by statistician not in-
volved in study 
Chevalley 2010 (Continued)

Intention-to-treat analysis: insufficient details provided

Lost to follow-up: insufficient details provided

Participants
Period of study: recruited March 1999-June 2000
45 participants
Inclusion criteria: women older than 60 years with a recent hip fracture, i.e. within two weeks, that was
attributable to osteoporosis such as occurring on a fall from standing height, and with the ability to
give a written informed consent.
Exclusion criteria: pathologic fracture; fracture caused by severe trauma; cardiac or pulmonary failure;
advanced renal insufficiency with plasma creatinine concentration 200 mmol/L or more; hepatic fail-
ure; severe mental impairment; acute illness before the fracture that could interfere with the study pro-
tocol; active metabolic bone disease; consumption of protein supplement or of anti-osteoporotic ac-
tive drugs or medication known to alter bone metabolism, such as sex hormones or corticosteroids; se-
vere malnutrition (serum albumin level < $15 \mathrm{~g} / \mathrm{L}$ ); life expectancy of less than one year

Sex: all female

Age: mean 81.3 (SD 7.4) years

Fracture type: not given

Interventions

Timing of intervention: from a mean of $10 \mathrm{~d}$ post fracture for $28 \mathrm{~d}$

a) $20 \mathrm{~g}$ milk protein (casein) in $200 \mathrm{ml}$ water, including $550 \mathrm{mg}$ calcium and $500 \mathrm{IU}$ vitamin D3, daily for $28 \mathrm{~d}$

b) $20 \mathrm{~g}$ whey protein in $200 \mathrm{ml}$ water, including $550 \mathrm{mg}$ calcium and $500 \mathrm{IU}$ vitamin D3, daily for $28 \mathrm{~d}$

c) $15 \mathrm{~g}$ whey protein and $5 \mathrm{~g}$ of essential amino acids in ratio identical to casein in $200 \mathrm{ml}$ water, including $550 \mathrm{mg}$ calcium and 500 IU vitamin D3, daily for $28 \mathrm{~d}$

Allocated: 15/15/15

Assessed: unclear

Outcomes Length of follow-up: $28 \mathrm{~d}$

Main outcomes:

Putative adverse events from supplements

Other outcomes:

Compliance

Notes

Emailed thierry.chevalley@hcuge.ch 9 October 2014 to ask for further information on outcomes, reply received 14 October 2014 with details of putative side effects and compliance

\section{Risk of bias}

\begin{tabular}{lll}
\hline Bias & Authors' judgement & Support for judgement \\
\hline $\begin{array}{l}\text { Random sequence genera- } \\
\text { tion (selection bias) }\end{array}$ & Low risk & $\begin{array}{l}\text { States " randomization was performed in blocks of 15 patients...table of ran- } \\
\text { domization was established by a statistician who was not directly involved in } \\
\text { the study" }\end{array}$ \\
\hline
\end{tabular}


Chevalley 2010 (Continued)

Allocation concealment Low risk States " randomization was performed in blocks of 15 patients...table of ran(selection bias) domization was established by a statistician who was not directly involved in the study"

\begin{tabular}{|c|c|c|}
\hline $\begin{array}{l}\text { Blinding of participants } \\
\text { and personnel (perfor- } \\
\text { mance bias) }\end{array}$ & Unclear risk & $\begin{array}{l}\text { States "dietician as well as both the medical staff and subjects involved in the } \\
\text { study were blinded to the experimental groups" but no further details on how } \\
\text { this was achieved }\end{array}$ \\
\hline
\end{tabular}

\begin{tabular}{|c|c|c|}
\hline $\begin{array}{l}\text { Blinding of outcome as- } \\
\text { sessment (detection bias) } \\
\text { Primary outcomes }\end{array}$ & Unclear risk & $\begin{array}{l}\text { No details provided and putative adverse events from supplements may have } \\
\text { been influenced by unblinding }\end{array}$ \\
\hline
\end{tabular}

\begin{tabular}{|c|c|c|}
\hline $\begin{array}{l}\text { Blinding of outcome as- } \\
\text { sessment (detection bias) } \\
\text { Secondary and other out- } \\
\text { comes }\end{array}$ & Unclear risk & No details provided and compliance may have been influenced by unblinding \\
\hline
\end{tabular}

\begin{tabular}{lll}
\hline $\begin{array}{l}\text { Incomplete outcome data } \\
\text { (attrition bias) } \\
\text { Primary outcomes }\end{array}$ & High risk & $\begin{array}{l}\text { Numbers in email differ from publication: give 11 dropouts (5 casein, } 4 \text { whey, } 2 \\
\text { whey and amino acids), with } 12 \text { mentioned in publication }\end{array}$ \\
\hline $\begin{array}{l}\text { Incomplete outcome data } \\
\text { (attrition bias) } \\
\begin{array}{l}\text { Secondary and other out- } \\
\text { comes }\end{array}\end{array}$ & High risk & $\begin{array}{l}\text { Numbers in email differ from publication: give } 11 \text { dropouts (5 casein, } 4 \text { whey, } 2 \\
\text { whey and amino acids), with } 12 \text { mentioned in publication }\end{array}$ \\
\hline $\begin{array}{l}\text { Selective reporting (re- } \\
\text { porting bias) }\end{array}$ & High risk & No details on outcome activities of daily living provided \\
\hline \begin{tabular}{l} 
Other bias \\
\hline
\end{tabular} & High risk & Supported by Novartis Cosumer Health (Berne, Switzerland) \\
\hline
\end{tabular}

\section{Day 1988}

$\begin{array}{ll}\text { Methods } & \text { Method of randomisation: computer-generated random sequence, insufficient indication of adequate } \\ \text { safeguards } & \text { Assessor blinding: blinded assessment of mental state, other outcomes not stated } \\ \text { Intention-to-treat analysis: analysis performed } \\ \text { Lost to follow-up: details given }\end{array}$

Interventions

Timing of intervention: 2 doses of vitamin preparation given preoperatively, and then 1 dose daily for 5 d postoperatively
(a) Intravenous Parentrovite IVHP (containing $250 \mathrm{mg}$ thiamine hydrochloride, $4 \mathrm{mg}$ riboflavine, $50 \mathrm{mg}$
pyridoxine, $160 \mathrm{mg}$ nicotinamide, $500 \mathrm{mg}$ ascorbic acid, $1 \mathrm{~g}$ anhydrous dextrose)
(b) No supplement
Allocated: $28 / 32$ 
Day 1988 (Continued)

Assessed: $28 / 32$ for abbreviated mental test at day 2

$\begin{array}{ll}\text { Outcomes } & \text { Length of follow-up: } 3 \text { months } \\ & \text { Main outcomes: } \\ & \text { Mortality } \\ & \text { Morbidity and complications: total number of complications, numbers of participants with complica- } \\ \text { tions } & \\ \text { Length of stay: hospital } \\ \text { Postoperative functional status: acute confusional state, acute on chronic confusional state, abbreviat- } \\ \text { ed mental test, objective learning test, Ishihara Colour Plates } \\ \text { Care required after discharge: final placement } \\ \text { Putative side effects of treatment: serious and other adverse events } \\ \text { Request for further details (method of randomisation, constituents of Parentrovite IVHP, other out- } \\ \text { comes) sent. Reply from trialists (27 May 1999) gave details of the intervention, randomisation, and in- } \\ \text { formation on fracture type, baseline albumin levels, complications and hospital stay }\end{array}$

\section{Risk of bias}

Bias Authors' judgement Support for judgement

Random sequence genera- Low risk "Allocation of patients was based on randomly generated numbers (0 or 1$)$ " tion (selection bias)

Allocation concealment $\quad$ Unclear risk States "randomly allocated", no further details provided
(selection bias)

Blinding of participants $\quad$ High risk $\quad$ No placebo
and personnel (perfor-
mance bias)
All outcomes

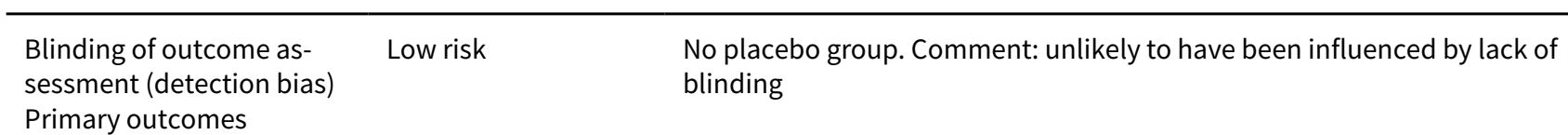

\begin{tabular}{|c|c|c|}
\hline $\begin{array}{l}\text { Blinding of outcome as- } \\
\text { sessment (detection bias) } \\
\text { Secondary and other out- } \\
\text { comes }\end{array}$ & Unclear risk & $\begin{array}{l}\text { No placebo group. Comment: may have been influenced by lack of blinding, } \\
\text { apart from mental health status which was "assessed by a psychology techni- } \\
\text { cian who remained blind as to the treatment group of each patient" }\end{array}$ \\
\hline $\begin{array}{l}\text { Incomplete outcome data } \\
\text { (attrition bias) } \\
\text { Primary outcomes }\end{array}$ & Unclear risk & $\begin{array}{l}\text { Data provided for all participants, apart from putative adverse events (no data } \\
\text { provided for control group) }\end{array}$ \\
\hline $\begin{array}{l}\text { Incomplete outcome data } \\
\text { (attrition bias) } \\
\text { Secondary and other out- } \\
\text { comes }\end{array}$ & Unclear risk & $\begin{array}{l}\text { Data provided for all participants, apart from putative adverse events (no data } \\
\text { provided for control group) }\end{array}$ \\
\hline $\begin{array}{l}\text { Selective reporting (re- } \\
\text { porting bias) }\end{array}$ & High risk & Data on outcome final placement not available \\
\hline Other bias & High risk & Bencard provided Parenterovite \\
\hline
\end{tabular}


Delmi 1990

\begin{tabular}{ll}
\hline Methods & $\begin{array}{l}\text { Method of randomisation: not stated } \\
\text { Intention-to-treat analysis: appears intention-to-treat, but denominators unclear } \\
\text { Lost to follow-up: mortality reported, but unclear if other losses to follow-up }\end{array}$ \\
\hline Participants & Location: orthopaedic unit in hospital and recovery hospital, Geneva, Switzerland \\
& Period of study: 1 March-15 May 1985 \\
& 59 participants \\
Inclusion criteria: femoral neck fracture after an accidental fall, aged over 60 years \\
Exclusion criteria: fracture from violent external trauma, pathological fracture due to tumour or non- \\
osteoporotic osteopathy; overt dementia; renal, hepatic, or endorine disease; gastrectomy or malab- \\
sorption; taking phenytoin, steroids, barbiturates, fluorin \\
Sex: 53 female, 6 male \\
Age: mean age 82 years \\
Fracture type: 26 femoral neck, 33 inter-trochanteric
\end{tabular}

Interventions

Timing of intervention: from admission to orthopaedic unit to end of stay in second (recovery) hospital, supplement given once daily at 20:00 hours for a mean period of $32 \mathrm{~d}$

(a) $250 \mathrm{ml}$ oral nutritional supplement (1.06 MJ or $254 \mathrm{kcal}, 20.4 \mathrm{~g}$ protein, $29.5 \mathrm{~g}$ carbohydrate, $5.8 \mathrm{~g}$ lipid, $525 \mathrm{mg}$ calcium, $750 \mathrm{IU}$ vitamin A, 25 IU vitamin D3, nicotinamide, folate, calcium pantothenate, biotin, minerals; and vitamins E, B1, B2, B6, B12, C) and standard hospital diet

(b) Standard hospital diet

Allocated: 27/32

Assessed: ?25/?27 at 6 months

\begin{tabular}{ll}
\hline Outcomes & Length of follow-up: 6 months \\
& Main outcomes: \\
& Mortality \\
& Morbidity and complications: complications (total, bedsore, severe anaemia, cardiac failure, infection, \\
& gastrointestinal ulcer, other), favourable clinical course (excludes death, major complication, or two or \\
more minor complications) \\
Length of stay: orthopaedic unit and recovery hospital \\
Other outcomes: \\
Energy, protein and calcium intake \\
\hline Numbers of complications unclear, request for further details sent 24 May 1999, re-sent 7 February \\
\hline
\end{tabular}

\section{Risk of bias}

\begin{tabular}{lll}
\hline Bias & Authors' judgement & Support for judgement \\
\hline $\begin{array}{l}\text { Random sequence genera- } \\
\text { tion (selection bias) }\end{array}$ & Unclear risk & States "randomised", no other details provided \\
\hline $\begin{array}{l}\text { Allocation concealment } \\
\text { (selection bias) }\end{array}$ & Unclear risk & States "randomised", no other details provided \\
\hline $\begin{array}{l}\text { Blinding of participants } \\
\text { and personnel (perfor- } \\
\text { mance bias) }\end{array}$ & High risk & No placebo group. Comment: likely to have been influenced by lack of blinding \\
All outcomes & \\
\hline
\end{tabular}

\begin{tabular}{|c|c|c|}
\hline $\begin{array}{l}\text { Blinding of outcome as- } \\
\text { sessment (detection bias) }\end{array}$ & Low risk & $\begin{array}{l}\text { No placebo group. Comment: unlikely to have been influenced by lack of } \\
\text { blinding }\end{array}$ \\
\hline
\end{tabular}

Primary outcomes

$\begin{aligned} & \text { Blinding of outcome as- } \\ & \text { sessment (detection bias) }\end{aligned} \quad$ Unclear risk $\quad$ No placebo group. Comment: may have been influenced by lack of blinding


Delmi 1990 (Continued)

Secondary and other out-

comes

\begin{tabular}{|c|c|c|}
\hline $\begin{array}{l}\text { Incomplete outcome data } \\
\text { (attrition bias) } \\
\text { Primary outcomes }\end{array}$ & High risk & Data provided for only $25 / 27$ intervention group and $27 / 32$ control group \\
\hline $\begin{array}{l}\text { Incomplete outcome data } \\
\text { (attrition bias) } \\
\text { Secondary and other out- } \\
\text { comes }\end{array}$ & High risk & $\begin{array}{l}\text { Length of stay data not provided for } 6 / 27 \text { intervention group and } 4 / 32 \text { control } \\
\text { group, i.e. length of stay for survivors presented }\end{array}$ \\
\hline $\begin{array}{l}\text { Selective reporting (re- } \\
\text { porting bias) }\end{array}$ & Unclear risk & Insufficient details provided \\
\hline Other bias & High risk & $\begin{array}{l}\text { Sandoz-Wander supplied the supplement, but do not appear to have funded } \\
\text { the study }\end{array}$ \\
\hline
\end{tabular}

\section{Duncan 2006}

$\begin{array}{ll}\text { Methods } & \text { Method of randomisation: sequentially numbered opaque sealed envelopes, initially in blocks of } 20, \\ & \text { later reduced to blocks of 10, prepared by member of staff outside trial, opened sequentially } \\ \text { Intention-to-treat analysis: post-randomisation exclusion of people for conservative care of hip frac- } & \text { ture } \\ \text { Lost to follow-up: details given }\end{array}$

Participants Location: single trauma ward, University Hospital of Wales, Cardiff, UK

Period of study: recruitment May 2000-August 2003

318 participants

Inclusion criteria: women aged over 65 years presenting to trauma ward with acute non-pathological

hip fracture, consent or assent to trial

Exclusion criteria: none

Sex: all female

Age: mean age 84 years

Fracture type: further details not given

Interventions Timing of intervention: unclear when commenced, during stay in acute trauma ward, median $16-17 \mathrm{~d}$. Dietetic assistant present on ward $6 \mathrm{~h} / \mathrm{d}$ for $7 \mathrm{~d} /$ week

(a) Additional attention of dietetic assistant (previous NHS experience, given 14-d period of orientation and training), working closely with specialist dietitian. Asked to ensure participants met nutritional needs, including by: checking personal and cultural food preferences; co-ordinating appropriate meal orders with catering staff; ordering nutritional supplements; provision of feeding aids; assisting with food choice, portion size and positioning at mealtimes; sitting with, encouraging and feeding; collecting information to aid nutritional assessment by dietitian

(b) Nurse- and dietitian-led care, including routine provision of oral nutritional supplements to all participants

Allocated: $153 / 165$

Assessed: $145 / 157$ for mortality

$\begin{array}{ll}\text { Outcomes } & \text { Length of follow-up: } 4 \text { months } \\ & \text { Main outcomes: } \\ & \text { Mortality } \\ & \text { Morbidity and complications: on trauma ward in survivors } \\ & \text { Length of trauma ward and hospital stay } \\ & \text { Other outcomes: energy intake }\end{array}$


Duncan 2006 (Continued)

Notes
Request for further details on participants with complications sent 15 March 2006. Reply from trialists (15 March 2006) provided number and per cent of live participants having had complications on trauma ward.

A letter to the editor in Age and Ageing Advance Access (24 June 2006) by Hewitt and Torgerson pointed out the numerical difference between the two groups was higher than expected given the reported block size of 10 . The reply from Duncan indicated that they initially started the study with a block size of 20.

\section{Risk of bias}

\begin{tabular}{lll}
\hline Bias & Authors' judgement & Support for judgement \\
\hline $\begin{array}{l}\text { Random sequence genera- } \\
\text { tion (selection bias) }\end{array}$ & Unclear risk & $\begin{array}{l}\text { "Randomisation was by sequentially numbered, opaque, sealed envelope } \\
\text { method in blocks of 10, prepared by a member of staff not directly involved in } \\
\text { the trial." No further details }\end{array}$ \\
\hline $\begin{array}{l}\text { Allocation concealment } \\
\text { (selection bias) }\end{array}$ & Low risk & $\begin{array}{l}\text { "Randomisation was by sequentially numbered, opaque, sealed envelope } \\
\text { method in blocks of 10, prepared by a member of staff not directly involved in } \\
\text { the trial." }\end{array}$ \\
\hline $\begin{array}{l}\text { Blinding of participants } \\
\text { and personnel (perfor- } \\
\text { mance bias) } \\
\text { All outcomes }\end{array}$ & High risk & Not blinded \\
\hline
\end{tabular}

\begin{tabular}{|c|c|c|}
\hline $\begin{array}{l}\text { Blinding of outcome as- } \\
\text { sessment (detection bias) }\end{array}$ & Low risk & $\begin{array}{l}\text { No placebo group. Comment: unlikely to have been influenced by lack of } \\
\text { blinding }\end{array}$ \\
\hline
\end{tabular}

Primary outcomes

\begin{tabular}{lll}
\hline $\begin{array}{l}\text { Blinding of outcome as- } \\
\text { sessment (detection bias) } \\
\text { Secondary and other out- } \\
\text { comes }\end{array}$ & Unclear risk & No placebo group. Comment: may have been influenced by lack of blinding \\
\hline $\begin{array}{l}\text { Incomplete outcome data } \\
\text { (attrition bias) }\end{array}$ & Low risk & $\begin{array}{l}\text { Missing outcome data balanced in numbers across intervention groups, with } \\
\text { similar reasons for missing data across groups and unlikely to relate to out- } \\
\text { come }\end{array}$ \\
\hline
\end{tabular}

\begin{tabular}{|c|c|c|}
\hline $\begin{array}{l}\text { Incomplete outcome data } \\
\text { (attrition bias) } \\
\text { Secondary and other out- } \\
\text { comes }\end{array}$ & Low risk & $\begin{array}{l}\text { Missing outcome data balanced in numbers across intervention groups, with } \\
\text { similar reasons for missing data across groups and unlikely to relate to out- } \\
\text { come }\end{array}$ \\
\hline $\begin{array}{l}\text { Selective reporting (re- } \\
\text { porting bias) }\end{array}$ & Unclear risk & $\begin{array}{l}\text { Appears Waterlow score of pressure sore risk and Abbreviated Mental Test } \\
\text { score collected as outcomes, but not provided }\end{array}$ \\
\hline Other bias & Unclear risk & $\begin{array}{l}\text { Funding from Women's Royal Voluntary Service, British Dietetic Assocation, In- } \\
\text { novations in Care, Wales Office of Research and Development, Shire Pharma- } \\
\text { ceuticals (funded nutritional assessments, research assessments) }\end{array}$ \\
\hline
\end{tabular}

\section{Eneroth 2006}

Methods

Method of randomisation: block randomisation conducted by research nurse, using closed, numbered envelopes

Intention-to-treat analysis: appears so 
Eneroth 2006 (Continued)

Lost to follow-up: details given

Participants
Period of study: before August 2005
80 participants
Inclusion criteria: $>60$ years with a cervical or trochanteric hip fracture, written informed consent,
surgery < $48 \mathrm{~h}$ from trauma
Exclusion criteria: multiple fractures, pathological fractures, malignancy, inflammatory joint disease,
pain or functional impairment other than hip fracture which might hamper mobilisation, dementia, de-
pression, acute psychosis, known alcohol or medication abuse, epilepsy, mini-mental test score < 6 ,
warfarin, insulin-treated diabetes; heart, kidney or liver insufficiency, suspected acute myocardial in-
farction, haematemesis.
Sex: 63 female, 17 male
Age: mean age 81 years
Fracture type: 45 cervical, 35 trochanteric

Interventions Timing of intervention: first $10 \mathrm{~d}$ in hospital

(a) $1000 \mathrm{ml}$ Vitrimix (Kabi Pharmacia AB, Sweden) intravenously (amino acids, fat, carbohydrate, electrolytes daily for $3 \mathrm{~d}$ ( $100 \mathrm{kcal}, 53 \mathrm{~g}$ protein daily), then $7 \mathrm{~d}$ oral Fortimel $400 \mathrm{ml}$ ( $400 \mathrm{kcal}$.day; Nutricia AB, Netherlands). Trace elements (Tracel, Kabi Pharmacia AB), water and fat soluble vitamins (Soluvit Novum and Vitalipid Novum, Kabi Pharmacia $A B$ ) were added to Vitrimix

(b) Usual hospital diet

Allocated: $40 / 40$

Assessed: $40 / 40$ for mortality

Lutcomes
Main outcomes:
Mortality
Complications: wound infection, pneumonia, urinary infections, thrombophlebitis, deep vein throm-
bosis, pulmonary embolism, pulmonary oedema, myocardial infarction
Length of acute hospital stay
Level of care: discharge to own home
Other outcomes: energy intake, fluid intake

Emailed on 22nd January 2009 in an attempt to clarify denominators. Author replied 10th February
confirming denominators

\section{Risk of bias}

\begin{tabular}{lll}
\hline Bias & Authors' judgement & Support for judgement \\
\hline $\begin{array}{l}\text { Random sequence genera- } \\
\text { tion (selection bias) }\end{array}$ & Unclear risk & States "randomised" with no further details. \\
\hline $\begin{array}{l}\text { Allocation concealment } \\
\text { (selection bias) }\end{array}$ & Unclear risk & $\begin{array}{l}\text { States "patient were randomised by the research nurse (UBO) to either the } \\
\text { control or the treatment group using block randomisation with 40 closed and } \\
\text { numbered envelopes in each block". }\end{array}$ \\
\hline $\begin{array}{l}\text { Blinding of participants } \\
\text { and personnel (perfor- } \\
\text { mance bias) } \\
\begin{array}{l}\text { All outcomes } \\
\text { Blinding of outcome as- } \\
\text { sessment (detection bias) }\end{array}\end{array}$ & High risk & Now placebo intervention \\
$\begin{array}{l}\text { Primary outcomes } \\
\begin{array}{l}\text { Blinding of outcome as- } \\
\text { sessment (detection bias) }\end{array}\end{array}$ & Unclear risk & $\begin{array}{l}\text { No placebo group. Comment: unlikely to have been influenced by lack of } \\
\text { blinding }\end{array}$ \\
\hline
\end{tabular}


Eneroth 2006 (Continued) Secondary and other outcomes

\begin{tabular}{lll}
\hline $\begin{array}{l}\text { Incomplete outcome data } \\
\text { (attrition bias) } \\
\text { Primary outcomes }\end{array}$ & Low risk & All participants accounted for, with no dropouts \\
\hline $\begin{array}{l}\text { Incomplete outcome data } \\
\text { (attrition bias) }\end{array}$ & Low risk & All participants accounted for, with no dropouts \\
$\begin{array}{l}\text { Secondary and other out- } \\
\text { comes }\end{array}$ & \\
\hline $\begin{array}{l}\text { Selective reporting (re- } \\
\text { porting bias) }\end{array}$ & Unclear risk & Insufficient details provided \\
\hline \begin{tabular}{l} 
Other bias \\
\hline
\end{tabular} & Low risk & Funded by Medical Faculty of Lund University \\
\hline
\end{tabular}

\section{Espaulella 2000}

$\begin{array}{ll}\text { Methods } & \text { Method of randomisation: computer-generated assignment, balanced in blocks of 4, with sealed en- } \\ \text { velopes, opened by pharmacist } \\ \text { Intention-to-treat analysis: } 10 \text { excluded: } 8 \text { excluded for protocol violation and } 2 \text { excluded because they } \\ \text { could not swallow. Intention-to-treat analysis not possible } \\ \text { Lost to follow-up: details given }\end{array}$

Location: Hospital General de Vic, Barcelona, Spain
Period of study: July 1994-July 1996
171 participants
Inclusion criteria: hospitalised for fracture of the proximal femur, aged 70 years and over
Exclusion criteria: advanced dementia, needing intravenous nutrition, pathological fracture, fracture
not due to accidental fall
Sex: 135 female, 36 male
Age: mean 82.6 years
Fracture type: 115 extracapsular, 56 intracapsular hip fractures

Interventions

Timing of intervention: begun within $48 \mathrm{~h}$ of study entry, consumed once daily at night for $60 \mathrm{~d}$ (a) $200 \mathrm{ml}$ oral supplement in 3 flavours $(0.62 \mathrm{MJ}$ or $149 \mathrm{kcal}, 20 \mathrm{~g}$ protein, $1.5 \mathrm{~g}$ carbohydrate, $7 \mathrm{~g}$ fat, $800 \mathrm{mg}$ calcium, $3 \mathrm{IU}$ vitamin A, $1.7 \mathrm{mg}$ thiamin, $2.02 \mathrm{mg}$ riboflavin, $2.25 \mathrm{mg}$ pyridoxine, $5.5 \mathrm{mcg}$ vitamin B12, $122.25 \mathrm{mg}$ vitamin C, 25 IU vitamin D3, $10 \mathrm{mg}$ calcium pantothenate, $16.87 \mathrm{mg}$ vitamin $\mathrm{E}, 0.45 \mathrm{mg}$ biotin, $500 \mathrm{mcg}$ folic acid, $22.5 \mathrm{mg}$ nicotinamide), prepared by pharmaceutical company (Clinical Nutrition S.A. Spain)

(b) $200 \mathrm{ml}$ oral supplement in 3 flavours $(0.65 \mathrm{MJ}$ or $155 \mathrm{kcal}$ as $25.3 \mathrm{~g}$ carbohydrate and $6 \mathrm{~g}$ fat), prepared by pharmaceutical company Allocated: $85 / 86$

Assessed: $61 / 67$ for all outcomes

Length of follow-up: 6 months
Main outcomes:
Mortality: all-cause and related to fracture, days between fracture and death (survival curve)
Morbidity and complications: including delirium, bed sore, urinary tract infection
Length of stay: acute hospital ward
Postoperative functional status: Barthel Index, Mobility Index, days from surgery to walking
Level of care and extent of support required after discharge: discharge home or geriatric rehabilitation
unit, use of walking aids at 6 months
Other outcomes:
Patient compliance


Espaulella 2000 (Continued)

Notes
Request for further details (including follow-up data on excluded participants, details of supplement) sent 14 February 2000 and 6 June 2000. Replies from Heidi Guyer (6 March 2000 and 13 June 2000) confirmed assessor blinding, gave other details of methodology and contents of supplement, as well as details of outcome of the excluded participants

\section{Risk of bias}

\begin{tabular}{lll}
\hline Bias & Authors' judgement & Support for judgement \\
\hline $\begin{array}{l}\text { Random sequence genera- } \\
\text { tion (selection bias) }\end{array}$ & Low risk & $\begin{array}{l}\text { Computer-generated assignment, balanced in blocks of 4, with sealed en- } \\
\text { velopes, prepared by epidemiology unit. "Upon being advised of a patient's in- } \\
\text { clusion, the pharmacist assigned the patient a study number and opened the } \\
\text { envelope ..." }\end{array}$ \\
\hline $\begin{array}{l}\text { Allocation concealment } \\
\text { (selection bias) }\end{array}$ & Low risk & $\begin{array}{l}\text { Computer-generated assignment, balanced in blocks of 4, with sealed en- } \\
\text { velopes, prepared by epidemiology unit. "Upon being advised of a patient's in- } \\
\text { clusion, the pharmacist assigned the patient a study number and opened the } \\
\text { envelope ..." }\end{array}$
\end{tabular}

\begin{tabular}{|c|c|c|}
\hline $\begin{array}{l}\text { Blinding of participants } \\
\text { and personnel (perfor- }\end{array}$ & Low risk & $\begin{array}{l}\text { Double-blinded and reports that supplement and placebo available in } 3 \\
\text { flavours that did not differ in taste and appearance }\end{array}$ \\
\hline
\end{tabular}

All outcomes

\begin{tabular}{|c|c|c|}
\hline $\begin{array}{l}\text { Blinding of outcome as- } \\
\text { sessment (detection bias) } \\
\text { Primary outcomes }\end{array}$ & Low risk & $\begin{array}{l}\text { Double-blinded, although not clear if outcome assessors blinded, but unlikely } \\
\text { to have been influenced by lack of blinding }\end{array}$ \\
\hline $\begin{array}{l}\text { Blinding of outcome as- } \\
\text { sessment (detection bias) } \\
\text { Secondary and other out- } \\
\text { comes }\end{array}$ & Low risk & $\begin{array}{l}\text { Double-blinded, although not clear if outcome assessors blinded, but unlikely } \\
\text { to have been influenced by lack of blinding }\end{array}$ \\
\hline $\begin{array}{l}\text { Incomplete outcome data } \\
\text { (attrition bias) } \\
\text { Primary outcomes }\end{array}$ & Low risk & $\begin{array}{l}\text { Missing outcome data balanced in numbers across groups and with similar } \\
\text { reasons across groups }\end{array}$ \\
\hline $\begin{array}{l}\text { Incomplete outcome data } \\
\text { (attrition bias) } \\
\text { Secondary and other out- } \\
\text { comes }\end{array}$ & Unclear risk & $\begin{array}{l}5 \text { from intervention group and } 3 \text { from control group withdrawn due to protocol } \\
\text { violations }\end{array}$ \\
\hline $\begin{array}{l}\text { Selective reporting (re- } \\
\text { porting bias) }\end{array}$ & Low risk & No protocol available, but expected outcomes reported \\
\hline Other bias & High risk & $\begin{array}{l}\text { Funded by Spanish Ministry of Health and authors thank Clinical Nutrition SA } \\
\text { for the preparation of the supplements. } 34 \% \text { of controls and } 18 \% \text { of interven- } \\
\text { tion group on psychotropic medication }\end{array}$ \\
\hline
\end{tabular}

Fabian 2011

\begin{tabular}{l} 
Method of randomisation: states "randomly divided" only \\
Intention-to-treat: unclear \\
Lost to follow-up: unclear \\
\hline
\end{tabular}


Fabian 2011 (Continued)

Participants

Location: Trauma Center Meidling, Vienna, Austria

Period of study: before September 2010

23 participants

Inclusion criteria: aged > 65 years with hip fractures (femoral neck, intertrochanteric and subtrochanteric)

Exclusion criteria: acute or chronic renal disease, liver failure, severe congestive heart failure, severe pulmonary disease, and any gastrointestinal condition that might preclude the participant from adequate oral nutritional intake

Sex: all female

Age: mean age 84 years

Fracture type: further details not given

a) Oral supplements administered individually when energy and/or protein intake calculated by dietary records did not exceed a level of 20-25 kcal and/or 1-1.5 g protein/ $\mathrm{kg}$ body weight/ day as recommended by the European Society for Clinical Nutrition and Metabolism per $1000 \mathrm{ml}-4.2 \mathrm{MJ}$ (40\% energy as protein), $1.88 \mathrm{mg}$ vitamin A, $13 \mathrm{mcg}$ vitamin D, $23 \mathrm{mg}$ vitamin $\mathrm{E}, 0.1 \mathrm{mg}$ vitamin $\mathrm{K}, 190 \mathrm{mg}$ vitamin C, 2.8 $\mathrm{mg}$ thiamine, $3.1 \mathrm{mg}$ riboflavin, $34 \mathrm{mg}$ niacin, $3.3 \mathrm{mg}$ pyridoxine, $0.5 \mathrm{mg}$ folate, $10 \mathrm{mg}$ pantothenic acid, $7 \mathrm{mcg}$ vitamin B12, $75 \mathrm{mcg}$ biotin, $500 \mathrm{mg}$ sodium, $2 \mathrm{~g}$ potassium, $420 \mathrm{mg}$ magnesium, $2.8 \mathrm{~g}$ calcium, $2 \mathrm{~g}$ phosphorus, $900 \mathrm{mg}$ chloride, $23 \mathrm{mg}$ zinc, $30 \mathrm{mg}$ iron, $3.4 \mathrm{mg}$ copper, $0.25 \mathrm{mg}$ iodine, $0.13 \mathrm{mg}$ chromate, $1.9 \mathrm{mg}$ fluoride, $6.3 \mathrm{mg}$ manganese, $0.19 \mathrm{mg}$ molybdenum, $0.11 \mathrm{mg}$ selenium

b) Usual care

Allocated: $14 / 9$

Assessed: 14/9 (numbers not certain)

\begin{tabular}{|c|c|c|}
\hline Outcomes & \multicolumn{2}{|c|}{ Length of follow-up: length of hospitalisation } \\
\hline & \multicolumn{2}{|l|}{ Main outcomes: } \\
\hline & \multicolumn{2}{|l|}{ Length of hospital stay } \\
\hline Notes & \multicolumn{2}{|c|}{ Emailed ibrahim.elmadfa@univie.ac.at 31 December 2014 to request more details of denominators } \\
\hline \multicolumn{3}{|l|}{ Risk of bias } \\
\hline Bias & Authors' judgement & Support for judgement \\
\hline $\begin{array}{l}\text { Random sequence genera- } \\
\text { tion (selection bias) }\end{array}$ & Unclear risk & States "randomly divided" only \\
\hline $\begin{array}{l}\text { Allocation concealment } \\
\text { (selection bias) }\end{array}$ & Unclear risk & States "randomly divided" only \\
\hline $\begin{array}{l}\text { Blinding of participants } \\
\text { and personnel (perfor- } \\
\text { mance bias) } \\
\text { All outcomes }\end{array}$ & High risk & No placebo group. Comment: likely to have been influenced by lack of blinding \\
\hline
\end{tabular}

Blinding of outcome as- Unclear risk No placebo group. Comment: may have been influenced by lack of blinding sessment (detection bias) 
Fabian 2011 (Continued) Secondary and other outcomes

\begin{tabular}{|c|c|c|}
\hline $\begin{array}{l}\text { Incomplete outcome data } \\
\text { (attrition bias) } \\
\text { Secondary and other out- } \\
\text { comes }\end{array}$ & Unclear risk & Denominators not given for length of stay \\
\hline $\begin{array}{l}\text { Selective reporting (re- } \\
\text { porting bias) }\end{array}$ & High risk & $\begin{array}{l}\text { Length of stay only provided, with no other details of clinical outcomes. } \\
\text { Length of stay not included in methods }\end{array}$ \\
\hline Other bias & Low risk & Funded by Trauma Center, Meidling, Vienna \\
\hline
\end{tabular}

Flodin 2014

Methods

Method of randomisation: randomised into 3 groups in blocks of 12, using a sealed envelope technique

Intention-to-treat analysis: appears undertaken

Lost to follow-up: $20 \%$ of groups examined here

Participants Location: 4 university hospitals in Stockholm, Sweden

Period of study: before 2014

54 participants

Inclusion criteria: age 60 years or older, no severe cognitive impairment (Short Portable Mental Questionnaire score $\geq 3$ ), ambulatory before fracture, body mass index $28 \mathrm{~kg} / \mathrm{m} 2$ or lower

Exclusion criteria: pathological fractures and bisphosphonate treatment within the last year; alcohol/drug abuse or overt psychiatric disorders; abnormal hepatic or renal laboratory parameters such as serum-alanine aminotransferase or serum-aspartate-aminotransferase twice the normal reference range or higher, respectively; serum-creatinine levels higher than $130 \mu \mathrm{mol} / \mathrm{L}$ or glomerular filtration rate lower than $30 \mathrm{~mL} /$ minute; bone metabolic disorders such as primary hyperparathyroidism, osteogenesis imperfecta, Paget's disease, or myeloma; lactose intolerance, dysphagia, oesophagitis, gastric ulcer, or malignancy; diabetes mellitus associated with nephropathy or retinopathy; active iritis or uveitis

Sex: 37 female, 17 male

Age: mean 81 years

Fracture type: $41 \%$ femoral neck fracture, $59 \%$ trochanteric fracture

Interventions

Timing of intervention: as soon as participants were stable from a cardiovascular standpoint, able to take food by mouth, and able to sit in an upright position for $1 \mathrm{~h}$ after taking their tablets for 6 months

(a) Fresubin (Fresenius Kabi, Bad Homburg, Germany) protein energy drink, $200 \mathrm{~mL}$ twice daily, totaling $600 \mathrm{kcal}$ with $40 \mathrm{~g}$ protein and $35 \mathrm{mg}$ risedronate once weekly for 12 months

(b) $35 \mathrm{mg}$ risedronate once weekly for 12 months

Allocated: $26 / 28$

Assessed: $18 / 25$

Outcomes Length of follow-up: 1 year

Main outcomes: 
Flodin 2014 (Continued)

\author{
Mortality \\ Complications \\ Putative side effects \\ Other outcomes: \\ Compliance
}

Notes

Emailed lena.flodin@karolinska.se on 9 December 2014 to enquire if more data on outcomes available. Author provided more details 15 December 2014

A third group ('control') was not included in this review

\title{
Risk of bias
}

\begin{tabular}{|c|c|c|}
\hline Bias & Authors' judgement & Support for judgement \\
\hline $\begin{array}{l}\text { Random sequence genera- } \\
\text { tion (selection bias) }\end{array}$ & Unclear risk & $\begin{array}{l}\text { States "randomized into three groups in blocks of twelve, using a sealed enve- } \\
\text { lope technique", no details of sequence generation }\end{array}$ \\
\hline $\begin{array}{l}\text { Allocation concealment } \\
\text { (selection bias) }\end{array}$ & Low risk & $\begin{array}{l}\text { States "randomized into three groups in blocks of twelve, using a sealed enve- } \\
\text { lope technique" }\end{array}$ \\
\hline $\begin{array}{l}\text { Blinding of participants } \\
\text { and personnel (perfor- } \\
\text { mance bias) } \\
\text { All outcomes }\end{array}$ & High risk & No placebo intervention \\
\hline $\begin{array}{l}\text { Blinding of outcome as- } \\
\text { sessment (detection bias) } \\
\text { Primary outcomes }\end{array}$ & Low risk & $\begin{array}{l}\text { No placebo group. Comment: unlikely to have been influenced by lack of } \\
\text { blinding. }\end{array}$ \\
\hline $\begin{array}{l}\text { Blinding of outcome as- } \\
\text { sessment (detection bias) } \\
\text { Secondary and other out- } \\
\text { comes }\end{array}$ & Unclear risk & No placebo group. Comment: may have been influenced by lack of blinding \\
\hline $\begin{array}{l}\text { Incomplete outcome data } \\
\text { (attrition bias) } \\
\text { Primary outcomes }\end{array}$ & High risk & $8 / 26$ nutrition group lost to follow-up versus $3 / 28$ in control group \\
\hline $\begin{array}{l}\text { Incomplete outcome data } \\
\text { (attrition bias) } \\
\text { Secondary and other out- } \\
\text { comes }\end{array}$ & High risk & $8 / 26$ nutrition group lost to follow-up versus $3 / 28$ in control group \\
\hline $\begin{array}{l}\text { Selective reporting (re- } \\
\text { porting bias) }\end{array}$ & Unclear risk & Insufficient details provided \\
\hline Other bias & Unclear risk & $\begin{array}{l}\text { About } 10 \% \text { difference in weight between groups, although BMI only differs by } \\
1.3 \mathrm{~kg} / \mathrm{m} 2 \text { Fresenius Kabi provided supplement, but states not involved in the } \\
\text { planning or implementation of the study, nor in the analyses, conclusions, or } \\
\text { manuscript writing }\end{array}$ \\
\hline
\end{tabular}


Gallagher 1992

\begin{tabular}{|c|c|}
\hline Methods & $\begin{array}{l}\text { Method of randomisation: not stated } \\
\text { Intention-to-treat analysis: not reported } \\
\text { Lost to follow-up: not reported }\end{array}$ \\
\hline Participants & $\begin{array}{l}\text { Location: hospital, Cincinnati, USA } \\
\text { Period of study: over } 15 \text { months } \\
97 \text { participants } \\
\text { Inclusion criteria: people with hip fracture having surgery, serum albumin }<3.5 \mathrm{~g} / \mathrm{dL} \text { on admission } \\
\text { Exclusion criteria: no details } \\
\text { Sex: male and female, numbers not given } \\
\text { Age: not given } \\
\text { Fracture type: further details not given }\end{array}$ \\
\hline Interventions & $\begin{array}{l}\text { Timing of intervention: tube placed in surgery, supplementary feeding began first postoperative night, } \\
11 \text { h per night, continued until participant ate } 75 \% \text { of their calorie needs for } 3 \text { consecutive days } \\
\text { (a) Small-bore nasogastric tube providing } 3.90 \mathrm{MJ} \text { or } 933 \mathrm{kcal}, 33 \mathrm{~g} \text { protein each night; normal diet and } \\
\text { snacks } \\
\text { (b) Normal diet and snacks } \\
\text { Allocated: ?/? } \\
\text { Assessed: ?/? }\end{array}$ \\
\hline Outcomes & $\begin{array}{l}\text { Length of follow-up: no details ( } 21+\text { days) } \\
\text { Main outcomes: } \\
\text { Morbidity and complications: surgical and gastrointestinal } \\
\text { Length of stay: rehabilitation stay } \\
\text { Postoperative functional status: days to meet physical therapy goals }\end{array}$ \\
\hline Notes & $\begin{array}{l}\text { Conference abstract with no denominators, so cannot use data in analysis. Notes taken by Ronald Ko- } \\
\text { retz of an oral conference presentation by Gallagher indicated a quasi-randomised study with dropouts } \\
\text { being placed in control group; thus denominators remain unclear. The notes gave details of total } \\
\text { length of stay, numbers pulling out nasogastric tube, mortality, and medical and surgical complica- } \\
\text { tions. } \\
\text { Request for further details (including denominators) sent } 26 \text { February 1999, re-sent } 3 \text { February } 2000\end{array}$ \\
\hline
\end{tabular}

\section{Risk of bias}

\begin{tabular}{|c|c|c|}
\hline Bias & Authors' judgement & Support for judgement \\
\hline $\begin{array}{l}\text { Random sequence genera- } \\
\text { tion (selection bias) }\end{array}$ & Unclear risk & Abstract only. States "randomized". No further details provided \\
\hline $\begin{array}{l}\text { Allocation concealment } \\
\text { (selection bias) }\end{array}$ & Unclear risk & Abstract only. States "randomized". No further details provided \\
\hline $\begin{array}{l}\text { Blinding of participants } \\
\text { and personnel (perfor- } \\
\text { mance bias) } \\
\text { All outcomes }\end{array}$ & High risk & Abstract only. No placebo group. Comment: probably not done \\
\hline $\begin{array}{l}\text { Blinding of outcome as- } \\
\text { sessment (detection bias) } \\
\text { Primary outcomes }\end{array}$ & Low risk & $\begin{array}{l}\text { Abstract only. No placebo group. Comment: unlikely to have been influenced } \\
\text { by lack of blinding }\end{array}$ \\
\hline $\begin{array}{l}\text { Blinding of outcome as- } \\
\text { sessment (detection bias) } \\
\text { Secondary and other out- } \\
\text { comes }\end{array}$ & Unclear risk & Abstract only. No placebo group. Comment: probably not done \\
\hline
\end{tabular}


Gallagher 1992 (Continued)

Incomplete outcome data (attrition bias)

Primary outcomes
Unclear risk Abstract only. Insufficient details on attrition and exclusions provided

\begin{tabular}{|c|c|c|}
\hline $\begin{array}{l}\text { Incomplete outcome data } \\
\text { (attrition bias) } \\
\text { Secondary and other out- } \\
\text { comes }\end{array}$ & Unclear risk & Abstract only. Insufficient details on attrition and exclusions provided \\
\hline $\begin{array}{l}\text { Selective reporting (re- } \\
\text { porting bias) }\end{array}$ & High risk & $\begin{array}{l}\text { Abstract only. Insufficient details provided. Differences found between notes } \\
\text { on conference presentation and abstract }\end{array}$ \\
\hline Other bias & Unclear risk & Abstract only. Insufficient details provided. No details on sponsor \\
\hline
\end{tabular}

\section{Glendenning 2009}

Method of randomisation: block randomised, double-blind. Randomisation was performed by the Roy-
al Perth Hospital Pharmacy Department, and those involved in this process had no other study involve-
ment.
Intention-to-treat analysis: not undertaken
Lost to follow-up: $26 \%$ did not complete study

Participants
Period of study: before November 2008
95 participants
Inclusion criteria: vitamin D-deficient (serum $250 \mathrm{HD}$ b50 nmol/L) by DiaSorin radioimmunoassay
Exclusion criteria: ionised hypercalcaemia, chronic kidney disease (serum creatinine $>150 \mu$ mol/L),
history of thyrotoxicosis or Cushing's syndrome, concomitant anticonvulsant drug therapy, and use
of other medications affecting bone metabolism (including oestrogen, raloxifene, calcitriol, anabolic
steroids, bisphosphates, sodium fluoride, oral glucocorticoids $>7.5$ mg/day or inhaled glucocorticoids
$>1000 \mu$ g/day) within the preceding 3 months; poor prognosis or who were unlikely to comply with
therapy
Sex: not given
Age: mean 83 years
Fracture type: further details not given

Interventions Timing of intervention: 3 months from inpatient stay

(a) Vitamin D3 $1000 \mathrm{IU} / \mathrm{d}$ and 1 placebo daily and calcium carbonate equivalent to $600 \mathrm{mg} / \mathrm{d}$

(b) Vitamin D2 $1000 \mathrm{IU} / \mathrm{d}$ and 1 placebo daily and calcium carbonate equivalent to $600 \mathrm{mg} / \mathrm{d}$

Allocated: $47 / 48$

Assessed: $36 / 34$ for compliance

Outcomes

Length of follow-up: 3 months

Main outcomes:

Mortality, 
Glendenning 2009 (Continued)

Hypercalcaemia

Other outcomes:

Compliance

$\begin{array}{ll}\text { Notes } & \text { Boots Health Care provided vitamin D2 and matching placebo. Study funded by Royal Perth Hospital } \\ \text { Medical Research Foundation }\end{array}$

Medical Research Foundation

\section{Risk of bias}

\begin{tabular}{lll}
\hline Bias & Authors' judgement & Support for judgement \\
\hline $\begin{array}{l}\text { Random sequence genera- } \\
\text { tion (selection bias) }\end{array}$ & Unclear risk & $\begin{array}{l}\text { States "Randomization was performed by the Royal Perth Hospital Pharma- } \\
\text { cy Department, and those involved in this process had no other study involve- } \\
\text { ment", no further details }\end{array}$ \\
\hline $\begin{array}{l}\text { Allocation concealment } \\
\text { (selection bias) }\end{array}$ & Low risk & $\begin{array}{l}\text { States "Randomization was performed by the Royal Perth Hospital Pharma- } \\
\text { cy Department, and those involved in this process had no other study involve- } \\
\text { ment" }\end{array}$ \\
\hline $\begin{array}{l}\text { Blinding of participants } \\
\text { and personnel (perfor- } \\
\text { mance bias) }\end{array}$ & Low risk & States double-blind \\
All outcomes &
\end{tabular}

Blinding of outcome as-
sessment (detection bias) $\quad$ Low risk States double-blind and unlikely to have been influenced by lack of blinding

Primary outcomes

\begin{tabular}{|c|c|c|}
\hline $\begin{array}{l}\text { Blinding of outcome as- } \\
\text { sessment (detection bias) } \\
\text { Secondary and other out- } \\
\text { comes }\end{array}$ & Unclear risk & $\begin{array}{l}\text { States double-blind but blinding of outcome assessment not described and } \\
\text { may have been influenced by lack of blinding }\end{array}$ \\
\hline $\begin{array}{l}\text { Incomplete outcome data } \\
\text { (attrition bias) } \\
\text { Primary outcomes }\end{array}$ & High risk & $\begin{array}{l}8 / 47 \text { on vitamin } D 3 \text { and } 7 / 48 \text { on vitamin D2 appear not to have been included } \\
\text { in follow-up }\end{array}$ \\
\hline $\begin{array}{l}\text { Incomplete outcome data } \\
\text { (attrition bias) } \\
\text { Secondary and other out- } \\
\text { comes }\end{array}$ & High risk & $\begin{array}{l}8 / 47 \text { on vitamin D3 and } 7 / 48 \text { on vitamin D2 appear not to have been included } \\
\text { in follow-up }\end{array}$ \\
\hline $\begin{array}{l}\text { Selective reporting (re- } \\
\text { porting bias) }\end{array}$ & Unclear risk & Insufficient details provided \\
\hline Other bias & Unclear risk & $\begin{array}{l}\text { Boots Health Care provided vitamin D2 and matching placebo. Study funded } \\
\text { by Royal Perth Hospital Medical Research Foundation }\end{array}$ \\
\hline
\end{tabular}

Hankins 1996

$\begin{array}{ll}\text { Methods } & \text { Method of randomisation: sealed, opaque envelopes in blocks of 10, appears stratified by place of resi- } \\ \text { dence } & \text { Assessor blinding: not done } \\ \text { Intention-to-treat analysis: carried out }\end{array}$


Hankins 1996 (Continued)

Lost to follow-up: details given

Location: acute care in Hornsby-Kuringai Hospital and rehabilitation hospitals, Sydney, Australia
Period of study: admissions from 16 May-8 August 1996
32 participants
Inclusion criteria: fractured neck of femur after accidental fall; admitted from home, hostel or nursing
home; age 65 years or older; mid-upper arm circumference less than or equal to 25 th centile for sex and
age
Exclusion criteria: malignancy, chronic renal failure, hepatic disease, no consent from patient or next
of kin, did not reside locally, not notified of admission, unstable diabetes
Sex: 27 female, 5 male
Age: mean 86 years
Fracture type: further details not given

Interventions Timing of intervention: started within $5 \mathrm{~d}$ of surgery, given once in the morning and once in the evening for $30 \mathrm{~d}$, served on meal tray in hospital by nurses, given by family or self-administered out of hospital

(a) Oral supplement of $250 \mathrm{ml}$ Sustagen twice daily (total daily intake $22.5 \mathrm{~g}$ protein, $10 \mathrm{~g}$ fat, $60 \mathrm{~g}$ carbohydrate, $1.712 \mathrm{MJ}$ or $409 \mathrm{kcal}$ energy, $500 \mathrm{mcg}$ vitamin A, $6.6 \mathrm{mcg}$ vitamin D, $50.8 \mathrm{mg}$ vitamin C, 1.2 $\mathrm{mg}$ thiamin, $1.15 \mathrm{mg}$ riboflavin, $13 \mathrm{mg}$ niacin, $1.3 \mathrm{mcg}$ vitamin B12, $825 \mathrm{mg}$ calcium, $670 \mathrm{mg}$ phosphorus, $8 \mathrm{mg}$ iron, $66 \mathrm{mcg}$ iodine, $1.2 \mathrm{~g}$ potassium, $370 \mathrm{mg}$ sodium) plus standard hospital diet

(b) Standard hospital diet

Allocated: $17 / 15$

Assessed: $17 / 14$

$\begin{array}{ll}\text { Outcomes } & \text { Length of follow-up: } 2 \text { months } \\ & \text { Main outcomes: } \\ & \text { Mortality } \\ & \text { Morbidity and complications: complications (total, infection, pressure sores, pulmonary embolism, } \\ & \text { delirium, anaemia, cardiac failure, acute renal failure), favourable clinical course (excludes death, ma- } \\ \text { jor complication, or } 2 \text { or more minor complications) } \\ \text { Length of stay:acute hospital, rehabilitation hospital, and total stay } \\ \text { Postoperative functional status: Barthel Index } \\ \text { Care required after discharge: place of residence at } 2 \text { months } \\ \text { Other outcomes: } \\ \text { Energy, protein intakes from food and supplement; calcium, iron and vitamin C intakes from food } \\ \text { Patient compliance: numbers completing full } 30 \mathrm{~d} \text { of supplement }\end{array}$

Notes

Request for further details (blinding of outcome assessors, details of supplement administration, further information on outcomes) sent. Reply from trialists (11 June 1999) gave details of outcome assessor blinding, supplement administration and outcomes

\section{Risk of bias}

\begin{tabular}{|c|c|c|}
\hline Bias & Authors' judgement & Support for judgement \\
\hline $\begin{array}{l}\text { Random sequence genera- } \\
\text { tion (selection bias) }\end{array}$ & Unclear risk & $\begin{array}{l}\text { "Sealed, numbered opaque envelopes in blocks of } 10 \text { ". Information from lan } \\
\text { Cameron }\end{array}$ \\
\hline $\begin{array}{l}\text { Allocation concealment } \\
\text { (selection bias) }\end{array}$ & Low risk & $\begin{array}{l}\text { "Sealed, numbered opaque envelopes in blocks of } 10 \text { ". Information from lan } \\
\text { Cameron }\end{array}$ \\
\hline $\begin{array}{l}\text { Blinding of participants } \\
\text { and personnel (perfor- } \\
\text { mance bias) } \\
\text { All outcomes }\end{array}$ & High risk & No placebo group. Comment: likely to have been influenced by lack of blinding \\
\hline $\begin{array}{l}\text { Blinding of outcome as- } \\
\text { sessment (detection bias) } \\
\text { Primary outcomes }\end{array}$ & Low risk & $\begin{array}{l}\text { No placebo group. Comment: unlikely to have been influenced by lack of } \\
\text { blinding }\end{array}$ \\
\hline
\end{tabular}


Hankins 1996 (Continued)

Blinding of outcome as- Unclear risk No placebo group. Comment: may have been influenced by lack of blinding sessment (detection bias)

Secondary and other out-

comes

$\begin{array}{ll}\begin{array}{l}\text { Incomplete outcome data } \\ \text { (attrition bias) }\end{array} & \text { Low risk }\end{array}$

Primary outcomes

Incomplete outcome data Low risk

(attrition bias)

Only one participant withdrew in control group, data provided by lan Cameron

Secondary and other out-

for all other participants

comes

Selective reporting (re- Low risk Thesis provides details that all outcomes reported
porting bias)

Other bias High risk Mead Johnson pharmaceutical company provided Sustagen supplement

\section{Hartgrink 1998}

Methods Method of randomisation: computer-generated randomisation list. Use of numbered envelopes Assessor blinding: no, but statistician appeared blinded

Intention-to-treat analysis: attempted, but 11 randomised participants subsequently excluded for not

fulfilling entry criteria

Lost to follow-up: details given

Location: teaching hospital, The Hague, the Netherlands
Period of study: May 1993-November 1995
140 participants
Inclusion criteria: hip fracture, pressure sore risk score of 8 or above (out of a possible 30), gave con-
sent
Exclusion criteria: pressure sores of grade 2 (blister formation) or more at admission
Sex: 122 female, 18 male
Age: mean 83.6 years
Fracture type (of 129$): 60$ medial, 15 lateral, 53 trochanteric, 1 other hip fracture

Interventions

Timing of intervention: nasogastric tube placed during surgery or within $12 \mathrm{~h}$ afterwards. Feeding started within $24 \mathrm{~h}$ of surgery. Intended duration of feeding 2 weeks. Feed administered between 21:00 hours and 05:00 hours to minimise interference with standard hospital diet.

(a) Nasogastric tube feed of $1 \mathrm{~L}$ Nutrison Steriflo Energy-plus $(340 \mathrm{mosmol} / \mathrm{L}, 6.28 \mathrm{MJ}$ or $1500 \mathrm{kcal}, 60$ g protein, $184 \mathrm{~g}$ carbohydrate, $58 \mathrm{~g}$ fat, $800 \mathrm{mg}$ sodium, $1350 \mathrm{mg}$ potassium, $1250 \mathrm{mg}$ chloride, $570 \mathrm{mg}$ calcium, $570 \mathrm{mg}$ phosphate, $200 \mathrm{mg}$ magnesium, $10 \mathrm{mg}$ iron, $10 \mathrm{mg}$ zinc, $1.5 \mathrm{mg}$ copper, $3 \mathrm{mg}$ manganese, $1 \mathrm{mg}$ fluoride, $50 \mathrm{mcg}$ molybdenum, $43 \mathrm{mcg}$ selenium, $33 \mathrm{mcg}$ chromium, $0.1 \mathrm{mg}$ iodide, 670 mcg retinol equivalents, $5 \mathrm{mcg}$ vitamin $\mathrm{D}, 8.1 \mathrm{mg}$ alpha tocopherol, $40 \mathrm{mcg}$ vitamin $\mathrm{K}, 1 \mathrm{mg}$ thiamin, 1.1 mg riboflavin, $26 \mathrm{mg}$ niacin, $4 \mathrm{mg}$ pantothenic acid, $1.3 \mathrm{mg}$ vitamin B6, $130 \mathrm{mcg}$ folic acid, $2 \mathrm{mcg}$ vitamin B12, $100 \mathrm{mcg}$ biotin, $50 \mathrm{mg}$ vitamin C, $200 \mathrm{mg}$ choline) plus normal hospital diet. If participant removed tube, replaced a maximum of 3 times.

(b) Standard hospital diet

Allocated: $70 / 70$

Assessed: $48 / 53$

Outcomes

Length of follow-up: 2 weeks

Main outcomes:

Mortality

Morbidity and complications: clinically relevant pressure sore

Length of stay: numbers discharged at 1 and 2 weeks 
Hartgrink 1998 (Continued)

Putative side effects of treatment: aspiration pneumonia

Other outcomes:

Energy and protein intake

Patient compliance: compliance with tube feeding

Notes

Request for further details (including supplement details and administration, randomisation process, blinding of outcome assessors, details of 11 post-randomised participants excluded, other outcomes) sent. Reply from trialists (23 June 1999) gave baseline details on all participants randomised, method of randomisation, assessor blinding, supplement details and administration.

\section{Risk of bias}

\begin{tabular}{lll} 
Bias & Authors' judgement & Support for judgement \\
\hline $\begin{array}{l}\text { Random sequence genera- } \\
\text { tion (selection bias) }\end{array}$ & Unclear risk & $\begin{array}{l}\text { "Randomisation list prior to trial was made by computer". "If informed con- } \\
\text { sent a numbered envelope was opened". No information on adequate safe- } \\
\text { guards }\end{array}$ \\
\hline $\begin{array}{l}\text { Allocation concealment } \\
\text { (selection bias) }\end{array}$ & Unclear risk & $\begin{array}{l}\text { "Randomisation list prior to trial was made by computer". "If informed con- } \\
\text { sent a numbered envelope was opened". No information on adequate safe- } \\
\text { guards }\end{array}$ \\
\hline
\end{tabular}

\begin{tabular}{l}
\hline Blinding of participants High risk No placebo group. Comment: likely to have been influenced by lack of blinding \\
and personnel (perfor- \\
mance bias) \\
All outcomes
\end{tabular}

$\begin{array}{lll}\begin{array}{l}\text { Blinding of outcome as- } \\ \text { sessment (detection bias) }\end{array} & \text { Low risk } & \begin{array}{l}\text { No placebo group. Comment: unlikely to have been influenced by lack of } \\ \text { blinding }\end{array} \\ \text { Primary outcomes } & \end{array}$

\begin{tabular}{|c|c|c|}
\hline $\begin{array}{l}\text { Blinding of outcome as- } \\
\text { sessment (detection bias) } \\
\text { Secondary and other out- } \\
\text { comes }\end{array}$ & Unclear risk & No placebo group. Comment: may have been influenced by lack of blinding \\
\hline $\begin{array}{l}\text { Incomplete outcome data } \\
\text { (attrition bias) } \\
\text { Primary outcomes }\end{array}$ & Unclear risk & $\begin{array}{l}11 \text { participants excluded after randomisation ( } 4 \text { had pressure sores already, } 7 \\
\text { pressure sore risk too low), groups not given }\end{array}$ \\
\hline
\end{tabular}

Incomplete outcome data Unclear risk (attrition bias)

Secondary and other outcomes

\begin{tabular}{lll}
\hline $\begin{array}{l}\text { Selective reporting (re- } \\
\text { porting bias) }\end{array}$ & Unclear risk & Insufficient details provided \\
\hline Other bias & High risk & $\begin{array}{l}\text { Nutricia corp provided support for Nutrison tube feeding and nasogastric } \\
\text { tubes }\end{array}$ \\
\hline
\end{tabular}

\section{Hoikka 1980}

$\begin{array}{ll}\text { Methods } & \text { Method of randomisation: quasi-randomised by date of birth } \\ \text { Intention-to-treat analysis: not reported }\end{array}$


Hoikka 1980 (Continued)

Lost to follow-up: not reported

Timing of intervention: start time unclear, 4 months' treatment
(a) 1 mcg 1 -alpha-hydroxycholecalciferol and $1 \mathrm{~g}$ calcium as calcium carbonate daily
(b) Placebo and $1 \mathrm{~g}$ calcium as calcium carbonate daily
Allocated: $19 / 18$
Assessed: $13 / 15$ at 6 months for muscle strength

\begin{tabular}{ll} 
Outcomes & $\begin{array}{l}\text { Length of follow-up: } 6 \text { months } \\
\text { Main outcomes: } \\
\text { Putative side effects of treatment: hypercalcaemia }\end{array}$ \\
\hline Notes & $\begin{array}{l}\text { Request for further details (timing of intervention, denominators for some outcomes) sent 11 May 1999, } \\
\text { returned to sender. Details on method of randomisation received from Jane Robertson on 02 February } \\
1999 .\end{array}$
\end{tabular}

\section{Risk of bias}

\begin{tabular}{lll}
\hline Bias & Authors' judgement & Support for judgement \\
\hline $\begin{array}{l}\text { Random sequence genera- } \\
\text { tion (selection bias) }\end{array}$ & High risk & Quasi-randomised by date of birth (see Notes) \\
\hline $\begin{array}{l}\text { Allocation concealment } \\
\text { (selection bias) }\end{array}$ & Unclear risk & Quasi-randomised by date of birth, but states "double-blind" (see Notes) \\
\hline $\begin{array}{l}\text { Blinding of participants } \\
\text { and personnel (perfor- } \\
\text { mance bias) }\end{array}$ & Unclear risk & States "double-blind". No other details \\
All outcomes & \\
\hline
\end{tabular}

\begin{tabular}{|c|c|c|}
\hline $\begin{array}{l}\text { Blinding of outcome as- } \\
\text { sessment (detection bias) } \\
\text { Secondary and other out- } \\
\text { comes }\end{array}$ & Unclear risk & Insufficient details provided \\
\hline $\begin{array}{l}\text { Incomplete outcome data } \\
\text { (attrition bias) } \\
\text { Secondary and other out- } \\
\text { comes }\end{array}$ & Unclear risk & Insufficient details on attrition and exclusions provided \\
\hline $\begin{array}{l}\text { Selective reporting (re- } \\
\text { porting bias) }\end{array}$ & Unclear risk & Insufficient details provided \\
\hline Other bias & High risk & $\begin{array}{l}\text { Appears sponsored by pharmaceutical company (Laaketehdas Medica, Helsin- } \\
\text { ki, Finland) }\end{array}$ \\
\hline
\end{tabular}


Houwing 2003

\begin{tabular}{|c|c|}
\hline Methods & $\begin{array}{l}\text { Method of randomisation: use of a computer programme, balanced in blocks of four, by independent } \\
\text { person } \\
\text { Intention-to-treat analysis: probably - appears so } \\
\text { Lost to follow-up: probably none }\end{array}$ \\
\hline Participants & $\begin{array}{l}\text { Location: three centres, Arnhem, Deventer and Nieuwegein, in The Netherlands } \\
\text { Period of study: April } 1998 \text { to December } 1999 \\
103 \text { participants } \\
\text { Inclusion criteria: hip fracture, pressure ulcer score }>8 \text { (Dutch Consensus Meeting scoring system), con- } \\
\text { sent from patient or legal representative } \\
\text { Exclusion criteria: terminal care, metastatic hip fracture, insulin-dependent diabetes, renal disease, } \\
\text { hepatic disease, morbid obesity (BMI > 40), therapeutic diet incompatible with supplementation, preg- } \\
\text { nancy, lactation } \\
\text { Sex: } 84 \text { female, } 19 \text { male } \\
\text { Age: mean age } 81 \text { years } \\
\text { Fracture type: not given ( } 48 \text { internal fixation presumed extracapsular fractures, } 44 \text { hemi-arthroplasty } \\
\text { presumed intracapsular fractures) }\end{array}$ \\
\hline Interventions & $\begin{array}{l}\text { Timing of intervention: supplemented from immediately postoperative period for four weeks or until } \\
\text { discharge, given between regular meals } \\
\text { (a) } 400 \mathrm{ml} / \text { day oral supplement ( } 600 \mathrm{kcal} \text { or } 2.51 \mathrm{MJ}, 40 \mathrm{~g} \text { protein, } 6 \mathrm{mg} \text { arginine, } 20 \mathrm{mg} \text { zinc, } 500 \mathrm{mg} \\
\text { vitamin C, } 200 \mathrm{mg} \text { vitamin E as alpha-tocopherol, } 4 \mathrm{mg} \text { carotenoids (Cubitan, NV Nutricia, The Nether- } \\
\text { lands)); and regular diet } \\
\text { (b) Placebo supplement was a non-caloric, water-based drink with sweeteners, colourants and flavour- } \\
\text { ings in similar packaging, look and taste not identical to active supplement; and regular diet } \\
\text { Allocated: } 51 / 52 \\
\text { Assessed: } 51 / 52\end{array}$ \\
\hline
\end{tabular}

\begin{tabular}{ll} 
Outcomes & Length of follow-up: $28 \mathrm{~d}$ or earlier if discharged \\
& Main outcomes: \\
& Morbidity and complications: pressure sores \\
& Other outcomes: Patient compliance: mean percentage intake/day, days supplemented \\
\hline Notes & $\begin{array}{l}\text { Request for further details (method of randomisation, other complications, adverse events, length of } \\
\text { stay, further details of supplement) sent } 13 / 10 / 03 .\end{array}$ \\
& Further details of randomisation method received 29/10/03.
\end{tabular}

\section{Risk of bias}

\begin{tabular}{|c|c|c|}
\hline Bias & Authors' judgement & Support for judgement \\
\hline $\begin{array}{l}\text { Random sequence genera- } \\
\text { tion (selection bias) }\end{array}$ & Low risk & $\begin{array}{l}\text { Use of a computer programme, balanced in blocks of four, by an independent } \\
\text { person. Information from trialists. Comment: probably low risk. }\end{array}$ \\
\hline $\begin{array}{l}\text { Allocation concealment } \\
\text { (selection bias) }\end{array}$ & Low risk & $\begin{array}{l}\text { Use of a computer programme, balanced in blocks of four, by an independent } \\
\text { person. Information from trialists. }\end{array}$ \\
\hline $\begin{array}{l}\text { Blinding of participants } \\
\text { and personnel (perfor- } \\
\text { mance bias) } \\
\text { All outcomes }\end{array}$ & Low risk & $\begin{array}{l}\text { States "double-blind" but also states " look and taste of both supplements } \\
\text { were not exactly identical, but supplements were given in similar, blinded } \\
\text { packages to mask the differences". Comment: probably done. }\end{array}$ \\
\hline $\begin{array}{l}\text { Blinding of outcome as- } \\
\text { sessment (detection bias) } \\
\text { Primary outcomes }\end{array}$ & Low risk & $\begin{array}{l}\text { States "double-blind" but also states " look and taste of both supplements } \\
\text { were not exactly identical, but supplements were given in similar, blinded } \\
\text { packages to mask the differences". Assessed by nurses and unlikely to have } \\
\text { been influenced by unblinding. Comment: probably done. }\end{array}$ \\
\hline $\begin{array}{l}\text { Blinding of outcome as- } \\
\text { sessment (detection bias) }\end{array}$ & Low risk & $\begin{array}{l}\text { States "double-blind" but also states " look and taste of both supplements } \\
\text { were not exactly identical, but supplements were given in similar, blinded }\end{array}$ \\
\hline
\end{tabular}


Houwing 2003 (Continued) Secondary and other outcomes packages to mask the differences". Assessed by nurses. Comment: probably done.

\begin{tabular}{lll}
\hline $\begin{array}{l}\text { Incomplete outcome data } \\
\text { (attrition bias) } \\
\text { Primary outcomes }\end{array}$ & Low risk & All participants accounted for in data. \\
\hline $\begin{array}{l}\text { Incomplete outcome data } \\
\text { (attrition bias) } \\
\begin{array}{l}\text { Secondary and other out- } \\
\text { comes }\end{array}\end{array}$ & Low risk & All participants accounted for in data. \\
\hline $\begin{array}{l}\text { Selective reporting (re- } \\
\text { porting bias) }\end{array}$ & Unclear risk & $\begin{array}{l}\text { Pressure ulcer reporting agrees with methods, but would expect reporting of } \\
\text { other complications }\end{array}$ \\
\hline $\begin{array}{l}\text { Other bias } \\
\text { High risk }\end{array}$ & Funded by Numico Research BV, nutrition company.
\end{tabular}

\section{Kang 2012}

\begin{tabular}{l} 
Methods \\
Intention-to-treat analysis: no details \\
Lost to follow-up: no details \\
\hline Location: Daejin Medical Center, Bundang Jesaeng General Hospital, Korea \\
Period of study: before September 2012 \\
60 participants \\
Inclusion criteria: aged over 65 years admitted to hospital for hip fracture surgery \\
Exclusion criteria: none provided \\
Sex: not given \\
Age: mean age 81 years \\
Fracture type: further details not given
\end{tabular}

Interventions

Timing of intervention: 2 weeks postoperatively

(a) Oral nutritional supplements, trace element supplements and dietetic counselling

(b) Usual care

Allocated: $30 / 30$

Assessed: unclear

Length of follow-up: mean of 120 days
Main outcomes:
Mortality
Complications


Kang 2012 (Continued)

Risk of bias

\begin{tabular}{|c|c|c|}
\hline Bias & Authors' judgement & Support for judgement \\
\hline $\begin{array}{l}\text { Random sequence genera- } \\
\text { tion (selection bias) }\end{array}$ & Unclear risk & Abstract only. States randomized controlled trial, no further details \\
\hline $\begin{array}{l}\text { Allocation concealment } \\
\text { (selection bias) }\end{array}$ & Unclear risk & Abstract only. States randomized controlled trial, no further details \\
\hline $\begin{array}{l}\text { Blinding of participants } \\
\text { and personnel (perfor- } \\
\text { mance bias) } \\
\text { All outcomes }\end{array}$ & High risk & Abstract only. No placebo group. Comment: probably not done \\
\hline $\begin{array}{l}\text { Blinding of outcome as- } \\
\text { sessment (detection bias) } \\
\text { Primary outcomes }\end{array}$ & Low risk & $\begin{array}{l}\text { Abstract only. No placebo group. Comment: unlikely to have been influenced } \\
\text { by lack of blinding }\end{array}$ \\
\hline $\begin{array}{l}\text { Blinding of outcome as- } \\
\text { sessment (detection bias) } \\
\text { Secondary and other out- } \\
\text { comes }\end{array}$ & Unclear risk & Abstract only. No placebo group. Comment: unclear if done \\
\hline $\begin{array}{l}\text { Incomplete outcome data } \\
\text { (attrition bias) } \\
\text { Primary outcomes }\end{array}$ & Unclear risk & Abstract only. No details provided \\
\hline $\begin{array}{l}\text { Incomplete outcome data } \\
\text { (attrition bias) } \\
\text { Secondary and other out- } \\
\text { comes }\end{array}$ & Unclear risk & Abstract only. No details provided \\
\hline $\begin{array}{l}\text { Selective reporting (re- } \\
\text { porting bias) }\end{array}$ & Unclear risk & Abstract only. Insufficient details provided \\
\hline Other bias & Unclear risk & Abstract only. Insufficient details provided. No details on sponsor \\
\hline
\end{tabular}

Luo 2015

\begin{tabular}{ll}
\hline Methods & $\begin{array}{l}\text { Method of randomisation: computer-generated randomisation plan in 1:1 ratio. Each study centre had } \\
\text { its own randomisation schedule. Randomisation envelopes were opened and used in ascending nu- } \\
\text { merical order. }\end{array}$ \\
Intention-to-treat analysis: not undertaken \\
Lost to follow-up: $64 \%$ \\
\hline Location: 6 hospitals, Russia \\
Period of study: $2009-2010$ \\
Participants \\
Inclusion criteria: age $\geq 45$ years, expected to undergo surgical hip fracture repair within $14 \mathrm{~d}$ of frac- \\
ture, admission total protein level $\leq 70 \mathrm{~g} / \mathrm{L}$ and screening serum albumin $\leq 38 \mathrm{~g} / \mathrm{L}$, Subjective Global As- \\
sessment score B or C, able to consume foods and beverages orally
\end{tabular}


Luo 2015 (Continued)

Exclusion criteria: type 1 diabetes; uncontrolled type 2 diabetes ( $\mathrm{HbA} 1 \mathrm{c}>8 \%$ ); active malignancy; chronic, contagious, infectious disease (e.g. active tuberculosis, Hepatitis B or C, or HIV); alcohol or substance abuse; severe dementia; gastrointestinal conditions that may interfere with nutrient intake or digestion, or known allergy or intolerance to any ingredient in supplements

Sex: 35 female, 11 male (of 46 evaluated)

Age: mean 69 years

Fracture type: further details not given

Interventions

Timing of intervention: from before surgery for $28 \mathrm{~d}$

a) Ensure TwoCal oral supplements; Abbott Nutrition, Columbus, Ohio, USA; nutritionally complete, energy and protein-dense drink including 30 vitamins and minerals. A total of two containers $(200 \mathrm{~mL}$ per container) were given 3 times/d: $100 \mathrm{~mL}$ between breakfast and noon meal, $100 \mathrm{~mL}$ serving between noon and evening meal, and $200 \mathrm{~mL}$ as a snack before going to bed. Provided an additional $798 \mathrm{kcal}$ and $34 \mathrm{~g}$ protein/d; and standard hospital food

b) Standard hospital food

Allocated: ?/? (total 127)

Assessed: $22 / 24$

\begin{tabular}{|c|c|}
\hline \multirow[t]{8}{*}{ Outcomes } & Length of follow-up: $28 \mathrm{~d}$ \\
\hline & Main outcomes: \\
\hline & Mortality \\
\hline & Functional status \\
\hline & Complications \\
\hline & Putative side effects \\
\hline & Other outcomes: \\
\hline & Compliance \\
\hline
\end{tabular}

Notes Abstract provides results for only 46 of 127 randomised participants. Emailed Abbott Nutrition 8 October 2014. Dr Menghua Luo replied providing full publication 17 November 2014

\section{Risk of bias}

\begin{tabular}{lll}
\hline Bias & Authors' judgement & Support for judgement \\
\hline $\begin{array}{l}\text { Random sequence genera- } \\
\text { tion (selection bias) }\end{array}$ & Low risk & States used "using a computer generated randomization plan on a 1:1 ratio". \\
\hline $\begin{array}{l}\text { Allocation concealment } \\
\text { (selection bias) }\end{array}$ & Unclear risk & $\begin{array}{l}\text { States "Each study center had its own randomization schedule. As eligible sub- } \\
\text { jects were enrolled, they were assigned a subject number sequentially starting } \\
\text { with the first envelope indicating the group assignment. Randomization en- } \\
\text { velopes were opened and used in ascending numerical order." No indication } \\
\text { that envelopes were opaque }\end{array}$ \\
\hline $\begin{array}{l}\text { Blinding of participants } \\
\text { and personnel (perfor- } \\
\text { mance bias) }\end{array}$ & High risk & No placebo. Comment: probably not done \\
\begin{tabular}{l} 
All outcomes \\
\hline
\end{tabular} & \\
\hline
\end{tabular}


Luo 2015 (Continued)

Blinding of outcome as- Low risk No placebo group. Comment: unlikely to have been influenced by lack of sessment (detection bias) blinding

Primary outcomes

Blinding of outcome as- Unclear risk No placebo group. Comment: may have been influenced by lack of blinding
sessment (detection bias)
Secondary and other out-
comes

Incomplete outcome data High risk

Only 46 of 127 enrolled assessed. States "72 excluded due to missing records"

(attrition bias)

Primary outcomes

Incomplete outcome data High risk

Only 46 of 127 enrolled assessed. States "72 excluded due to missing records"

(attrition bias)

Secondary and other out-

comes

\begin{tabular}{lll}
\hline $\begin{array}{l}\text { Selective reporting (re- } \\
\text { porting bias) }\end{array}$ & High risk & $\begin{array}{l}\text { Insufficient data on adverse events, including denominators. No details of } \\
\text { length of stay }\end{array}$ \\
\hline Other bias & High risk & Supported by Abbott Nutrition, and 3 of the authors were employees \\
\hline
\end{tabular}

\section{Madigan 1994}

Methods Method of randomisation: not stated

Intention-to-treat analysis: not carried out, results presented for 30 participants of 34 randomised, re-

sults from the 2 supplemented groups were combined

Lost to follow-up: details given

Participants
Lecation: Illawarra Regional Hospital, Port Kembla Campus, Woolongong, Australia
Period of study: admissions from 6 September-6 December 1993, 7 February-31 March 1994
34 participants
Inclusion criteria: femoral neck fracture resulting from an accidental fall, age over 60 years, informed
consent
Exclusion criteria: pathological fracture due to tumour; fracture due to violent external trauma; elec-
tive total hip replacement; renal, hepatic, metastatic or endocrine (affecting skeletal metabolism) dis-
ease; admitted from nursing home; failure to gain consent; transferred to another hospital for surgery
Sex: 22 female, 8 male (of 30 )
Age: all over 60 years
Fracture type: further details not given

Interventions Timing of intervention: started on admission for $10 \mathrm{~d}$, once daily after evening meal

(a) $250 \mathrm{ml}$ oral supplement prepared by dietitian from ProMod (protein powder) and Polyjoule (glucose polymer) providing $1.30 \mathrm{MJ}$ or $310 \mathrm{kcal} ; 16 \mathrm{~g}$ protein, $41.4 \mathrm{~g}$ carbohydrate, $9.2 \mathrm{~g}$ fat, $0.19 \mathrm{mg}$ riboflavin, $245 \mathrm{mg}$ calcium, phosphorus $171 \mathrm{mg}$, and standard hospital diet

(b) One multivitamin/mineral tablet daily (ELEVIT RDI, Roche) providing $750 \mathrm{mcg}$ vitamin A, $1.1 \mathrm{mg}$ thiamin, $1.7 \mathrm{mg}$ riboflavin, $20 \mathrm{mg}$ nicotinamide, $7 \mathrm{mg}$ pantothenic acid, $1.9 \mathrm{mg}$ pyridoxine, $2 \mathrm{mcg}$ vitamin B12, 200 mcg biotin, 200 mcg folic acid, 30 mg vitamin C, 200 IU vitamin D3, 15 IU vitamin E, 125 mg calcium, $100 \mathrm{mg}$ magnesium, $125 \mathrm{mg}$ phosphorus, $5 \mathrm{mg}$ iron, $1 \mathrm{mg}$ copper, $1 \mathrm{mg}$ manganese, $7.5 \mathrm{mg}$ zinc $250 \mathrm{ml}$ ), plus oral supplement as above, and standard hospital diet

(c) Standard hospital diet

Allocated: ?/?/?

Assessed: $18 / 12(a+b / c)$ 
Madigan 1994 (Continued)

\section{Mortality}

Morbidity and complications - numbers of complications (urinary infections, wound infections/de-

layed healing, pressure sores, pneumonia, deep venous thrombosis, sepsis)

Length of stay: acute hospital

Postoperative functional status: number transferred to rehabilitation hospital, days to reach partial or

full weight bearing with support, days to reach independent mobility

Care required after discharge: discharge to home, hostel, nursing home, number of subjects returning

to pre-morbid mobility

Other outcomes:

Total energy, protein, vitamin and mineral intakes from food and supplements

Patient compliance: number taking protein supplement for only $7 \mathrm{~d}$

Notes

In the trial report, the two supplemented groups were combined for analysis for comparison with control group. 3 subjects eliminated post-randomisation from analysis because only took protein supplement for $7 \mathrm{~d}$, and 1 eliminated for developing diabetes. Numbers of participants assigned/assessed not always clear. Request for further details sent 4 February 2000

\section{Risk of bias}

\begin{tabular}{|c|c|c|}
\hline Bias & Authors' judgement & Support for judgement \\
\hline $\begin{array}{l}\text { Random sequence genera- } \\
\text { tion (selection bias) }\end{array}$ & Unclear risk & No information: just states "randomised" \\
\hline $\begin{array}{l}\text { Allocation concealment } \\
\text { (selection bias) }\end{array}$ & Unclear risk & No information: just states "randomised" \\
\hline $\begin{array}{l}\text { Blinding of participants } \\
\text { and personnel (perfor- } \\
\text { mance bias) } \\
\text { All outcomes }\end{array}$ & High risk & No blinding undertaken \\
\hline $\begin{array}{l}\text { Blinding of outcome as- } \\
\text { sessment (detection bias) } \\
\text { Primary outcomes }\end{array}$ & Low risk & $\begin{array}{l}\text { No placebo group. Comment: unlikely to have been influenced by lack of } \\
\text { blinding }\end{array}$ \\
\hline $\begin{array}{l}\text { Blinding of outcome as- } \\
\text { sessment (detection bias) } \\
\text { Secondary and other out- } \\
\text { comes }\end{array}$ & Unclear risk & No placebo group. Comment: may have been influenced by lack of blinding \\
\hline $\begin{array}{l}\text { Incomplete outcome data } \\
\text { (attrition bias) } \\
\text { Primary outcomes }\end{array}$ & High risk & $\begin{array}{l}\text { In the trial report, the two supplemented groups were combined for analysis } \\
\text { for comparison with control group. Three subjects eliminated post-randomisa- } \\
\text { tion from analysis because only took protein supplement for } 7 \mathrm{~d} \text {, and one elim- } \\
\text { inated for developing diabetes. Numbers of participants assigned/assessed } \\
\text { not always clear }\end{array}$ \\
\hline $\begin{array}{l}\text { Incomplete outcome data } \\
\text { (attrition bias) } \\
\text { Secondary and other out- } \\
\text { comes }\end{array}$ & High risk & $\begin{array}{l}\text { In the trial report, the two supplemented groups were combined for analysis } \\
\text { for comparison with control group. Three subjects eliminated post-randomisa- } \\
\text { tion from analysis because only took protein supplement for } 7 \mathrm{~d} \text {, and one elim- } \\
\text { inated for developing diabetes. Numbers of participants assigned/assessed } \\
\text { not always clear }\end{array}$ \\
\hline $\begin{array}{l}\text { Selective reporting (re- } \\
\text { porting bias) }\end{array}$ & Low risk & Thesis available, all outcomes accounted for \\
\hline Other bias & Unclear risk & No details available on funding source \\
\hline
\end{tabular}


Miller 2006

$\begin{array}{ll}\text { Methods } & \text { Method of randomisation: computer-generated sequence, stratified by admission accommodation. } \\ & \text { Sealed opaque envelopes, prepared remote from recruitment by pharmacy } \\ \text { Intention-to-treat analysis: carried out } \\ \text { Lost to follow-up: details given }\end{array}$

Interventions Timing of intervention: from $7 \mathrm{~d}$ after fracture, given daily for 6 weeks

(a) Nutrition-only intervention: Fortisip (Nutricia Australia Pty Ltd) oral protein and energy supplement ( $1.5 \mathrm{kcal} / \mathrm{ml}, 16 \%$ protein, $35 \%$ fat, $49 \%$ carbohydrate) to provide $45 \%$ of estimated energy intakes. (Individually prescribed and delivered.) 4 doses of equal volume given by nurses from drug trolley, continued after hospital discharge as twice/d or more. Once weekly visits on weeks 7-12

(b) Attention control. Usual care and general nutrition and exercise advice. Twice weekly visits on weeks 1 to 6 , once weekly on weeks 7 to 12 .

Allocated: $23 / 20$

Assessed: $23 / 20$ (mortality)

\begin{tabular}{ll}
\hline Outcomes & Length of follow-up: 12 months \\
& Main outcomes: \\
& Mortality (for participants with hip fracture) \\
& Length of hospital stay (acute, rehabilitation, total) (not available for participants with hip fracture) \\
\hline Notes & Trial population also included 49 other participants (43 with hip fracture), who were allocated to the \\
& two other intervention groups: exercise; and nutrition plus exercise. Data from these two groups are \\
& not included in this review. \\
& Email to Professor Crotty 14 January 2009 asking for data for participants with hip fracture only; mor- \\
& tality data provided 20th February 2009
\end{tabular}

\section{Risk of bias}

\begin{tabular}{lll}
\hline Bias & Authors' judgement & Support for judgement \\
\hline $\begin{array}{l}\text { Random sequence genera- } \\
\text { tion (selection bias) }\end{array}$ & Low risk & $\begin{array}{l}\text { States "The Pharmacy department maintained a computer generated alloca- } \\
\text { tion sequence in sealed opaque envelopes." }\end{array}$ \\
\hline $\begin{array}{l}\text { Allocation concealment } \\
\text { (selection bias) }\end{array}$ & Low risk & $\begin{array}{l}\text { States "The Pharmacy department maintained a computer generated alloca- } \\
\text { tion sequence in sealed opaque envelopes." }\end{array}$ \\
\hline $\begin{array}{l}\text { Blinding of participants } \\
\text { and personnel (perfor- } \\
\text { mance bias) }\end{array}$ & High risk & $\begin{array}{l}\text { No placebo group. Comment: likely to have been influenced by lack of blind- } \\
\text { ing. }\end{array}$ \\
\hline $\begin{array}{l}\text { Bll outcomes } \\
\text { sessment (detection bias) }\end{array}$ & Low risk & $\begin{array}{l}\text { No placebo group but states that research staff were blinded. Comment: un- } \\
\text { likely to have been influenced by lack of blinding. }\end{array}$
\end{tabular}


Miller 2006 (Continued)

Primary outcomes

\begin{tabular}{lll}
$\begin{array}{l}\text { Incomplete outcome data } \\
\text { (attrition bias) } \\
\text { Primary outcomes }\end{array}$ & Low risk & No missing outcome data. \\
\hline $\begin{array}{l}\text { Selective reporting (re- } \\
\text { porting bias) }\end{array}$ & Low risk & $\begin{array}{l}\text { Expected outcomes for all trial participants reported (hip fracture patients } \\
\text { were a sub group of all participants). }\end{array}$ \\
\hline Other bias & High risk & $\begin{array}{l}\text { Funded bu NHMRC Public Health Research Scholarship, Flinders University-In- } \\
\text { dustry Collaborative Grant and Nutricia Australia Pty Ltd }\end{array}$ \\
\hline
\end{tabular}

\section{Myint 2013}

Methods of randomisation: sealed opaque envelope containing the randomised group from blocks of 12
was drawn for each participant by a member of the ward staff who was not a co-investigator
Intention-to-treat analysis: not undertaken, 5 excluded after randomisation
Lost to follow-up: details given

Participants

Location: Department of Rehabilitation of Kowloon Hospital, China

Period of study: before June 2012

126 participants

Inclusion criteria: 60 years or older, recent low impact osteoporotic fracture of the proximal femur surgically repaired within 4 weeks before recruitment

Exclusion criteria: required tube feeding, those in unstable medical condition, BMI $\geq 25$, malignancy, conditions with contraindication for high-protein diet, mentally incapacitated and inability to communicate or understand written consent

Sex: 80 female, 41 male (of 121 assessed)

Age: mean age 82 years

Fracture type: 52 neck of femur, 63 trochanteric, 6 sub-trochanteric

Interventions Timing of intervention: started within $3 \mathrm{~d}$ of admission to rehabilitation hospital for 4 weeks or until discharged.

a) A ready-to-use oral liquid nutritional supplement (18-24 g protein and $500 \mathrm{kcal}$ per day). The oral nutritional supplementation was a drink of about $240 \mathrm{ml}$ in volume given twice daily on top of the standard hospital diet. 4 types of nutritional supplements were offered according to participant's dietary preferences. These were brands Ensure by Abbott, Resource Breeze by Nestle Nutrition (orange or peach flavour), Compleat by Nestle Nutrition and Glucerna by Abbott. Oral 800-1000 IU vitamin D and tablets containing $1200 \mathrm{mg}$ calcium daily

b) Standard hospital diet. Oral 800-1000 IU vitamin D and tablets containing $1200 \mathrm{mg}$ calcium daily

Allocated: $65 / 61$

Assessed: $61 / 60$

Outcomes Length of follow-up: 6 months after discharge

Main outcomes:

Mortality 
Myint 2013 (Continued)

\author{
Complications \\ Rehabilitation hospital stay \\ Functional status, \\ Nursing home and acute hospital care \\ Putative side effects \\ Other outcomes: \\ Compliance
}

Emailed maww@ha.org.hk 5 January 2015 to clarify data for complications. Reply received 6 January
2015 providing numbers of participants with complications in groups
Participants recruited if $\mathrm{BMI}<25$ and mean BMI 21.7 , consultant geriatrician advised that participants
in this trial be considered under 'malnourished targeted' category of subgroup analysis

\title{
Risk of bias
}

\begin{tabular}{lll}
\hline Bias & Authors' judgement & Support for judgement \\
\hline $\begin{array}{l}\text { Random sequence genera- } \\
\text { tion (selection bias) }\end{array}$ & Unclear risk & $\begin{array}{l}\text { States "sealed opaque envelope containing the randomised group from blocks } \\
\text { of twelve. }\end{array}$ \\
\hline $\begin{array}{l}\text { Allocation concealment } \\
\text { (selection bias) }\end{array}$ & Low risk & $\begin{array}{l}\text { States "sealed opaque envelope containing the randomised group from blocks } \\
\text { of twelve was drawn for each patient by a member of the ward staff who was } \\
\text { not a co-investigator" }\end{array}$ \\
\hline
\end{tabular}

Blinding of participants High risk No placebo group. Comment: likely to have been influenced by lack of blinding and personnel (performance bias)

All outcomes

\begin{tabular}{|c|c|c|}
\hline $\begin{array}{l}\text { Blinding of outcome as- } \\
\text { sessment (detection bias) } \\
\text { Primary outcomes }\end{array}$ & Low risk & $\begin{array}{l}\text { States that assessment of complications, treatment decisions were made by } \\
\text { ward team and not investigators. Although unblinded unlikely to have influ- } \\
\text { enced outcome assessment }\end{array}$ \\
\hline
\end{tabular}

\begin{tabular}{|c|c|c|}
\hline $\begin{array}{l}\text { Blinding of outcome as- } \\
\text { sessment (detection bias) } \\
\text { Secondary and other out- }\end{array}$ & Low risk & $\begin{array}{l}\text { States that assessment of treatment and discharge decisions were made by } \\
\text { ward team and not investigators. Functional status assessed by physiothera- } \\
\text { pist blinded to allocation }\end{array}$ \\
\hline
\end{tabular}
comes

\begin{tabular}{lll}
\hline $\begin{array}{l}\text { Incomplete outcome data } \\
\text { (attrition bias) }\end{array}$ & High risk & 4 intervention group and 1 control group excluded by investigators \\
Primary outcomes & \\
\hline $\begin{array}{l}\text { Incomplete outcome data } \\
\text { (attrition bias) }\end{array}$ & High risk & 4 intervention group and 1 control group excluded by investigators \\
Secondary and other out- & & \\
comes
\end{tabular}

Selective reporting (re- Low risk Protocol not available but all expected outcomes accounted provided
porting bias)

\begin{tabular}{ll}
\hline Other bias $\quad$ Low risk $\quad$ Funded by rehabilitation hospital, no commercial sponsorship \\
\hline
\end{tabular}


Neumann 2004

$\begin{array}{ll}\text { Methods } & \text { Method of randomisation: not stated, stratified by type of hip fracture } \\ & \text { Intention-to-treat analysis: unclear } \\ & \text { Lost to follow-up: details given }\end{array}$

Interventions Timing of intervention: consecutive 28-d period at least two 8 oz cans/d

(a) Boost HP high protein liquid supplement (Mead Johnson, Evansville, Indiana, USA) providing per 8 oz can: $240 \mathrm{kcal}, 15 \mathrm{~g}$ protein, $33 \mathrm{~g}$ carbohydrate, $6 \mathrm{~g}$ fat, $1110 \mathrm{IU}$ vitamin A, 89 IU vitamin D, 6.7 IU vitamin E, $27 \mathrm{mcg}$ vitamin K, $13.3 \mathrm{mg}$ vitamin C, $89 \mathrm{mcg}$ folic acid, $0.33 \mathrm{mg}$ thiamin, $0.4 \mathrm{mg}$ riboflavin, 0.47 $\mathrm{mg}$ vitamin B6, $1.33 \mathrm{mcg}$ vitamin B12, $4.7 \mathrm{mg}$ niacin, $56 \mathrm{mg}$ choline, $67 \mathrm{mcg}$ biotin, $2.3 \mathrm{mg}$ pantothenic acid, $220 \mathrm{mg}$ sodium, $490 \mathrm{mg}$ potassium, $350 \mathrm{mg}$ chloride, $240 \mathrm{mg}$ calcium, $220 \mathrm{mg}$ phosphorus, $90 \mathrm{mg}$ magnesium, 33mg iodine, $0.67 \mathrm{mg}$ manganese, $0.47 \mathrm{mg}$ copper, $3.3 \mathrm{mg}$ zinc, $4 \mathrm{mg}$ iron, $15.8 \mathrm{mcg}$ selenium, 27 mcg chromium, 16.9 mcg molybdenum

(b) Ensure liquid supplement (Ross Labs, Columbus, Ohio, USA) providing per 8 oz can: $250 \mathrm{kcal}, 8.8 \mathrm{~g}$ protein, $40 \mathrm{~g}$ carbohydrate, $6.1 \mathrm{~g}$ fat, $1250 \mathrm{IU}$ vitamin A, $100 \mathrm{IU}$ vitamin D, $7.5 \mathrm{IU}$ vitamin E, $20 \mathrm{mcg}$ vitamin $\mathrm{K}, 30 \mathrm{mg}$ vitamin C, $100 \mathrm{mcg}$ folic acid, $0.38 \mathrm{mg}$ thiamin, $0.43 \mathrm{mg}$ riboflavin, $0.50 \mathrm{mg}$ vitamin B6, $1.50 \mathrm{mcg}$ vitamin B12, $5.0 \mathrm{mg}$ niacin, $100 \mathrm{mg}$ choline, $75 \mathrm{mcg}$ biotin, $2.5 \mathrm{mg}$ pantothenic acid, $200 \mathrm{mg}$ sodium, $370 \mathrm{mg}$ potassium, $310 \mathrm{mg}$ chloride, $300 \mathrm{mg}$ calcium, $300 \mathrm{mg}$ phosphorus, $100 \mathrm{mg}$ magnesium, $38 \mathrm{mcg}$ iodine, $1.3 \mathrm{mg}$ manganese, $0.50 \mathrm{mg}$ copper, $3.8 \mathrm{mg}$ zinc, $4.5 \mathrm{mg}$ iron, $18 \mathrm{mcg}$ selenium, $30 \mathrm{mcg}$ chromium, 38 mcg molybdenum

Allocated: $22 / 24$

Assessed: $18 / 20$ for length of stay

Outcomes Length of follow-up: 3 months

Main outcomes:

Mortality

Morbidity: complications (nr), adverse events (nr)

Length of rehabilitation hospital stay

Location for discharge

Postoperative functional status: mobility subscale of FIM instrument (Uniform Data System for Medical

Rehabilitation)

Other outcomes:

Days of supplement consumption

Notes

Request for further details (mortality, denominators for length of stay, complications) sent 13 October 2004. Details of mortality and denominators received 06 January 2005

\section{Risk of bias}

Bias Authors' judgement Support for judgement

Random sequence genera- Unclear risk tion (selection bias) 
Neumann 2004 (Continued)

Allocation concealment Unclear risk No information other than: "randomized, double-blind, parallel-group study" (selection bias)

Blinding of participants Unclear risk States double-blind but no further details
and personnel (perfor-
mance bias)
All outcomes

\begin{tabular}{|c|c|c|}
\hline $\begin{array}{l}\text { Blinding of outcome as- } \\
\text { sessment (detection bias) } \\
\text { Primary outcomes }\end{array}$ & Low risk & States double-blind and unlikely to have been influenced by lack of blinding \\
\hline
\end{tabular}

\begin{tabular}{|c|c|c|}
\hline $\begin{array}{l}\text { Blinding of outcome as- } \\
\text { sessment (detection bias) } \\
\text { Secondary and other out- } \\
\text { comes }\end{array}$ & Unclear risk & $\begin{array}{l}\text { States double-blind but no further details, and may have been influenced by } \\
\text { lack of blinding }\end{array}$ \\
\hline
\end{tabular}

\begin{tabular}{lll}
\hline $\begin{array}{l}\text { Incomplete outcome data } \\
\text { (attrition bias) } \\
\text { Primary outcomes }\end{array}$ & Unclear risk & No details on denominators for complications provided \\
\hline $\begin{array}{l}\text { Incomplete outcome data } \\
\text { (attrition bias) }\end{array}$ & High risk & $\begin{array}{l}\text { Length of stay data for } 4 \text { participants on Boost, and } 4 \text { on Ensure not provided. } \\
\text { Numbers for purported adverse events, mobility and discharge destination not } \\
\text { provided }\end{array}$ \\
comes & &
\end{tabular}

\begin{tabular}{lll}
\hline $\begin{array}{l}\text { Selective reporting (re- } \\
\text { porting bias) }\end{array}$ & Unclear risk & Insufficient details provided \\
\hline Other bias & High risk & Part funded by Mead Johnson, manufacturer of Boost HP \\
\hline
\end{tabular}

Papaioannou 2011

\begin{tabular}{|c|c|}
\hline Methods & $\begin{array}{l}\text { Method of randomisation: randomised in blocks according to computer-generated randomisation, in- } \\
\text { patient pharmacy co-ordinated the randomisation and drug distribution } \\
\text { Intention-to-treat analysis: not carried out } \\
\text { Lost to follow-up: } 18 / 65 \text { lost to follow-up }\end{array}$ \\
\hline Participants & $\begin{array}{l}\text { Location: two academic hospital sites, Hamilton, Ontario, Canada } \\
\text { Period of study: October 2007-April } 2009 \\
65 \text { participants } \\
\text { Inclusion criteria: over age } 50 \text { with an acute fragility hip fracture (defined as femoral neck, trochanteric, } \\
\text { subtrochanteric or subcapital) which was the result of a minimal trauma accident, defined as a fall } \\
\text { from standing height or less } \\
\text { Exclusion criteria: pelvic fractures; pathological fractures secondary to malignancy or intrinsic bone } \\
\text { disease (e.g. Paget's disease); pre-existing bone abnormality; cancer in the past } 10 \text { years likely to } \\
\text { metastasize to bone; renal insufficiency (creatinine < } 30 \text { mls/min); renal stones in past } 10 \text { years; hyper- } \\
\text { calcaemia (primary hyperparathyroidism; granulomatous diseases); hypocalcaemia; stroke within the } \\
\text { last } 3 \text { months; or had taken hormone replacement therapy, calcitonin, bisphosphates, raloxifene, or } \\
\text { parathyroid hormone during the previous } 24 \text { months; admitted from long-term care facilities/nursing } \\
\text { homes }\end{array}$ \\
\hline
\end{tabular}


Papaioannou 2011 (Continued)

Sex: 36 female, 25 male

Age: mean 69 years

Fracture type: further details not given

Interventions Timing of intervention: day 1 for $90 \mathrm{~d}$

(a) Oral placebo bolus day 1 , then a daily tablet of $1000 \mathrm{IU}$ vitamin D3 for $90 \mathrm{~d}$

(b) 50,000 IU vitamin D2 oral bolus day 1, then a daily tablet of 1000 IU vitamin D3 for $90 \mathrm{~d}$

(c) 100,000 IU vitamin D2 oral bolus day 1, then a daily tablet of 1000 IU vitamin D3 for $90 \mathrm{~d}$

Allocated: $22 / 22 / 21$

Assessed: $12 / 18 / 17$ at $90 \mathrm{~d}$

\begin{tabular}{ll}
\hline Outcomes & Length of follow-up: $90 \mathrm{~d}$ \\
& Main outcomes: \\
& Mortality \\
& Adverse events \\
& Other outcomes: \\
Compliance & \\
\hline Notes & Emailed PAPAIOANNOU@HHSC.CA 6 November 2014 for details of allocation of participants who died \\
\end{tabular}

\section{Risk of bias}

\begin{tabular}{|c|c|c|}
\hline Bias & Authors' judgement & Support for judgement \\
\hline $\begin{array}{l}\text { Random sequence genera- } \\
\text { tion (selection bias) }\end{array}$ & Low risk & $\begin{array}{l}\text { States "Patients were randomized in blocks according to a computer-generat- } \\
\text { ed randomization list" }\end{array}$ \\
\hline $\begin{array}{l}\text { Allocation concealment } \\
\text { (selection bias) }\end{array}$ & Low risk & $\begin{array}{l}\text { States "The central in-patient pharmacy at McMaster University Medical Cen- } \\
\text { tre coordinated the randomization procedure and the distribution of study } \\
\text { drugs" }\end{array}$ \\
\hline $\begin{array}{l}\text { Blinding of participants } \\
\text { and personnel (perfor- } \\
\text { mance bias) } \\
\text { All outcomes }\end{array}$ & Low risk & $\begin{array}{l}\text { Blinded, placebo-controlled trial and states "The medication treatment group } \\
\text { was concealed and all participants, study coordinators, physicians, staff, and } \\
\text { caregivers were blinded to treatment group allocation" }\end{array}$ \\
\hline $\begin{array}{l}\text { Blinding of outcome as- } \\
\text { sessment (detection bias) } \\
\text { Primary outcomes }\end{array}$ & Low risk & $\begin{array}{l}\text { Blinded, placebo-controlled trial and states "The medication treatment group } \\
\text { was concealed and all participants, study coordinators, physicians, staff, and } \\
\text { caregivers were blinded to treatment group allocation" }\end{array}$ \\
\hline $\begin{array}{l}\text { Blinding of outcome as- } \\
\text { sessment (detection bias) } \\
\text { Secondary and other out- } \\
\text { comes }\end{array}$ & Low risk & $\begin{array}{l}\text { Blinded, placebo-controlled trial and states "The medication treatment group } \\
\text { was concealed and all participants, study coordinators, physicians, staff, and } \\
\text { caregivers were blinded to treatment group allocation" }\end{array}$ \\
\hline $\begin{array}{l}\text { Incomplete outcome data } \\
\text { (attrition bias) } \\
\text { Primary outcomes }\end{array}$ & High risk & 18 participants from 65 lost to follow-up by 90 -d final follow-up \\
\hline
\end{tabular}


Papaioannou 2011 (Continued)
Incomplete outcome data
Unclear risk
18 participants from 65 lost to follow-up by 90 -day final follow-up

(attrition bias)

Secondary and other out-

comes

\begin{tabular}{lll}
\hline $\begin{array}{l}\text { Selective reporting (re- } \\
\text { porting bias) }\end{array}$ & Low risk & Principally a study of vitamin D dose responses and adverse events \\
\hline Other bias & High risk & $\begin{array}{l}\text { Signficant imbalance in age between two intervention groups (reported P = } \\
\text { 0.024). Study supported by Merck Frosst Canada Ltd }\end{array}$ \\
\end{tabular}

Parker 2010

\begin{tabular}{|c|c|}
\hline \multirow[t]{2}{*}{ Methods } & $\begin{array}{l}\text { Method of randomisation: sealed opaque numbered envelopes } \\
\text { Intention-to-treat analysis: undertaken }\end{array}$ \\
\hline & Lost to follow-up: no participants lost to follow-up \\
\hline
\end{tabular}

Participants
Lecation: Peterborough District Hospital, UK
300 participants
Inclusion criteria: postoperative haemoglobin level of $<110 \mathrm{~g} / \mathrm{L}$ within $5 \mathrm{~d}$ after hip fracture surgery.
Exclusion criteria: participant unwilling to give written informed consent or for whom the relative or
next of kin was unavailable or declined to give assent, postoperative haemoglobin level of $\ddagger 110 \mathrm{~g} / \mathrm{L}$,
multiple trauma (defined as either $>2$ other fractures or any other fracture requiring surgery other than
simple manipulation), participant unable to take oral iron medication because of adverse effects, par-
ticipant taking iron therapy at time of admission, haemoglobin level of $<110 \mathrm{~g} / \mathrm{L}$ at time of admission,
participant unable to attend routine follow-up in the hip fracture clinic, age of $<60$ years

Sex: 245 female, 55 male

Age: mean age 82 years

Fracture type: 45\% intracapsular fracture, 21\% intramedullary nail and 34\% extramedullary fixation (presumed not intracapsular fractures)

Interventions

Timing of intervention: immediately post-randomisation for $28 \mathrm{~d}$

(a) Oral iron therapy (ferrous sulphate, $200 \mathrm{mg}$ twice daily)

(b) No iron supplement

Allocated: $150 / 150$

Assessed: $150 / 150$ at 12 months

\begin{tabular}{l} 
Length of follow-up: 12 months \\
Main outcomes: \\
Mortality, \\
Hospital length of stay \\
Putative side effects of treatment \\
\hline
\end{tabular}


Parker 2010 (Continued)

Notes

Emailed Dr Martyn Parker (Martyn.Parker@pbh-tr.nhs.uk) 16 October 2014 about further details on length of hospital stay data, reply received 16 October 2014

\section{Risk of bias}

\begin{tabular}{lll}
\hline Bias & Authors' judgement & Support for judgement \\
\hline $\begin{array}{l}\text { Random sequence genera- } \\
\text { tion (selection bias) }\end{array}$ & Unclear risk & No details provided on sequence generation \\
\hline $\begin{array}{l}\text { Allocation concealment } \\
\text { (selection bias) }\end{array}$ & Low risk & $\begin{array}{l}\text { States "randomization was accomplished by opening a sealed opaque num- } \\
\text { bered envelope for each patient" }\end{array}$ \\
\hline $\begin{array}{l}\text { Blinding of participants } \\
\begin{array}{l}\text { and personnel (perfor- } \\
\text { mance bias) }\end{array}\end{array}$ & High risk & No placebo group \\
All outcomes & & \\
\hline
\end{tabular}

\begin{tabular}{l}
\hline $\begin{array}{l}\text { Blinding of outcome as- } \\
\text { sessment (detection bias) }\end{array}$ \\
\begin{tabular}{l} 
Primary outcomes \\
\hline
\end{tabular}
\end{tabular}

Blinding of outcome as- $\quad$ Unclear risk No placebo group. Comment: may have been influenced by unblinding
sessment (detection bias)
Secondary and other out-
comes

Incomplete outcome data Low risk Data for all participants randomised provided
(attrition bias)
Primary outcomes

\begin{tabular}{|c|c|c|}
\hline $\begin{array}{l}\text { Incomplete outcome data } \\
\text { (attrition bias) } \\
\text { Secondary and other out- } \\
\text { comes }\end{array}$ & Unclear risk & $\begin{array}{l}\text { 13/150 discontinued iron therapy in intervention group and } 5 \text { in control group } \\
\text { commenced iron therapy. } 7 / 150 \text { in intervention group unable to attend outpa- } \\
\text { tient follow-up and } 16 / 150 \text { in control group likely to have influenced putative } \\
\text { side effects of treatment }\end{array}$ \\
\hline $\begin{array}{l}\text { Selective reporting (re- } \\
\text { porting bias) }\end{array}$ & Unclear risk & Study protocol not available and unclear if all expected outcomes provided \\
\hline Other bias & Low risk & $\begin{array}{l}\text { Non-pharmaceutical funding (funded by Peterborough Hospital Hip Fracture } \\
\text { Fund) }\end{array}$ \\
\hline
\end{tabular}

Prasad 2009

Methods Method of randomisation: randomised into 2 groups independently by a nurse practitioner using computer-generated random numbers

Intention-to-treat analysis: 2 participants excluded for moving out of area

Lost to follow-up: 2 participants lost to follow-up

Larticipants
Period of study: recruitment February 2005-October 2005
68 participants


Prasad 2009 (Continued)

Inclusion criteria: acute hip fracture confirmed on X-ray, postoperative anaemia (( $\mathrm{Hb}$ between 8-12 g\% in men and $8-11 \mathrm{~g} \%$ in women).

Exclusion criteria: pre-operative serum ferritin less than $15 \mathrm{mg} / \mathrm{l}$ or more than $200 \mathrm{mg} / \mathrm{l}$, admission CRP $>3$, serum iron/total iron binding capacity ratio $(T I B C)<15, T I B C>60$, already on iron tablets, pre-existing anaemic disorders, underlying medical conditions (malignancy, chronic renal failure, inflammatory bowel disease, chronic peptic ulcer, oesophageal varices, rheumatoid arthritis), medication interfering with iron absorption e.g. antacids, tetracyclines, bisphosphates; no consent

Sex: 55 female, 11 male

Age: mean age 82 years

Fracture type: 53\% intertrochanteric fracture, $47 \%$ cervical

Interventions Timing of intervention: from 2 nd postoperative day for 4 weeks

(a) Oral iron therapy (ferrous sulphate, $200 \mathrm{mg}$ three times daily)

(b) No iron supplement

Allocated: ?/?

Assessed: $32 / 34$ at 4 weeks

\begin{tabular}{ll}
\hline Outcomes & Length of follow-up: 4 weeks \\
& Main outcomes: \\
& Putative side effects of supplements \\
\hline Notes & Emailed Mr Prasad (nport@yahoo.com) 24 October 2014 about further details on outcomes, replied 24 \\
& October 2014 indicating "no deaths or any other complications" in the study or control group
\end{tabular}

\section{Risk of bias}

\begin{tabular}{|c|c|c|}
\hline Bias & Authors' judgement & Support for judgement \\
\hline $\begin{array}{l}\text { Random sequence genera- } \\
\text { tion (selection bias) }\end{array}$ & Low risk & States used "using computer generated random numbers" \\
\hline $\begin{array}{l}\text { Allocation concealment } \\
\text { (selection bias) }\end{array}$ & Unclear risk & $\begin{array}{l}\text { States "the patients were then randomised into two groups; independently } \\
\text { by a nurse practitioner using computer generated random numbers...The ran- } \\
\text { domisation was implemented by the senior author (JM)." }\end{array}$ \\
\hline $\begin{array}{l}\text { Blinding of participants } \\
\text { and personnel (perfor- } \\
\text { mance bias) } \\
\text { All outcomes }\end{array}$ & High risk & No placebo group. Comment: likely to have been influenced by lack of blinding \\
\hline $\begin{array}{l}\text { Blinding of outcome as- } \\
\text { sessment (detection bias) } \\
\text { Primary outcomes }\end{array}$ & High risk & $\begin{array}{l}\text { Putative adverse events only primary outcome reported and data only report- } \\
\text { ed for intervention group, clinical staff also not blinded, although states "first } \\
\text { author was blinded" }\end{array}$ \\
\hline $\begin{array}{l}\text { Incomplete outcome data } \\
\text { (attrition bias) } \\
\text { Primary outcomes }\end{array}$ & High risk & $\begin{array}{l}\text { Data for putative adverse events only provided for intervention group, also } \\
\text { two participants of unknown allocation excluded }\end{array}$ \\
\hline $\begin{array}{l}\text { Selective reporting (re- } \\
\text { porting bias) }\end{array}$ & Unclear risk & Insufficient details provided \\
\hline
\end{tabular}


Prasad 2009 (Continued)

Other bias Unclear risk Insufficient details provided

\section{Schürch 1998}

$\begin{array}{ll}\text { Methods } & \text { Method of randomisation: states random number table and double-blind study, but unclear if those } \\ \text { who assigned were blinded } \\ \text { Intention-to-treat analysis: unclear } \\ \text { Lost to follow-up: incomplete report of drop outs } \\ \text { Location: orthopaedic ward in hospital and recovery hospital, Geneva, Switzerland } \\ \text { Period of study: April 1992-February } 1994 \\ 82 \text { participants } \\ \text { Inclusion criteria: hip fracture within } 2 \text { weeks attributable to osteoporosis (minor trauma), aged over } \\ 60 \text { years, able to give written consent } \\ \text { Exclusion criteria: pathological fracture; fracture caused by severe trauma; history of contralateral hip } \\ \text { fracture; severe mental impairment; active metabolic bone disease; renal failure (plasma creatinine } \\ \text { equal to or greater than } 200 \text { mcmol/L); acute illness that could interfere with study protocol; severe } \\ \text { malnutrition (serum albumin less than } 15 \mathrm{~g} / \mathrm{L}) ; \text { on drugs known to alter bone metabolism, e.g. calci- } \\ \text { tonin, fluoride, sex hormones, corticosteroids, bisphosphates; life expectancy less than } 1 \text { year } \\ \text { Sex: } 74 \text { female, } 8 \text { male } \\ \text { Age: mean } 80.7 \text { years } \\ \text { Fracture type: } 31 \text { cervical, } 51 \text { trochanteric }\end{array}$

Interventions

Timing of intervention: mean randomisation time 6.5 (SD 1.9) $\mathrm{d}$ after fracture, supplemented $5 \mathrm{~d}$ a week for 6 months

(a) Oral protein supplement (1.05 MJ or $250 \mathrm{kcal}, 20 \mathrm{~g}$ protein, $3.1 \mathrm{~g}$ fat, $35.7 \mathrm{~g}$ carbohydrate, $1000 \mathrm{IU}$ vitamin A, 30 mcg vitamin K1, $20 \mathrm{mg}$ vitamin C, $550 \mathrm{mg}$ calcium, $91 \mathrm{mg}$ magnesium, $429 \mathrm{mg}$ phosphorus, $228 \mathrm{mg}$ sodium) plus oral 200,000 IU vitamin D3 once at baseline during study

(b) Placebo without protein made isocaloric by addition of maltodextrins, plus oral 200,000 IU vitamin D3 once at baseline during study

Allocated: $41 / 41$

Assessed: ?/?

\begin{tabular}{|c|c|c|}
\hline Outcomes & \multicolumn{2}{|c|}{$\begin{array}{l}\text { Length of follow-up: } 12 \text { months } \\
\text { Main outcomes: } \\
\text { Mortality } \\
\text { Length of stay: orthopaedic ward, rehabilitation stay } \\
\text { Postoperative functional status: activities of daily living score } \\
\text { Putative side effects: drop outs due to nausea and diarrhoea } \\
\text { Other outcomes: } \\
\text { Patient compliance: refusals }\end{array}$} \\
\hline Notes & \multicolumn{2}{|c|}{$\begin{array}{l}\text { Composition of placebo unclear, denominators not clear. Request for further details sent } 27 \text { May } 1999 \text {, } \\
\text { re-sent } 7 \text { February } 2000\end{array}$} \\
\hline \multicolumn{3}{|l|}{ Risk of bias } \\
\hline Bias & Authors' judgement & Support for judgement \\
\hline $\begin{array}{l}\text { Random sequence genera- } \\
\text { tion (selection bias) }\end{array}$ & Unclear risk & "Using a random number table", no further details provided \\
\hline $\begin{array}{l}\text { Allocation concealment } \\
\text { (selection bias) }\end{array}$ & Unclear risk & $\begin{array}{l}\text { "Using a random number table, we assigned ..." } \\
\text { Although "double-blind", it is unclear whether allocation was concealed }\end{array}$ \\
\hline
\end{tabular}


Schürch 1998 (Continued)

Blinding of participants Low risk Oral protein supplement and placebo made isocaloric, states "double-blind". and personnel (perforComment: probably done mance bias)

All outcomes

\begin{tabular}{|c|c|c|}
\hline $\begin{array}{l}\text { Blinding of outcome as- } \\
\text { sessment (detection bias) }\end{array}$ & Low risk & $\begin{array}{l}\text { Oral protein supplement and placebo made isocaloric, states "double-blind" } \\
\text { and unlikely to be influenced by unblinding. Comment: probably done }\end{array}$ \\
\hline
\end{tabular}

\begin{tabular}{|c|c|c|}
\hline $\begin{array}{l}\text { Blinding of outcome as- } \\
\text { sessment (detection bias) } \\
\text { Secondary and other out- } \\
\text { comes }\end{array}$ & Unclear risk & $\begin{array}{l}\text { Oral protein supplement and placebo made isocaloric, states "double-blind" } \\
\text { and may have been influenced by unblinding as no details on who assessed } \\
\text { outcomes }\end{array}$ \\
\hline
\end{tabular}

\begin{tabular}{lll}
\hline $\begin{array}{l}\text { Incomplete outcome data } \\
\text { (attrition bias) } \\
\text { Primary outcomes }\end{array}$ & Low risk & $\begin{array}{l}\text { All participants accounted for and drop-outs do not appear to differ between } \\
\text { groups }\end{array}$ \\
\hline $\begin{array}{l}\text { Incomplete outcome data } \\
\text { (attrition bias) } \\
\begin{array}{l}\text { Secondary and other out- } \\
\text { comes }\end{array}\end{array}$ & Unclear risk & No denominators for lengths of stay, activities of daily living unclear \\
\hline $\begin{array}{l}\text { Selective reporting (re- } \\
\text { porting bias) }\end{array}$ & Unclear risk & Insufficient details provided \\
\hline Other bias & High risk & Study supported by Sandoz Nutrition Ltd \\
\hline
\end{tabular}

Scivoletto 2010

\begin{tabular}{|c|c|}
\hline Methods & $\begin{array}{l}\text { Method of randomisation: multicentre, randomised, open-label clinical trial } \\
\text { Intention-to-treat analysis: not carried out, exclusions for poor compliance } \\
\text { Lost to follow-up: } 50 \% \text { lost to follow-up }\end{array}$ \\
\hline Participants & $\begin{array}{l}\text { Location: hospitals, Milan, Italy } \\
\text { Period of study: up to } 2009 \\
107 \text { participants } \\
\text { Inclusion criteria: Men and women > } 65 \text { y of age with hip fracture who were eligible for surgery } \\
\text { Exclusion criteria: dementia; inability to follow instructions; swallowing difficulties; complex 'patholog- } \\
\text { ical' fractures } \\
\text { Sex: } 90 \text { female, } 17 \text { male } \\
\text { Age: mean } 80 \text { years } \\
\text { Fracture type: } 31 \% \text { intracapsular, } 69 \% \text { extracapsular }\end{array}$ \\
\hline
\end{tabular}


Scivoletto 2010 (Continued)

(b) No intervention

Allocated: 54/53

Assessed: 27/26

\begin{tabular}{ll}
\hline Outcomes & Length of follow-up: 16 weeks \\
Main outcomes: & Length of acute hospital stay \\
& Time to ambulation \\
Complications: pressure sores \\
Functional status: participants reaching a functional recovery \\
\hline Notes & Italian speaker (Miriam Brazzelli) extracted data. Funder unclear
\end{tabular}

\section{Risk of bias}

\begin{tabular}{lll}
\hline Bias & Authors' judgement & Support for judgement \\
\hline $\begin{array}{l}\text { Random sequence genera- } \\
\text { tion (selection bias) }\end{array}$ & Unclear risk & Randomised trial, no further details \\
\hline $\begin{array}{l}\text { Allocation concealment } \\
\text { (selection bias) }\end{array}$ & Unclear risk & Randomised trial, no further details \\
\hline $\begin{array}{l}\text { Blinding of participants } \\
\text { and personnel (perfor- } \\
\text { mance bias) } \\
\text { All outcomes }\end{array}$ & High risk & No placebo group. Comment: likely to have been influenced by lack of blinding \\
\hline
\end{tabular}

\begin{tabular}{|c|c|c|}
\hline $\begin{array}{l}\text { Blinding of outcome as- } \\
\text { sessment (detection bias) } \\
\text { Primary outcomes }\end{array}$ & Low risk & $\begin{array}{l}\text { No placebo group. Comment: unlikely to have been influenced by lack of } \\
\text { blinding }\end{array}$ \\
\hline
\end{tabular}

Blinding of outcome as- $\quad$ Unclear risk No placebo group. Comment: may have been influenced by lack of blinding
sessment (detection bias)
Secondary and other out-
comes

\begin{tabular}{ll}
\hline $\begin{array}{l}\text { Incomplete outcome data } \\
\text { (attrition bias) }\end{array}$ & High risk
\end{tabular} $\begin{aligned} & \begin{array}{l}50 \% \text { lost to follow-up, including protocol violations, and because of clinical } \\
\text { complications }\end{array} \\
& \text { Primary outcomes }\end{aligned}$

\begin{tabular}{lll}
\hline $\begin{array}{l}\text { Incomplete outcome data } \\
\text { (attrition bias) }\end{array}$ & High risk & $\begin{array}{l}50 \% \text { lost to follow-up, including protocol violations, and because of clinical } \\
\text { complications }\end{array}$ \\
$\begin{array}{l}\text { Secondary and other out- } \\
\text { comes }\end{array}$ & \\
\hline $\begin{array}{l}\text { Selective reporting (re- } \\
\text { porting bias) }\end{array}$ & Unclear risk & Insufficient details to assess, unusual for no mortality to be reported \\
\hline Other bias & Unclear risk & Italian speaker (Miriam Brazzelli) extracted data. Funder unclear \\
\hline
\end{tabular}


Intention-to-treat analysis: not undertaken (4 participants excluded from analysis as died before surgery although received intervention)

Lost to follow-up: all participants accounted for

Participants

Location: Orthopedic and Trauma Surgery Unit of the Hospital Reina Sofia in Córdoba, Spain

Period of study: October 2006-October 2008

200 participants

Inclusion criteria: aged over 65 years, surgical management of hip fracture

Exclusion criteria: diseases diagnosed before the admission of participant (iron overload disorders, hypersensitivity to oral or parenteral iron preparations, asthma or other severe atopic, active infection or neoplasm), treatment with clopidogrel or with acetylsalicylic acid at dose rates greater than $150 \mathrm{mg} / 24$ $\mathrm{h}$, no surgical indication for the current fracture, disorders impaired coagulation (partial thromboplastin time $>2.5 \%$, international normalised ratio $>1.5$ ), liver disorders with elevated transaminases (aspartase aminotransferase $>70 \mathrm{U} / \mathrm{L}$, alanine aminotransferase $>55 \mathrm{U} / \mathrm{L}$ ), and chronic kidney failure (creatinine $>2 \mathrm{mg} / \mathrm{dL}$ ) or patients including in dialysis.

Sex: all female

Age: mean 83 years

Fracture type: $35 \%$ intracapsular fracture, $65 \%$ extracapsular fracture

Interventions

Timing of intervention: first dose was administered in the first $24 \mathrm{~h}$ after admission, always before surgical intervention. The following doses were administered before or after surgery, depending on the time of surgery.

(a) $600 \mathrm{mg}$ of iron sucrose IV (Venofer,Vifor France Company, Levallois-Perret, France) in 3 doses of 200 $\mathrm{mg}$ at 48 -h intervals, starting on the day of admission; administration was by slow perfusion of two 100$\mathrm{mg}$ ampoules diluted in $250 \mathrm{~mL}$ of $0.9 \%$ saline solution over a 90 -min period

(b) no iron supplement

Allocated: $100 / 100$

Assessed: $99 / 97$ at $30 \mathrm{~d}$ post discharge

Length of follow-up: $30 \mathrm{~d}$ post discharge
Main outcomes:
Mortality
Complications including infections
Length of acute hospital stay
Purported side effects of treatment

Notes Emailed jserranot@gmail.com on 4 November 2014 to clarify length of stay data which differ between text and table. Data from table used for review as no reply

\section{Risk of bias}

Bias Authors' judgement Support for judgement


Serrano-Trenas 2011 (Continued)

Random sequence genera- Unclear risk tion (selection bias)
States "Randomization lists were generated in blocks of 10 to ensure equal group sizes, and allocation was made using sequentially numbered opaque sealed envelopes, so that neither the patient nor the investigator could know which group the subject was assigned to before his or her consent to participation." Comment: sequence generation unclear.

Allocation concealment Low risk
(selection bias)

States "Randomization lists were generated in blocks of 10 to ensure equal group sizes, and allocation was made using sequentially numbered opaque sealed envelopes, so that neither the patient nor the investigator could know which group the subject was assigned to before his or her consent to participation."

\begin{tabular}{|c|c|c|}
\hline $\begin{array}{l}\text { Blinding of participants } \\
\text { and personnel (perfor- } \\
\text { mance bias) } \\
\text { All outcomes }\end{array}$ & High risk & No placebo group \\
\hline $\begin{array}{l}\text { Blinding of outcome as- } \\
\text { sessment (detection bias) }\end{array}$ & Low risk & $\begin{array}{l}\text { No placebo group. Comment: unlikely to have been influenced by lack of } \\
\text { blinding }\end{array}$ \\
\hline
\end{tabular}

\begin{tabular}{|c|c|c|}
\hline $\begin{array}{l}\text { Blinding of outcome as- } \\
\text { sessment (detection bias) } \\
\text { Secondary and other out- } \\
\text { comes }\end{array}$ & Unclear risk & No placebo group. Comment: may have been influenced by lack of blinding \\
\hline $\begin{array}{l}\text { Incomplete outcome data } \\
\text { (attrition bias) } \\
\text { Primary outcomes }\end{array}$ & High risk & $\begin{array}{l}3 \text { participants in control group and } 1 \text { participant in intervention group exclud- } \\
\text { ed as died before surgery although may have had intervention, purported ad- } \\
\text { verse events from iron only provided for intervention group }\end{array}$ \\
\hline $\begin{array}{l}\text { Incomplete outcome data } \\
\text { (attrition bias) } \\
\text { Secondary and other out- } \\
\text { comes }\end{array}$ & High risk & $\begin{array}{l}3 \text { participants in control group and } 1 \text { participant in intervention group exclud- } \\
\text { ed as died before surgery although may have had intervention, purported ad- } \\
\text { verse events from iron only provided for intervention group }\end{array}$ \\
\hline $\begin{array}{l}\text { Selective reporting (re- } \\
\text { porting bias) }\end{array}$ & Low risk & $\begin{array}{l}\text { Study protocol not available, but all reported and expected outcomes provid- } \\
\text { ed }\end{array}$ \\
\hline Other bias & Low risk & Funded by the Spanish Ministry of Health and Consumer Affairs \\
\hline
\end{tabular}

\section{Stableforth 1986}

\begin{tabular}{ll}
\hline Methods & Method of randomisation: not stated \\
Intention-to-treat analysis: 3 excluded, intention-to-treat analysis not possible \\
Lost to follow-up: none
\end{tabular}


Stableforth 1986 (Continued)

Interventions
Timing of intervention: started after surgery and 24-36 h of crystalloid intravenous fluids. Intervention provided during waking hours for $10 \mathrm{~d}$

(a) Encouraged to drink flavoured, Carnation Instant Breakfast in $300 \mathrm{ml}$ milk (1.34 MJ or $320 \mathrm{kcal}, 18.5$

$\mathrm{g}$ protein, $11 \mathrm{~g}$ fat, $40 \mathrm{~g}$ carbohydrate, vitamins and minerals) plus ward diet

(b) Ward diet alone

Allocated: ?/? 61 in all

Assessed: ?/? 61 in all

\begin{tabular}{ll}
\hline Outcomes & Length of follow-up: 4 weeks \\
& Main outcomes: \\
& Mortality: all causes \\
& Morbidity and complications: anaesthetic, surgical infection, gastrointestinal, urinary \\
\hline Notes & Limited functional outcomes. \\
& Request for further details, especially on longer-term follow-up, sent 13 April 1999, re-sent 7 February \\
& 2000
\end{tabular}

\section{Risk of bias}

\begin{tabular}{lll}
\hline Bias & Authors' judgement & Support for judgement \\
\hline $\begin{array}{l}\text { Random sequence genera- } \\
\text { tion (selection bias) }\end{array}$ & Unclear risk & $\begin{array}{l}\text { States "randomly selected group of 24 patients were encouraged to drink liq- } \\
\text { uid supplement feeds" }\end{array}$ \\
\hline $\begin{array}{l}\text { Allocation concealment } \\
\text { (selection bias) }\end{array}$ & Unclear risk & $\begin{array}{l}\text { States "randomly selected group of 24 patients were encouraged to drink liq- } \\
\text { uid supplement feeds" }\end{array}$ \\
\hline $\begin{array}{l}\text { Blinding of participants } \\
\text { and personnel (perfor- } \\
\text { mance bias) } \\
\text { All outcomes }\end{array}$ & High risk & No placebo group \\
\hline
\end{tabular}

Blinding of outcome as-
sessment (detection bias) $\quad$ Low risk likely to have been influenced by lack of blinding

Primary outcomes

Blinding of outcome as- Unclear risk No placebo group. Comment: may not have been done

sessment (detection bias)

Secondary and other out-

comes

\begin{tabular}{|c|c|c|}
\hline $\begin{array}{l}\text { Incomplete outcome data } \\
\text { (attrition bias) } \\
\text { Primary outcomes }\end{array}$ & Unclear risk & Insufficient details on attrition and exclusions provided \\
\hline $\begin{array}{l}\text { Incomplete outcome data } \\
\text { (attrition bias) } \\
\text { Secondary and other out- } \\
\text { comes }\end{array}$ & Unclear risk & Insufficient details on attrition and exclusions provided \\
\hline $\begin{array}{l}\text { Selective reporting (re- } \\
\text { porting bias) }\end{array}$ & Unclear risk & Insufficient details provided \\
\hline Other bias & High risk & $\begin{array}{l}\text { Imbalance in weights: trochanteric fracture and subcapital fixation supple- } \\
\text { mented group mean } 65 \mathrm{~kg} \text {, controls } 53 \mathrm{~kg}\end{array}$ \\
\hline
\end{tabular}


Sullivan 1998

\begin{tabular}{ll}
\hline Methods & Method of randomisation: sealed opaque envelopes opened sequentially \\
Intention-to-treat analysis: appears so \\
Lost to follow-up: none, all participants accounted for
\end{tabular}

Interventions

Timing of intervention: small-bore nasogastric feeding tube placed in theatre or recovery room. Feeding started postoperatively, nightly from 19:00 hours, until volitional intake greater than $90 \%$ of predicted requirements for 3 consecutive days or participant discharged home

(a) Nasogastric feeding via small bowel (or more proximally if low risk of aspiration): $1375 \mathrm{ml}$ of polymeric enteral formula (Promote, Ross Laboratories, 85.8 g protein, $4.31 \mathrm{MJ}$ or $1031 \mathrm{kcal}$ non-nitrogenous energy, $71.5 \mathrm{~g}$ carbohydrate, $35.8 \mathrm{~g}$ fat, $88 \mathrm{mcg}$ vitamin $\mathrm{K}, 77 \mathrm{mcg}$ selenium, $110 \mathrm{mcg}$ chromium, $165 \mathrm{mcg}$ molybdenum, $165 \mathrm{mg}$ carnitine, $165 \mathrm{mg}$ taurine), given at $125 \mathrm{ml} / \mathrm{h}$ over $11 \mathrm{~h}$, plus standard care of 3 meals daily

(b) Standard care of 3 meals daily

Allocated: $8 / 10$

Assessed: $8 / 7$ for discharge statistics

Length of follow-up: 6 months
Main outcomes:
Mortality: in hospital and at 6 months
Morbidity and complications: postoperative life-threatening and minor complications
Length of stay: total acute care stay for survivors
Postoperative functional status: mini mental state exam score, Katz index of activities of daily living
Care required after discharge: discharge to institution, total number of medications
Putative side effects of treatment: gastrointestinal
Other outcomes:
Average daily volitional energy intake over first 7 postoperative days
Pilot study
Request for further details (such as control group denominators) sent. Reply from trialists (10 February
2000) gave further details of randomisation, place of care, complications, mortality, volitional food in-
take, nature of fracture, and content of supplement

\section{Risk of bias}

\begin{tabular}{lll}
\hline Bias & Authors' judgement & Support for judgement \\
\hline $\begin{array}{l}\text { Random sequence genera- } \\
\text { tion (selection bias) }\end{array}$ & Unclear risk & $\begin{array}{l}\text { Information from trialists "The actual randomization was prepared by the bio- } \\
\text { statistician..". No other details provided }\end{array}$ \\
\hline $\begin{array}{l}\text { Allocation concealment } \\
\text { (selection bias) }\end{array}$ & Low risk & $\begin{array}{l}\text { "The actual randomization was prepared by the biostatistician... using sealed } \\
\text { envelopes. Security (lined) envelopes were used to assure that the assignment } \\
\text { cannot be read without opening the envelope. After consent had been ob- } \\
\text { tained and the baseline assessment was completed, the next envelope was } \\
\text { opened to reveal the group assignment ..." Information from trialists }\end{array}$ \\
\hline
\end{tabular}

Blinding of participants High risk No placebo group. Comment: likely to have been influenced by lack of blinding and personnel (performance bias) 
Sullivan 1998 (Continued)

All outcomes

\begin{tabular}{|c|c|c|}
\hline $\begin{array}{l}\text { Blinding of outcome as- } \\
\text { sessment (detection bias) }\end{array}$ & Low risk & $\begin{array}{l}\text { No placebo group. Comment: unlikely to have been influenced by lack of } \\
\text { blinding }\end{array}$ \\
\hline
\end{tabular}

Primary outcomes

Blinding of outcome as- $\quad$ Unclear risk No placebo group. Comment: may have been influenced by lack of blinding
sessment (detection bias)
Secondary and other out-
comes

\begin{tabular}{lll}
\hline $\begin{array}{l}\text { Incomplete outcome data } \\
\text { (attrition bias) } \\
\text { Primary outcomes }\end{array}$ & Low risk & \\
\hline $\begin{array}{l}\text { Incomplete outcome data } \\
\text { (attrition bias) } \\
\begin{array}{l}\text { Secondary and other out- } \\
\text { comes }\end{array}\end{array}$ & Low risk & All participants accounted for, with no dropouts \\
\hline $\begin{array}{l}\text { Selective reporting (re- } \\
\text { porting bias) }\end{array}$ & Unclear risk & No protocol available and insufficient details available \\
\hline $\begin{array}{l}\text { Other bias } \\
\text { High risk }\end{array}$ & $\begin{array}{l}\text { Funding from Ross Laboratories, who manufactured the nasogastric feed, and } \\
\text { Department of Veterans Affairs }\end{array}$ \\
\hline
\end{tabular}

Sullivan 2004

$\begin{array}{ll}\text { Methods } & \text { Method of randomisation: sealed opaque envelopes opened sequentially } \\ \text { Intention-to-treat analysis: appears so } \\ \text { Lost to follow-up: details given }\end{array}$

Participants
Rock, Arkansas, USA
Period of study: recruitment June 1996-October 1997
57 participants
Inclusion criteria: over 64 years, acute femoral neck or intertrochanteric fracture treated surgically
Exclusion criteria: incapable of informed consent and no legal guardian, pathological fracture (cancer
or not osteoporotic), significant trauma to other organ systems (e.g. motor vehicle accident), metasta-
tic cancer, cirrhosis, enteral feeding contraindicated (e.g. short bowel), organ failure making interven-
tion inappropriate
Sex: 18 female, 39 male
Age: mean age 79 years
Fracture type: 19 required endoprosthesis
Timing of intervention: small bore feeding tube placed within $12 \mathrm{~h}$ of surgery, confirmed by X-ray in
place until deficit between requirements and oral intake < $480 \mathrm{kcal} /$ day for at least 2 consecutive days
or until discharged Given nightly over $11 \mathrm{~h}$
(a) Harris-Benedict equation with stress and activity factors used to predict requirements to make up
deficit after food intake calculated - given as Promote (Ross Laboratories), $1000 \mathrm{kcal}, 62.5 \mathrm{~g}$ protein,
$130 \mathrm{~g}$ carbohydrate, $26 \mathrm{~g}$ fat per litre, if deficit $>480 \mathrm{kcal} /$ day. If deficit $240-480 \mathrm{kcal} / \mathrm{day}$, participant
asked to drink supplement instead of tube feeding. Tube feeding begun at 50 ml/hour and increased by
$25 \mathrm{ml} /$ hour to maximum of $125 \mathrm{ml} /$ hour. Given with standard care
(b) Standard care
Allocated: $27 / 30$
Assessed: $27 / 30$


Sullivan 2004 (Continued)
Outcomes
Length of follow-up: 6 months
Main outcomes:
Mortality
Morbidity: postoperative and postoperative life-threatening complications, diarrhoea
Length of hospital stay
Level of care: discharge to an institution, medications at discharge
Postoperative functional status: Katz index of activities of daily living, Mini Mental State Exam score
Other outcomes:
Energy intake

Notes

Request for further details on randomisation and tube feeding sent 15 March 2006. Reply, received 14

April 2006, gave further details of randomisation method

\title{
Risk of bias
}

\begin{tabular}{lll}
\hline Bias & Authors' judgement & Support for judgement \\
\hline $\begin{array}{l}\text { Random sequence genera- } \\
\text { tion (selection bias) }\end{array}$ & Low risk & $\begin{array}{l}\text { States that "The randomization process was prepared by the biostatisti- } \\
\text { cian...Subjects were randomized to either treatment or control within blocks } \\
\text { to assure that there were roughly equal numbers of subjects in each group at } \\
\text { the end of the study. The block sizes were randomly varied to minimize the } \\
\text { ability to deduce the assignment for a particular patient before opening the } \\
\text { envelope." Reply from trialists }\end{array}$
\end{tabular}

Allocation concealment Low risk
(selection bias)

(selection bias)

\begin{abstract}
"The randomization process was prepared by the biostatistician, using a series of sealed envelopes. Security (lined) envelopes were used to assure that the assignment could not be read without opening the envelope. After consent had been obtained and the baseline assessment was completed, the next envelope in order was opened to reveal the group assignment. Each envelope contained a card. The card had the assignment for treatment or control preprinted. Space was provided to enter the patient name and ID as well as the date, time and person responsible for randomization. The study nurse completed the card, photocopied it, and returned the original to the biostatistician as a check that the randomization process was progressing appropriately. Subjects were randomized to either treatment or control within blocks to assure that there were roughly equal numbers of subjects in each group at the end of the study. The block sizes were randomly varied to minimize the ability to deduce the assignment for a particular patient before opening the envelope." Reply from trialists
\end{abstract}

\begin{tabular}{|c|c|c|}
\hline $\begin{array}{l}\text { Blinding of participants } \\
\text { and personnel (perfor- } \\
\text { mance bias) } \\
\text { All outcomes }\end{array}$ & High risk & No placebo group. Comment: likely to have been influenced by lack of blinding \\
\hline $\begin{array}{l}\text { Blinding of outcome as- } \\
\text { sessment (detection bias) } \\
\text { Primary outcomes }\end{array}$ & Low risk & $\begin{array}{l}\text { No placebo group. Comment: unlikely to have been influenced by lack of } \\
\text { blinding }\end{array}$ \\
\hline $\begin{array}{l}\text { Blinding of outcome as- } \\
\text { sessment (detection bias) } \\
\text { Secondary and other out- } \\
\text { comes }\end{array}$ & Unclear risk & No placebo group. Comment: may have been influenced by lack of blinding \\
\hline $\begin{array}{l}\text { Incomplete outcome data } \\
\text { (attrition bias) } \\
\text { Primary outcomes }\end{array}$ & Low risk & No missing outcome data \\
\hline
\end{tabular}


Sullivan 2004 (Continued)

Incomplete outcome data Low risk Missing outcome data for one participant only in intervention group (attrition bias)

Secondary and other outcomes

\begin{tabular}{lll}
\hline $\begin{array}{l}\text { Selective reporting (re- } \\
\text { porting bias) }\end{array}$ & Low risk & No protocol available, but expected outcomes reported \\
\hline Other bias & High risk & $\begin{array}{l}\text { Control group more than } 5 \text { years older. Funded by a National Insititute on Ag- } \\
\text { ing Grant. Ross Laboratories supplied nutritional supplements and nasogastric } \\
\text { feeding tubes }\end{array}$ \\
\hline
\end{tabular}

Tidermark 2004

Methods Method of randomisation: numbered opaque sealed envelopes, unclear if randomisation fully concealed since the envelopes prepared and opened by the same research nurse

Assessor blinding: not reported

Intention-to-treat analysis: appears so

Lost to follow-up: details given

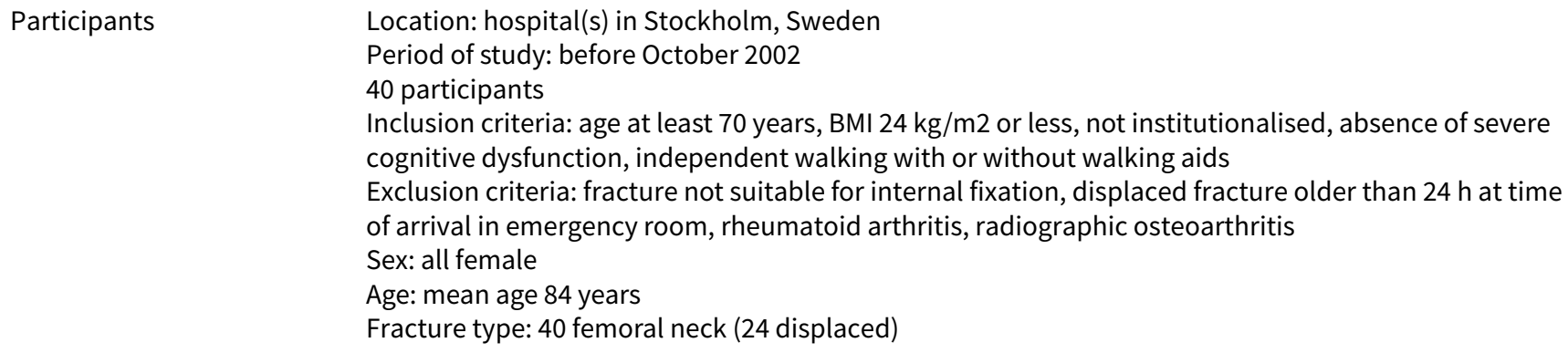

Interventions Timing of intervention: 6 months, unclear when started

(a) Fortimel protein-rich liquid oral supplement, $20 \mathrm{~g}$ protein/200 ml, unclear if 200 or up to $400 \mathrm{ml} /$ day

(b) Standard treatment

(c) Nandrolone decanoate (anabolic steroid) $25 \mathrm{mg}$ intramuscular injection/3 weeks and Fortimel as in

(a): group not included in review

Allocated: $20 / 20$

Assessed: $20 / 20$ for mortality

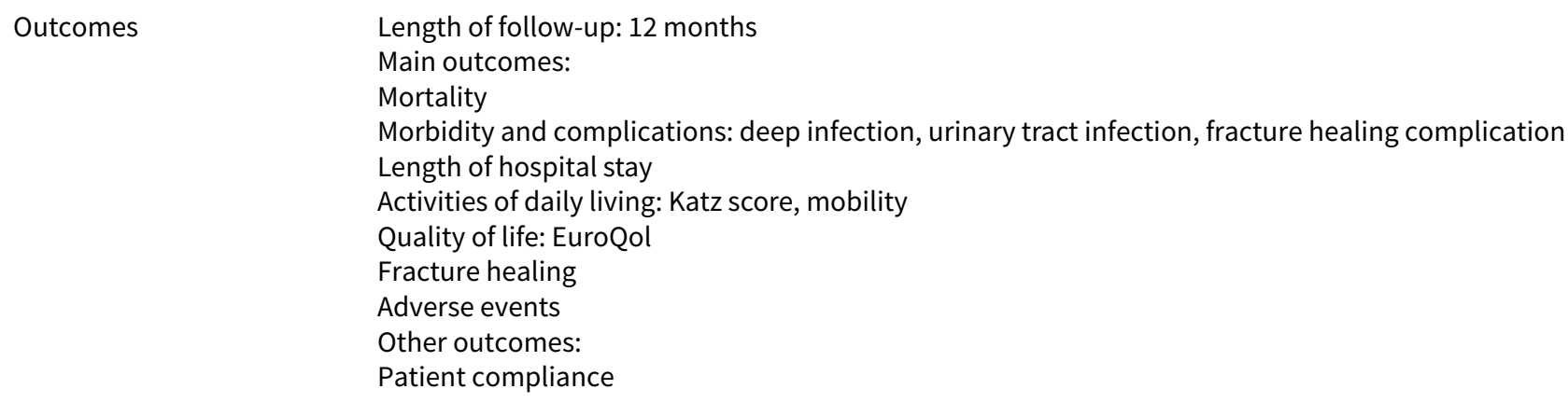

Notes

Request for further details (complications) sent. Reply from trialists (14 October 2004) gave further details of infections. Request for further details (randomisation) sent. Reply from trialists (10 November 2004) gave full details of randomisation process

\section{Risk of bias}


Tidermark 2004 (Continued)

\begin{tabular}{lll} 
Bias & Authors' judgement & Support for judgement \\
\hline $\begin{array}{l}\text { Random sequence genera- } \\
\text { tion (selection bias) }\end{array}$ & Unclear risk & States randomised, but no further details on sequence generation \\
\hline $\begin{array}{l}\text { Allocation concealment } \\
\text { (selection bias) }\end{array}$ & Unclear risk & $\begin{array}{l}\text { "Patients were randomised, using opaque sealed envelopes". (Also num- } \\
\text { bered.) However, the envelopes were prepared and opened by the same re- } \\
\text { search nurse, involved in the trial }\end{array}$ \\
\hline $\begin{array}{l}\text { Blinding of participants } \\
\begin{array}{l}\text { and personnel (perfor- } \\
\text { mance bias) }\end{array}\end{array}$ & High risk & No placebo group. Comment: likely to have been influenced by lack of blinding \\
All outcomes &
\end{tabular}

\begin{tabular}{lll}
\hline $\begin{array}{l}\text { Blinding of outcome as- } \\
\text { sessment (detection bias) } \\
\begin{array}{l}\text { Primary outcomes } \\
\hline\end{array}\end{array}$ & Low risk & $\begin{array}{l}\text { No placebo group. States that " A research nurse not involved in the surgery or } \\
\text { clinical decisions assessed all clinical variables." Comment: unlikely to have } \\
\text { been influenced by lack of blinding }\end{array}$ \\
\hline
\end{tabular}

\begin{tabular}{lll}
\hline Blinding of outcome as- & Unclear risk & $\begin{array}{l}\text { No placebo group. States that " A research nurse not involved in the surgery or } \\
\text { sessment (detection bias) }\end{array}$ \\
Secondary and other out- & fluenced by lack of blinding
\end{tabular}

ry and other outfluenced by lack of blinding

comes

Incomplete outcome data Unclear risk

(attrition bias)

Primary outcomes
Two in control group and one in supplement group lost to follow-up, unlikely to have an impact on outcome assessment

\begin{tabular}{|c|c|c|}
\hline $\begin{array}{l}\text { Incomplete outcome data } \\
\text { (attrition bias) }\end{array}$ & Unclear risk & $\begin{array}{l}\text { Two in control group and one in supplement group lost to follow-up, unlikely } \\
\text { to have an impact on outcome assessment }\end{array}$ \\
\hline
\end{tabular}

(attrition bias)

to have an impact on outcome assessment

ary and other out-

comes

\begin{tabular}{|c|c|c|}
\hline $\begin{array}{l}\text { Selective reporting (re- } \\
\text { porting bias) }\end{array}$ & Low risk & Protocol not available, but expected outcomes provided \\
\hline Other bias & High risk & $\begin{array}{l}\text { Displaced fractures in } 75 \% \text { of controls and } 45 \% \text { of supplement group. Fund- } \\
\text { ed by Trygg-Hansa Insurance Company, the Swedish Orthopaedic Association, } \\
\text { the Swedish Research Council, Novo Nordic Fund, Nutricia Nordic AB and Ny- } \\
\text { comed AB }\end{array}$ \\
\hline
\end{tabular}

\section{Tkatch 1992}

$\begin{array}{ll}\text { Methods } & \text { Method of randomisation: not stated } \\ \text { Intention-to-treat analysis: not carried out, at least } 6 \text { participants excluded after randomisation } \\ \text { Lost to follow-up: none, all participants accounted for }\end{array}$

Participants Location: orthopaedic ward, hospital and recovery hospital, Geneva, Switzerland

Period of study: 17 consecutive weeks, probably prior to 1992

72 participants

Inclusion criteria: subcapital or trochanteric fracture of the proximal femur following moderate trau-

ma, aged over 60 years

Exclusion criteria: fracture resulting from violent injury, primary or metastatic bone tumour; renal osteodystrophy; hepatic insufficiency; endocrine disorders affecting skeletal metabolism; chronic alcoholism; advanced dementia; contralateral reunited hip fracture; refusal to participate; corticosteroid, fluoride, phenytoin treatment; Paget's disease; non residence in Geneva, left orthopaedic unit prematurely after conservative treatment for subcapital fracture 
Tkatch 1992 (Continued)

Sex: 54 female, 8 male (of 62 )

Age: mean age 82 years

Fracture type: 32 subcapital, 30 trochanteric

Interventions Timing of intervention: started on admission to orthopaedic clinic, continued in recovery hospital. Given once daily at 20:00 hours

(a) Protein supplement ( $20.4 \mathrm{~g}$ protein from milk) in $250 \mathrm{ml}$ of oral supplement ( $5.8 \mathrm{~g}$ fat, $29.5 \mathrm{~g}$ carbohydrate, $525 \mathrm{mg}$ calcium, $70 \mathrm{mg}$ magnesium, $270 \mathrm{mg}$ phosphorus, 25 IU vitamin D3, 750 IU vitamin A)

(b) $250 \mathrm{ml}$ of oral supplement alone

Allocated: ?/?

Assessed: $33 / 29$

\begin{tabular}{ll}
\hline Outcomes & Length of follow-up: 7 months \\
& Main outcomes: \\
& Mortality \\
& Morbidity and complications: complications (bedsore, anaemia, cardiac failure, infection, digestive \\
disturbance, other), favourable clinical course (excludes death, major complication, or two or more mi- \\
nor complications) \\
Length of stay: orthopaedic ward and recovery hospital \\
Care required after discharge: still in hospital at 7 months, returned home at 7 months \\
Other outcomes: \\
Patient compliance: non compliance taking supplement, controls taking protein supplement \\
Post-randomisation exclusions: 3 in protein intervention group excluded for non-compliance, 3 con- \\
trols excluded (2 took protein supplements, one severe diarrhoea), 4 of unspecified group left or- \\
thopaedic unit prematurely. Numbers of complications unclear. Request for further details (exclusions, \\
complications) sent 24 May 1999, re-sent 7 February 2000
\end{tabular}

\section{Risk of bias}

\begin{tabular}{|c|c|c|}
\hline Bias & Authors' judgement & Support for judgement \\
\hline $\begin{array}{l}\text { Random sequence genera- } \\
\text { tion (selection bias) }\end{array}$ & Unclear risk & No information: just "randomized into two groups" \\
\hline $\begin{array}{l}\text { Allocation concealment } \\
\text { (selection bias) }\end{array}$ & Unclear risk & No information: just "randomized into two groups" \\
\hline $\begin{array}{l}\text { Blinding of participants } \\
\text { and personnel (perfor- } \\
\text { mance bias) } \\
\text { All outcomes }\end{array}$ & Unclear risk & $\begin{array}{l}\text { Both groups received } 250 \mathrm{ml} \text { supplements daily, but not clear if different in } \\
\text { taste or appearance }\end{array}$ \\
\hline $\begin{array}{l}\text { Blinding of outcome as- } \\
\text { sessment (detection bias) } \\
\text { Primary outcomes }\end{array}$ & Low risk & Unlikely to have been influenced by lack of blinding \\
\hline $\begin{array}{l}\text { Blinding of outcome as- } \\
\text { sessment (detection bias) } \\
\text { Secondary and other out- } \\
\text { comes }\end{array}$ & Unclear risk & $\begin{array}{l}\text { Both groups received } 250 \mathrm{ml} \text { supplements daily, but not clear if different in } \\
\text { taste or appearance }\end{array}$ \\
\hline $\begin{array}{l}\text { Incomplete outcome data } \\
\text { (attrition bias) } \\
\text { Primary outcomes }\end{array}$ & High risk & $\begin{array}{l}\text { Post-randomisation exclusions: } 3 \text { in protein intervention group excluded for } \\
\text { non-compliance, } 3 \text { controls excluded ( } 2 \text { took protein supplements, one severe } \\
\text { diarrhoea), } 4 \text { of unspecified group left orthopaedic unit prematurely }\end{array}$ \\
\hline $\begin{array}{l}\text { Incomplete outcome data } \\
\text { (attrition bias) }\end{array}$ & High risk & $\begin{array}{l}\text { Post-randomisation exclusions: } 3 \text { in protein intervention group excluded for } \\
\text { non-compliance, } 3 \text { controls excluded ( } 2 \text { took protein supplements, one severe } \\
\text { diarrhoea), } 4 \text { of unspecified group left orthopaedic unit prematurely }\end{array}$ \\
\hline
\end{tabular}


Tkatch 1992 (Continued) Secondary and other outcomes

\begin{tabular}{lll}
\hline $\begin{array}{l}\text { Selective reporting (re- } \\
\text { porting bias) }\end{array}$ & Unclear risk & Insufficient details provided \\
\hline Other bias & High risk & Sandoz-Wander (Switzerland) supplied the dietary supplements \\
\hline
\end{tabular}

\section{Van Stijn 2015}

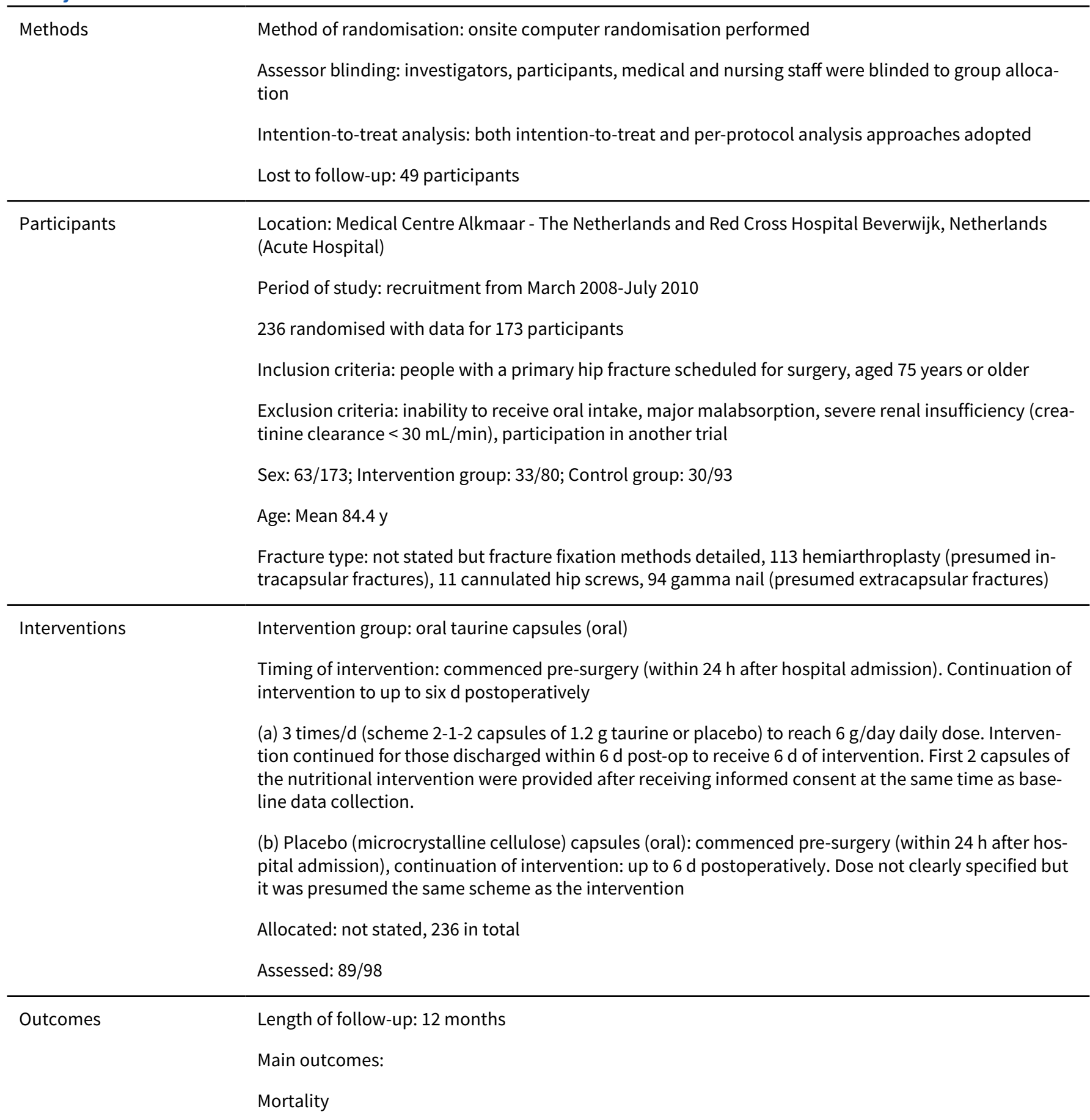


Van Stijn 2015 (Continued)

Length of hospital stay

Morbidity and complications: infection, cardiovascular events, stroke, delirium, requirement for blood

transfusion, requirement for reoperation

Notes

\section{Risk of bias}

Bias Authors' judgement Support for judgement

Random sequence genera- Low risk

tion (selection bias)

"Computerized randomisation table using block randomisation of 30 patients per block, generated by a local statistician, used by the pharmacological department to label the capsules for the interventions." (page 12300 section 3.2, Line3-5)

\begin{tabular}{|c|c|c|}
\hline $\begin{array}{l}\text { Allocation concealment } \\
\text { (selection bias) }\end{array}$ & Low risk & $\begin{array}{l}\text { Allocation "generated by a local statistician, used by the pharmacological de- } \\
\text { partment to label the capsules for the interventions." (page } 12300 \text { section 3.2, } \\
\text { Line 4-5) }\end{array}$ \\
\hline
\end{tabular}

Blinding of participants Low risk "patients...unaware of intervention allocation" (page 12300 section 3.2 line 7 )
and personnel (performance bias)

All outcomes

\begin{tabular}{|c|c|c|}
\hline $\begin{array}{l}\text { Blinding of outcome as- } \\
\text { sessment (detection bias) } \\
\text { Primary outcomes }\end{array}$ & Low risk & $\begin{array}{l}\text { "investigators, patients, medical and nursing staff were unaware of interven- } \\
\text { tions allocation" (page } 12300 \text { section 3.2, line 7-9) }\end{array}$ \\
\hline $\begin{array}{l}\text { Blinding of outcome as- } \\
\text { sessment (detection bias) } \\
\text { Secondary and other out- } \\
\text { comes }\end{array}$ & Low risk & $\begin{array}{l}\text { "Two investigators, who were unaware of treatment allocation, independent- } \\
\text { ly determines the occurrence of postoperative complications and morbidi- } \\
\text { ty" (page } 12300 \text { section 3.3, line 4-6) }\end{array}$ \\
\hline
\end{tabular}

\begin{tabular}{lll}
\hline $\begin{array}{l}\text { Incomplete outcome data } \\
\text { (attrition bias) } \\
\text { Primary outcomes }\end{array}$ & High risk & $\begin{array}{l}\text { Reasons for missing data and attrition not clear by group allocation and rea- } \\
\text { son not provided (Figure 1) }\end{array}$ \\
\hline $\begin{array}{l}\text { Incomplete outcome data } \\
\text { (attrition bias) } \\
\begin{array}{l}\text { Secondary and other out- } \\
\text { comes }\end{array}\end{array}$ & High risk & $\begin{array}{l}\text { Reasons for missing data and attrition not clear by group allocation and rea- } \\
\text { son not provided (Figure 1) }\end{array}$ \\
\hline $\begin{array}{l}\text { Selective reporting (re- } \\
\text { porting bias) }\end{array}$ & Low risk & Study protocol provided (page 12299, section 3.1, line 8) \\
\hline $\begin{array}{l}\text { Other bias } \\
\text { High risk }\end{array}$ & $\begin{array}{l}\text { Underpowered analysis (page 12301 section 3.5, line 1-2), unrealistic 50\% re- } \\
\text { duction in mortality at 1 year presumed in power calculation }\end{array}$ \\
\hline
\end{tabular}

\section{Wyers 2013}

\section{Methods}

Method of randomisation: computer-generated random-number sequence list after pre-stratification for hospital, gender and age (55-74 years vs 75 years and above) with allocation ratio 1:1. Independent allocation by phone call to research assistant

Intention-to-treat analysis: undertaken 
Wyers 2013 (Continued)

Lost to follow-up: $6 \%$ lost to follow-up

Participants

Location: 3 hospitals in South Limburg, Netherlands

Period of study: recruitment July 2007-December 2009

152 participants

Inclusion criteria: admitted for surgical treatment of hip fracture, aged $\geq 55$ years

Exclusion criteria: pathological or periprosthetic fracture; a disease of bone metabolism (Paget's, hyperparathyroidism); an estimated life expectancy < 1 year due to underlying disease; used an oral nutritional supplement before hospital admission; unable to speak Dutch, lived outside the region or had been bedridden before their hip fracture; dementia or were cognitively impaired, defined as score of $<7$ on the Abbreviated Mental Test, as assessed before inclusion

Sex: 108 female, 44 male

Age: median 79 years

Fracture type: 81 neck of femur, 65 pertrochanteric, 6 subtrochanteric

a) 5 dietetic visits to counsel, 5 phone calls, tailored advice stopped when met requirements with diet. Energy- and protein-enriched diet, and recommendations were given with regard to choice, quantity and timing of food products. In addition, participants were advised to consume two bottles of ONS daily in between main meals. The ONS was a milk-protein based, or a yogurt- or juice-style supplement (Cubitan, Nutridrink Yoghurt style, or Nutridrink Juice style, N.V. Nutricia, Zoetermeer, the Netherlands) providing $2.1 \mathrm{MJ}(500 \mathrm{kcal})$ and $40 \mathrm{~g}$ of protein per $500 \mathrm{ml}$. The dietitian made arrangements to solve any problems, e.g. feeding difficulties, in collaboration with the hospital medical and nursing staff

b) Usual care in hospital, rehabilitation clinic or home. Dietetic care or nutritional supplements only provided on request of doctor

Allocated: $73 / 79$

Assessed: $73 / 79$

Outcomes

Length of follow-up: 1 year

Main outcomes:

Mortality

Complications

Length of acute hospital and rehabilitation hospital stay

Functional status

Readmissions

Level of care

Quality of life

Adverse effects

Other outcomes:

Compliance

Economic outcomes 
Wyers 2013 (Continued)

Notes Data up to 1 year on mortality and complications taken from thesis

\section{Risk of bias}

\begin{tabular}{lll}
\hline Bias & Authors' judgement & Support for judgement \\
\hline $\begin{array}{l}\text { Random sequence genera- } \\
\text { tion (selection bias) }\end{array}$ & Low risk & $\begin{array}{l}\text { States "the patient was randomised according to a computer-generated ran- } \\
\text { dom-number sequence list after pre-stratification for hospital, gender and age } \\
(55-74 \text { years vs. } 75 \text { years and above)." }\end{array}$ \\
\hline $\begin{array}{l}\text { Allocation concealment } \\
\text { (selection bias) }\end{array}$ & Low risk & $\begin{array}{l}\text { States "The researcher made a telephone call to an independent research as- } \\
\text { sistant who took a sequentially numbered and sealed envelope, and informed } \\
\text { the researcher to which group the patient had been allocated." }\end{array}$ \\
\hline $\begin{array}{l}\text { Blinding of participants } \\
\begin{array}{l}\text { and personnel (perfor- } \\
\text { mance bias) }\end{array}\end{array}$ & High risk & No placebo group. Comment: likely to have been influenced by lack of blinding \\
All outcomes &
\end{tabular}

\begin{tabular}{ll}
\hline $\begin{array}{l}\text { Blinding of outcome as- } \\
\text { sessment (detection bias) } \\
\begin{array}{l}\text { Primary outcomes }\end{array}\end{array} \quad$ Low risk & $\begin{array}{l}\text { No placebo group. Comment: unlikely to have been influenced by lack of } \\
\text { blinding }\end{array}$
\end{tabular}

Primary outcomes

Blinding of outcome as- Unclear risk

No placebo group. Comment: may have been influenced by lack of blinding

sessment (detection bias)

Secondary and other out-

comes

\begin{tabular}{|c|c|c|}
\hline $\begin{array}{l}\text { Incomplete outcome data } \\
\text { (attrition bias) } \\
\text { Primary outcomes }\end{array}$ & Unclear risk & All participants accounted for, with no imbalance in few dropouts \\
\hline $\begin{array}{l}\text { Incomplete outcome data } \\
\text { (attrition bias) } \\
\text { Secondary and other out- } \\
\text { comes }\end{array}$ & Unclear risk & All participants accounted for, with no imbalance in few dropouts \\
\hline $\begin{array}{l}\text { Selective reporting (re- } \\
\text { porting bias) }\end{array}$ & Low risk & Based on PhD thesis, all prespecified and expected outcomes reported \\
\hline Other bias & High risk & $\begin{array}{l}\text { Oral nutritional supplements were provided by Nutricia Advanced Medical Nu- } \\
\text { trition (Danone Research, Centre for Specialized Nutrition, Wageningen, The } \\
\text { Netherlands). Unclear extent of involvement in trial }\end{array}$ \\
\hline
\end{tabular}

BMI: body mass index

mosmol/L: milliosmol/L, a measure of osmolality

NHS: UK National Health Service

nr: no results

SD: standard deviation

Characteristics of excluded studies [ordered by study ID]

\begin{tabular}{ll}
\hline Study & Reason for exclusion \\
\hline Ashworth 2006 & $\begin{array}{l}\text { Pilot study for RCT of snacks versus oral nutritional supplements. Trial stopped early as only } 4 \text { out } \\
\text { of } 95 \text { patients were eligible for recruitment. No relevant outcomes }\end{array}$ \\
\hline
\end{tabular}




\begin{tabular}{ll}
\hline Study & Reason for exclusion \\
\hline Bachrach 2000 & $\begin{array}{l}\text { RCT of total hip arthroplasty versus osteosynthesis for hip fracture, but not of nutritional supple- } \\
\text { mentation. The second half of each surgical treatment group received nutritional supplementa- } \\
\text { tion; thus, the supplementation and control groups were also not concurrent. }\end{array}$ \\
\hline Bachrach 2001 & $\begin{array}{l}\text { Study of protein and energy supplementation after hip fracture. Not a RCT: non concurrent study } \\
\text { groups }\end{array}$ \\
\hline Bell 2014 & $\begin{array}{l}\text { Prospective, controlled before and after study of new model of nutritional care promoting nutrition } \\
\text { as a medicine, multidisciplinary nutritional care, food service enhancements and improved nutri- } \\
\text { tion knowledge and awareness. Not a RCT }\end{array}$ \\
\hline
\end{tabular}

RCT. Comparison between $880 \mathrm{mg}$ calcium and $80 \mathrm{mg}$ calcium with $5 \mathrm{mg}$ of anabolic steroid
stanozolol. Not both nutrition interventions, and required outcomes not evaluated

\begin{tabular}{ll}
\hline Boudville 2002 & Short-term study on the effect of 250 kcal supplement on the appetite of people with hip or pelvic \\
fracture. Unclear if RCT. No relevant outcomes
\end{tabular}

\begin{tabular}{ll}
\hline Bradley 1995 & Not a RCT: nursing education programme targeting specific problems including nutritional deficits \\
\hline Brocker 1994 & $\begin{array}{l}\text { The } 194 \text { ambulatory elderly participants in the trial were unlikely to include people with hip frac- } \\
\text { ture. No response from study author }\end{array}$ \\
\hline Cameron 2011 & $\begin{array}{l}\text { Randomised trial of oral nutritional supplementation for older women after fracture (hip, pelvis, } \\
\text { humerus, femoral shaft). Personal communication from lan Cameron on 26th November } 2014 \text { stat- } \\
\text { ed that data for participants with hip fracture are not available }\end{array}$
\end{tabular}

\begin{tabular}{ll}
\hline Carlsson 2005 & RCT of protein-rich liquid supplement versus supplement with nandrolone decanoate injections. \\
Not in scope of review
\end{tabular}

\begin{tabular}{ll}
\hline Crossley 1977 & Unable to contact study author. Contacted project supervisor, thesis no longer available \\
\hline Gegerle 1986 & $\begin{array}{l}\text { RCT of } 250 \mathrm{ml} \text { oral supplement providing } 20 \mathrm{~g} \text { protein, } 254 \mathrm{kcal} \text {, minerals and vitamins. Study re- } \\
\text { ports only effects of supplement on intake of intervention group, compared with control group. No } \\
\text { other outcomes provided. French paper - checked by French translator }\end{array}$ \\
\hline
\end{tabular}

\begin{tabular}{ll}
\hline Giaccaglia 1986 & Not a RCT. Italian paper - checked by Italian translator \\
\hline Goldsmith 1967 & Not people with hip fracture \\
\hline Groth 1988 & Not people with hip fracture nor a RCT \\
\hline Gunnarsson 2009 & $\begin{array}{l}\text { Quasi-experimental, pre- and post-test comparison group design without random group assign- } \\
\text { ment of } 100 \text { people with hip fractures to nutritional supplements according to nutritional guide- } \\
\text { lines plus usual care compared with usual care only. Not a RCT }\end{array}$ \\
\hline Harju 1989 & $\begin{array}{l}\text { Comparison of } 0.25 \text { mcg 1-alpha-hydroxyvitamin D3, } 100 \text { IU calcitonin and placebo in women after } \\
\text { femoral neck fracture. No outcomes of interest reported and probably not a RCT }\end{array}$ \\
\hline Harwood 2004 & $\begin{array}{l}\text { RCT, involving } 150 \text { women after hip fracture, comparing single injection of } 300,000 \text { IU vitamin D2, } \\
\text { injected vitamin D2 and } 1000 \text { mg/d oral calcium, } 800 \text { IU/d oral vitamin D3 and } 1000 \text { mg/d calcium, } \\
\text { or no treatment. Secondary prevention trial }\end{array}$ \\
\hline Hedström 2002 & $\begin{array}{l}\text { RCT, involving } 63 \text { women after hip fracture, comparing nandrolone decanoate (25 mg intramuscu- } \\
\text { larly every } 3 \text { weeks), 0.25 mcg 1-alpha-hydroxyvitamin D3 daily and } 500 \text { mg calcium daily versus } \\
500 \text { mg calcium daily. Thus this evaluated anabolic steroid and vitamin D together. }\end{array}$ \\
\hline
\end{tabular}




\begin{tabular}{ll}
\hline Study & Reason for exclusion \\
\hline Hitz 2007 & RCT of daily $1200 \mathrm{mg}$ calcium as calcium carbonate and 1400 IU vitamin D3 versus 200 IU vitamin \\
D3 in people with low-energy upper and lower limb fractures. No separate data available for the \\
participants with hip fracture
\end{tabular}

\begin{tabular}{ll} 
Hoekstra 2011 & Comparative study of usual nutritional care versus multidisciplinary care for hip fracture; not a RCT \\
\hline Holst 2012 & $\begin{array}{l}\text { Non-randomised comparison of standard plan to improve nutritional intake versus usual care for } \\
\text { hip fracture }\end{array}$ \\
\hline Hommel 2007 & $\begin{array}{l}\text { Quasi-experimental before and after study of best practices for people with hip fracture, with nutri- } \\
\text { tional drink as one component of the intervention (clinical pathway) }\end{array}$ \\
\hline Kacmaz 2007 & $\begin{array}{l}\text { Non-randomised comparison of bran supplements and nursing intervention versus usual nursing } \\
\text { care in postoperative orthopaedic patients, mean age } 69 \text { years. Unclear if any participant had a hip } \\
\text { fracture }\end{array}$
\end{tabular}

\begin{tabular}{ll}
\hline Kuzdenbaeva 1981 & $\begin{array}{l}\text { Comparative study, not explicitly randomised. Mixed group of hip fracture and femoral shaft frac- } \\
\text { ture participants aged } 17-67 \text { years; thus majority of hip fracture participants were not over } 65 \text { years. } \\
\text { Russian paper - checked by Russian translator }\end{array}$
\end{tabular}

Larsson 1990

Randomised trial of older people, of whom 89 had fractures, newly admitted to long-term medical care. No response from lead author to requests for separate results for participants with hip fracture

Lauque 2000
RCT of protein and energy supplementation in nursing homes; not specifically directed at people
after hip fracture

\begin{tabular}{ll}
\hline Lawson 2003 & Not a RCT. Mixed group of orthopaedic patients \\
\hline Li 2012 & $\begin{array}{l}\text { RCT of interdisciplinary intervention (geriatric assessment/consultation, discharge planning and } \\
\text { rehabilitation in hospital and up to } 3 \text { months post discharge, with nutrition only part of the inter- } \\
\text { vention) versus usual care for hip fracture }\end{array}$
\end{tabular}

Moller-Madsen 1988

Nusbickel 1989

\begin{tabular}{ll}
\hline Olofsson 2007 & $\begin{array}{l}\text { Randomised trial of a multidisciplinary intervention programme for people after hip fracture. The } \\
\text { nutritional intervention was only one component of the complex intervention }\end{array}$ \\
\hline
\end{tabular}

No usable results published in conference abstract reporting trial of oral supplements for 25 people with hip fracture. No response from authors

\section{No response from author. No information in the two conference abstracts reports of the trial of} how many people with hip fracture were included, nor their results

Pedersen 1999
Intervention and control groups were not concurrent, nor randomised. The trial investigated the effects of active involvement of orthopaedic patients in their own dietary care; thus the intervention was not direct nutritional supplementation but rather a means of enhancing update by patients. Mixed patient population with hip fracture, or undergoing knee or hip arthroplasty

\begin{tabular}{ll}
\hline Ravetz 1959 & Two hip fracture patients only. Unlikely to be a RCT \\
\hline Shaikhiev 1984 & $\begin{array}{l}\text { Comparative study; not explicitly randomised. Mixed group of hip fracture and femoral shaft frac- } \\
\text { ture participants aged 17-65 years; thus majority of hip fracture participants were not over } 65 \text { years. } \\
\text { Russian paper - checked by Russian translator }\end{array}$
\end{tabular}

Stumm 2001

RCT testing the addition of pear juice or high fibre supplement to normal diet versus normal diet alone in a mixed group of orthopaedic patients admitted for elective surgery or after traumatic 


\begin{tabular}{|c|c|}
\hline Study & Reason for exclusion \\
\hline & $\begin{array}{l}\text { fracture. Aimed at the management of constipation and not for improvement of nutritional status; } \\
\text { no relevant outcomes }\end{array}$ \\
\hline Tassler 1981 & Not RCT. German paper \\
\hline Taylor 1974 & $\begin{array}{l}\text { Quasi-randomised placebo-controlled trial of vitamin C: participants recruited with pressure sores, } \\
\text { not because of hip fracture, although } 9 \text { of the } 20 \text { participants had hip fracture }\end{array}$ \\
\hline Thomas 2008 & $\begin{array}{l}\text { RCT of resistance training and nutrition therapy combined versus attention control for hip fracture. } \\
\text { Unable to assess effect of nutrition separately }\end{array}$ \\
\hline Volkert 1996 & $\begin{array}{l}\text { RCT involving a mixed group of medical, general surgical and orthopaedic patients aged over } 75 \\
\text { years. Author indicates that only a few participants had hip fractures }\end{array}$ \\
\hline Williams 1989 & $\begin{array}{l}\text { This trial appears to form part of one of three consecutive studies published in the PhD thesis of } \\
\text { Driver (Driver LT. Evaluation of supplemental nutrition in elderly orthopaedic patients [PhD the- } \\
\text { sis]. Surrey (UK): Univ. of Surrey, 1994). All three studies evaluated nutritional supplementation in } \\
\text { a combined group of people with hip fracture and elective hip replacement. There were major de- } \\
\text { fects in the randomisation process, as well as numerical discrepancies, which suggest intention-to- } \\
\text { treat problems. We have been unable to contact Driver to obtain clarification of the status of the } \\
\text { three studies, the trial populations and further specific information on the participants with hip } \\
\text { fracture. For the purposes of this review, the } 3 \text { studies have been represented as } 1 \text { trial. }\end{array}$ \\
\hline Wong 2004 & $\begin{array}{l}\text { RCT of dietetic counselling versus usual care in a mixed patient group with osteoporotic fractures } \\
\text { (forearm, vertebral, hip). Limited outcomes only (energy, protein and calcium intake, weight and } \\
\text { BMI) }\end{array}$ \\
\hline Zauber 1992 & $\begin{array}{l}\text { RCT. Mixed group of people with elective hip replacement and hip fracture. Some participants were } \\
\text { excluded from the analysis. Limited outcomes only (haemoglobin and reticulocyte count) }\end{array}$ \\
\hline
\end{tabular}

$\mathrm{RCT}$ : randomised controlled trial

Characteristics of studies awaiting assessment [ordered by study ID]

Benati 2011

\begin{tabular}{ll}
\hline Methods & Unclear if RCT \\
\hline Participants & People with hip fracture \\
\hline Interventions & $\begin{array}{l}\text { (a) Oral nutritional supplements enriched with arginine and micronutrients plus standard hospital } \\
\text { diet }\end{array}$ \\
(b) Standard hospital diet
\end{tabular}

Outcomes Follow-up: at least $15 \mathrm{~d}$ after surgery

Outcomes: pressure ulcers, wound infections

Notes

Letter to Dr Benati requesting further details sent 7 October 2014

Bernabeu-Wittel 2016

Methods Multicentre, randomised placebo-controlled trial


Bernabeu-Wittel 2016 (Continued)
Participants
303 participants aged 65 years or more with osteoporotic hip fracture requiring surgical repair; haemoglobin $90-120 \mathrm{~g} / \mathrm{L}$

Interventions

(a) 40,000 IU erythropoietin and ferric carboxymaltose $1000 \mathrm{mg}$ as 20-min infusion

(b) Erythropoietin placebo and ferric carboxymaltose $1000 \mathrm{mg}$ as 20-min infusion

(c) Erythropoietin placebo and ferric carboxymaltose placebo as 20-min infusion

Follow-up: $60 \mathrm{~d}$ after hospital discharge
Outcomes: mortality, adverse events, quality of life

Notes

Email 22 September 2014 related to status of trial publication. Now published

Ekinci 2015

\begin{tabular}{ll}
\hline Methods & RCT \\
\hline Participants & 75 participants with lower extremity fracture \\
\hline Interventions & $\begin{array}{l}\text { (a) } 3 \text { g calcium } \beta \text {-hydroxy- } \beta \text {-methylbutyrate, } 1000 \text { IU vitamin D and } 36 \text { g protein supplementation } \\
\text { and standard postoperative nutrition } \\
\text { (b) standard postoperative nutrition }\end{array}$
\end{tabular}

Outcomes

Follow-up: $30 \mathrm{~d}$

Oucomes: muscle strength, mobilisation time, wound healing, hospitalisations

Notes

Gerstorfer 2008

\begin{tabular}{ll}
\hline Methods & Controlled trial: "randomly divided" \\
\hline Participants & 46 women with hip fracture, mean age 83 years \\
\hline Interventions & $\begin{array}{l}\text { (a) Nutritional therapeutic regime (protocols, protein enriched food, oral and/or parenteral supple- } \\
\text { mentation) }\end{array}$ \\
\hline (b) Usual care \\
\hline Nutcomes & Nutritional biochemistry \\
\hline $\begin{array}{l}\text { Email to Dr Elmadfa on } 3 \text { October 2008 asking for further details, and Dr Elmadfa (ibrahim.elmad- } \\
\text { fa@univie.ac.at) and Dr Fabian (elisabeth.fabian@univie.ac.at) on 3 November 2016 for further de- } \\
\text { tails }\end{array}$
\end{tabular}

Ish-Shalom 2008

Methods Randomised three-arm trial


Ish-Shalom 2008 (Continued)

Participants $\quad 48$ women who had surgery for hip fracture

Interventions
(a) Vitamin D3 1,500 IU/day
(b) Vitamin D3 10,500 IU weekly
(c) Vitamin D3 45,000 IU every $28 \mathrm{~d}$

Outcomes Follow-up: $56 \mathrm{~d}$

Outcomes: Hypercalcaemia

\begin{tabular}{ll}
\hline Notes & $\begin{array}{l}\text { Emailed Sophia Ish-Shalom (s-ish-shalom@rambam.health.gov.il) } 21 \text { November } 2014 \text { requesting } \\
\text { details of outcomes relevant to this review }\end{array}$ \\
\hline
\end{tabular}

Stratton 2006

\begin{tabular}{ll}
\hline Methods & RCT \\
\hline Participants & 50 men and women with fractured neck of femur, at risk of malnutrition \\
\hline
\end{tabular}

\begin{tabular}{ll}
\hline Interventions & (a) Liquid multinutrient oral nutritional support \\
& (b) Food snacks
\end{tabular}

Outcomes Follow-up: at least $7 \mathrm{~d}$

Compliance, patient satisfaction

Notes

Emailed r.j.stratton@soton.ac.uk on 5 September 2014 asking for further details

RCT: randomised controlled trial

Characteristics of ongoing studies [ordered by study ID]

\section{ACTRN12609000241235}

Trial name or title Does a high dose fish oil intervention improve outcomes in older adults recovering from hip fracture?

\begin{tabular}{ll}
\hline Methods & Randomised controlled double-blind trial \\
\hline Participants & $\begin{array}{l}150 \text { men and women, aged } 65 \text { years or over, within } 7 \mathrm{~d} \text { of surgical fixation of femoral fracture, histo- } \\
\text { ry of recent unexplained weight loss and at risk of further weight loss and current poor appetite, el- } \\
\text { evated C reactive protein }(6 \mathrm{mg} / \mathrm{L} \text { or more), serum albumin }<35 \mathrm{~g} / \mathrm{L} \text {, raised energy expenditure }\end{array}$ \\
\hline
\end{tabular}

Interventions

(a) $15 \mathrm{ml} /$ day liquid fish oil orally (4.9 g eicosapentaenoic acid and $3.4 \mathrm{~g}$ docosahexaenoic acid) and individualised nutrition therapy

(b) Low-dose plant and fish oil supplement $15 \mathrm{ml} /$ day $(0.49 \mathrm{~g}$ eicosapentaenoic acid and $0.39 \mathrm{~g}$ do-

cosahexaenoic acid) and individualised nutrition therapy

Both for 12 weeks

\section{Outcomes}

Follow-up: 6, 12 weeks and 12 months

Outcomes: mortality, place of residence, frailty index, health-related quality of life, physical func-

tion, nutritional status, resting energy expenditure, inflammatory markers 
ACTRN12609000241235 (Continued)

\begin{tabular}{ll} 
Starting date & February 2010 \\
\hline Contact information & Dr Michelle Miller \\
& Department of Nutrition and Dietetics \\
& Flinders University \\
& GPO Box 2100 \\
& Adelaide SA 5001 \\
& Australia \\
& E-Mail: michelle.miller@flinders.edu.au
\end{tabular}

Notes $\quad$ Emailed michelle.miller@flinders.edu.au 5 September 2014 to enquire status of trial. Replied 7

September 2014 that trial completed and results being analysed

\section{ACTRN12610000392066}

\begin{tabular}{ll}
\hline Trial name or title & REVITAHIP \\
\hline Methods & Multicentre, randomised, controlled, double-blind trial \\
\hline Participants & 340 men and women aged 65 y or over with hip fracture requiring surgery \\
\hline Interventions & a) 250,000 IU vitamin $D_{3}(5$ tablets of 50,000 IU) within 7 d postsurgery \\
& b) 5 placebo tablets \\
& Followed by daily calcium ( 500 mg) and vitamin D ( 800 IU) for 6 months for both groups \\
\hline Outcomes & Follow-up: $2,4,12$ and 24 weeks \\
& $\begin{array}{l}\text { Outcomes: functional status e.g. gait velocity, falls, fractures, quality of life, hospitalisation, mor- } \\
\text { bidity, mortality }\end{array}$ \\
\hline Starting date & 2010 \\
\hline Contact information & Jenson Mak: jmak@nsccahs.health.nsw.gov.au \\
\hline Notes & Trial completed, results being written up for publication
\end{tabular}

\section{ACTRN12612000448842}

Trial name or title

Does intravenous iron therapy reduce the need for blood transfusion and improve post operative blood count following surgery for broken neck of femur?

\begin{tabular}{ll}
\hline Methods & Randomised placebo controlled trial \\
\hline Participants & 270 participants with planned surgical fixation of fractured neck of femur \\
\hline Interventions & $\begin{array}{l}\text { (a) Single } 50 \mathrm{ml} \text { infusion of } 1000 \mathrm{mg} \text { iron polymaltose over } 20 \text { min for participants }<70 \mathrm{~kg}, \text { or } 1500 \\
\text { mg for heavier participants }\end{array}$ \\
(b) Saline placebo
\end{tabular}

Outcomes Length of stay, mortality


ACTRN12612000448842 (Continued)

\begin{tabular}{ll} 
Starting date & 1 July 2012 \\
\hline Contact information & Matt Harper \\
& Fremantle Hospital \\
& PO Box 480 \\
& WA 4160 \\
& Australia \\
& matthew.harper@health.wa.gov.au
\end{tabular}

Notes

NCT00497978

Trial name or title The effect of taurine on morbidity and mortality in the elderly hip fracture patient

\begin{tabular}{ll}
\hline Methods & Randomised controlled double-blind trial \\
\hline Participants & Aged over 75 years, surgery for hip fracture, both genders, number recruited unclear \\
\hline
\end{tabular}

\begin{tabular}{ll}
\hline Interventions & (a) 3 g taurine/day or 6 g taurine/day \\
(b) placebo
\end{tabular}

\begin{tabular}{ll}
\hline Outcomes & Follow-up: 1 year \\
& Outcomes: morbidity and mortality
\end{tabular}

\begin{tabular}{ll}
\hline Starting date & July 2007, expected completion July 2010 \\
\hline Contact information & Dr Alexander PJ Houdijk \\
& Medical Center Alkmaar \\
& Alkmaar \\
& Noord-Holland \\
& 1800 AM \\
& The Netherlands \\
& Telephone: +31725484444 ext: 5383 \\
& E-mail: a.p.j.houdijk@mca.nl \\
& Emailed a.p.j.houdijk@mca.nl 5 September 2014 to enquire about status of trial. Reply received 18 \\
& September 2014 indicating that manuscript in preparation and results not yet available \\
\hline \multirow{2}{*}{ Notes } &
\end{tabular}

\section{NCT01404195}

\begin{tabular}{ll}
\hline Trial name or title & HIPERPROT-GER study \\
\hline Methods & Single centre, RCT \\
\hline Participants & 100 participants aged 65 years and over after surgery for hip fracture starting rehabilitation \\
\hline Interventions & $\begin{array}{l}\text { (a) } 2 \text { bottles Ensure Plus Advance per day for } 30 \mathrm{~d} \text { in hospital (enriched with } \beta \text {-hydroxy- } \beta \text {-methylbu- } \\
\text { tyrate, vitamin D3 and calcium) }\end{array}$
\end{tabular}


NCT01404195 (Continued)

(b) Usual care

\begin{tabular}{ll}
\hline Outcomes & Follow-up: 1 year \\
& Outcomes: functional status, mortality \\
\hline Starting date & 2012 \\
\hline Contact information & vmalafarina@gmail.com \\
\hline Notes & $\begin{array}{l}\text { Emailed Dr Malafarina 22 September 2014 enquiring about progress with study, replied 25 Septem- } \\
\text { ber 2014 indicating that recruitment continuing }\end{array}$ \\
\hline
\end{tabular}

\section{NCT01505985}

\begin{tabular}{ll}
\hline Trial name or title & Hip fracture surgery and oral nutritional supplements (HIATUS) \\
\hline Methods & RCT \\
\hline Participants & 24 participants 70 years and over after acute hip fracture and surgical treatment \\
\hline Interventions & (a) Oral nutritional supplement \\
& (b) Placebo \\
\hline Outcomes & Short Physical Performance Battery, quality of life \\
\hline Starting date & January 2012 \\
\hline Contact information & Heike Bischoff-Ferrari \\
& University of Zurich \\
& Department of Rheumatology and Institute of Physical Medicine \\
& Zurich \\
\hline Switzerland 8091 & Heike.Bischoff@usz.ch \\
\hline & Sponsored by Nestlé \\
\hline
\end{tabular}

\section{Rowlands}

Trial name or title

Methods

Participants

Interventions
The effect of intravenous iron on postoperative transfusion requirements in hip fracture patients

\section{Single-centre RCT}

80 men and women undergoing surgical repair of fractured neck of femur, aged 70 years or more

(a) $200 \mathrm{mg}$ iron sucrose within $24 \mathrm{~h}$ or admission, repeated day 1 after operation and day 2

(b) Usual care 
Rowlands (Continued)

\begin{tabular}{ll} 
Outcomes & Follow-up: \\
& $\begin{array}{l}\text { Outcomes: mortality, postoperative infections, cardiovascular complications, length of acute hos- } \\
\text { pital stay, functional status, costs }\end{array}$ \\
\hline Starting date & June 2012 \\
\hline Contact information & iain.moppett@nottingham.ac.uk \\
\hline Notes & Emailed lain Moppett 25 September 2014 to enquire about status of trial, replied 17 November \\
& 2014 indicating that trial still in progress
\end{tabular}

ADL: activities of daily living

$\mathrm{RCT}$ : randomised controlled trial

\section{DATA AND ANALYSES}

Comparison 1. Multinutrient supplements (oral, nasogastric, intravenous) versus control

\begin{tabular}{|c|c|c|c|c|}
\hline Outcome or subgroup title & No. of studies & $\begin{array}{l}\text { No. of partici- } \\
\text { pants }\end{array}$ & Statistical method & Effect size \\
\hline 1 Mortality by end of study & 20 & 1385 & $\begin{array}{l}\text { Risk Ratio (M-H, Fixed, 99\% } \\
\mathrm{Cl} \text { ) }\end{array}$ & $0.79[0.55,1.15]$ \\
\hline 1.1 Oral supplements & 15 & 968 & $\begin{array}{l}\text { Risk Ratio (M-H, Fixed, 99\% } \\
\mathrm{Cl} \text { ) }\end{array}$ & $0.81[0.49,1.32]$ \\
\hline 1.2 Nasogastric tube feeding & 3 & 280 & $\begin{array}{l}\text { Risk Ratio (M-H, Fixed, 99\% } \\
\mathrm{Cl} \text { ) }\end{array}$ & $0.99[0.50,1.97]$ \\
\hline $\begin{array}{l}1.3 \text { Nasogastric tube feeding and oral } \\
\text { supplements }\end{array}$ & 1 & 57 & $\begin{array}{l}\text { Risk Ratio (M-H, Fixed, 99\% } \\
\mathrm{Cl} \text { ) }\end{array}$ & $0.74[0.23,2.35]$ \\
\hline $\begin{array}{l}1.4 \text { Intravenous feeding and oral sup- } \\
\text { plements }\end{array}$ & 1 & 80 & $\begin{array}{l}\text { Risk Ratio (M-H, Fixed, 99\% } \\
\mathrm{Cl} \text { ) }\end{array}$ & $0.11[0.01,2.00]$ \\
\hline $\begin{array}{l}2 \text { Participants with complications at } \\
\text { end of study }\end{array}$ & 14 & 882 & $\begin{array}{l}\text { Risk Ratio (M-H, Fixed, 99\% } \\
\text { Cl) }\end{array}$ & $0.69[0.59,0.81]$ \\
\hline 2.1 Oral supplements & 11 & 727 & $\begin{array}{l}\text { Risk Ratio (M-H, Fixed, 99\% } \\
\text { Cl) }\end{array}$ & $0.71[0.59,0.86]$ \\
\hline 2.2 Nasogastric tube feeding & 1 & 18 & $\begin{array}{l}\text { Risk Ratio (M-H, Fixed, 99\% } \\
\mathrm{Cl} \text { ) }\end{array}$ & $1.09[0.73,1.64]$ \\
\hline $\begin{array}{l}2.3 \text { Nasogastric tube feeding and oral } \\
\text { supplements }\end{array}$ & 1 & 57 & $\begin{array}{l}\text { Risk Ratio (M-H, Fixed, 99\% } \\
\mathrm{Cl} \text { ) }\end{array}$ & $1.11[0.75,1.65]$ \\
\hline $\begin{array}{l}2.4 \text { Intravenous feeding and oral sup- } \\
\text { plements }\end{array}$ & 1 & 80 & $\begin{array}{l}\text { Risk Ratio (M-H, Fixed, 99\% } \\
\mathrm{Cl} \text { ) }\end{array}$ & $0.21[0.10,0.46]$ \\
\hline $\begin{array}{l}3 \text { Participants with complications at } \\
\text { end of study: random-effects model }\end{array}$ & 14 & 882 & $\begin{array}{l}\text { Risk Ratio (M-H, Random, } \\
99 \% \mathrm{Cl})\end{array}$ & $0.70[0.53,0.91]$ \\
\hline
\end{tabular}




\begin{tabular}{|c|c|c|c|c|}
\hline Outcome or subgroup title & No. of studies & $\begin{array}{l}\text { No. of partici- } \\
\text { pants }\end{array}$ & Statistical method & Effect size \\
\hline 3.1 Oral supplements & 11 & 727 & $\begin{array}{l}\text { Risk Ratio (M-H, Random, } \\
99 \% \mathrm{Cl})\end{array}$ & $0.72[0.58,0.89]$ \\
\hline 3.2 Nasogastric tube feeding & 1 & 18 & $\begin{array}{l}\text { Risk Ratio (M-H, Random, } \\
99 \% \mathrm{Cl})\end{array}$ & $1.09[0.73,1.64]$ \\
\hline $\begin{array}{l}\text { 3.3 Nasogastric tube feeding and oral } \\
\text { supplements }\end{array}$ & 1 & 57 & $\begin{array}{l}\text { Risk Ratio (M-H, Random, } \\
99 \% \mathrm{Cl})\end{array}$ & $1.11[0.75,1.65]$ \\
\hline $\begin{array}{l}3.4 \text { Intravenous feeding and oral sup- } \\
\text { plements }\end{array}$ & 1 & 80 & $\begin{array}{l}\text { Risk Ratio (M-H, Random, } \\
99 \% \mathrm{Cl})\end{array}$ & $0.21[0.10,0.46]$ \\
\hline $\begin{array}{l}4 \text { Unfavourable outcome (death or } \\
\text { complications) at end of study }\end{array}$ & 6 & 334 & $\begin{array}{l}\text { Risk Ratio (M-H, Fixed, 99\% } \\
\mathrm{Cl})\end{array}$ & $0.67[0.51,0.89]$ \\
\hline 4.1 Oral supplements & 6 & 334 & $\begin{array}{l}\text { Risk Ratio (M-H, Fixed, 99\% } \\
\mathrm{Cl})\end{array}$ & $0.67[0.51,0.89]$ \\
\hline 4.2 Nasogastric tube feeding & 0 & 0 & $\begin{array}{l}\text { Risk Ratio (M-H, Fixed, 99\% } \\
\mathrm{Cl})\end{array}$ & $0.0[0.0,0.0]$ \\
\hline $\begin{array}{l}\text { 4.3 Nasogastric tube feeding and oral } \\
\text { supplements }\end{array}$ & 0 & 0 & $\begin{array}{l}\text { Risk Ratio (M-H, Fixed, 99\% } \\
\mathrm{Cl})\end{array}$ & $0.0[0.0,0.0]$ \\
\hline $\begin{array}{l}4.4 \text { Intravenous feeding and oral sup- } \\
\text { plements }\end{array}$ & 0 & 0 & $\begin{array}{l}\text { Risk Ratio (M-H, Fixed, 99\% } \\
\text { Cl) }\end{array}$ & $0.0[0.0,0.0]$ \\
\hline $\begin{array}{l}5 \text { Unfavourable outcome (death or } \\
\text { complications) - oral supplements ex- } \\
\text { tra analyses }\end{array}$ & 6 & & $\begin{array}{l}\text { Risk Ratio (M-H, Fixed, 99\% } \\
\mathrm{Cl})\end{array}$ & Subtotals only \\
\hline $\begin{array}{l}5.1 \text { Oral supplements: worst case sce- } \\
\text { nario }\end{array}$ & 6 & 353 & $\begin{array}{l}\text { Risk Ratio (M-H, Fixed, 99\% } \\
\mathrm{Cl} \text { ) }\end{array}$ & $0.81[0.62,1.04]$ \\
\hline $\begin{array}{l}\text { 5.2 Oral supplements: Hankins } 1996 \\
\text { acute hospital data }\end{array}$ & 1 & 31 & $\begin{array}{l}\text { Risk Ratio (M-H, Fixed, 99\% } \\
\text { Cl) }\end{array}$ & $0.96[0.71,1.31]$ \\
\hline $\begin{array}{l}\text { 5.3 Oral supplements: Hankins } 1996 \\
\text { post discharge }\end{array}$ & 1 & 31 & $\begin{array}{l}\text { Risk Ratio (M-H, Fixed, 99\% } \\
\text { Cl) }\end{array}$ & $1.10[0.50,2.41]$ \\
\hline $\begin{array}{l}6 \text { Adverse effects (putatively related } \\
\text { to treatment) }\end{array}$ & 8 & & $\begin{array}{l}\text { Risk Ratio (M-H, Fixed, 99\% } \\
\mathrm{Cl} \text { ) }\end{array}$ & Subtotals only \\
\hline $\begin{array}{l}6.1 \text { Oral supplements (mainly diar- } \\
\text { rhoea or/and vomiting) }\end{array}$ & 6 & 442 & $\begin{array}{l}\text { Risk Ratio (M-H, Fixed, 99\% } \\
\mathrm{Cl})\end{array}$ & $0.99[0.47,2.05]$ \\
\hline 6.2 Nasogatric tube feeding & 1 & 18 & $\begin{array}{l}\text { Risk Ratio (M-H, Fixed, 99\% } \\
\mathrm{Cl})\end{array}$ & $8.56[0.51,144.86]$ \\
\hline $\begin{array}{l}6.3 \text { Intravenous feeding and oral sup- } \\
\text { plements }\end{array}$ & 1 & 57 & $\begin{array}{l}\text { Risk Ratio (M-H, Fixed, 99\% } \\
\mathrm{Cl} \text { ) }\end{array}$ & $1.85[0.49,7.03]$ \\
\hline $\begin{array}{l}\text { 6.4 Nasogastric tube feeding and oral } \\
\text { supplements }\end{array}$ & 0 & 0 & $\begin{array}{l}\text { Risk Ratio (M-H, Fixed, 99\% } \\
\mathrm{Cl})\end{array}$ & $0.0[0.0,0.0]$ \\
\hline
\end{tabular}


Analysis 1.1. Comparison 1 Multinutrient supplements (oral, nasogastric, intravenous) versus control, Outcome 1 Mortality by end of study.

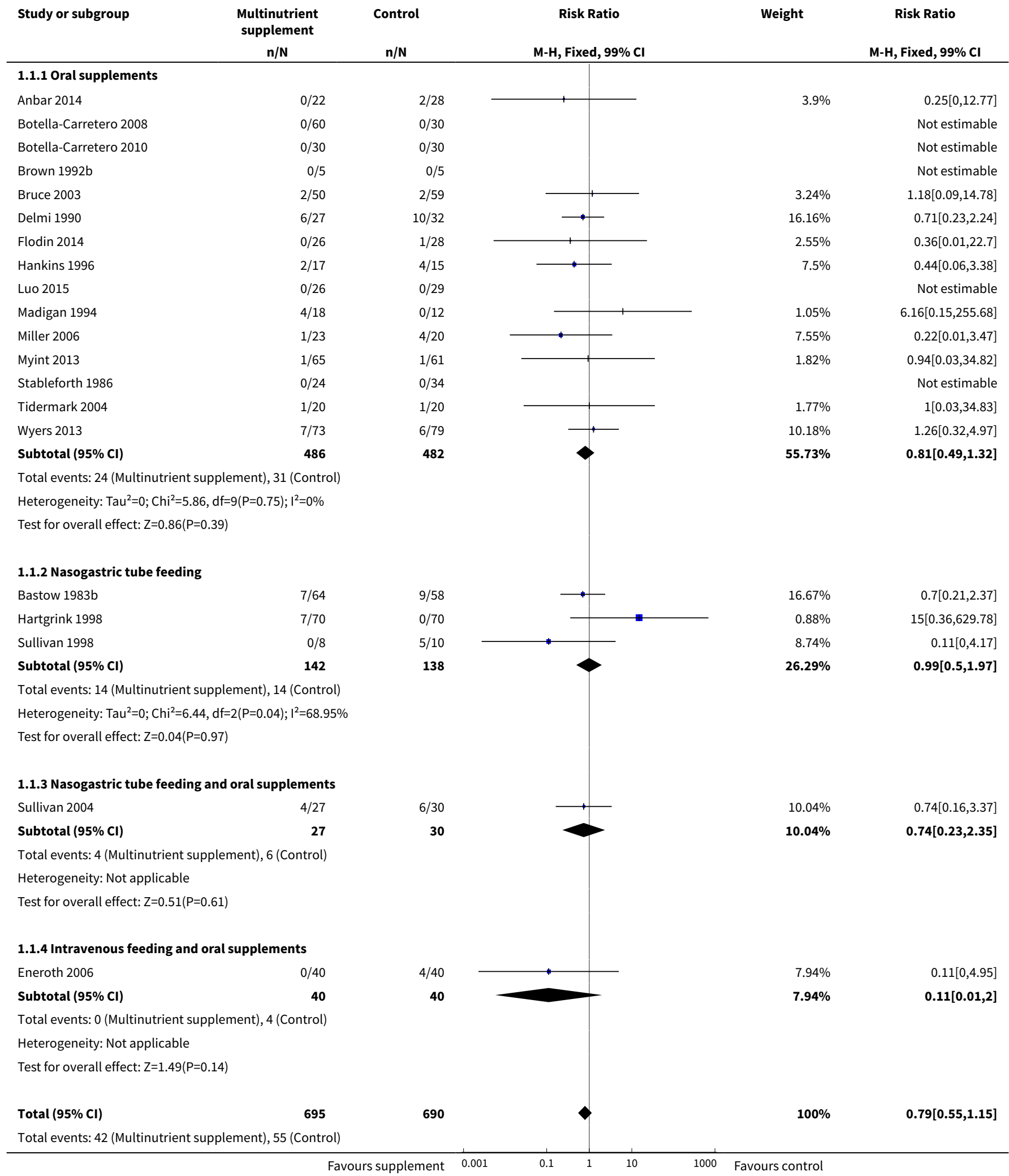




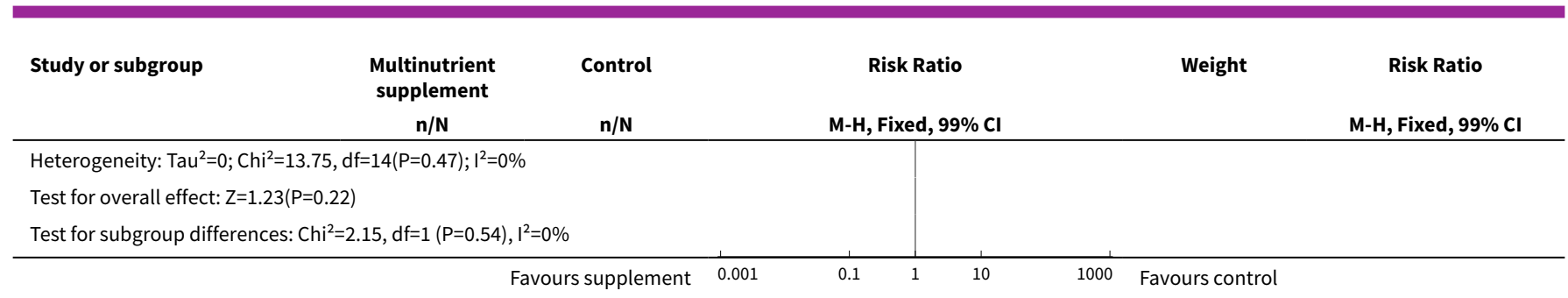

\section{Analysis 1.2. Comparison 1 Multinutrient supplements (oral, nasogastric, intravenous) versus control, Outcome 2 Participants with complications at end of study.}

\begin{tabular}{lr} 
Study or subgroup & $\begin{array}{c}\text { Multinutrient } \\
\text { supplement } \\
\text { n/N }\end{array}$ \\
\hline 1.2.1 Oral supplements & $6 / 22$ \\
Anbar 2014 & $32 / 60$ \\
Botella-Carretero 2008 & $6 / 30$ \\
Botella-Carretero 2010 & $4 / 25$ \\
Delmi 1990 & $6 / 20$ \\
Flodin 2014 & $5 / 17$ \\
Hankins 1996 & $6 / 18$ \\
Madigan 1994 & $25 / 61$ \\
Myint 2013 & $0 / 24$ \\
Stableforth 1986 & $3 / 20$ \\
Tidermark 2004 & $30 / 73$ \\
Wyers 2013 & $\mathbf{3 7 0}$ \\
Subtotal (95\% CI) &
\end{tabular}

Total events: 123 (Multinutrient supplement), 157 (Control) Heterogeneity: $\mathrm{Tau}^{2}=0 ; \mathrm{Chi}^{2}=10.35, \mathrm{df}=9(\mathrm{P}=0.32) ; \mathrm{I}^{2}=13.07 \%$

Test for overall effect: $Z=3.61(P=0)$

\subsubsection{Nasogastric tube feeding}

Sullivan 1998

Subtotal $(95 \% \mathrm{Cl})$

Control

Risk Ratio

Weight

Risk Ratio $\mathrm{n} / \mathrm{N}$ M-H, Fixed, $99 \% \mathrm{CI}$ M-H, Fixed, $99 \% \mathrm{Cl}$

Total events: 7 (Multinutrient supplement), 8 (Control) Heterogeneity: Not applicable

Test for overall effect: $\mathrm{Z}=0.43(\mathrm{P}=0.67)$

1.2.3 Nasogastric tube feeding and oral supplements

Total events: 18 (Multinutrient supplement), 18 (Control) Heterogeneity: Not applicable

Test for overall effect: $Z=0.52(P=0.6)$

1.2.4 Intravenous feeding and oral supplements

\section{$18 / 28$}

$18 / 28$
$15 / 30$

$12 / 30$

$10 / 27$

$14 / 25$

$6 / 12$

$4 / 12$

$38 / 60$

$0 / 34$

$5 / 20$

$35 / 79$

357
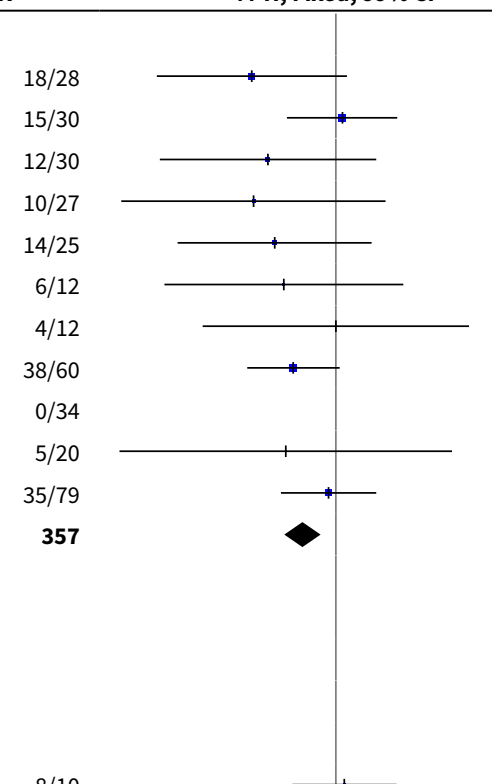

$8 / 10$

$3.37 \%$

$1.09[0.64,1.86]$
$0.42[0.16,1.12]$

$1.07[0.61,1.87]$

$0.5[0.17,1.51]$

$0.54[0.2,1.44]$

$0.59[0.17,1.99]$

$1[0.26,3.89]$

$0.65[0.4,1.04]$

Not estimable

$0.6[0.11,3.27]$

$0.93[0.57,1.51]$

$\mathbf{0 . 7 1}[0.59,0.86]$
$0.43[0.11,1.66]$

Total events: 6 (Multinutrient supplement), 28 (Control)

Heterogeneity: Not applicable

Test for overall effect: $Z=3.95(P<0.0001)$

10

$3.37 \%$

$1.09[0.73,1.64]$

$18 / 30$

30

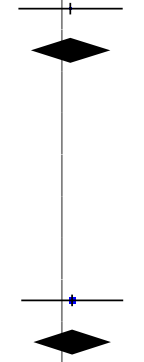

$8.09 \%$

$8.09 \%$

$1.11[0.66,1.87]$

$1.11[0.75,1.65]$ 


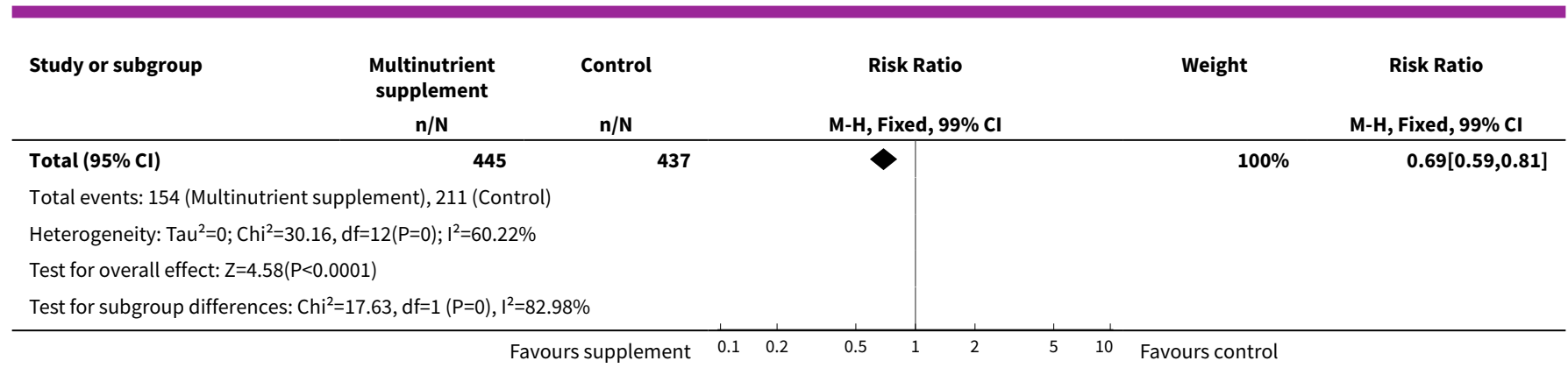

\section{Analysis 1.3. Comparison 1 Multinutrient supplements (oral, nasogastric, intravenous) versus control, Outcome 3 Participants with complications at end of study: random-effects model.}

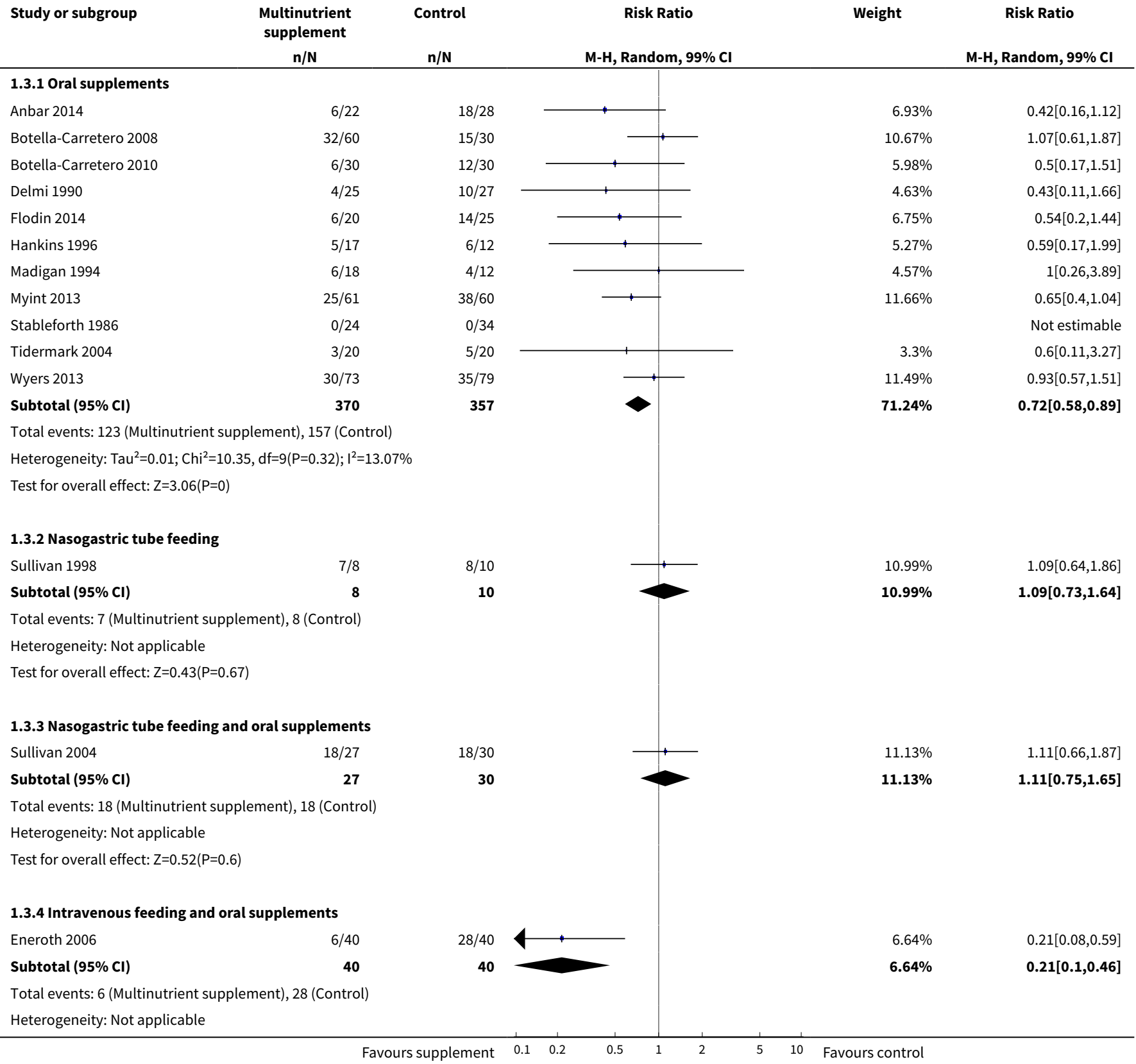




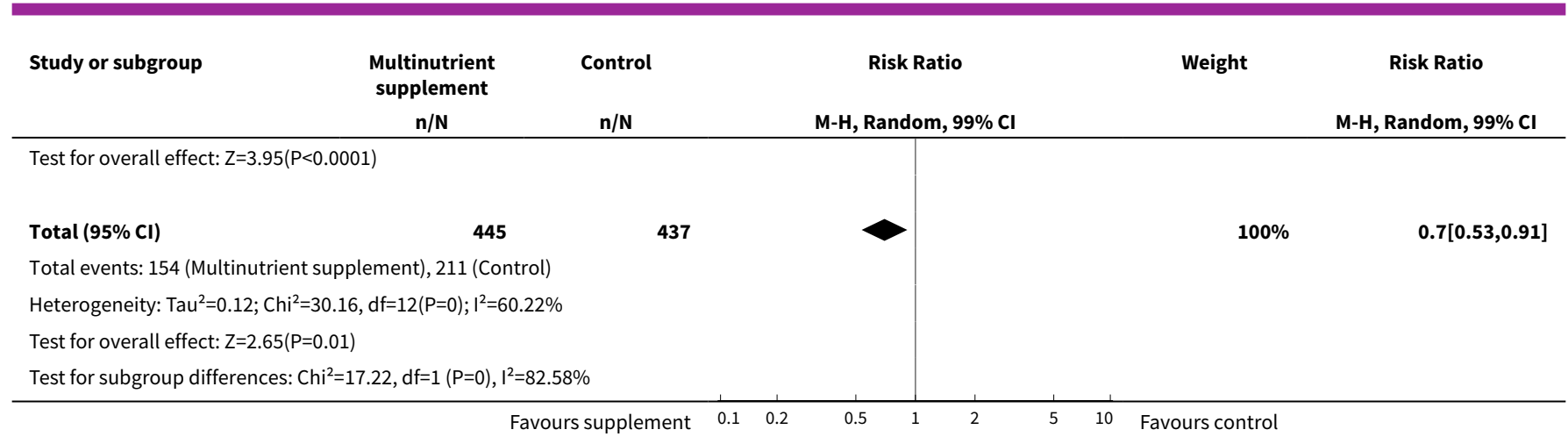

\section{Analysis 1.4. Comparison 1 Multinutrient supplements (oral, nasogastric, intravenous) versus control, Outcome 4 Unfavourable outcome (death or complications) at end of study.}

\begin{tabular}{|c|c|c|c|c|c|}
\hline Study or subgroup & $\begin{array}{c}\text { Multinutrient } \\
\text { supplement } \\
\mathrm{n} / \mathrm{N}\end{array}$ & $n / N$ & M-H, Fixed, 99\% CI & Weight & $\begin{array}{c}\text { Risk Ratio } \\
\text { M-H, Fixed, 99\% Cl }\end{array}$ \\
\hline 1.4.1 Oral supplements & & & & & \\
\hline Botella-Carretero 2008 & $32 / 60$ & $15 / 30$ & 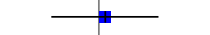 & $28.28 \%$ & $1.07[0.61,1.87]$ \\
\hline Botella-Carretero 2010 & $6 / 30$ & $12 / 30$ & 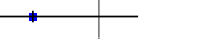 & $16.97 \%$ & $0.5[0.17,1.51]$ \\
\hline Delmi 1990 & $10 / 25$ & $20 / 27$ & & $27.2 \%$ & $0.54[0.27,1.08]$ \\
\hline Hankins 1996 & $4 / 17$ & $6 / 12$ & - & $9.95 \%$ & $0.47[0.12,1.81]$ \\
\hline Stableforth 1986 & $0 / 24$ & $0 / 34$ & & & Not estimable \\
\hline Subtotal (95\% Cl) & 176 & 158 & & $100 \%$ & $0.67[0.51,0.89]$ \\
\hline
\end{tabular}

Total events: 58 (Multinutrient supplement), 67 (Control) Heterogeneity: $\mathrm{Tau}^{2}=0 ; \mathrm{Chi}^{2}=6.38, \mathrm{df}=4(\mathrm{P}=0.17) ; \mathrm{I}^{2}=37.31 \%$

Test for overall effect: $\mathrm{Z}=2.8(\mathrm{P}=0.01)$

\subsubsection{Nasogastric tube feeding}

Total events: 0 (Multinutrient supplement), 0 (Control) Heterogeneity: Not applicable

Test for overall effect: Not applicable

1.4.3 Nasogastric tube feeding and oral supplements Subtotal $(95 \% \mathrm{Cl})$

Total events: 0 (Multinutrient supplement), 0 (Control) Heterogeneity: Not applicable

Test for overall effect: Not applicable

1.4.4 Intravenous feeding and oral supplements Subtotal $(95 \% \mathrm{CI})$

Total events: 0 (Multinutrient supplement), 0 (Control) Heterogeneity: Not applicable

Test for overall effect: Not applicable

Total events: 58 (Multinutrient supplement), 67 (Control) Heterogeneity: $\mathrm{Tau}^{2}=0 ; \mathrm{Chi}^{2}=6.38, \mathrm{df}=4(\mathrm{P}=0.17) ; \mathrm{I}^{2}=37.31 \%$ Test for overall effect: $\mathrm{Z}=2.8(\mathrm{P}=0.01)$

0

Not estimable

$100 \%$ 


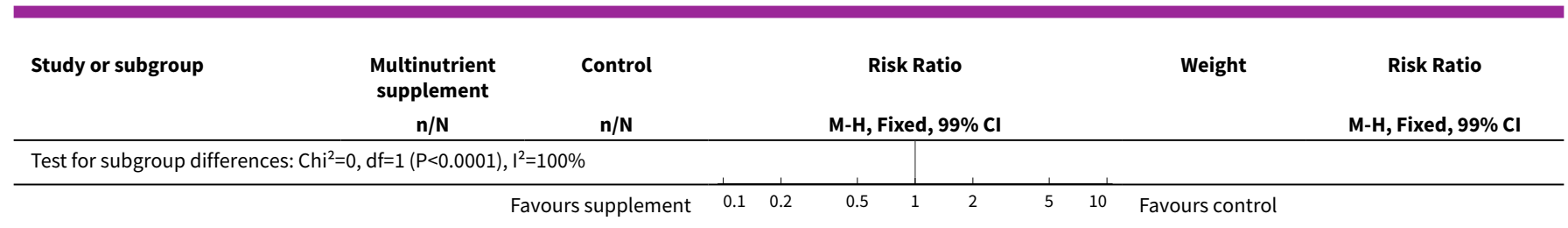

Analysis 1.5. Comparison 1 Multinutrient supplements (oral, nasogastric, intravenous) versus control, Outcome 5 Unfavourable outcome (death or complications) - oral supplements extra analyses.

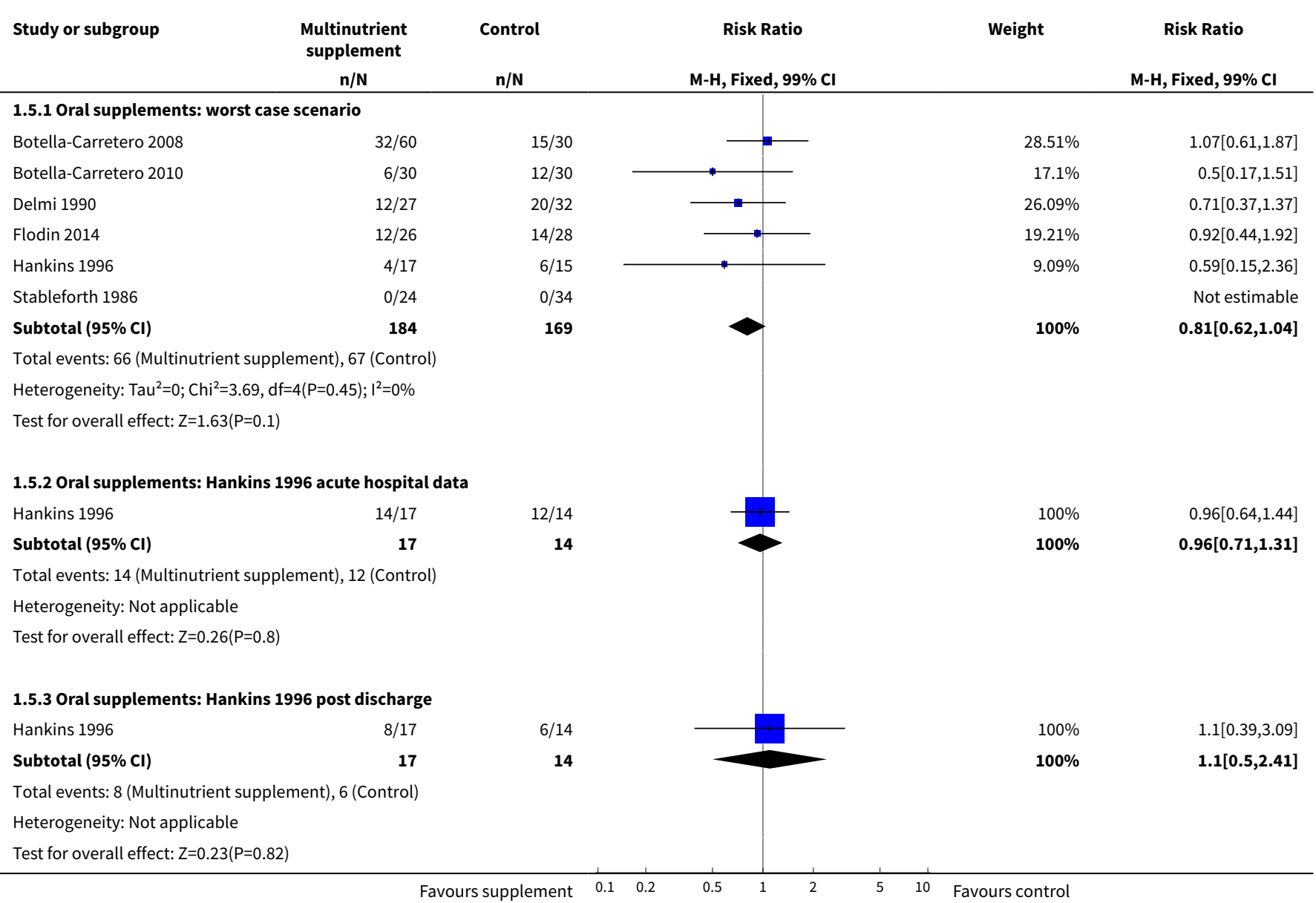

Analysis 1.6. Comparison 1 Multinutrient supplements (oral, nasogastric, intravenous) versus control, Outcome 6 Adverse effects (putatively related to treatment).

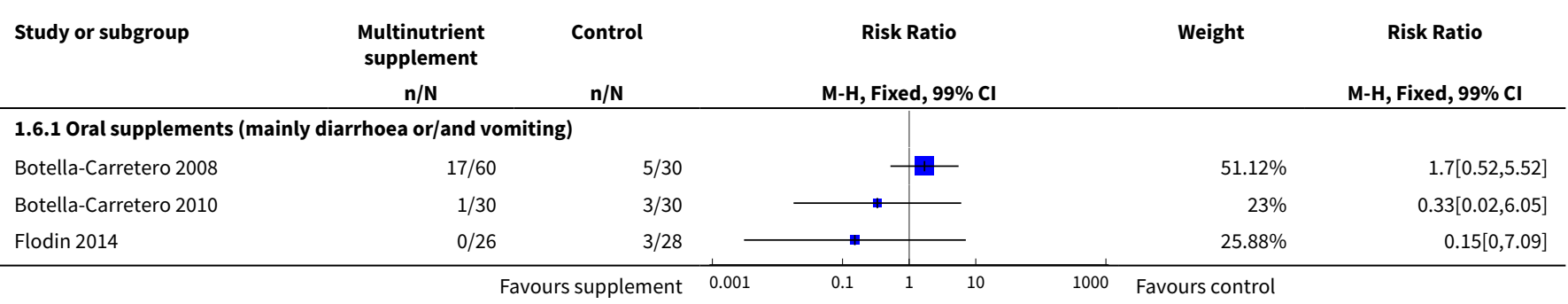




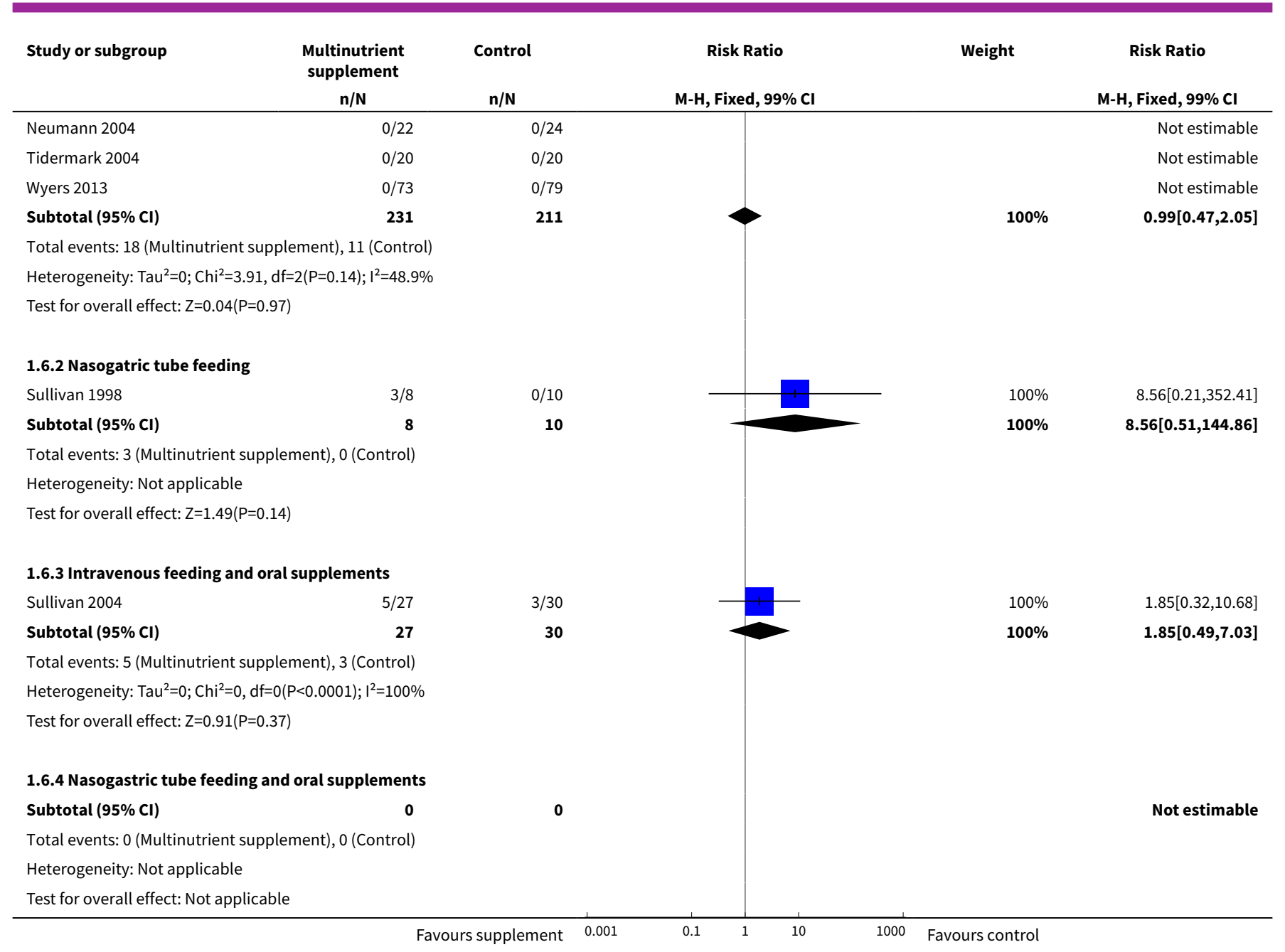

\section{Comparison 2. Multinutrient supplements (oral, nasogastric routes, intravenous) versus control (split by nutritional status)}

\begin{tabular}{|c|c|c|c|c|}
\hline Outcome or subgroup title & No. of studies & $\begin{array}{l}\text { No. of partici- } \\
\text { pants }\end{array}$ & Statistical method & Effect size \\
\hline 1 Mortality by end of study & 20 & 1385 & Risk Ratio (M-H, Fixed, 99\% Cl) & $0.79[0.55,1.15]$ \\
\hline 1.1 Malnourished targeted & 6 & 388 & Risk Ratio (M-H, Fixed, 99\% Cl) & $0.55[0.27,1.11]$ \\
\hline 1.2 Malnourished not targeted & 14 & 997 & Risk Ratio (M-H, Fixed, 99\% Cl) & $0.92[0.59,1.42]$ \\
\hline $\begin{array}{l}2 \text { Mortality by end of study - oral } \\
\text { supplements only }\end{array}$ & 15 & 968 & Risk Ratio (M-H, Fixed, 99\% Cl) & $0.81[0.49,1.32]$ \\
\hline 2.1 Malnourished targeted & 5 & 266 & Risk Ratio (M-H, Fixed, 99\% Cl) & $0.39[0.13,1.20]$ \\
\hline 2.2 Malnourished not targeted & 10 & 702 & Risk Ratio (M-H, Fixed, 99\% Cl) & $0.99[0.56,1.72]$ \\
\hline $\begin{array}{l}3 \text { Participants with complications } \\
\text { at end of study }\end{array}$ & 14 & 882 & Risk Ratio (M-H, Fixed, 99\% Cl) & $0.69[0.59,0.81]$ \\
\hline
\end{tabular}




\begin{tabular}{lllll}
\hline Outcome or subgroup title & No. of studies & $\begin{array}{l}\text { No. of partici- } \\
\text { pants }\end{array}$ & Statistical method & Effect size \\
\hline 3.1 Malnourished targeted & 2 & 150 & Risk Ratio (M-H, Fixed, 99\% Cl) & $0.64[0.46,0.89]$ \\
\hline $\begin{array}{lllll}\text { 3.2 Malnourished not targeted } \\
\text { 4 Unfavourable outcome (death or } \\
\text { complications) at end of study }\end{array}$ & 6 & 732 & Risk Ratio (M-H, Fixed, 99\% Cl) & $0.70[0.59,0.84]$ \\
\hline $\begin{array}{l}\text { 4.1 Malnourished targeted } \\
\text { 4.2 Malnourished not targeted }\end{array}$ & 12 & 334 & Risk Ratio (M-H, Fixed, 99\% Cl) & $0.67[0.51,0.89]$ \\
\hline
\end{tabular}

Analysis 2.1. Comparison 2 Multinutrient supplements (oral, nasogastric routes, intravenous) versus control (split by nutritional status), Outcome 1 Mortality by end of study.

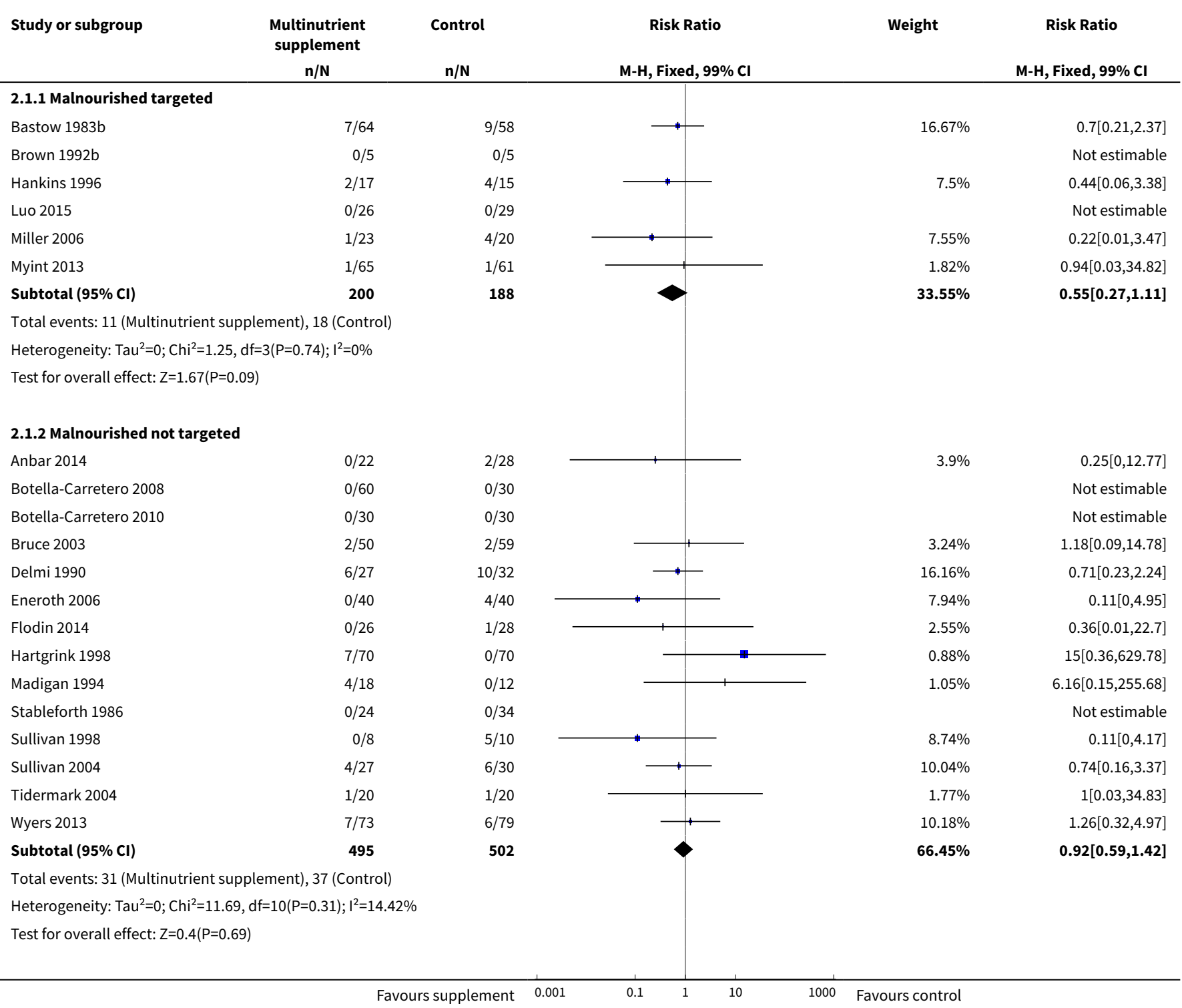




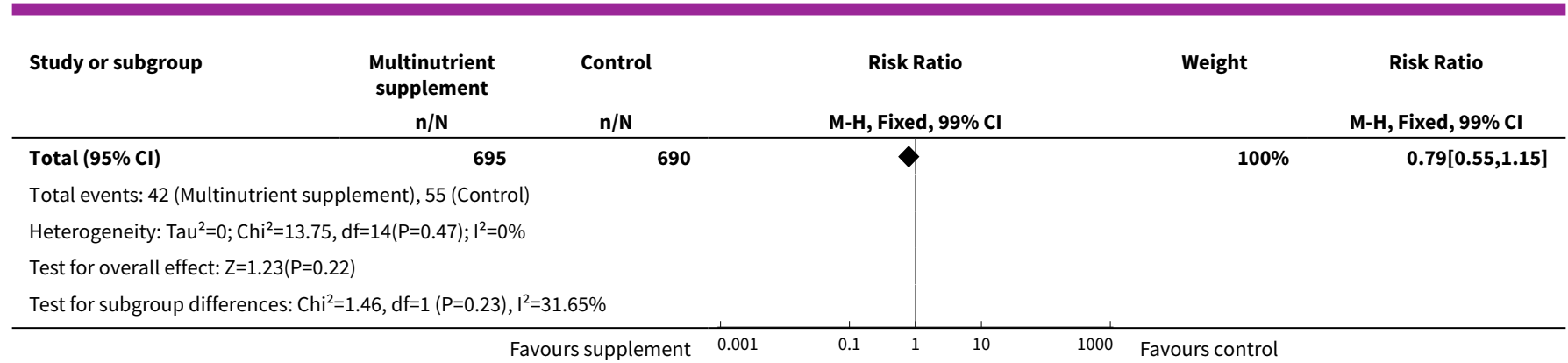

\section{Analysis 2.2. Comparison 2 Multinutrient supplements (oral, nasogastric routes, intravenous) versus control (split by nutritional status), Outcome 2 Mortality by end of study - oral supplements only.}

\begin{tabular}{|c|c|c|c|c|c|}
\hline \multirow[t]{2}{*}{ Study or subgroup } & $\begin{array}{l}\text { Multinutrient } \\
\text { supplement }\end{array}$ & Control & Risk Ratio & Weight & Risk Ratio \\
\hline & $n / N$ & $n / N$ & M-H, Fixed, $99 \% \mathrm{Cl}$ & & M-H, Fixed, 99\% Cl \\
\hline
\end{tabular}

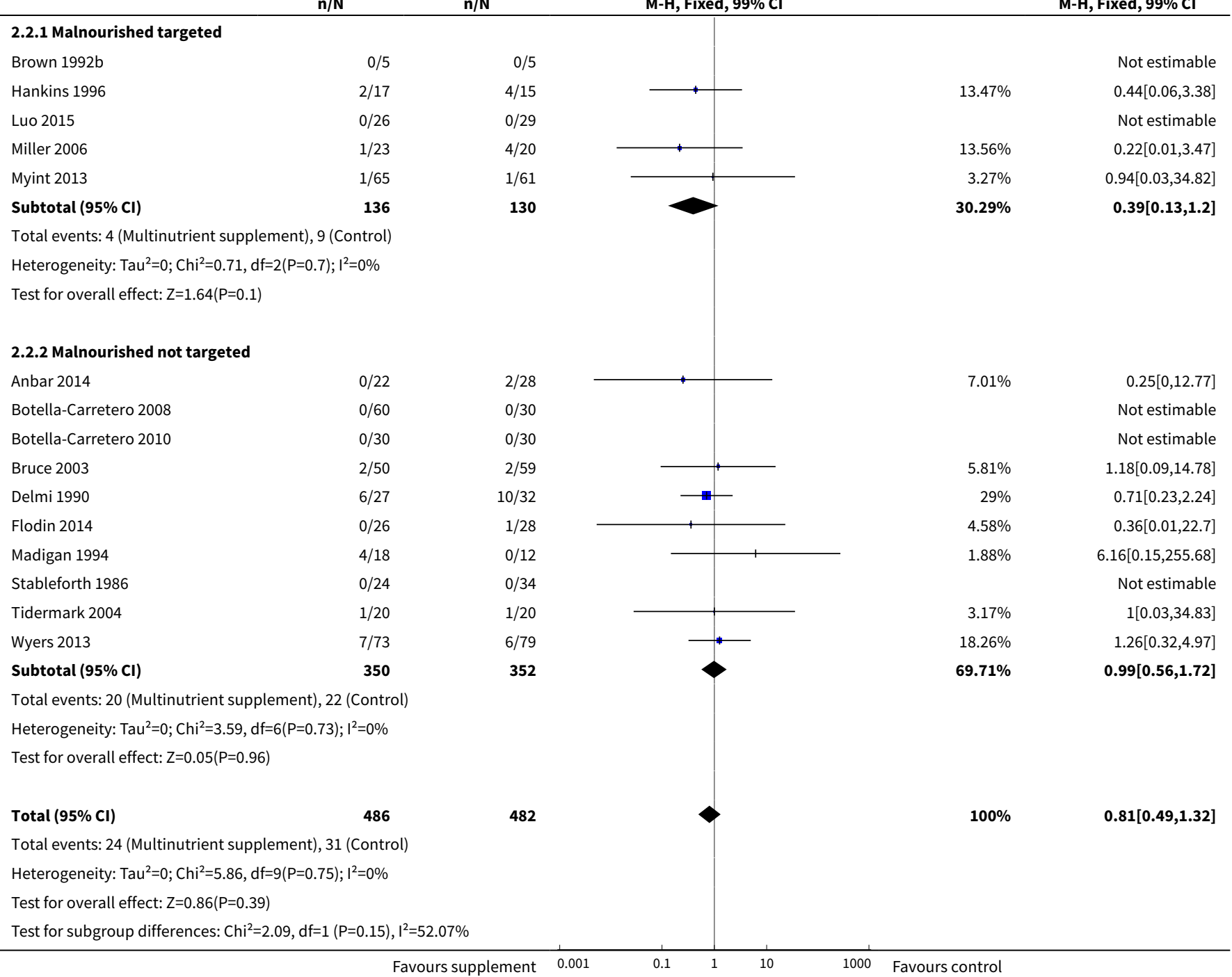


Analysis 2.3. Comparison 2 Multinutrient supplements (oral, nasogastric routes, intravenous) versus control (split by nutritional status), Outcome 3 Participants with complications at end of study.

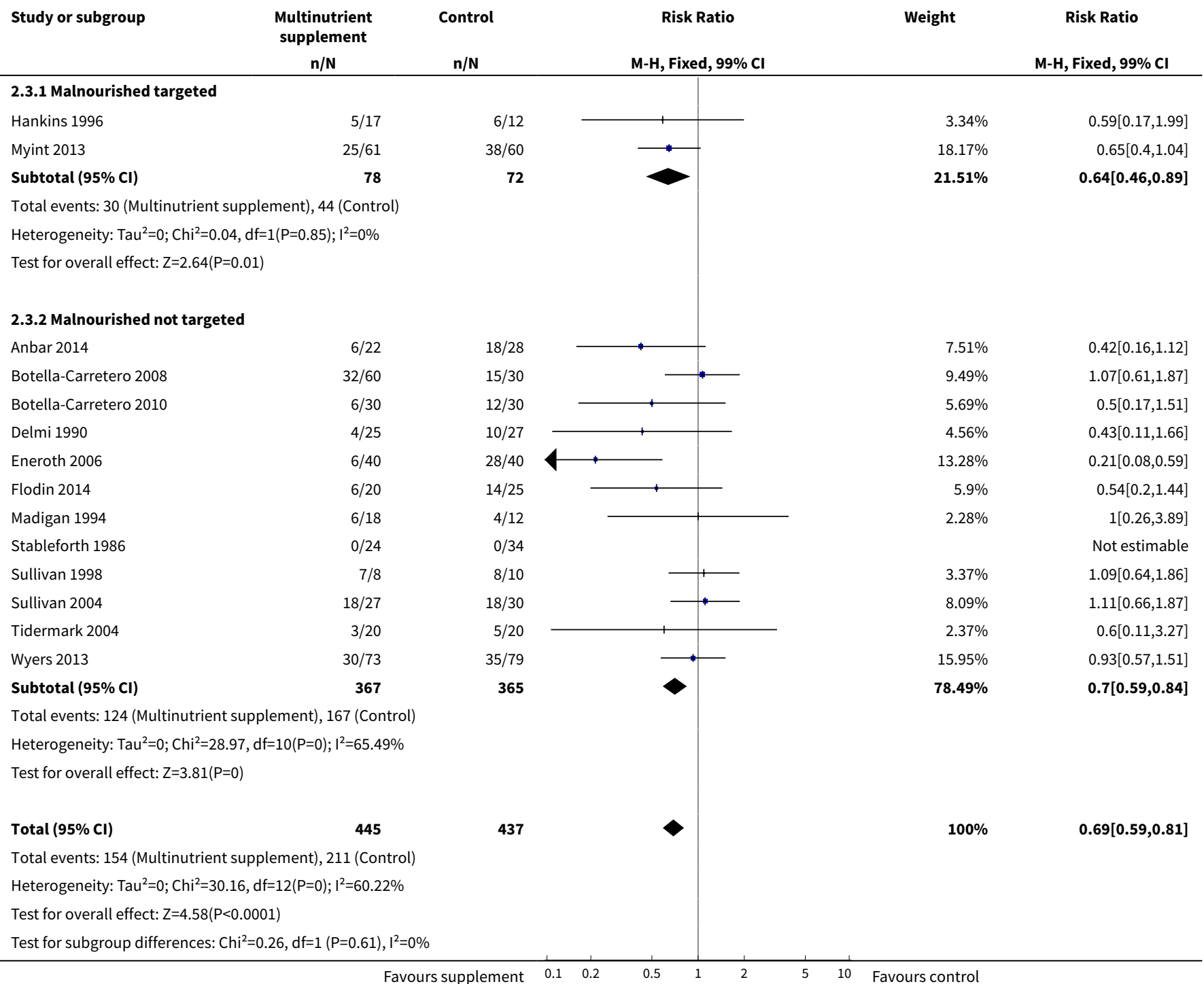

Analysis 2.4. Comparison 2 Multinutrient supplements (oral, nasogastric routes, intravenous) versus control (split by nutritional status), Outcome 4 Unfavourable outcome (death or complications) at end of study.

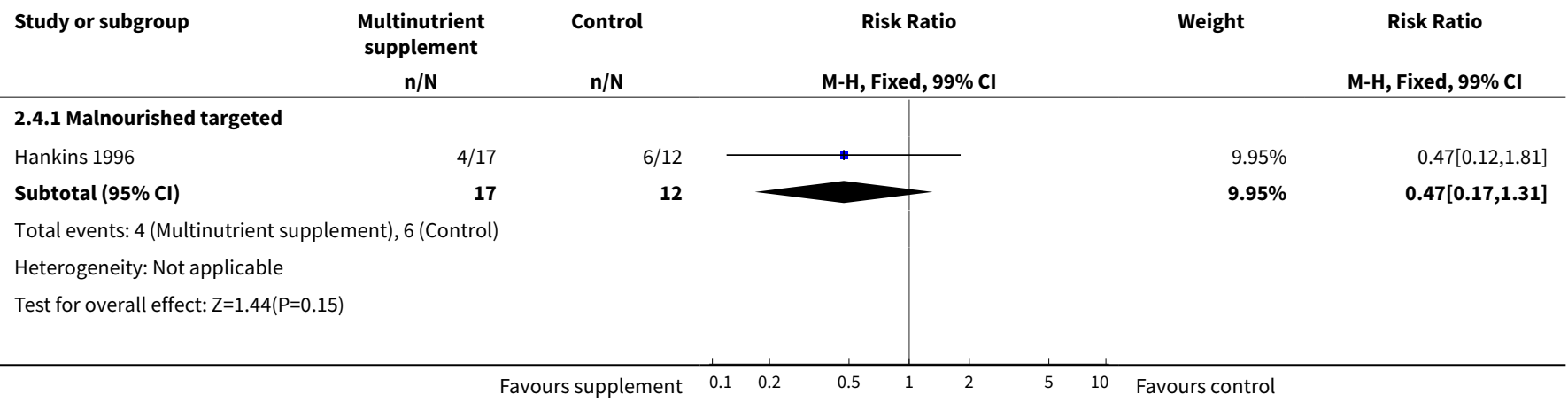




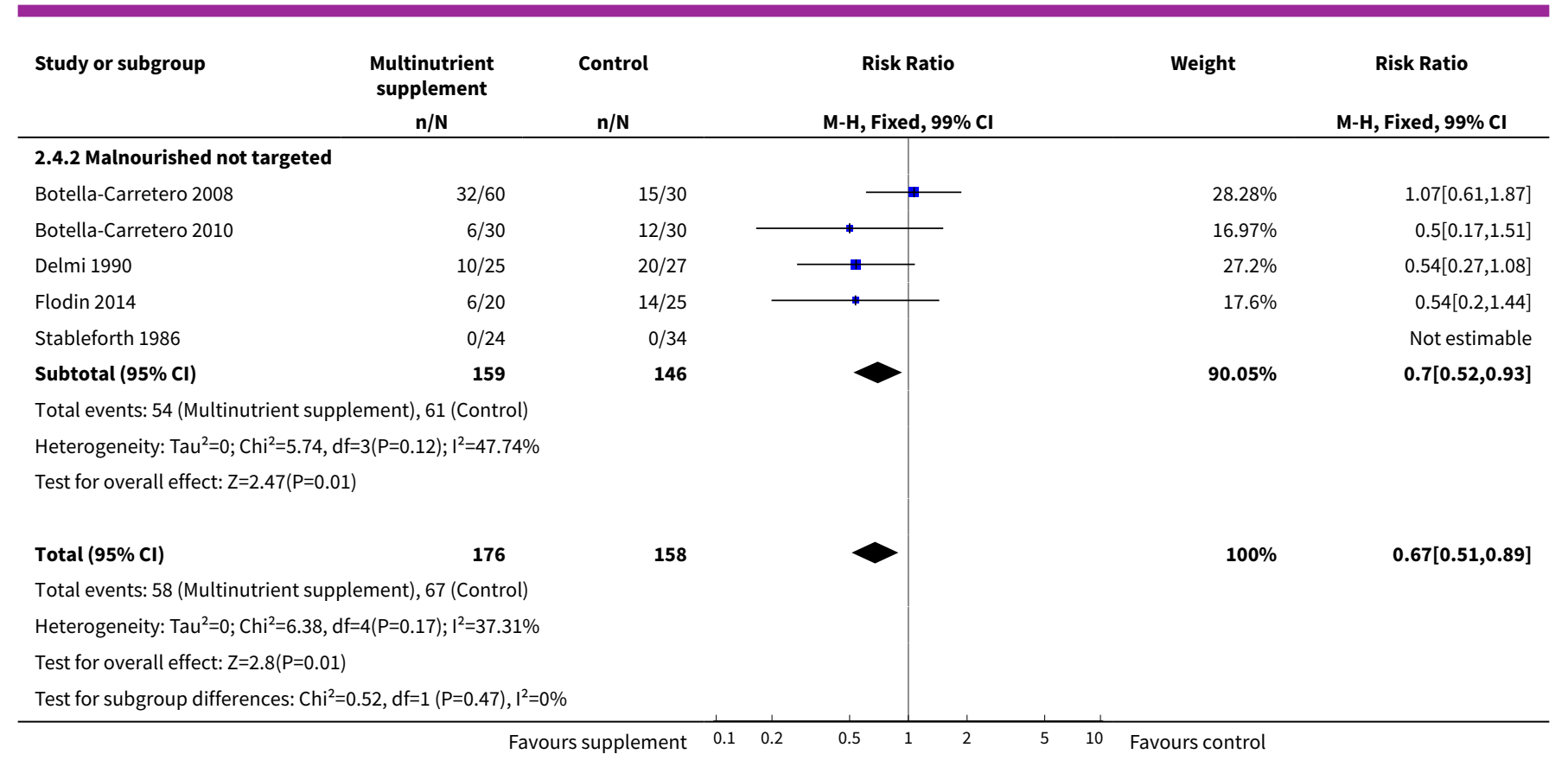

Comparison 3. Multinutrient supplements (oral, nasogastric routes, intravenous) versus control (by allocation concealment)

\begin{tabular}{|c|c|c|c|c|}
\hline Outcome or subgroup title & No. of studies & $\begin{array}{l}\text { No. of partici- } \\
\text { pants }\end{array}$ & Statistical method & Effect size \\
\hline $\begin{array}{l}1 \text { Mortality by end of study by risk of } \\
\text { bias for allocation concealment }\end{array}$ & 20 & 1385 & Risk Ratio (M-H, Fixed, 99\% Cl) & $0.79[0.55,1.15]$ \\
\hline 1.1 Low risk of bias & 10 & 682 & Risk Ratio (M-H, Fixed, 99\% Cl) & $0.57[0.32,1.01]$ \\
\hline 1.2 Unclear risk of bias & 7 & 462 & Risk Ratio (M-H, Fixed, 99\% Cl) & $1.22[0.65,2.28]$ \\
\hline 1.3 High risk of bias & 3 & 241 & Risk Ratio (M-H, Fixed, 99\% Cl) & $0.78[0.34,1.79]$ \\
\hline $\begin{array}{l}2 \text { Participants with complications at } \\
\text { end of study by risk of bias for allo- } \\
\text { cation concealment }\end{array}$ & 14 & 882 & Risk Ratio (M-H, Fixed, 99\% Cl) & $0.69[0.59,0.81]$ \\
\hline 2.1 Low risk of bias & 9 & 622 & Risk Ratio (M-H, Fixed, 99\% Cl) & $0.78[0.66,0.92]$ \\
\hline 2.2 Unclear risk of bias & 5 & 260 & Risk Ratio (M-H, Fixed, 99\% Cl) & $0.38[0.24,0.61]$ \\
\hline 2.3 High risk of bias & 0 & 0 & Risk Ratio (M-H, Fixed, 99\% Cl) & $0.0[0.0,0.0]$ \\
\hline
\end{tabular}


Analysis 3.1. Comparison 3 Multinutrient supplements (oral, nasogastric routes, intravenous) versus control (by allocation concealment), Outcome 1 Mortality by end of study by risk of bias for allocation concealment.

\begin{tabular}{|c|c|c|c|c|c|}
\hline Study or subgroup & $\begin{array}{c}\text { Multinutrient } \\
\text { supplement } \\
\mathrm{n} / \mathrm{N} \\
\end{array}$ & $\begin{array}{l}\text { Control } \\
n / N\end{array}$ & $\begin{array}{c}\text { Risk Ratio } \\
\text { M-H, Fixed, } 99 \% \mathrm{CI} \\
\end{array}$ & Weight & $\begin{array}{c}\text { Risk Ratio } \\
\text { M-H, Fixed, } 99 \% \mathrm{Cl} \\
\end{array}$ \\
\hline \multicolumn{6}{|l|}{ 3.1.1 Low risk of bias } \\
\hline Anbar 2014 & $0 / 22$ & $2 / 28$ & & $3.9 \%$ & $0.25[0,12.77]$ \\
\hline Botella-Carretero 2008 & $0 / 60$ & $0 / 30$ & & & Not estimable \\
\hline Botella-Carretero 2010 & $0 / 30$ & $0 / 30$ & & & Not estimable \\
\hline Flodin 2014 & $0 / 26$ & $1 / 28$ & & $2.55 \%$ & $0.36[0.01,22.7]$ \\
\hline Hankins 1996 & $2 / 17$ & $4 / 15$ & $\longrightarrow$ & $7.5 \%$ & $0.44[0.06,3.38]$ \\
\hline Miller 2006 & $1 / 23$ & $4 / 20$ & $\longrightarrow$ & $7.55 \%$ & $0.22[0.01,3.47]$ \\
\hline Myint 2013 & $1 / 65$ & $1 / 61$ & & $1.82 \%$ & $0.94[0.03,34.82]$ \\
\hline Sullivan 1998 & $0 / 8$ & $5 / 10$ & & $8.74 \%$ & $0.11[0,4.17]$ \\
\hline Sullivan 2004 & $4 / 27$ & $6 / 30$ & & $10.04 \%$ & $0.74[0.16,3.37]$ \\
\hline Wyers 2013 & $7 / 73$ & $6 / 79$ & +1 & $10.18 \%$ & $1.26[0.32,4.97]$ \\
\hline \multicolumn{6}{|c|}{ Total events: 15 (Multinutrient supplement), 29 (Control) } \\
\hline \multicolumn{6}{|c|}{ Heterogeneity: $\mathrm{Tau}^{2}=0 ; \mathrm{Chi}^{2}=5.19, \mathrm{df}=7(\mathrm{P}=0.64) ; \mathrm{I}^{2}=0 \%$} \\
\hline \multicolumn{6}{|c|}{ Test for overall effect: $Z=1.94(P=0.05)$} \\
\hline \multicolumn{6}{|l|}{ 3.1.2 Unclear risk of bias } \\
\hline Delmi 1990 & $6 / 27$ & $10 / 32$ & - & $16.16 \%$ & $0.71[0.23,2.24]$ \\
\hline Eneroth 2006 & $0 / 40$ & $4 / 40$ & $\rightarrow$ & $7.94 \%$ & $0.11[0,4.95]$ \\
\hline Hartgrink 1998 & $7 / 70$ & $0 / 70$ & & $0.88 \%$ & $15[0.36,629.78]$ \\
\hline Luo 2015 & $0 / 26$ & $0 / 29$ & & & Not estimable \\
\hline Madigan 1994 & $4 / 18$ & $0 / 12$ & & $1.05 \%$ & $6.16[0.15,255.68]$ \\
\hline Stableforth 1986 & $0 / 24$ & $0 / 34$ & & & Not estimable \\
\hline Tidermark 2004 & $1 / 20$ & $1 / 20$ & & $1.77 \%$ & $1[0.03,34.83]$ \\
\hline Subtotal $(95 \% \mathrm{Cl})$ & 225 & 237 & & $27.8 \%$ & $1.22[0.65,2.28]$ \\
\hline \multicolumn{6}{|c|}{ Test for overall effect: $Z=0.61(P=0.54)$} \\
\hline \multicolumn{6}{|l|}{ 3.1.3 High risk of bias } \\
\hline Bastow 1983b & $7 / 64$ & $9 / 58$ & $\longrightarrow$ & $16.67 \%$ & $0.7[0.21,2.37]$ \\
\hline Brown 1992b & $0 / 5$ & $0 / 5$ & & & Not estimable \\
\hline Bruce 2003 & $2 / 50$ & $2 / 59$ & & $3.24 \%$ & $1.18[0.09,14.78]$ \\
\hline Subtotal $(95 \% \mathrm{Cl})$ & 119 & 122 & & $19.91 \%$ & $0.78[0.34,1.79]$ \\
\hline \multicolumn{6}{|c|}{ Total events: 9 (Multinutrient supplement), 11 (Control) } \\
\hline \multicolumn{6}{|c|}{ Heterogeneity: $\operatorname{Tau}^{2}=0 ; \mathrm{Chi}^{2}=0.22, \mathrm{df}=1(\mathrm{P}=0.64) ; \mathrm{I}^{2}=0 \%$} \\
\hline \multicolumn{6}{|c|}{ Test for overall effect: $Z=0.58(P=0.56)$} \\
\hline Total $(95 \% \mathrm{Cl})$ & 695 & 690 & & $100 \%$ & $0.79[0.55,1.15]$ \\
\hline \multicolumn{6}{|c|}{ Total events: 42 (Multinutrient supplement), 55 (Control) } \\
\hline \multicolumn{6}{|c|}{ Heterogeneity: $\operatorname{Tau}^{2}=0 ; \mathrm{Chi}^{2}=13.75, \mathrm{df}=14(\mathrm{P}=0.47) ; \mathrm{I}^{2}=0 \%$} \\
\hline \multicolumn{6}{|c|}{ Test for overall effect: $Z=1.23(P=0.22)$} \\
\hline Test for subgroup differ & $.08, d f=1(P=0.21)$, & $13 \%$ & & & \\
\hline
\end{tabular}


Analysis 3.2. Comparison 3 Multinutrient supplements (oral, nasogastric routes, intravenous) versus control (by allocation concealment), Outcome 2 Participants with complications at end of study by risk of bias for allocation concealment.

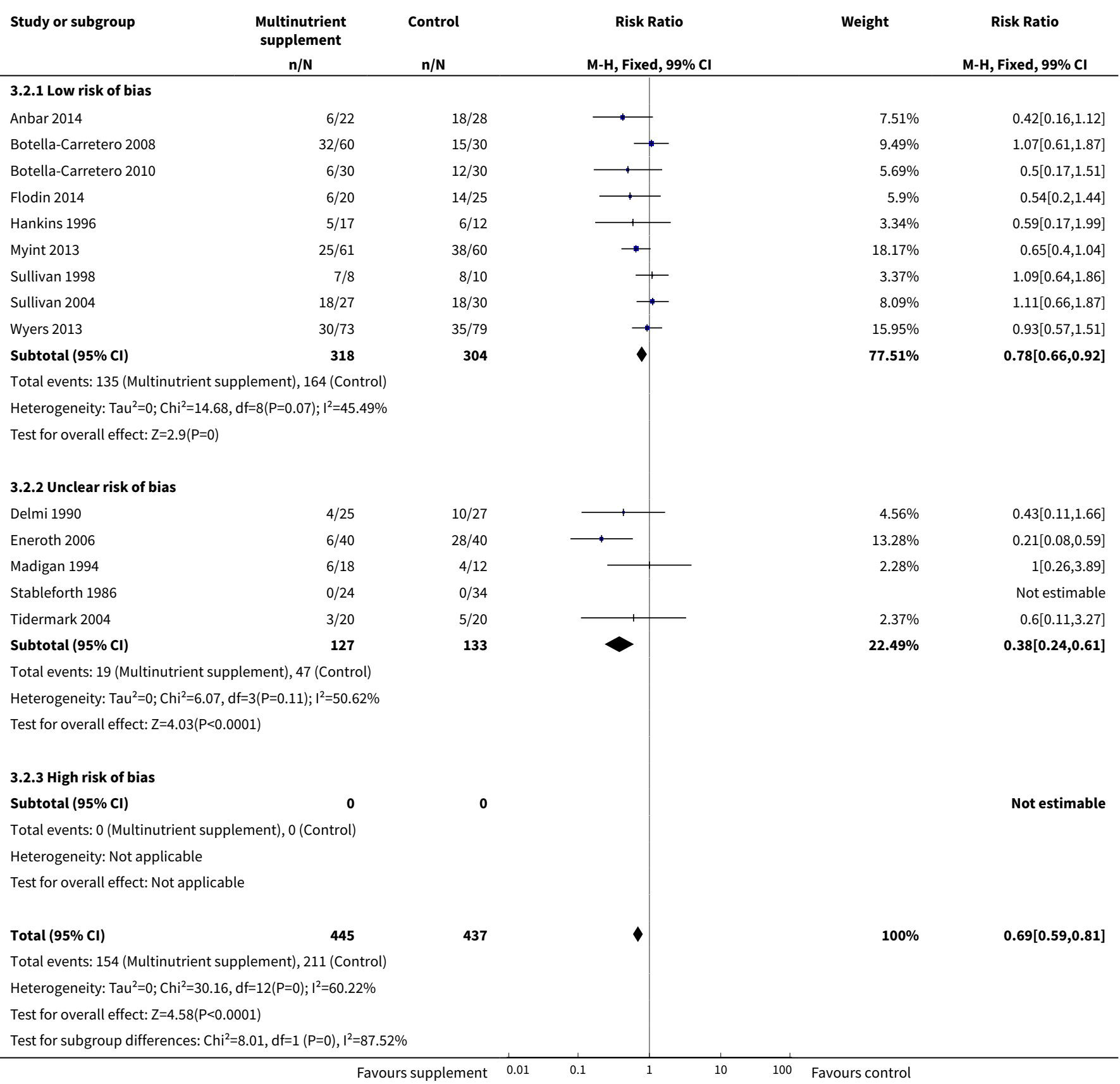

\section{Comparison 4. High protein-containing supplements versus low protein- or non-protein-containing supplements}

\begin{tabular}{lllll}
\hline Outcome or subgroup title & No. of studies & $\begin{array}{l}\text { No. of partici- } \\
\text { pants }\end{array}$ & Statistical method & Effect size \\
\hline 1 Mortality by end of study & 4 & 361 & $\begin{array}{l}\text { Risk Ratio (M-H, Fixed, } \\
99 \% \mathrm{Cl})\end{array}$ & $1.42[0.85,2.37]$ \\
\hline
\end{tabular}




\begin{tabular}{lllll}
\hline Outcome or subgroup title & No. of studies & $\begin{array}{l}\text { No. of partici- } \\
\text { pants }\end{array}$ & Statistical method & Effect size \\
\hline $\begin{array}{l}\text { 1.1 Protein-containing supplement v non- } \\
\text { protein-containing supplement }\end{array}$ & 3 & 315 & $\begin{array}{l}\text { Risk Ratio (M-H, Fixed, } \\
99 \% \mathrm{Cl})\end{array}$ & $1.38[0.82,2.34]$ \\
\hline $\begin{array}{l}1.2 \text { High protein-containing supplement v } \\
\text { low protein-containing supplement }\end{array}$ & 1 & 46 & $\begin{array}{l}\text { Risk Ratio (M-H, Fixed, } \\
99 \% \mathrm{Cl})\end{array}$ & $2.18[0.21,22.42]$ \\
\hline $\begin{array}{l}\text { 2 Unfavourable outcome (death or compli- } \\
\text { cations) at end of study }\end{array}$ & 2 & 223 & $\begin{array}{l}\text { Risk Ratio (M-H, Fixed, } \\
99 \% \mathrm{Cl})\end{array}$ & $0.78[0.65,0.95]$ \\
\hline $\begin{array}{l}\text { 2.1 Protein-containing supplement v non- } \\
\text { protein-containing supplement }\end{array}$ & 2 & 223 & $\begin{array}{l}\text { Risk Ratio (M-H, Fixed, } \\
99 \% \mathrm{Cl})\end{array}$ & $0.78[0.65,0.95]$ \\
\hline
\end{tabular}

Analysis 4.1. Comparison 4 High protein-containing supplements versus low protein-
or non-protein-containing supplements, Outcome 1 Mortality by end of study.

Study or subgroup

$\begin{array}{cc}\begin{array}{c}\text { Protein Sup- } \\ \text { plement }\end{array} & \text { Non- Protein } \\ \text { Supplement }\end{array}$

$n / N \quad n / N$

Risk Ratio

Weight

Risk Ratio

M-H, Fixed, $99 \% \mathrm{CI}$

M-H, Fixed, $99 \% \mathrm{Cl}$

$\begin{array}{lcr}\begin{array}{l}\text { 4.1.1 Protein-containing supplement } \mathbf{v} \text { non-protein-containing supple- } \\ \text { ment }\end{array} & & \\ \text { Espaulella } 2000 & 21 / 85 & 13 / 86 \\ \text { Schürch } 1998 & 4 / 41 & 3 / 41 \\ \text { Tkatch } 1992 & 3 / 33 & 4 / 29 \\ \text { Subtotal (95\% Cl) } & \mathbf{1 5 9} & \mathbf{1 5 6}\end{array}$

Total events: 28 (Protein Supplement), 20 ( Non- Protein Supplement)

Heterogeneity: $\mathrm{Tau}^{2}=0 ; \mathrm{Chi}^{2}=1.34, \mathrm{df}=2(\mathrm{P}=0.51) ; \mathrm{I}^{2}=0 \%$

Test for overall effect: $Z=1.22(P=0.22)$

4.1.2 High protein-containing supplement $v$ low protein-containing supplement

Neumann 2004

Subtotal $(95 \% \mathrm{CI})$

22

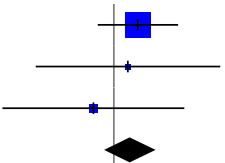

$61.14 \%$

1.63[0.72,3.71]

$14.19 \%$

$1.33[0.2,8.77]$

$0.66[0.1,4.21]$

$1.38[0.82,2.34]$

Total events: 2 (Protein Supplement), 1 ( Non- Protein Supplement)

Heterogeneity: Not applicable

Test for overall effect: $\mathrm{Z}=0.66(\mathrm{P}=0.51)$

Total events: 30 ( Protein Supplement ), 21 ( Non- Protein Supplement)

Heterogeneity: $\mathrm{Tau}^{2}=0 ; \mathrm{Chi}^{2}=1.47, \mathrm{df}=3(\mathrm{P}=0.69) ; \mathrm{I}^{2}=0 \%$

Test for overall effect: $Z=1.35(P=0.18)$

Test for subgroup differences: $\mathrm{Chi}^{2}=0.14, \mathrm{df}=1(\mathrm{P}=0.71), \mathrm{I}^{2}=0 \%$

$\begin{array}{lllllll}\text { Favours Protein } & 0.01 & 0.1 & 1 & 10 & 100 & \text { Favours Non-Protein }\end{array}$


Analysis 4.2. Comparison 4 High protein-containing supplements versus low protein- or non-proteincontaining supplements, Outcome 2 Unfavourable outcome (death or complications) at end of study.

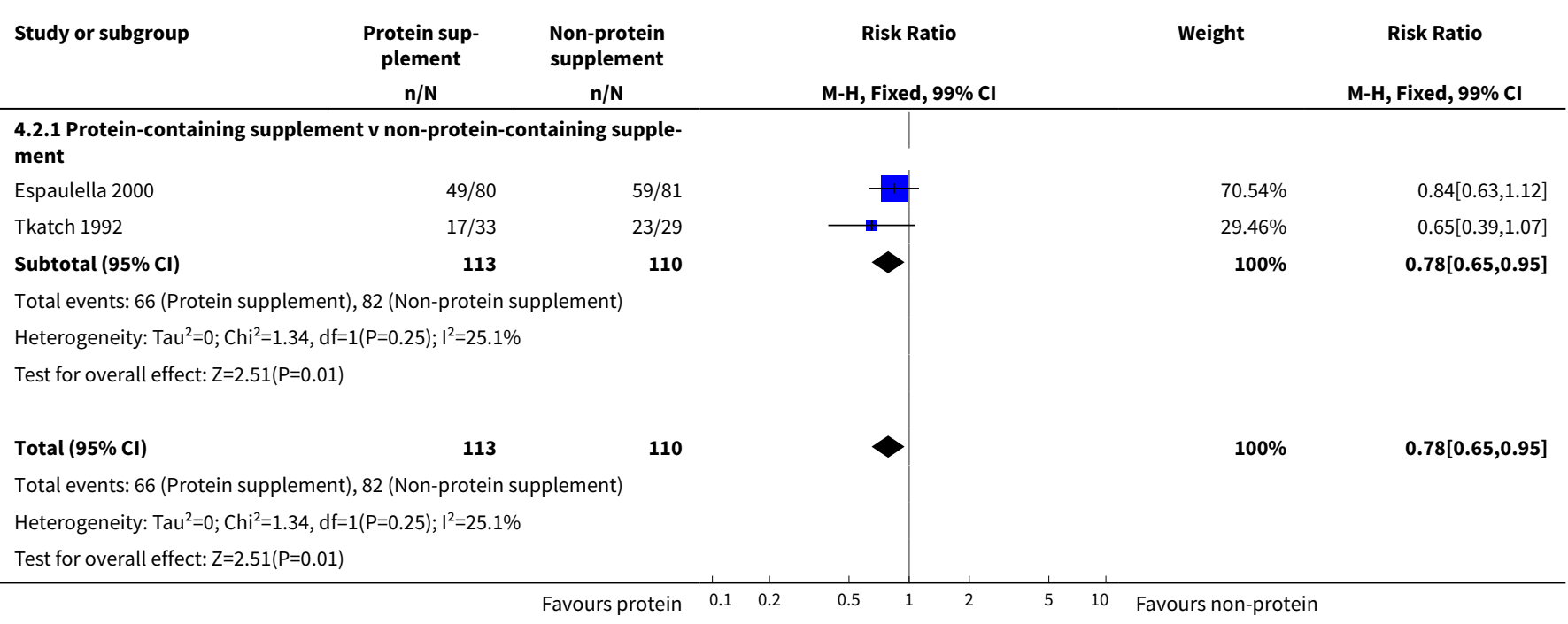

Comparison 5. Thiamin (vitamin B1) and water soluble vitamins versus control

\begin{tabular}{lllll}
\hline Outcome or subgroup title & No. of studies & $\begin{array}{l}\text { No. of partici- } \\
\text { pants }\end{array}$ & Statistical method & Effect size \\
\hline 1 Mortality by end of study & 1 & $\begin{array}{l}\text { Risk Ratio (M-H, Fixed, 99\% } \\
\text { Cl) }\end{array}$ & Totals not selected \\
\hline $\begin{array}{l}\text { 2 Participants with complications at } \\
\text { end of study }\end{array}$ & 1 & $\begin{array}{l}\text { Risk Ratio (M-H, Fixed, 99\% } \\
\text { Cl) }\end{array}$ & Totals not selected \\
\hline
\end{tabular}

Analysis 5.1. Comparison 5 Thiamin (vitamin B1) and water soluble vitamins versus control, Outcome 1 Mortality by end of study.

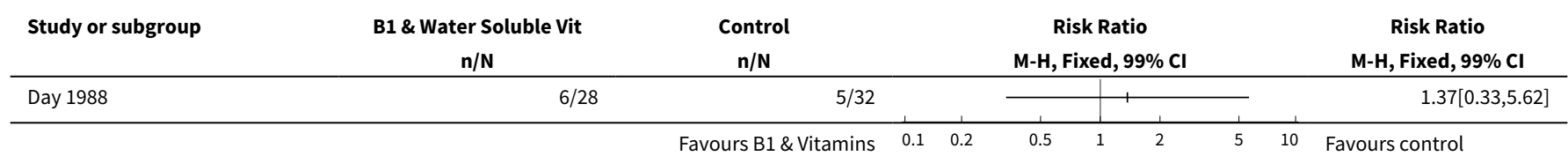

Analysis 5.2. Comparison 5 Thiamin (vitamin B1) and water soluble vitamins versus control, Outcome 2 Participants with complications at end of study.

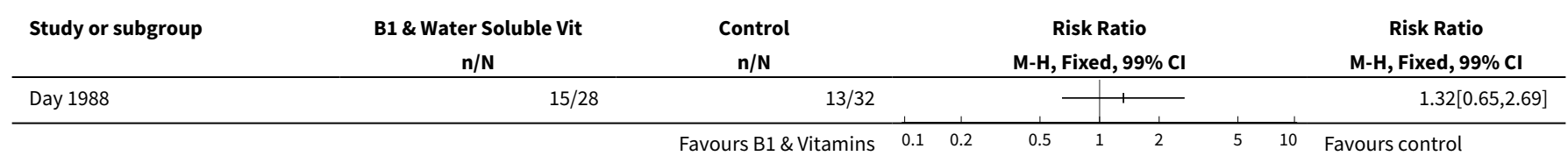


Comparison 6. Vitamin D versus control or lower dose supplementation

\begin{tabular}{lllll}
\hline Outcome or subgroup title & No. of studies & $\begin{array}{l}\text { No. of partici- } \\
\text { pants }\end{array}$ & Statistical method & Effect size \\
\hline $\begin{array}{l}1 \text { Participants with complications at } \\
\text { end of study }\end{array}$ & 1 & $\begin{array}{l}\text { Risk Ratio (M-H, Fixed, 99\% } \\
\mathrm{Cl})\end{array}$ & Totals not selected \\
\hline 2 Mortality by end of study & 1 & $\begin{array}{l}\text { Risk Ratio (M-H, Fixed, 95\% } \\
\mathrm{Cl})\end{array}$ & Totals not selected \\
\hline
\end{tabular}

Analysis 6.1. Comparison 6 Vitamin D versus control or lower dose supplementation, Outcome 1 Participants with complications at end of study.

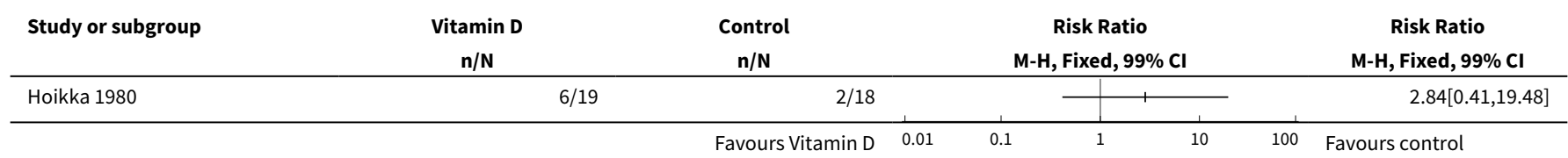

Analysis 6.2. Comparison 6 Vitamin D versus control or lower dose supplementation, Outcome 2 Mortality by end of study.

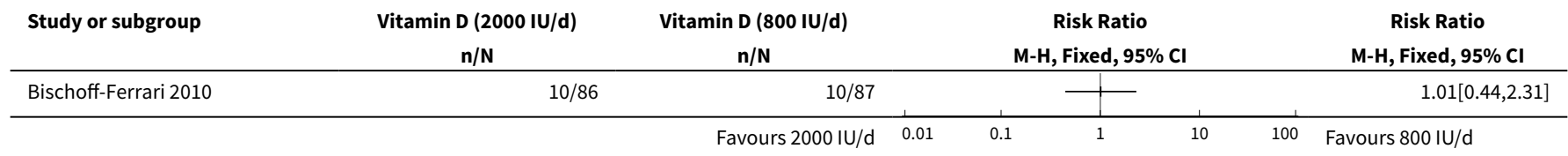

\section{Comparison 7. Iron supplementation versus control}

\begin{tabular}{lllll}
\hline Outcome or subgroup title & No. of studies & $\begin{array}{l}\text { No. of partici- } \\
\text { pants }\end{array}$ & Statistical method & Effect size \\
\hline 1 Mortality by end of study & 3 & 566 & $\begin{array}{l}\text { Risk Ratio (M-H, Fixed, 99\% } \\
\text { Cl) }\end{array}$ & $0.98[0.65,1.46]$ \\
\hline $\begin{array}{l}\text { 2 Participants with complications at } \\
\text { end of study }\end{array}$ & 2 & 266 & $\begin{array}{l}\text { Risk Ratio (M-H, Fixed, 99\% } \\
\text { Cl) }\end{array}$ & $1.23[0.63,2.42]$ \\
\hline
\end{tabular}

Analysis 7.1. Comparison 7 Iron supplementation versus control, Outcome 1 Mortality by end of study.

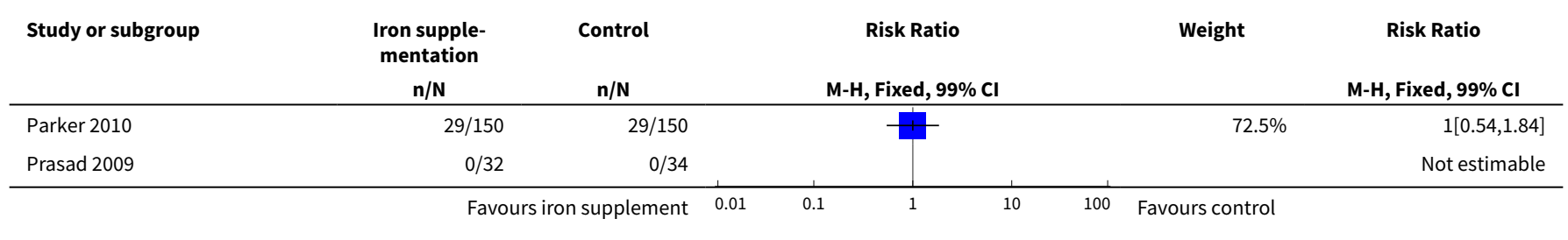




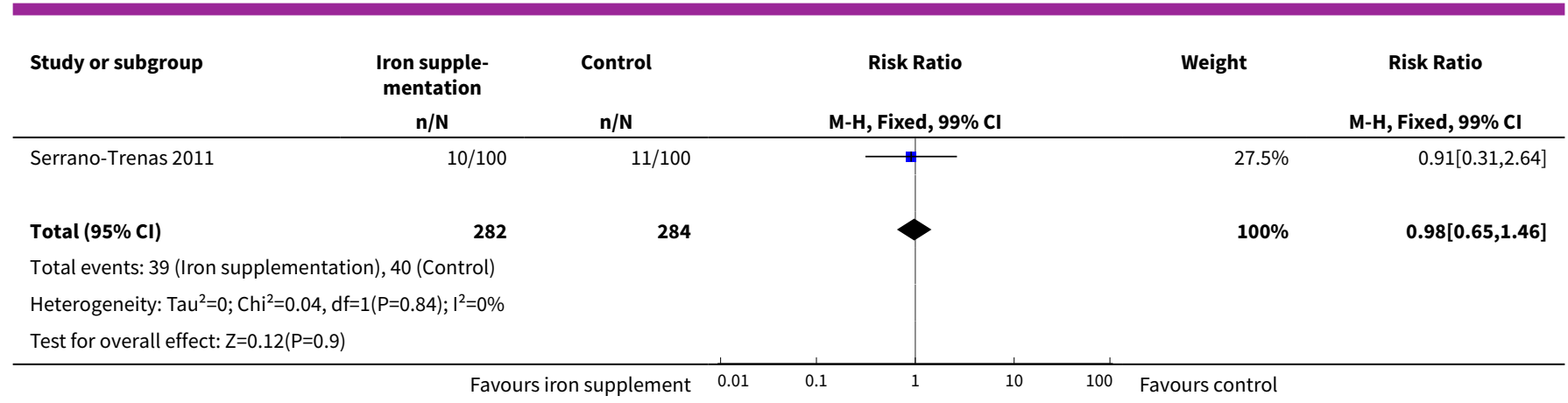

Analysis 7.2. Comparison 7 Iron supplementation versus control, Outcome 2 Participants with complications at end of study.

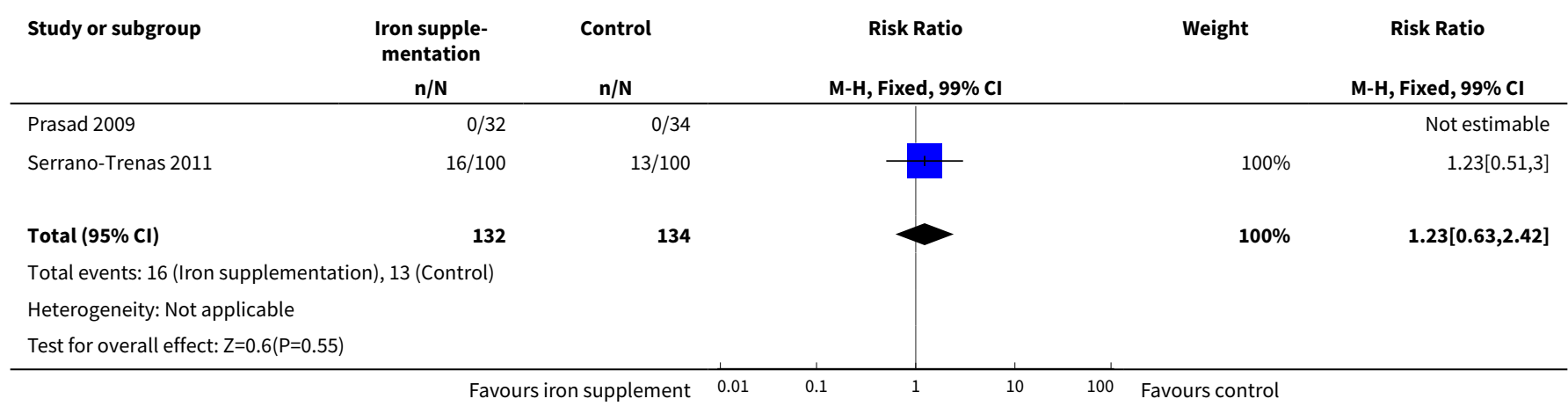

\section{Comparison 8. Taurine versus placebo}

\begin{tabular}{lllll}
\hline Outcome or subgroup title & No. of studies & $\begin{array}{l}\text { No. of partici- } \\
\text { pants }\end{array}$ & Statistical method & Effect size \\
\hline 1 Mortality by end of study & 1 & & Risk Ratio (M-H, Fixed, 99\% Cl) & Totals not selected \\
\hline
\end{tabular}

Analysis 8.1. Comparison 8 Taurine versus placebo, Outcome 1 Mortality by end of study.

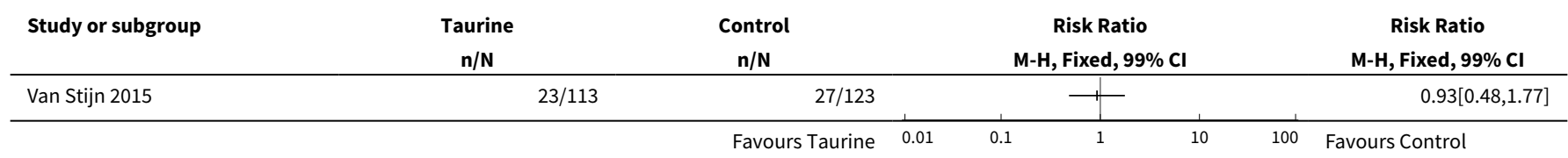


Comparison 9. Dietetic assistants versus usual care

\begin{tabular}{lllll}
\hline Outcome or subgroup title & No. of studies & $\begin{array}{l}\text { No. of partici- } \\
\text { pants }\end{array}$ & Statistical method & Effect size \\
\hline 1 Mortality by end of study & 1 & & $\begin{array}{l}\text { Risk Ratio (M-H, Fixed, 99\% } \\
\mathrm{Cl})\end{array}$ & Totals not selected \\
\hline $\begin{array}{l}\text { 2 Participants with complications at } \\
\text { end of study }\end{array}$ & 1 & $\begin{array}{l}\text { Risk Ratio (M-H, Fixed, 99\% } \\
\mathrm{Cl})\end{array}$ & Totals not selected \\
\hline
\end{tabular}

Analysis 9.1. Comparison 9 Dietetic assistants versus usual care, Outcome 1 Mortality by end of study.

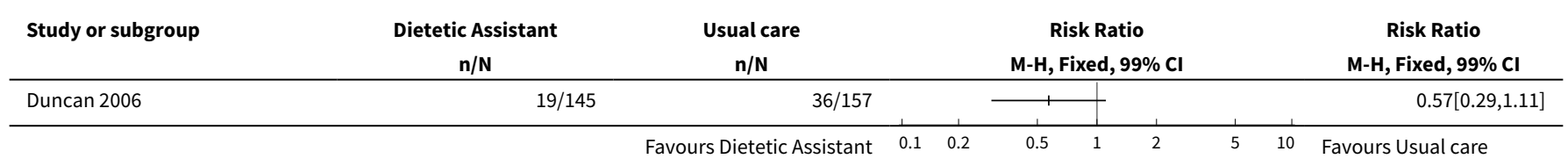

Analysis 9.2. Comparison 9 Dietetic assistants versus usual care, Outcome 2 Participants with complications at end of study.

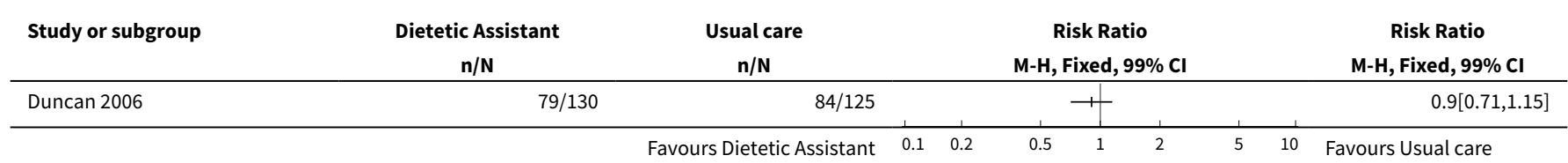




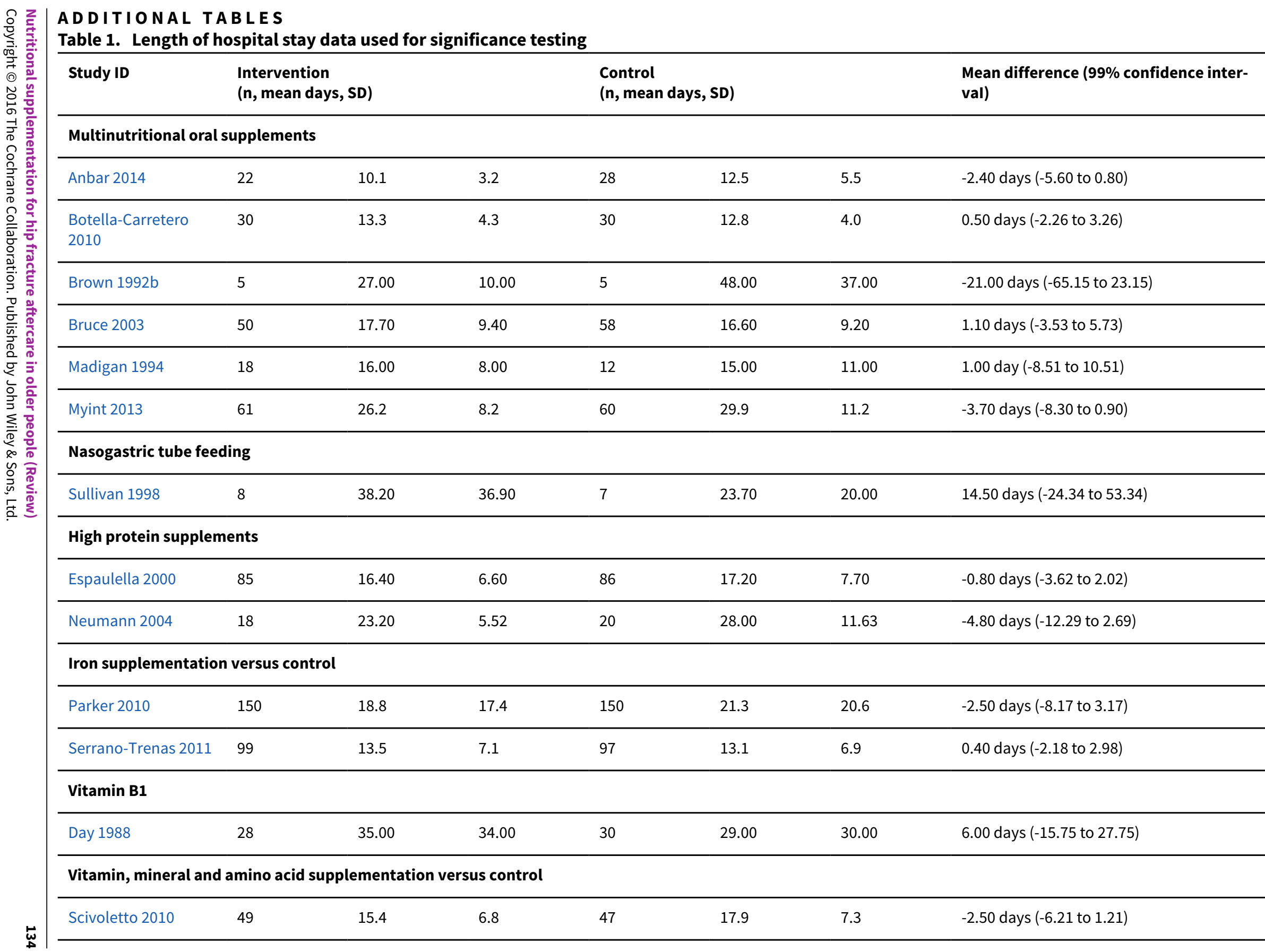




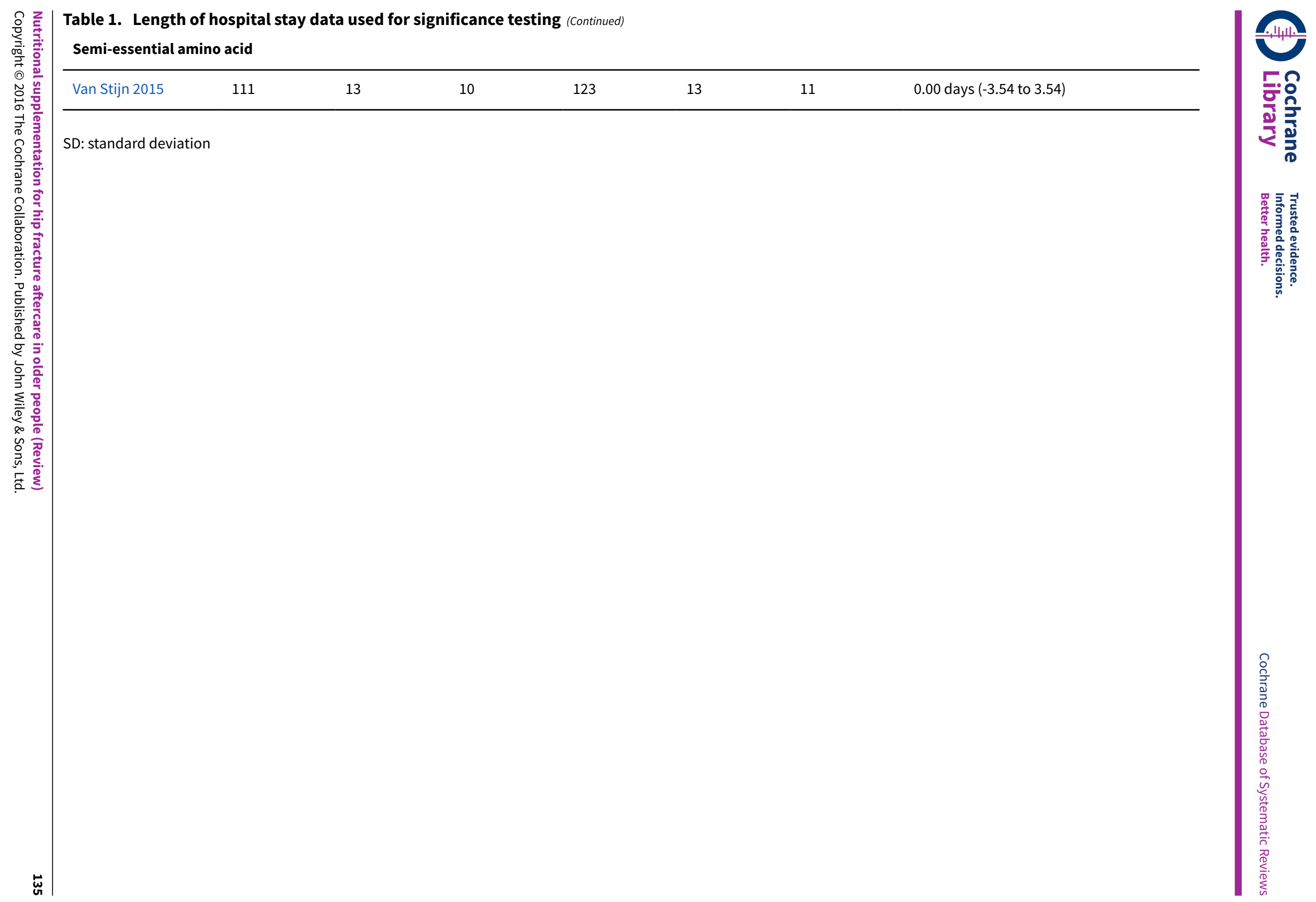




\section{AP PE N D I C E S}

\section{Appendix 1. Search strategies used for this update \\ CENTRAL (Ovid Online)}

1 exp Hip Fractures/ (881)

2 ((hip* or femur $^{\star}$ or femoral ${ }^{\star}$ or trochant ${ }^{\star}$ or pertrochant ${ }^{\star}$ or intertrochant* or subtrochant $^{\star}$ or intracapsular ${ }^{\star}$ or extracapsular $\left.^{\star}\right)$ adj3 fracture*).tw. (2531)

31 or $2(2613)$

$4 \exp$ Food/ (31621)

5 exp Diet/ (11888)

6 Nutritional Status/ (1475)

7 Nutritional Requirements/ (474)

8 Nutrition assessment/ (373)

9 exp Nutrition Therapy/ (6544)

10 exp Nutrition Disorders/ (9355)

11 Dietetics/ (73)

12 (food $^{\star}$ or feed ${ }^{\star}$ or fed or diet ${ }^{\star}$ or nutri* or supplement ${ }^{\star}$ or calorie* or energy intake or macronutrient ${ }^{\star}$ or micronutrient ${ }^{\star}$ ).tw. (75436)

13 Calcium, Dietary/ or Iron, Dietary/ or Phosphorus, Dietary/ or Potassium, Dietary/ or Sodium, Dietary/ or exp Magnesium/ or Sulfur/ or Fluorides/ (3265)

14 exp Trace Elements/ (4024)

15 (magnesium or chloride* or sulfate* or sulphate* or fluoride* or zinc or copper or selen* or manganese or molybdenum or chromium

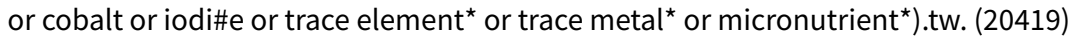

16 exp Vitamins/ (11325)

17 exp Carotenoids/ (2634)

18 (vitamin*or ascorb*or thiamin* or riboflavin* or pyridox*or niacin*or fola* or folic or biotin or cobalamin* or retino* or caroten* or tocopher* or dihydrotachysterol or calcitriol or cholecalciferol or alfacalcidol or alphacalcidol).tw. (9627)

19 or/4-18 (114255)

203 and $19(340)$

\section{MEDLINE (Ovid Online)}

1 exp Hip Fractures/ (18900)

2 ((hip ${ }^{\star}$ or femur $^{\star}$ or femoral $^{\star}$ or trochant ${ }^{\star}$ or pertrochant ${ }^{\star}$ or intertrochant ${ }^{\star}$ or subtrochant $^{\star}$ or intracapsular $^{\star}$ or extracapsular $^{\star}$ ) adj3 fracture $\left.{ }^{\star}\right)$.tw. (29214)

31 or 2 (34052)

$4 \exp$ Food/ (1132277)

5 exp Diet/ (212311)

6 Nutritional Status/ (25768)

7 Nutritional Requirements/ (17713)

8 Nutrition Assessment/ (8832)

9 exp Nutrition Therapy/ (85077)

10 exp Nutrition Disorders/ (281563)

11 Dietetics/ (5321)

12 (food $^{\star}$ or feed ${ }^{\star}$ or fed or diet $^{\star}$ or nutri $^{\star}$ or supplement ${ }^{\star}$ or calorie* or energy intake or macronutrient ${ }^{\star}$ or micronutrient $^{\star}$ ).tw. (1277335)

13 Calcium, Dietary/ or Iron, Dietary/ or Phosphorus, Dietary/ or Potassium, Dietary/ or Sodium, Dietary/ or exp Magnesium/ or Sulfur/ or Fluorides/ (113180)

14 exp Trace Elements/ (280342)

15 (magnesium or chloride* or sulfate* or sulphate* or fluoride* or zinc or copper or selen ${ }^{\star}$ or manganese or molybdenum or chromium or cobalt or iodi\#e or trace element ${ }^{\star}$ or trace metal ${ }^{\star}$ or micronutrient $\left.{ }^{\star}\right)$.tw. (626881)

16 exp Vitamins/ (279429)

17 exp Carotenoids/ (70869)

18 (vitamin ${ }^{\star}$ or ascorb* or thiamin ${ }^{\star}$ or riboflavin* or pyridox* or niacin*or fola* or folic or biotin or cobalamin ${ }^{\star}$ or retino* or caroten ${ }^{\star}$ or tocopher* or dihydrotachysterol or calcitriol or cholecalciferol or alfacalcidol or alphacalcidol).tw. (197485)

19 or/4-18 (2974627)

203 and 19 (3061)

21 Randomized controlled trial.pt. (415161)

22 Controlled clinical trial.pt. (91996)

23 randomized.ab. (337237)

24 placebo.ab. (169335)

25 Drug therapy.fs. (1851378) 
26 randomly.ab. (243329)

27 trial.ab. (351376)

28 groups.ab. (1515273)

29 or/21-28 (3690561)

30 exp Animals/ not Humans/ (4137930)

3129 not 30 (3175177)

3220 and 31 (1043)

$33\left(2008^{\star}\right.$ or $2009^{\star}$ or $2010^{\star}$ or $2011^{\star}$ or $2012^{\star}$ or $2013^{\star}$ or $2014^{\star}$ or $\left.2015^{\star}\right)$.ed,dc. $(8171541)$

3432 and 33 (483)

\section{Embase (Ovid Online)}

1 exp Hip Fracture/ (32421)

2 ((hip ${ }^{\star}$ or femur ${ }^{\star}$ or femoral ${ }^{\star}$ or trochant ${ }^{\star}$ or pertrochant ${ }^{\star}$ or intertrochant* or subtrochant $^{\star}$ or intracapsular $^{\star}$ or extracapsular $^{\star}$ ) adj3 fracture $\left.{ }^{\star}\right)$.tw. (36361)

31 or 2 (47054)

4 exp Nutrition/ (1598956)

5 exp Nutritional Disorder/ (634610)

6 Dietetics/ or Dietitian/ (10947)

7 exp Feeding/ (138744)

8 (food $^{\star}$ or feed ${ }^{\star}$ or fed or diet* or nutri* or supplement $\left.{ }^{\star}\right)$.tw. (1503689)

9 Calcium intake/ or Iron intake/ or Phosphate intake/ or Potassium intake/ or Salt intake/ or Sodium intake/ or Magnesium/ or Phosphorus/ or Sulfur/ or Fluoride/ (197235)

10 exp Trace Element/ (29882)

11 (magnesium or chloride* or sulfate* or sulphate* or fluoride* or zinc or copper or selen* or manganese or molybdenum or chromium or cobalt or iodi\#e or trace element ${ }^{\star}$ or trace metal ${ }^{\star}$ or micronutrient $\left.{ }^{\star}\right)$.tw. (693705)

12 exp Vitamin/ (500209)

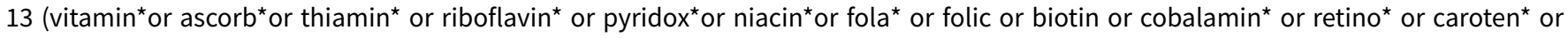
tocopher* or dihydrotachysterol or calcitriol or cholecalciferol or colecalciferol or alfacalcidol or alphacalcidol).tw. (224774)

14 or/4-13 (3739226)

153 and 14 (7532)

16 exp Randomized Controlled Trial/ or exp Single Blind Procedure/ or exp Double Blind Procedure/ or Crossover Procedure/ (437780)

17 (random ${ }^{\star}$ or RCT or placebo or allocat ${ }^{*}$ or crossover ${ }^{\star}$ or 'cross over' or trial or (doubl* adj1 blind ${ }^{\star}$ ) or (singl ${ }^{\star}$ adj1 blind $\left.^{\star}\right)$ ).ti,ab. (1446337)

1816 or $17(1524910)$

19 (exp Animal/ or animal.hw. or Nonhuman/) not (exp Human/ or Human Cell/ or (human or humans).ti.) (5407531)

2018 not $19(1343809)$

2115 and $20(1253)$

$22\left(2008^{\star}\right.$ or $2009^{\star}$ or $2010^{\star}$ or $2011^{\star}$ or $2012^{\star}$ or $2013^{\star}$ or $2014^{\star}$ or $\left.2015^{\star}\right) . e m$, dd. $(10439093)$

2321 and $22(847)$

\section{CAB Abstracts (Ovid Online)}

1 Hips/ (2306)

2 Bone Fractures/ (5244)

31 and 2 (347)

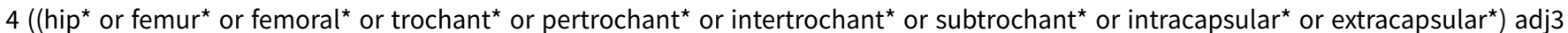
fracture*).tw. (1551)

53 or $4(1625)$

6 exp Food/ or exp Intake/ (393838)

7 exp Nutrition/ or Elderly nutrition/ or Clinical nutrition/ or Nutrition planning/ or Nutrition programmes/ or Nutritional support/ or Nutritional intervention/ or Nutritional state/ or Nutritional assessment/ or Mineral nutrition/ (122401)

8 exp Therapeutic Diets/ (11760)

9 Dietetics/ or Diet planning/ or Diet treatment/ or Dietitians/ (7241)

10 exp Supplements/ (98759)

11 (food $^{\star}$ or feed ${ }^{\star}$ or fed or diet* or nutri $^{\star}$ or supplement $\left.{ }^{\star}\right)$.tw. (1761385)

12 Calcium/ or Phosphorus/ or Potassium/ or Sodium/ or Magnesium/ or Sulfur/ or Fluorides/ or Chromium/ or Cobalt/ or Copper/ or lodine/ or Iron/ or Manganese/ or Molybdenum/ or Nutrients/ or Zinc/ or Trace elements/ (460000)

13 (magnesium or chloride* or sulfate* or sulphate* or fluoride* or zinc or copper or selen* or manganese or molybdenum or chromium or cobalt or iodi\#e or trace element ${ }^{\star}$ or trace metal ${ }^{\star}$ or micronutrient $\left.{ }^{\star}\right)$.tw. (434877)

14 Vitamin supplements/ or exp Vitamins/ (149456)

15 exp Carotenoids/ (47975)

16 (vitamin ${ }^{\star}$ or ascorb* or thiamin ${ }^{\star}$ or riboflavin* or pyridox* or niacin* or fola* or folic or biotin or cobalamin ${ }^{\star}$ or retino* or caroten ${ }^{\star}$ or tocopher* or dihydrotachysterol or calcitriol or cholecalciferol or alfacalcidol or alphacalcidol).tw. (102792) 
17 or/6-16 (2285965)

185 and $17(683)$

19 Randomized controlled trials/ (13766)

20 (random ${ }^{\star}$ or RCT or placebo or allocat ${ }^{\star}$ or crossover ${ }^{\star}$ or 'cross over' or trial or (doubl* adj1 blind ${ }^{\star}$ ) or (singl ${ }^{\star}$ adj1 blind $\left.{ }^{\star}\right)$ ).ti,ab. (428246)

2119 or $20(428824)$

2218 and $21(176)$

235 and $21(234)$

\section{CINAHL (Ebsco)}

S1 (MH "Hip Fractures+") $(6,423)$

S2 TX ((hip ${ }^{\star}$ or femur ${ }^{\star}$ or femoral ${ }^{\star}$ or trochant $^{\star}$ or pertrochant ${ }^{\star}$ or intertrochant ${ }^{\star}$ or subtrochant ${ }^{\star}$ or intracapsular $^{\star}$ or extracapsular $\left.^{\star}\right)$ n3 fracture $\left.^{\star}\right)(11,703)$

S3 S1 OR S2 (11,703)

S4 (MH "Food+") $(108,154)$

S5 (MH "Nutrition+") (103,313)

S6 (MH "Nutritional Support+") $(25,077)$

S7 (MH "Nutritional Assessment") $(11,360)$

S8 (MH "Nutrition Disorders+") $(84,425)$

S9 (MH "Diet Therapy+") $(20,493)$

S10 (MH "Dietetics") (1,684)

S11 (MH "Dietitians") $(3,655)$

S12 (MH "Nutrition Services+") $(2,223)$

S13 TX (food* or feed $^{*}$ or fed or diet ${ }^{\star}$ or nutri* or supplement $\left.^{\star}\right)(460,521)$

S14 (MH "Calcium, Dietary") OR (MH "Iron") OR (MH "Phosphorus") OR (MH "Potassium") OR (MH "Sodium, Dietary+") OR (MH "Magnesium") OR (MH "Sulfur") OR (MH "Fluorides") $(19,289)$

S15 (MH "Trace Elements+") $(14,475)$

S16 TX (magnesium or chloride* or sulfate* or sulphate* or fluoride ${ }^{\star}$ or zinc or copper or selen ${ }^{\star}$ or manganese or molybdenum or chromium or cobalt or iodine or iodide or trace element ${ }^{\star}$ or trace metal ${ }^{\star}$ or micronutrient $\left.{ }^{\star}\right)(38,568)$

S17 (MH "Vitamins+") $(35,678)$

S18 (MH "Carotenoids+") (6,752)

S19 TX (vitamin*or ascorb*or thiamin* or riboflavin* or pyridox*or niacin*or fola* or folic or biotin or cobalamin* or retino* or caroten* or tocopher* or dihydrotachysterol or calcitriol or cholecalciferol or alfacalcidol or alphacalcidol) $(21,526)$

S20 S4 OR S5 OR S6 OR S7 OR S8 OR S9 OR S10 OR S11 OR S12 OR S13 OR S14 OR S15 OR S16 OR S17 OR S18 OR S19 (565,320)

S21 S3 AND S20 $(1,603)$

S22 (MH "Clinical Trials+") $(194,386)$

S23 (MH "Evaluation Research+") $(21,724)$

S24 (MH "Comparative Studies") $(82,272)$

S25 (MH "Crossover Design") $(13,423)^{\sim}$

S26 PT Clinical Trial $(78,919)$

S27 (MH "Random Assignment") (40,165)

S28 S22 or S23 or S24 or S25 or S26 or S27 $(304,749)$

S29 TX ((clinical or controlled or comparative or placebo or prospective or randomi?ed) and (trial or study)) $(811,835)$

S30 TX (random* and (allocat ${ }^{\star}$ or allot ${ }^{\star}$ or assign ${ }^{\star}$ or basis ${ }^{\star}$ or divid or $\left.\left.^{\star} \operatorname{order}^{\star}\right)\right)(76,678)$

S31 TX ((singl* or doubl* or trebl* or tripl*) and (blind* or mask $\left.\left.{ }^{\star}\right)\right)(821,470)$

S32 TX ( crossover* or 'cross over' ) or TX cross n1 over $(17,186)$

S33 TX ((allocat* or allot* or assign ${ }^{\star}$ or divid*) and (condition* or experiment* or intervention* or treatment* or therap* or control* or group $\left.\left.{ }^{\star}\right)\right)(100,866)$

S34 S29 or S30 or S31 or S32 or S33 $(1,495,149)$

S35 S28 or S34 $(1,505,395)$

S36 S21 AND S35 (869)

S37 EM 2008 OR EM 2009 OR EM 2010 OR EM 2011 OR EM 2012 OR EM 2013 OR EM 2014 OR EM 2015 (2,879,808)

S38 S36 AND S37 (548)

\section{Trial register search strategies}

Current Controlled Trials, the WHO International Clinical Trials Registry Platform and the UK clinical research network study portfolio were searched using the following terms:

1 Fracture

2 Hip or femur or femoral

3 Nutrition

41 and 2 and 3 


\section{Appendix 2. Previous search methods for identification of studies (Avenell 2008)}

\section{Electronic searches}

We searched the Cochrane Bone, Joint and Muscle Trauma Group Specialised Register (September 2008), the Cochrane Central Register of Controlled Trials (The Cochrane Library 2008, Issue 3), MEDLINE (1966 to July 2008), Nutrition Abstracts and Reviews (1984 to July 2008), EMBASE (1980 to week 32 2008), BIOSIS (1985 to 14 August 2008), CINAHL (1982 to August week 2 2008), and HEALTHSTAR (1975 to March 2002).

In MEDLINE (Ovid) the first two phases of the standard Cochrane search strategy (Higgins 2006) were combined with subject-specific terms. This strategy was modified for use in other databases. No language restrictions were applied.

We also searched Current Controlled Trials (14 August 2008), WHO International Clinical Trials Registry Platform (6 October 2009) and the National Research Register (NRR) Archive (to September 2007) to identify ongoing trials.

\section{Searching other resources}

We handsearched Nutrition Abstracts and Reviews (publication database) from 1960 to 1983; Clinical Nutrition: Clinical nutrition: official journal of the European Society of Parenteral and Enteral Nutrition vol 1 to vol 27 (3) 2008; American Journal of Clinical Nutrition vol 2 to vol 88 (2) 2008; Journal of Parenteral and Enteral Nutrition vol 1 to vol 32 (2) 2008; and Proceedings of the Nutrition Society vol 1 to vol 67 (3) 2008. We also checked reference lists of articles, searched books related to orthopaedics, geriatric medicine and nutrition, and corresponded with colleagues and investigators.

\section{Appendix 3. Previous results of the search (Avenell 2008)}

Overall, of the 66 studies identified via the search strategy: 24 are included, 36 are excluded, four are ongoing and two are awaiting assessment.

Only 13 included trials were identified via the MEDLINE search strategy. One further trial (Stableforth 1986), located via EMBASE, was indexed by MEDLINE, but was not retrieved by the first two phases of the optimum Cochrane search strategy for randomised controlled trials (Dickersin 1994; Higgins 2006). BIOSIS yielded two further studies (Bean 1994; Brown 1992b). Gallagher 1992 was initially found from handsearching the Journal of Parenteral and Enteral Nutrition, but also appeared in the reference list of another published trial. Bean 1994 and Gallagher 1992 were only available as abstracts from conference proceedings. The two presently unpublished trials (Hankins 1996; Madigan 1994) and two previously unpublished trials (Duncan 2006; Espaulella 2000) were provided by personal contacts (Ian Cameron, Heidi Guyer, Donna Duncan and Antony Johansen). Bruce 2003, Houwing 2003 and Tidermark 2004 were initially identified by handsearching Clinical Nutrition and Neumann 2004 by searching Nutrition. A separate examination of the search strategy and findings prior to 2001 is available (Avenell 2001a). All 24 included trials were published in English.

\section{WHAT'S NEW}

\begin{tabular}{lll}
\hline Date Event & Description
\end{tabular}

30 October $2016 \quad$ New search has been performed
In this seventh update of the review, we updated our trial search to November 2015.

Of the newly identified studies for this update, 17 trials were selected for inclusion (Anbar 2014; Bischoff-Ferrari 2010; Botella-Carretero 2010; Chevalley 2010; Fabian 2011; Flodin 2014; Glendenning 2009; Kang 2012; Luo 2015; Myint 2013; Papaioannou 2011; Parker 2010; Prasad 2009; Scivoletto 2010; Serrano-Trenas 2011; Van Stijn 2015; Wyers 2013), one of which (Wyers 2013) was previously an ongoing study. Six new studies were excluded (Bell 2014; Gunnarsson 2009; Hitz 2007; Hoekstra 2011; Holst 2012; Li 2012) and one previously ongoing study was excluded (Cameron 2011). Five were placed in ongoing trials (ACTRN12610000392066; ACTRN12612000448842; NCT01404195; NCT01505985; Rowlands) and five await classification (Benati 2011; Bernabeu-Wittel 2016; Ekinci 2015; Ish-Shalom 2008; Stratton 2006).

New interventions examined were: high dose bolus vitamin D; different oral doses or sources of vitamin D; intravenous or oral 


\begin{tabular}{lll}
\hline Date Event Description & Den
\end{tabular}

iron; types of protein supplement; a supplement with vitamins, minerals and amino acids; and taurine (an amino acid).

We have assessed the risk of bias for all new trials and all previously included trials with the Cochrane 'Risk of bias' tool. This replaces our former assessment of methodological quality.

We have assessed the quality of the evidence using GRADE.

We have constructed and presented 'Summary of findings' tables.

30 October $2016 \quad$ New citation required and conclusions have changed
Conclusions were changed for oral multinutrient supplements, which now have low-quality evidence for prevention of complications.

There have been changes to the byline.

\section{H I S T O R Y}

Protocol first published: Issue 1, 1999

Review first published: Issue 1, 2000

\begin{tabular}{lll}
\hline Date & Event & Description \\
\hline \multirow{2}{*}{12 November 2009} & $\begin{array}{l}\text { New citation required and conclusions } \\
\text { have changed }\end{array}$ & $\begin{array}{l}\text { In this sixth update, published in Issue 1, 2010 of The Cochrane } \\
\text { Library, we updated our trial search to September 2008. Of the } \\
\end{array}$ \\
& $\begin{array}{l}10 \text { newly identified studies for this update, one trial is included } \\
\text { (Botella-Carretero 2008), five trials are excluded (Boudville 2002; }\end{array}$ \\
& Hommel 2007; Kacmaz 2007; Olofsson 2007; Thomas 2008) and \\
& one trial awaits classification (Gerstorfer 2008a). Three new trials \\
& are ongoing (Dagneliea; NCT00497978; ACTRN12609000241235). \\
& Of previously identified trials: one former ongoing trial is now in- \\
& cluded (Eneroth 2006), and one trial formerly awaiting classifica- \\
& tion (Miller 2006) is now included. A new category (intravenous \\
& feeding and oral supplements) was set up for one new trial.
\end{tabular}

There was slight modification to the conclusions that reflected reappraisal of the available evidence.

\begin{tabular}{|c|c|c|}
\hline 15 August 2008 & Amended & Converted to new review format. \\
\hline 4 August 2006 & New search has been performed & $\begin{array}{l}\text { In the fifth update, published in The Cochrane Library Issue 4, } \\
2006, \text { we updated our trial search to January 2006. Of the six } \\
\text { newly identified studies for this update, one trial is included (Sul- } \\
\text { livan 2004), three trials are excluded (Ashworth 2006; Carlsson } \\
2005 ; \text { Wong 2004) and two trials await assessment (Eneroth 2005; } \\
\text { Stratton 2005). Of two former ongoing trials, one is now includ- } \\
\text { ed (Duncan 2006, formerly Johansen 2002) and the other awaits } \\
\text { assessment (Miller 2006, formerly Crotty 2003). One trial former- } \\
\text { ly awaiting assessment is now included (Neumann 2004). Two } \\
\text { existing categories were modified to accommodate two newly } \\
\text { included trials. A new category (dietetic assistants versus usual } \\
\text { care) was set up for the third new trial. }\end{array}$ \\
\hline
\end{tabular}

3 November $2003 \quad$ New search has been performed

In the fourth update, published in The Cochrane Library Issue 1, 2004, we updated our trial search to August 2003. Two new trials 


\begin{tabular}{ll}
\hline Date & Description \\
\hline & $\begin{array}{l}\text { were included (Bruce 2003; Houwing 2003). Two newly identified } \\
\text { trials were excluded (Hedström 2002; Stumm 2001). One newly } \\
\text { identified trial is awaiting assessment (Tidermark 2003). Updates }\end{array}$ \\
& $\begin{array}{l}\text { to all three ongoing trials were provided (Cameron 2000; Crotty } \\
\text { 2003; Johansen 2002). The review conclusions were unchanged. }\end{array}$
\end{tabular}

1 May $2002 \quad$ New search has been performed
In the third update, published in Issue 3, 2002 of The Cochrane Library, we updated our trial search to April 2002. No new trials were included. Two newly identified trials were excluded (Bachrach 2001; Lauque 2000). Four trials previously awaiting assessment were now excluded. Two newly identified trials (Crotty 2003; Johansen 2002) were included as ongoing trials. The review conclusions were unchanged.

1 May $2001 \quad$ New search has been performed

In the second update, published in Issue 3, 2001 of The Cochrane Library, the trial search was updated to April 2001. No new trials were included. Two more trials were excluded: one previously awaiting assessment (Doshi 1998) on the basis of a full journal publication (Lawson 2000) and the other (Bachrach 2000) was newly identified. One newly identified trial, only available as a conference abstract, was placed in Studies awaiting assessment (Moller-Madsen 1988) and further details sought. The review conclusions were unchanged.
1 August $2000 \quad$ New search has been performed

\begin{abstract}
In the first update, published in Issue 4, 2000 of The Cochrane Library, we extended our trial search to January 2000. We identified one new ongoing trial (Cameron 2000), and obtained new information on four included trials and two studies placed in the awaiting assessment category in the first version of this review. This extra information resulted in one included trial (Williams 1989) being excluded, and one of the two studies pending assessment being included (Espaulella 2000) and the other excluded (Pedersen 1999).

The inclusion of the new trial, which evaluated the effect of protein in an oral feed, and the other new information did not substantially alter the conclusions of the original review.

Relative risks instead of Peto odds ratios were presented for dichotomous outcomes. Again, this did not affect the conclusions of the review.
\end{abstract}

\section{CONTRIBUTIONSOF AUTHORS}

Alison Avenell, Toby Smith, Jenson Mak and James Curtain assessed and extracted data from trials for this version of the review. Alison Avenell and Toby Smith revised the analysis, performed the GRADE review, prepared the 'Summary of findings' tables and re-interpreted the data for this version of the review. Alison Avenell wrote the first draft of this version of the review and all authors revised drafts. All authors are guarantors of this review.

\section{DECLARATIONS OF INTEREST}

Alison Avenell: none known Toby O Smith: none known James P Curtain: none known Jenson CS Mak: none known Phyo K Myint: none known 


\section{SOURCESOF SUPPORT}

\section{Internal sources}

- University of Aberdeen, UK.

- University of East Anglia, Norwich, UK.

- Cambridge University Hospitals NHS Trust, UK.

- Gosford Hospital, Gosford, Australia.

\section{External sources}

- Chief Scientist Office of the Scottish Government Health Directorates, UK.

\section{DIFFERENCES BETWEEN PROTOCOLANDREVIEW}

We made the following changes in this update (2016).

\section{Types of interventions}

In response to feedback from an external referee, we added clarification that the nutritional interventions covered in this review were aimed at improving recovery from hip fracture.

\section{Risk of bias}

In the protocol and previous versions of this review (Avenell 2010), we assessed methodological quality using a subject-specific modification of the former generic evaluation tool developed by the Cochrane Bone, Muscle and Joint Trauma Group. In this update, we have changed to assessing the risk of bias of all included trials using the Cochrane 'Risk of bias' tool (Higgins 2011).

\section{Outcomes}

In this update to the review, we do not report on the following outcomes, which were listed under 'Other outcomes' in previous versions of this review (Avenell 2010):

- changes in anthropometric indices, such as weight, skinfold thickness, and mid-upper arm circumference

- new fractures

- changes in bone mineral density, assessed by techniques involving radiation, for example dual photon absorptiometry, dual energy Xray absorptiometry, quantitative computed tomography

- changes in nutritional indicators measured in blood, such as albumin, transferrin, vitamin and mineral levels, haemoglobin

- changes in functional markers of nutritional status, including delayed cutaneous hypersensitivity (a marker of immune function) and grip strength

\section{GRADE assessment}

We used the GRADE approach to assess the quality of evidence related to the each of the primary outcomes for all comparisons.

\section{N DEX TERMS}

\section{Medical Subject Headings (MeSH)}

*Aftercare; *Dietary Supplements [adverse effects]; Cause of Death; Hip Fractures [ ${ }^{\star}$ complications] [mortality]; Malnutrition [ ${ }^{\star}$ diet therapy] [mortality]; Nutritional Support [adverse effects] [ ${ }^{*}$ methods]; Randomized Controlled Trials as Topic

\section{MeSH check words}

Aged; Humans 